\title{
An overview of the MILAGRO 2006 Campaign: Mexico City emissions and their transport and transformation
}

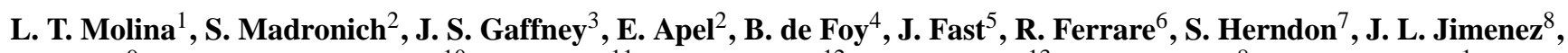 \\ B. Lamb ${ }^{9}$, A. R. Osornio-Vargas ${ }^{10}$, P. Russel1 ${ }^{11}$, J. J. Schauer ${ }^{12}$, P. S. Stevens ${ }^{13}$, R. Volkamer ${ }^{8}$, and M. Zavala ${ }^{1}$ \\ ${ }^{1}$ Molina Center for Energy and the Environment, California, and Massachusetts Institute of Technology, \\ Cambridge, Massachusetts, USA \\ ${ }^{2}$ National Center for Atmospheric Research, Boulder, Colorado, USA \\ ${ }^{3}$ University of Arkansas at Little Rock, Little Rock, Arkansas, USA \\ ${ }^{4}$ Saint Louis University, St. Louis, Missouri, USA \\ ${ }^{5}$ Pacific Northwest National Laboratory, Richland, Washington, USA \\ ${ }^{6}$ National Aeronautics and Space Administration, Langley Research Center, Hampton, VA, USA \\ ${ }^{7}$ Aerodyne Research Inc., Billerica, Massachusetts, USA \\ ${ }^{8}$ Cooperative Institute for Research in the Environmental Sciences (CIRES) and University of Colorado at Boulder, \\ Boulder, Colorado, USA \\ ${ }^{9}$ Washington State University, Pullman, Washington, USA \\ ${ }^{10}$ Instituto Nacional de Cancerología and Universidad Nacional Autónoma de México, México \\ ${ }^{11}$ NASA Ames Research Center, Moffett Field, California, USA \\ ${ }^{12}$ University of Wisconsin-Madison, Madison, Wisconsin, USA \\ ${ }^{13}$ Indiana University, Bloomington, Indiana, USA
}

Received: 10 March 2010 - Published in Atmos. Chem. Phys. Discuss.: 25 March 2010

Revised: 30 July 2010 - Accepted: 11 August 2010 - Published: 16 September 2010

\begin{abstract}
MILAGRO (Megacity Initiative: Local And Global Research Observations) is an international collaborative project to examine the behavior and the export of atmospheric emissions from a megacity. The Mexico City Metropolitan Area (MCMA) - one of the world's largest megacities and North America's most populous city - was selected as the case study to characterize the sources, concentrations, transport, and transformation processes of the gases and fine particles emitted to the MCMA atmosphere and to evaluate the regional and global impacts of these emissions. The findings of this study are relevant to the evolution and impacts of pollution from many other megacities.
\end{abstract}

The measurement phase consisted of a month-long series of carefully coordinated observations of the chemistry and physics of the atmosphere in and near Mexico City during

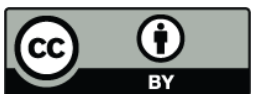

Correspondence to: L. T. Molina (ltmolina@mit.edu)
March 2006, using a wide range of instruments at ground sites, on aircraft and satellites, and enlisting over 450 scientists from 150 institutions in 30 countries. Three ground supersites were set up to examine the evolution of the primary emitted gases and fine particles. Additional platforms in or near Mexico City included mobile vans containing scientific laboratories and mobile and stationary upward-looking lidars. Seven instrumented research aircraft provided information about the atmosphere over a large region and at various altitudes. Satellite-based instruments peered down into the atmosphere, providing even larger geographical coverage. The overall campaign was complemented by meteorological forecasting and numerical simulations, satellite observations and surface networks. Together, these research observations have provided the most comprehensive characterization of the MCMA's urban and regional atmospheric composition and chemistry that will take years to analyze and evaluate fully.

Published by Copernicus Publications on behalf of the European Geosciences Union. 
In this paper we review over 120 papers resulting from the MILAGRO/INTEX-B Campaign that have been published or submitted, as well as relevant papers from the earlier MCMA-2003 Campaign, with the aim of providing a road map for the scientific community interested in understanding the emissions from a megacity such as the MCMA and their impacts on air quality and climate.

This paper describes the measurements performed during MILAGRO and the results obtained on MCMA's atmospheric meteorology and dynamics, emissions of gases and fine particles, sources and concentrations of volatile organic compounds, urban and regional photochemistry, ambient particulate matter, aerosol radiative properties, urban plume characterization, and health studies. A summary of key findings from the field study is presented.

\section{Introduction}

The world's population is projected to increase 33\% during the next three decades to 8.1 billion. Nearly all of the projected growth is expected to be concentrated in urban centers. Rapidly expanding urban areas and their surrounding suburbs are feeding to the phenomenon of megacities (metropolitan areas with populations exceeding 10 million inhabitants). Well planned and governed, densely populated settlements can reduce the need for land conversion and provide proximity to infrastructure and services. However, many urban areas experience uncontrolled growth leading to urban sprawl, a leading cause of environmental problems. These mega-centers of human population lead to increasing demands for energy, and industrial activity and transportation, all of which result in enhanced, concentrated atmospheric emissions of gases and particulate matter (PM) that impact air quality and climate. Air pollution and climate change are among the most important environmental challenges of this century. This challenge is particularly acute in the developing world where the rapid growth of megacities is producing atmospheric emissions of unprecedented severity and extent (Molina and Molina, 2004; Molina et al., 2004; Lawrence et al., 2007; Gurjar et al., 2008).

There is growing recognition that airborne emissions from major urban and industrial areas influence both air quality and climate on scales ranging from regional to continental and global (Molina and Molina, 2002; Molina et al., 2004; Lawrence et al., 2007; Parrish et al., 2009a). Urban/industrial emissions from the developed world, and increasingly from the megacities of the developing world, change the chemical content of the downwind troposphere in a number of fundamental ways. Emissions of nitrogen oxides $\left(\mathrm{NO}_{\mathrm{x}}\right)$, carbon monoxide (CO) and volatile organic compounds (VOCs) drive the formation of photochemical smog and its associated oxidants, degrading air quality and threatening both human and ecosystem health and agricultural productivity. On a larger scale, these same emissions drive the production of ozone (a powerful greenhouse gas) in the free troposphere, contributing substantially to global warming. Urban and industrial areas are also major sources of the important directly forcing greenhouse gases, including carbon dioxide $\left(\mathrm{CO}_{2}\right)$, methane $\left(\mathrm{CH}_{4}\right)$, nitrous oxide $\left(\mathrm{N}_{2} \mathrm{O}\right)$ and halocarbons, as well as other radiatively important species that contribute to climate change. Nitrogen oxide and sulfur dioxide emissions are also processed to strong acids by atmospheric photochemistry on regional to continental scales, driving acid deposition to sensitive ecosystems. Direct urban/industrial emissions of carbonaceous aerosol particles are compounded by the emission of high levels of secondary aerosol precursors, including: $\mathrm{NO}_{\mathrm{x}}, \mathrm{VOCs}, \mathrm{SO}_{2}$, and $\mathrm{NH}_{3}$, resulting in the production of copious amounts of fine aerosol, affecting the urban source areas and air quality, atmospheric radiation, cloud microphysical properties, and precipitation hundreds to thousands of kilometers downwind.

The geographic redistribution of urban emissions, the evolution of their chemical, physical, and optical properties, the interaction with clouds, and the mechanisms for their eventual removal from the atmosphere are very complex and obviously important, yet only partly understood at the present time.

MILAGRO (Megacity Initiative: Local And Global Research Observations) is an international collaborative project to examine the properties, evolution, and export of atmospheric emissions generated in a megacity. The Mexico City Metropolitan Area (MCMA) - one of the world's largest megacities and North America's most populous city - was selected as the case study to characterize the sources and processes of emissions from the urban center and to evaluate the regional and global impacts of the Mexico City emissions.

MILAGRO is organized under four coordinated components (MCMA-2006, MAX-Mex, MIRAGE-Mex and INTEX-B) that took place simultaneously during March 2006 and involved the participation of more than 150 institutions from Mexico, the United States and Europe and over 450 investigators and technicians representing 30 different nationalities. The measurement campaign was sponsored by the US National Science Foundation (NSF), Department of Energy (DOE), and National Aeronautic and Space Administration (NASA), and by many Mexican agencies, including the Mexican Ministry of the Environment (SEMARNAT), the Metropolitan Environmental Commission of the Valley of Mexico (CAM), Consejo Nacional de Ciencia y Technología (CONACyT) and Petróleos Mexicanos (PEMEX).

This paper provides an overview of the MILAGRO Campaign in Mexico City and is divided into 9 sections covering the following topics: scope of the MILAGRO Campaign (Sect. 3); meteorology and dynamics (Sect. 4), MCMA emissions of gases and fine particulate matter (Sect. 5); volatile organic compound sources and concentrations (Sect. 6); urban and regional photochemistry (Sect. 7); ambient particulate matter (Sect. 8); aerosol optical properties and radiative 

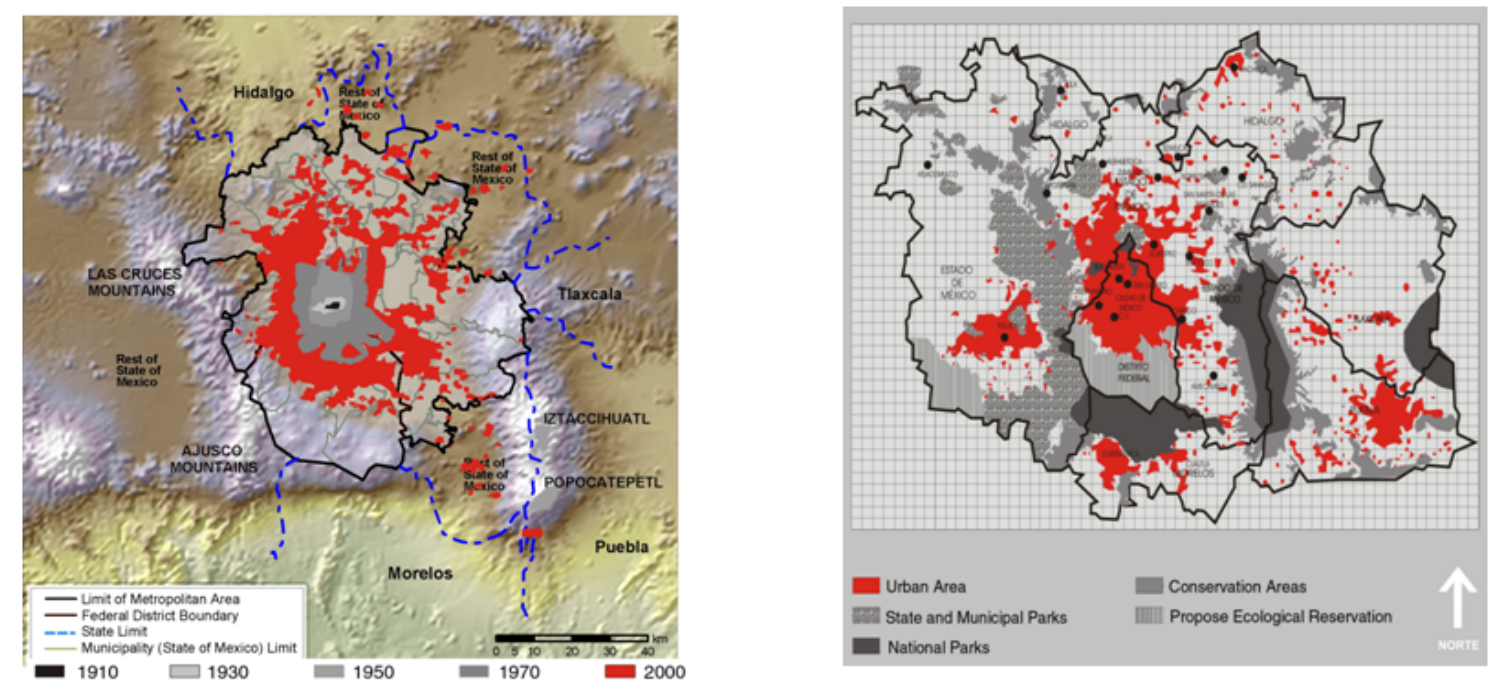

Fig. 1. Left Panel: topographical map of the MCMA; Right Panel: Megalopolis in the year 2000 (from Molina and Molina, 2002).

influences (Sect. 9); regional plume from INTEX-B flights over Mexico City and the Gulf (Sect. 10); and health studies (Sect. 11). A summary of key findings is presented in Sect. 12; while some directions for future research are presented in Sect. 13. A list of acronyms is provided in Appendix A.

\section{Air quality in the Mexico Megacity}

The MCMA lies in an elevated basin $2240 \mathrm{~m}$ above sea level. The basin is surrounded on three sides by mountain ridges, but with a broad opening to the north and a narrower gap to the south-southwest. Figure 1a shows the topographical map of the MCMA. During the twentieth century the MCMA experienced huge increases in population and urbanized area as it attracted migrants from other parts of the country and industrialization stimulated economic growth. The population grew from fewer than 3 million in 1950 to over 18 million in 2000; the urbanized area now covers about $1500 \mathrm{~km}^{2}$ - about 10 times as much land as it occupied just 50 years ago. The expansion of the MCMA is not unique in the region; the neighboring metropolitan areas (Puebla, Tlaxcala, Cuernavaca, Pachuca, and Toluca) are also extending their territories. This multiple expansion has produced a contiguous urban complex known as the Mexico "Megalopolis," which extends beyond the MCMA to include the surrounding "corona" or "crown" of cities including Puebla, Tlaxcala, Cuernavaca, Cuautla, Pachuca, and Toluca, extending 75$150 \mathrm{~km}$ from the city center with an estimated population of about 30 million (see Fig. 1b). The growth of the Megalopolis will clearly have important consequences for energy use and the regional ecology and environment (Lezama et al., 2002).
The MCMA's nearly 20 million inhabitants, over 40000 industries and 4 million vehicles consume more than 40 million liters of petroleum fuels per day and produce thousands of tons of pollutants. The high altitude and tropical insolation facilitate ozone production all year and contribute to the formation of secondary particulate matter. Air quality is generally worse in the winter, when rain is less common and thermal inversions are more frequent (Molina and Molina, 2002, 2004).

During the past decade, the Mexican government has made significant progress in improving air quality. Figure 2 shows the air quality trends of the MCMA; plots show the annual average concentrations for the criteria pollutants $\left(\mathrm{O}_{3}, \mathrm{NO}_{2}\right.$, $\mathrm{CO}, \mathrm{SO}_{2}, \mathrm{~Pb}, \mathrm{TSP}, \mathrm{PM}_{10}$ and $\mathrm{PM}_{2.5}$ ) Substantial reductions in the concentrations of some criteria pollutants (such as lead, $\mathrm{CO}$ and $\mathrm{SO}_{2}$ ) were achieved by developing and implementing comprehensive air quality management programs and improving air quality monitoring and evaluation programs (Molina et al., 2002). Despite these important gains, MCMA residents remain exposed to concentrations of airborne pollutants exceeding ambient air quality standards, especially PM and ozone, the two most important pollutants from the standpoint of public health (Evans et al., 2002).

\subsection{Intensive field studies}

As North America's most populated megacity, with a unique combination of meteorology, topography, population and multi-pollutant emission density, the MCMA has attracted a number of air quality field studies. The Mexico City Air Quality Research Initiative (MARI) project gathered surface and vertical profile observations of meteorology and pollutants during 1990-1994 (LANL and IMP, 1994; Streit and Guzman, 1996). The IMADA-AVER (Investigación 

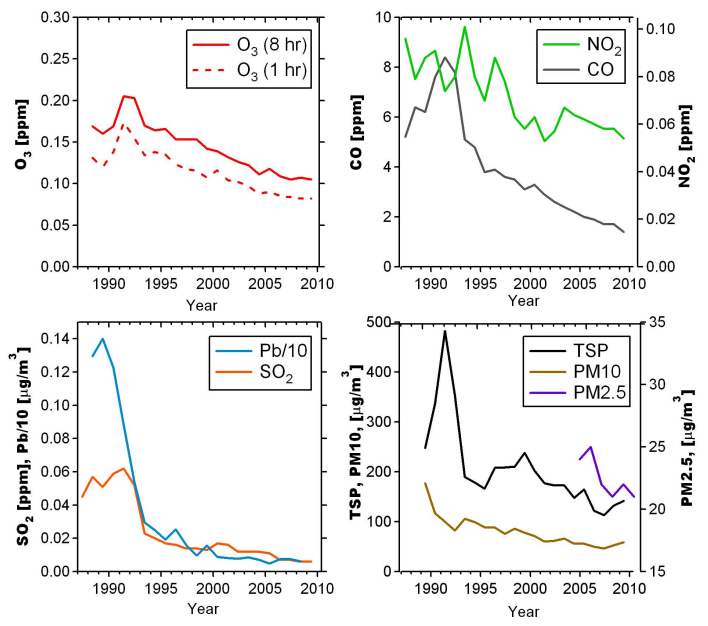

Fig. 2. Air quality trends of the MCMA. Plots show the concentrations estimated as the average of the 5th annual maximum from all stations with valid data for a given year for the following criteria pollutants: $\mathrm{O}_{3}, \mathrm{NO}_{2}, \mathrm{CO}, \mathrm{SO}_{2}, \mathrm{~Pb}$ (divided by 10), TSP (Total Suspended Particles), $\mathrm{PM}_{10}$ and $\mathrm{PM}_{2.5}$. (Data provided by SMA-GDF, 2009).

sobre Materia Particulada y Deterioro Atmosférico, Aerosol and Visibility Evaluation Research) campaign in FebruaryMarch 1997 yielded comprehensive meteorological measurements in the basin, and provided insights into particulate composition (IMP, 1998; Doran et al., 1998; Edgerton et al., 1999; Molina and Molina, 2002).

The MCMA-2003 measurement campaign was carried out during April 2003 to cover the height of the annual photochemical season just prior to the onset of the rainy season. It involved a highly-instrumented supersite located at the National Center for Environmental Research and Training (Centro Nacional de Investigatión y Capcitación Ambiental, CENICA), a component of the National Institute of Ecology (INE) of the Ministry of the Environment (SEMARNAT), with state-of-the-art instrumentation contributed by many US and European teams. A mobile laboratory from Aerodyne Research Inc. was deployed for vehicle-chase sampling measurements, as well as for fixed multi-day measurements at various locations in the MCMA. Many high time resolution instruments were deployed to the MCMA for the first time during this campaign. MCMA-2003 and an exploratory mission in February 2002 generated extensive measurements of many oxidant precursors and photochemical products and intermediates including radicals, speciated VOCs and PM, as well as meteorology and emissions. An overview of MCMA-2003 measurements has been published by Molina et al. (2007).

Observations and modeling studies from MCMA-2003 show that under most conditions, pollutant export from the basin is relatively rapid and that pollutant carryover from day to day is not a major factor in the valley's photochem-

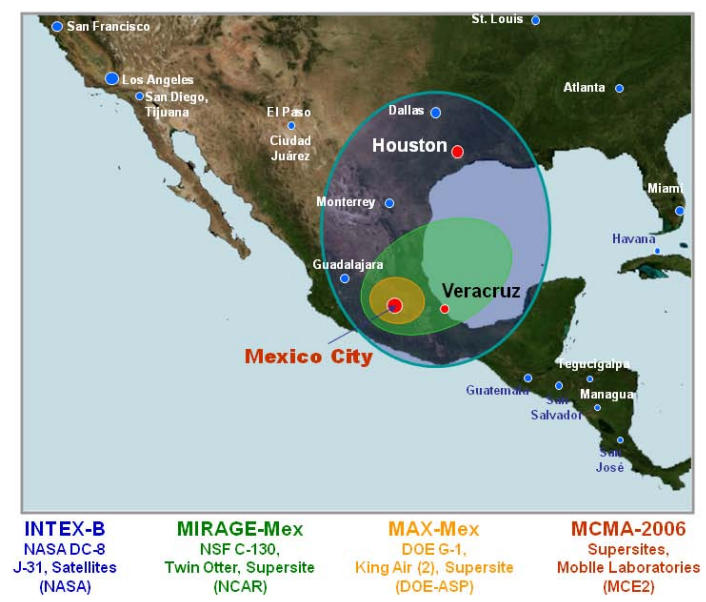

Fig. 3. MILAGRO Campaign: Geographic Coverage. Measurements were performed in the MCMA (see Fig. 4). The size of the circle (MAX-Mex, MIRAGE-Mex and INTEX-B) indicates the geographic coverage of the aircraft deployed.

istry. Emissions studies confirmed that motor vehicles play a major role in supplying the $\mathrm{NO}_{\mathrm{x}}$ and VOC precursors that fuel MCMA's extremely active photochemistry. Key results documented in Molina et al. (2007) included a vastly improved speciated emissions inventory from on-road vehicles, showing that the MCMA motor vehicles produce abundant amounts of primary PM, elemental carbon, particle-bound polycyclic aromatic hydrocarbons, carbon monoxide and a wide range of air toxics, including formaldehyde, acetaldehyde, benzene, toluene, and xylenes. The feasibility of using eddy covariance techniques to measure fluxes of volatile organic compounds in an urban core was demonstrated, proving a valuable tool for validating the local emissions inventory. A much better understanding of the sources and atmospheric loadings of VOCs was obtained, including the first spectroscopic detection of glyoxal in the atmosphere and a unique analysis of the high fraction of ambient formaldehyde from primary emission sources. A more comprehensive characterization of ozone formation and its sensitivity to VOCs and $\mathrm{NO}_{\mathrm{x}}$ and a much more extensive knowledge of the composition, size distribution and atmospheric mass loadings of both primary and secondary fine PM, including the fact that the rate of MCMA SOA production greatly exceeded that predicted by current atmospheric models were obtained. Intercomparisons between research grade and monitoring instruments demonstrate that significant errors can arise from standard air quality monitors for ozone and nitrogen dioxide. Comparison of aromatic hydrocarbon measurements using three different techniques highlights a potential problem in defining a VOC sampling strategy in urban environment that is meaningful for the comparison with photochemical transport models. Also, the implementation of an innovative Markov Chain Monte Carlo method for inorganic aerosol modeling provided a powerful tool to analyze aerosol data 


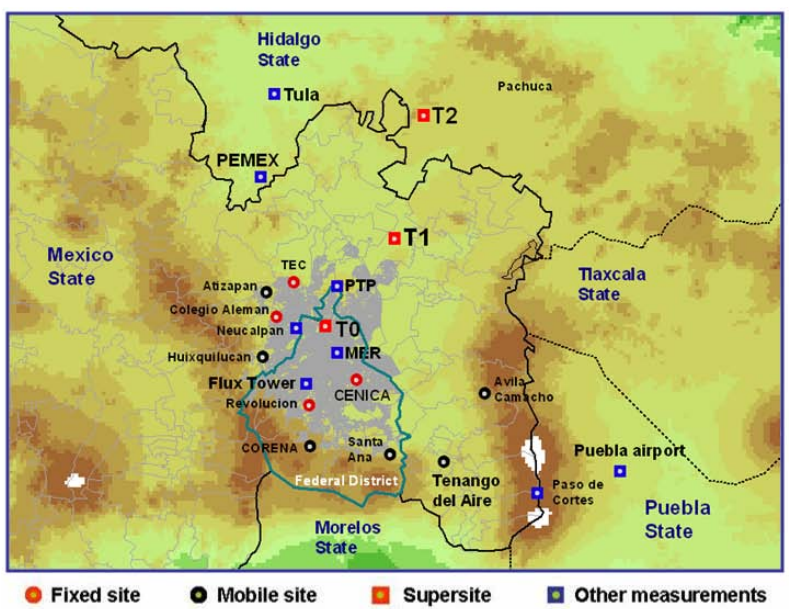

Fig. 4. MCMA-2006: Ground-Based Measurement Sites.

and predict precursor gas phase concentrations where these are unavailable. MCMA-2003 scientific findings were fundamental for the planning of the MILAGRO Campaign, the largest MCMA-focused field study to date.

MILAGRO's measurement phase consisted of a monthlong series of carefully coordinated observations of the chemistry and physics of the atmosphere in and near Mexico City during March 2006, using a wide range of instruments at ground sites and on aircraft. MILAGRO's measurements were complemented by meteorological forecasting and numerical simulations and data from satellite observations and surface monitoring networks. Together, these research observations have provided a wealth of information on MCMA pollutant emissions and ambient concentrations, their dispersion and transformation processes, and their urban, regional and hemispheric impacts.

Results from MCMA-2003 and from MILAGRO-2006 were presented at special sessions on air quality and climate impacts of megacities at the meetings of the American Geophysical Union in 2004 and 2007 and the European Geosciences Union in 2007-2010. Major findings from the MCMA-2003 and MILAGRO-2006 have been published in two special issues of Atmospheric Chemistry and Physics (ACP) as well as in other peer-reviewed journals. A complete list of publications is available at http://mce2.org/ publications.html.

\section{Scope of the MILAGRO campaign}

The MILAGRO Campaign is a large, international, multiagency, collaborative project to evaluate the regional impacts of the Mexico City air pollution plume as a means of understanding urban impacts on the regional and global air quality and climate. Specific goals of the campaign included: (i) quantifying the spatial and temporal extent of the urban plume; (ii) analyzing pollutant chemical and physical trans- formation in the plume; (iii) quantifying the regional impacts of the plume; and (iv) examining the interaction of the urban plume with surrounding sources.

After an initial planning phase which included model simulations of possible dispersion scenarios to guide site selection, the data-collection phase of MILAGRO took place during March 2006. The measurements included a wide range of instruments at ground sites, on aircraft, and satellites. Three supersites, spaced about $30 \mathrm{~km}$ apart to examine the pollutant plume evolution, were set up at the Instituto Mexicano del Petróleo (IMP, “T0”), Universidad Tecnológica de Tecámac in the State of Mexico ("T1") and Rancho La Bisnaga in the State of Hidalgo ("T2"). The designations "T0" (initial time), "T1" (first time step), and "T2" (second time step) refer to the timing of transport of the urban plume to different points in space and time. Additional platforms in or near Mexico City included mobile vans containing scientific laboratories and mobile and stationary upward-looking lidars, and fixed mobile units provided by Mexican institutions located at the boundary sites to measure criteria pollutants and meteorological parameters. Tables 1-4 list the key participating institutions and instrumentation deployed at the various surface sites.

Seven instrumented research aircraft participated in MILAGRO: five were based in Veracruz, Mexico, one in Puebla, Mexico and one in Houston, Texas. The five aircraft based in Veracruz were the NCAR/NSF C-130, the DOE Gulfstream1 (G-1), the US Forest Service Twin Otter, and the NASA J31 and King Air, while the NASA DC- 8 was based in Houston, Texas. The FZK-ENDURO Ultra-light aircraft was stationed at Hermanos Serdán Airport near Huejotzingo, Puebla (Grutter et al., 2008). The scientific payloads of the three larger aircraft are summarized in Table 5 for the C-130, Table 6 for the G-1, and Table 2a of Singh et al. (2009) for the DC-8. The J-31 carried mostly radiometric instruments used to measure aerosols, water vapor, clouds, Earth surface properties, and radiation fields (see Sect. 10 and Table 7), while the King Air carried the high spectral resolution lidar described by Rogers et al. (2009) (see Sect. 9). The Twin Otter focused its sampling on the outflow from biomass burning, with a payload that was described by Yokelson et al. (2007) and included an FTIR instrument, whole air sampling, a nephelometer, and particle sampling for subsequent analysis.

These airborne measurements provided information about the atmosphere over a large region, and at various altitudes. Satellite-based instruments peered down into the atmosphere, providing even larger geographical coverage. Figure 3 shows the geographic coverage and Fig. 4 shows the ground-based measurement sites. The overall campaign was supported by forecasts from meteorological and chemical models, satellite observations, the ambient air quality monitoring network operated by the Atmospheric Monitoring System of the Federal District (Sistema de Monitoreo Atmosférico, SIMAT) and meteorological measurements 
Table 1. List of participating institutions and instruments deployed at the urban sites.

\begin{tabular}{|c|c|c|c|c|}
\hline Institutions & $\begin{array}{l}\text { Principal } \\
\text { Investigators }\end{array}$ & Methods & Parameters & References* \\
\hline \multicolumn{5}{|l|}{ T0 (IMP) } \\
\hline CENICA & B. Cardenas & $\begin{array}{l}\text { tethered balloon, } \\
\text { ozonesondes, metsondes; } \\
\text { pilot balloons with } \\
\text { theodolites }\end{array}$ & $\begin{array}{l}\mathrm{O}_{3} \text { and met parameters } \\
\text { up to } 1000 \mathrm{~m} \text {, VOCs up to } 200 \mathrm{~m} \text {; } \\
\text { wind speed and wind } \\
\text { direction vertical profile }\end{array}$ & Velasco et al., 2008 \\
\hline $\begin{array}{l}\text { CENICA; } \\
\text { CSIC (Spain) }\end{array}$ & $\begin{array}{l}\text { B. Cardenas, } \\
\text { X. Querol }\end{array}$ & $\begin{array}{l}\text { (5) mini-vol samplers; (2) } \\
\text { HiVol, } 1 \text { RAAS and } 4 \text { mini- } \\
\text { vol manual samplers for } \\
\text { PM }_{2.5} \text {, TSP and } \text { PM }_{10} \text {; } \\
\text { Laser spectrometer }\end{array}$ & $\begin{array}{l}\text { OC, EC, thermal optical } \\
\text { reflectance and ions in } \\
\mathrm{PM}_{2.5} \text {; metals, morphology } \\
\text { by SEM; real time } \\
\text { measurement of } \mathrm{PM}_{10}, \\
\mathrm{PM}_{2.5}, \mathrm{PM}_{1}\end{array}$ & Querol et al., 2008 \\
\hline $\begin{array}{l}\text { MIT/MCE2/ } \\
\text { UCSD/Heidelberg }\end{array}$ & $\begin{array}{l}\text { L. T. Molina, } \\
\text { R. Volkamer, } \\
\text { U. Platt }\end{array}$ & $\begin{array}{l}\text { (2) LP-DOAS; } \\
\text { Spectroradiometer }\end{array}$ & $\begin{array}{l}\mathrm{NO}_{2}, \mathrm{HONO}, \mathrm{VOCs}, \\
\text { glyoxal, aromatic VOCs, } \\
\mathrm{SO}_{2} ; \mathrm{UV} \text { actinic fluxes }\end{array}$ & $\begin{array}{l}\text { Volkamer et al., 2007; } \\
\text { Dusanter et al., 2009b }\end{array}$ \\
\hline Texas A\&M & R. Zhang & PTR-MS; CIMS; & VOCs; $\mathrm{HNO}_{3}$ & $\begin{array}{l}\text { Fortner et al., 2009; } \\
\text { Zheng et al., } 2008\end{array}$ \\
\hline Texas A\&M & D. Collins & $\begin{array}{l}\text { TDMA; APS; CCN } \\
\text { separator }\end{array}$ & $\begin{array}{l}\text { Hygroscopicity; aerosol } \\
\text { supermicron size distri- } \\
\text { bution; CCN properties }\end{array}$ & Wang et al., 2010 \\
\hline MIT/Goteborg U. & $\begin{array}{l}\text { J. Pettersson, } \\
\text { J. Noda }\end{array}$ & $\begin{array}{l}\text { SPMS; AMS; Aerosol } \\
\text { Spectrometer (portable); } \\
\mathrm{PM}_{2.5} \text { samplers }\end{array}$ & $\begin{array}{l}\text { Aerosol number, size } \\
\text { distribution; } \mathrm{Na}, \mathrm{K}, \mathrm{Rb}, \mathrm{Cs} \\
\text { in } \mathrm{PM} ; 15 \text { size channel } \\
\text { count and mass distribution } \\
\text { in } 0.13-20 \mu \mathrm{m} \text { range; } \mathrm{PM}_{2.5}\end{array}$ & Aiken et al., 2010 \\
\hline ANL, UALR & $\begin{array}{l}\text { J. Gaffney, } \\
\text { N. Marley }\end{array}$ & $\begin{array}{l}\text { Aethalometer ( } 7 \text { channel); } \\
\text { Multi-angle Absorption } \\
\text { Photometer; nephelometer } \\
\text { ( } 3 \text { and } 1 \text { wavelengths); } \\
\text { filter sampler }\end{array}$ & $\begin{array}{l}\text { Aerosol absorption }(\mathrm{BC}) \text {; } \\
\text { dry and wet particle } \\
\text { scattering; OC/EC, Humic- } \\
\text { like substances, }{ }^{14} \mathrm{C},{ }^{40} \mathrm{~K} \text {, } \\
{ }^{210} \mathrm{~Pb},{ }^{7} \mathrm{Be},{ }^{210} \mathrm{Po},{ }^{210} \mathrm{Bi}\end{array}$ & Marley et al., 2009a, b \\
\hline ANL, UALR & $\begin{array}{l}\text { J. Gaffney, } \\
\text { N. Marley }\end{array}$ & $\begin{array}{l}\text { Vaisala Weather Station, } \\
\text { radiometer }\end{array}$ & $\begin{array}{l}\text { Wind speed/direction, rain, } \\
T, P, \mathrm{RH} \text {; broadband } \mathrm{UV} \\
\text { radiation }\end{array}$ & Marley et al., 2009a, b \\
\hline BNL & J. Wang & $\begin{array}{l}\text { CCN Counter; } \\
\text { SMPS }\end{array}$ & $\begin{array}{l}\mathrm{CCN} \text {; } \\
\text { aerosol size distributions }\end{array}$ & $\begin{array}{l}\text { Aiken et al., 2009; } \\
\text { Ervens et al., 2010; } \\
\text { Wang et al., } 2010\end{array}$ \\
\hline MIT/VT & $\begin{array}{l}\text { L. T. Molina, } \\
\text { L. Marr }\end{array}$ & $\begin{array}{l}\text { EcoChem PAS } 2000 \mathrm{CE} \text {; } \\
\text { DC } 2000 \text { CE monitors }\end{array}$ & $\begin{array}{l}\text { PAHs, } \\
\text { active surface }\end{array}$ & Thornhill et al., 2008 \\
\hline U. Colorado & J.L. Jimenez & $\begin{array}{l}\text { HR-ToF-AMS; thermal } \\
\text { denuder; aerosol } \\
\text { concentrator; optical } \\
\text { particle counter; SMPS; } \\
\text { DustTrak }\end{array}$ & $\begin{array}{l}\text { Aerosol size, composition, } \\
\text { number; nanoparticle size } \\
\text { distribution; aerosol } \\
\text { concentration }\end{array}$ & $\begin{array}{l}\text { Aiken et al., 2008, } \\
\text { 2009, 2010; Huffman } \\
\text { et al., 2009; Salcedo } \\
\text { et al., 2010; Paredes- } \\
\text { Miranda et al., 2009; }\end{array}$ \\
\hline ARI & D. Worsnop & $\begin{array}{l}\text { HR-ToOF-AMS with soft } \\
\text { ionization }\end{array}$ & $\begin{array}{l}\text { fine PM organic } \\
\text { composition }\end{array}$ & \\
\hline DRI, U Nevada & P. Arnott & $\begin{array}{l}\text { Photoacoustic } \\
\text { spectrometer }\end{array}$ & Aerosol absorption & $\begin{array}{l}\text { Paredes-Miranda et } \\
\text { al., } 2009\end{array}$ \\
\hline PNNL/EMSL & A. Laskin & $\begin{array}{l}\text { DRUM aerosol sampler; } \\
\text { TRAC aerosol sampler; } \\
\text { Cascade impactor }\end{array}$ & $\begin{array}{l}\text { Sampling for } \\
\text { PIXE/PESA/STEM; TEM, } \\
\text { SEM/EDX analysis }\end{array}$ & $\begin{array}{l}\text { Johnson et al., } 2005 \text {; } \\
\text { Aiken et al., } 2010\end{array}$ \\
\hline
\end{tabular}


Table 1. Continued.

\begin{tabular}{|c|c|c|c|c|}
\hline Institutions & $\begin{array}{l}\text { Principal } \\
\text { Investigators }\end{array}$ & Methods & Parameters & References* \\
\hline PNNL & $\begin{array}{l}\text { C. Doran, } \\
\text { W. Shaw }\end{array}$ & $\begin{array}{l}\text { MFRSR; Eppley B\&W } \\
\text { radiometer }\end{array}$ & $\begin{array}{l}\text { radiation, aerosol optical } \\
\text { depth }\end{array}$ & Doran et al., 2007 \\
\hline Colorado State U. & J. Slusser & MFRSR & $\begin{array}{l}\text { UV filter irradiances } \\
\text { (diffuse and total) }\end{array}$ & Doran et al., 2007 \\
\hline LANL & M. Dubey & $\mathrm{H}_{2} / \mathrm{CO} / \mathrm{C}_{2} \mathrm{H}_{4}$ Monitor & $\mathrm{H}_{2}, \mathrm{CO}, \mathrm{C}_{2} \mathrm{H}_{4}$ & \\
\hline Chalmers & B. Galle & 3 MAX-DOAS; & $\begin{array}{l}\text { Vertical and horizontal } \\
\text { mapping of } \mathrm{NO}_{2}\end{array}$ & $\begin{array}{l}\text { Johansson et al., } \\
2009\end{array}$ \\
\hline $\begin{array}{l}\text { U. Alabama at } \\
\text { Huntsville (UAH) }\end{array}$ & J. Walters & $\begin{array}{l}\text { wind profiler; ceilometer; } \\
12 \text {-channel passive } \\
\text { microwave radiometer }\end{array}$ & $\begin{array}{l}\text { Wind speed/direction } \\
\text { versus height }\end{array}$ & $\begin{array}{l}\text { Shaw et al., 2007; } \\
\text { de Foy et al., } 2009\end{array}$ \\
\hline IFU & W. Junkermann & $\mathrm{HCHO}$ instrument & $\mathrm{HCHO}$ & Dusanter et al., 2009b \\
\hline UCSD & K. Prather & ATOF-MS & $\begin{array}{l}\text { Single particle sice and } \\
\text { composition }\end{array}$ & Moffet et al., 2008a \\
\hline UW-Madison & J. Schauer & $\begin{array}{l}\text { Filter Sampler; Semi- } \\
\text { continuous EC/OC }\end{array}$ & $\begin{array}{l}\text { Organic speciation; } \\
\text { realtime EC/OC }\end{array}$ & $\begin{array}{l}\text { Stone et al., 2008, } \\
\text { 2010a; Aiken et al., } \\
\text { 2009, } 2010\end{array}$ \\
\hline UW-Madison & J. Schauer & $\begin{array}{l}\text { Tekran Ambient Mercury } \\
\text { Analyzer }\end{array}$ & $\begin{array}{l}\mathrm{Hg} \text { in gas and particulate } \\
\text { phase }\end{array}$ & Rutter et al., 2009 \\
\hline UAM-Azcapotzalco & V. Mugica & High Vol Samplers & $\mathrm{PM}_{10}, \mathrm{PM}_{2.5}$ & Mugica et al., 2009 \\
\hline U-Iowa & C. Stainier & $\begin{array}{l}\text { dry-ambient aerosol size } \\
\text { spectrometer; SMPS }\end{array}$ & $\begin{array}{l}\text { aerosol water content } \\
\text { using RH-controlled SMPS } \\
\& \text { APS }\end{array}$ & \\
\hline U. Iowa & W. Eichinger & $\begin{array}{l}\text { Vertically pointing lidar; } \\
\mathrm{H}_{2} \mathrm{O} / \mathrm{CO}_{2} \text { sensor; } \mathrm{CO} \\
\text { monitor; } T, P \text { and humidity } \\
\text { probes; up and down- } \\
\text { welling long \& short } \\
\text { wave radiation; } \\
\text { sonic anemometers }\end{array}$ & $\begin{array}{l}\text { aerosol vertical profile; } \\
\mathrm{H}_{2} \mathrm{O}, \mathrm{CO}_{2}, \mathrm{CO}, T, P, \\
\mathrm{RH}, \mathrm{WS}, \mathrm{WD} \text {, radiation }\end{array}$ & $\begin{array}{l}\text { Lewandowski et al., } \\
2010\end{array}$ \\
\hline Indiana U. & P. Stevens & $\begin{array}{l}\text { Laser and supporting } \\
\text { equipment for } \mathrm{HO}_{x} \\
\text { measurements }\end{array}$ & $\mathrm{HO}_{\mathrm{x}}$ concentrations & $\begin{array}{l}\text { Dusanter et al., } \\
\text { 2009a }\end{array}$ \\
\hline $\begin{array}{l}\text { Paul Scherrer } \\
\text { Institute }\end{array}$ & U. Baltensperger & IC-MS & $\begin{array}{l}\text { Organic acids (gas \& } \\
\text { aerosol) }\end{array}$ & Zheng et al., 2008 \\
\hline SMA-GDF & A. Retama & $\begin{array}{l}\text { commercial automatic } \\
\text { monitors }\end{array}$ & $\begin{array}{l}\mathrm{NO}_{\mathrm{x}}, \mathrm{CO}, \mathrm{O}_{3}, \mathrm{SO}_{2} \text {, and } \\
\mathrm{PM}_{10}\end{array}$ & Molina et al., 2007 \\
\hline \multicolumn{5}{|l|}{ SIMAT Site } \\
\hline WSU/MCE2 & $\begin{array}{l}\text { B. Lamb, } \\
\text { T. Jobson } \\
\text { L. T. Molina }\end{array}$ & $\begin{array}{l}\text { Flux tower; Fast Olefin } \\
\text { Sensor, PTR-MS, } \mathrm{CO}_{2} / \\
\mathrm{H}_{2} \mathrm{O} \text { IRGA, met station, } \\
\text { GC-FID for VOC flux samples }\end{array}$ & $\begin{array}{l}\text { fluxes of VOCs, } \mathrm{CO}_{2} \text {, } \\
\mathrm{H}_{2} \mathrm{O}, \mathrm{O}_{3}, \mathrm{PAH} \text {; sensible } \\
\text { and latent heat, radiation; } \\
\text { met data: } T, \mathrm{RH}, P, \mathrm{WS}, \mathrm{WD}\end{array}$ & Velasco et al., 2009, 2010 \\
\hline $\begin{array}{l}\text { PNNL/WSU/CEH/U. } \\
\text { Colorado }\end{array}$ & M. Alexander & Quadrupole AMS & $\begin{array}{l}\text { Size-resolved composition } \\
\text { and fluxes of speciated } \\
\text { non-refractory } \mathrm{PM}_{1} \text { aerosols }\end{array}$ & Yu et al., 2009 \\
\hline UCSD/SIO & L. Russell & $\begin{array}{l}\text { Submicron aerosol } \\
\text { samples (FTIR and XRF } \\
\text { analysis) }\end{array}$ & Organic functional groups & Gilardoni et al., 2009 \\
\hline UCLA & J. Stutz & LP-DOAS & $\begin{array}{l}\mathrm{O}_{3}, \mathrm{NO}_{2}, \mathrm{HCHO}, \mathrm{NO}_{3}, \\
\mathrm{HONO} \text {, and } \mathrm{SO}_{2}\end{array}$ & \\
\hline
\end{tabular}


Table 1. Continued.

\begin{tabular}{|c|c|c|c|c|}
\hline Institutions & $\begin{array}{l}\text { Principal } \\
\text { Investigators }\end{array}$ & Methods & Parameters & References* \\
\hline \multicolumn{5}{|l|}{ CENICA Site } \\
\hline CENICA & B. Cardenas & GC-FID & 55 speciated hydrocarbons & $\begin{array}{l}\text { Wöhrnschimmel et } \\
\text { al., } 2010\end{array}$ \\
\hline CENICA & B. Cardenas & $\begin{array}{l}\text { Commercial automatic } \\
\text { monitors at CENICA } \\
\text { Monitoring station for } \\
\text { criteria pollutants and } \\
\text { meteorological parameters }\end{array}$ & $\begin{array}{l}\mathrm{PM}_{10}, \mathrm{PM}_{2.5}, \mathrm{NOx}, \mathrm{CO}, \\
\mathrm{SO}_{2}, \mathrm{O}_{3} \text {, Total } \\
\text { hydrocarbons, carbon in } \\
\text { particles; UVA and UVB, } \\
\text { WS, WD, RH, } T\end{array}$ & Querol et al., 2008 \\
\hline $\begin{array}{l}\text { CENICA, CSIC } \\
\text { (Spain) }\end{array}$ & $\begin{array}{l}\text { B. Cardenas, } \\
\text { X. Querol }\end{array}$ & $2 \mathrm{Hi}-\mathrm{Vol}$ for $\mathrm{PM}_{10}$ & $\begin{array}{l}\text { chemical characterization } \\
\text { of: ions, metals, OC, } \\
\text { EC, TC, morphology by SEM }\end{array}$ & $\begin{array}{l}\text { Querol et al., 2008; } \\
\text { Moreno et al., 2008b }\end{array}$ \\
\hline \multicolumn{5}{|c|}{ Naucalpan Industrial Sites } \\
\hline ITESM & G. Mejia & $\begin{array}{l}\text { Automatic continuous } \\
\text { measurement of particles } \\
\text { Thermo DATA RAM, } \\
\text { CLIMET, PARTISOL }\end{array}$ & $\mathrm{PM}_{2.5}, \mathrm{PM}_{10}$ & \\
\hline ITESM & D. Tejeda & $\begin{array}{l}\text { Electron microscope; } \\
\text { Isokinetics }\end{array}$ & $\begin{array}{l}\text { particle size and shape; } \\
\text { concentration of various } \\
\text { combustion gases in stacks }\end{array}$ & \\
\hline \multicolumn{5}{|c|}{ MAX-DOAS Network } \\
\hline $\begin{array}{l}\text { MIT/MCE2, } \\
\text { UCSD, Heidelberg }\end{array}$ & $\begin{array}{l}\text { L. T. Molina, } \\
\text { R. Volkamer, } \\
\text { U. Platt }\end{array}$ & $\begin{array}{l}5 \text { passive multiple axis } \\
\text { DOAS (MAX-DOAS) } \\
\text { (at T0, T1, T2, Pico de } \\
\text { Tres Padres, Tenango del } \\
\text { Aire, Cerro Chiquevite) }\end{array}$ & $\begin{array}{l}\text { Vertical profiles of } \mathrm{NO}_{2} \\
\mathrm{SO}_{2}, \mathrm{HCHO}, \mathrm{CHOCHO} \\
\mathrm{O}_{3}, \mathrm{HONO}\end{array}$ & \\
\hline \multicolumn{5}{|c|}{ Sun Photometer Network } \\
\hline $\begin{array}{l}\text { MCE2/MIT, } \\
\text { NASA Goddard }\end{array}$ & $\begin{array}{l}\text { L. T. Molina, } \\
\text { V. Martins }\end{array}$ & $\begin{array}{l}5 \text { Microtops II sun } \\
\text { photometers and } 3 \text { CIMEL AERONET (at } \\
\text { Hidalgo, UNAM, Corena, } \\
\text { TEC, UAM-I, T0, T1, T2) }\end{array}$ & $\begin{array}{l}\text { Aerosol optical thickness, } \\
\text { retrievals of aerosol } \\
\text { optical parameters }\end{array}$ & Castanho et al., 2007 \\
\hline
\end{tabular}

* The related publications where the instruments or methods have been described or mentioned.

provided by the Mexican National Weather Service (Servicio Meteorológico Nacional, SMN).

The MILAGRO campaign was organized under the following four coordinated components that took place simultaneously during March 2006:

\subsection{The MCMA-2006 (Mexico City Metropolitan Area - 2006 Experiment)}

The MCMA-2006 examined emissions and surface concentrations within the Mexico City Basin, their transport and transformation in the atmosphere, and the effects on human health. MCMA-2006 was led by the Molina Center for Energy and the Environment (MCE2) with projects sponsored by NSF, DOE, and several Mexican research agencies, including CAM, INE/SEMARNAT, CONACyT and
PEMEX, as well as European agencies. The overall purpose of MCMA-2006 was to strengthen the scientific base for the design and evaluation of policies to improve the air quality in the MCMA by gathering scientific information that helps to better understand the generation and processing of pollutants in the MCMA, their dispersal, transport and transformation in the atmosphere, the exposure patterns of the population to these pollutants and the effects on human health. MCMA2006 also provided many of the urban measurements needed for understanding the larger scale pollutant evolution which was the focus of its sister campaigns. The required data on particles, VOCs and other gases, meteorology, and solar radiation was gathered at the T0 supersite, a flux tower located at the SIMAT headquarters in the city center (referred to as "SIMAT" site thereafter), measurements at the Tula refinery site and industrial zone in Naucalpan, in combination with a 
Table 2. List of participating institutions and instruments deployed at the T1 site.

\begin{tabular}{|c|c|c|c|c|}
\hline Institutions & $\begin{array}{l}\text { Principal } \\
\text { Investigators }\end{array}$ & Methods & Parameters & References* \\
\hline ANL, UALR & $\begin{array}{l}\text { J. Gaffney, } \\
\text { N. Marley }\end{array}$ & $\begin{array}{l}\text { Filter Sampler; Filter } \\
\text { Samplers for wet aerosols; } \\
\text { Precipitation Sampler; }\end{array}$ & $\begin{array}{l}{ }^{14} \mathrm{C},{ }^{40} \mathrm{~K},{ }^{210} \mathrm{~Pb},{ }^{7} \mathrm{Be},{ }^{210} \mathrm{Po}, \\
{ }^{210} \mathrm{Bi} \text {; OC/EC, Humic Like } \\
\text { Substances; C-14, } \\
\text { Radionuclides. }\end{array}$ & Marley et al., 2009a, b \\
\hline ANL, UALR & $\begin{array}{l}\text { J. Gaffney, } \\
\text { N. Marley }\end{array}$ & $\begin{array}{l}\text { Vaisala weather station; } \\
\text { RB radiometer; }\end{array}$ & $\begin{array}{l}\mathrm{WS}, \mathrm{WD}, T, \mathrm{RH}, \\
\text { precipitation rate; } \\
\text { broadband } \mathrm{UV} \text { radiation }\end{array}$ & Marley et al., 2009a,b \\
\hline $\begin{array}{l}\text { ANL, U. Alabama } \\
\text { at Huntsville }\end{array}$ & $\begin{array}{l}\text { R. Coulter, } \\
\text { J. Walters }\end{array}$ & $\begin{array}{l}\text { Radar wind profiler; } \\
\text { radiosondes; Sodar; } \\
\text { Micropulse lidar }\end{array}$ & $\begin{array}{l}\text { Wind speed, direction vs. } \\
\text { height; RH, } T \text { vs. height; } \\
\text { Lower wind fields; } \\
\text { aerosol concentration vs. height; }\end{array}$ & $\begin{array}{l}\text { Doran et al., 2007, 2008; } \\
\text { Shaw et al., } 2007\end{array}$ \\
\hline $\begin{array}{l}\text { CENICA, CSIC } \\
\text { (Spain) }\end{array}$ & $\begin{array}{l}\text { B. Cardenas, } \\
\text { X. Querol }\end{array}$ & $\begin{array}{l}\text { (5) minivol samplers; } \\
\text { (2) HiVol, } 1 \text { RAAS and } \\
4 \text { mini-vol manual samplers } \\
\text { for } \mathrm{PM}_{2.5} \text {, TSP and } \mathrm{PM}_{1} 0\end{array}$ & $\begin{array}{l}\text { OC, EC, thermal optical } \\
\text { reflectance and ions } \\
\text { in } \mathrm{PM}_{2.5} ; \text { metals, } \\
\text { morphology by SEM }\end{array}$ & $\begin{array}{l}\text { Querol et al., 2008; } \\
\text { Moreno et al., 2008b }\end{array}$ \\
\hline CENICA & $\begin{array}{l}\text { B. Cardenas, } \\
\text { G. Solórzano }\end{array}$ & Tekran $2537^{a}$ & $\mathrm{Hg}$ in gas phase & Rutter et al., 2009 \\
\hline DRI-Reno & P. Arnott & photoacoustic spectrometer & aerosol absorption & Doran et al., 2007 \\
\hline Georgia Inst. Tech. & $\begin{array}{l}\text { A. Nenes, } \\
\text { J. Smith }\end{array}$ & $\begin{array}{l}\text { HTDMA,CCN counter; } \\
\text { KSV tensiometer }\end{array}$ & $\begin{array}{l}\text { hygroscopicity size } \\
\text { resolved in } 10-150 \mathrm{~nm} \\
\text { range; } \mathrm{CCN} \text { concentration } \\
\text { surface tension }\end{array}$ & Padró et al., 2010 \\
\hline Georgia Inst. Tech. & G. Huey & CIMS; CLD & $\begin{array}{l}\mathrm{OH}, \mathrm{HO}_{2}+\mathrm{RO}_{2}, \mathrm{H}_{2} \mathrm{SO}_{4} \\
\mathrm{NO}, \mathrm{SO}_{2}, \mathrm{CO} \text { and } \mathrm{O}_{3}\end{array}$ & $\begin{array}{l}\text { Nunnermacker et al., 2008; } \\
\text { Smith et al., } 2008\end{array}$ \\
\hline Georgia Inst. Tech. & R. Weber & TEOM; Hi Vol & $\begin{array}{l}\mathrm{PM}_{2.5} \text { mass; } \\
\text { filter sampling }\end{array}$ & $\begin{array}{l}\text { Stone et al., 2008; } \\
\text { Padró et al., } 2010\end{array}$ \\
\hline Georgia Inst. Tech. & R. Weber & $\begin{array}{l}\text { PILS } \\
\text { and inorganics }\end{array}$ & $\begin{array}{l}\text { Bulk soluble organics } \\
\text { Hennigan et al., } 2008\end{array}$ & Fountoukis et al., 2009; \\
\hline IFU & W. Junkermann & HCHO instrument (Hantzsch) & $\mathrm{HCHO}$ & de Gouw et al., 2009 \\
\hline IIE, Morelos & $\begin{array}{l}\text { A. Salcido, } \\
\text { A. T. Celada }\end{array}$ & 3-D sonic anemometers & $\mathrm{WD}, \mathrm{WS}, T, \mathrm{RH}$, fluxes & $\begin{array}{l}\text { de Gouw et al., 2009; } \\
\text { Moreno et al., 2008b }\end{array}$ \\
\hline LBNL (LDRD) & M. Fischer & NIR-TDLAS & $\mathrm{NH}_{3}$ & Fountoukis et al., 2009 \\
\hline NCAR & $\begin{array}{l}\text { A. Guenther, } \\
\text { J. Greenberg, } \\
\text { A. Turnipseed }\end{array}$ & $\begin{array}{l}\text { Continuous profiling } \\
\text { tethered balloon } \\
\text { system; radiometers }\end{array}$ & $\begin{array}{l}\mathrm{O}_{3}, \text { particles, } \\
T, \mathrm{WS}, \mathrm{WD}, \mathrm{RH}, \\
\text { direct diffuse PAR }\end{array}$ & Greenberg et al., 2009 \\
\hline NCAR & Mike Coffey & $\begin{array}{l}\text { mobile Fourier } \\
\text { Transform Spectrometer }\end{array}$ & $\begin{array}{l}\text { Column: } \mathrm{H}_{2} \mathrm{O}, \mathrm{CO}_{2}, \\
\mathrm{CF}_{2} \mathrm{Cl}_{2}, \mathrm{HCN}, \mathrm{N}_{2} \mathrm{O}, \mathrm{HCL}, \\
\mathrm{HDO}, \mathrm{CO}, \mathrm{CFCl}{ }_{3}, \mathrm{OCS}, \\
\mathrm{NO}, \mathrm{HF}, \mathrm{O} 3, \mathrm{CH}_{4}, \mathrm{SO}_{2}, \\
\mathrm{NO}_{2}, \mathrm{C}_{2} \mathrm{H}_{6}, \mathrm{HNO}_{3}, \mathrm{PAN}, \\
\mathrm{C}_{2} \mathrm{H}_{2}, \mathrm{CH}_{2} \mathrm{O}, \mathrm{CHF}_{2} \mathrm{Cl}\end{array}$ & \\
\hline $\begin{array}{l}\text { NOAA, } \\
\text { Univ Colorado }\end{array}$ & $\begin{array}{l}\text { J. de Gouw. } \\
\text { C. Warneke, }\end{array}$ & $\begin{array}{l}\text { GC-FID; } \\
\text { PIT-MS }\end{array}$ & $\begin{array}{l}\text { Alkanes, alkenes; } \\
\text { VOCs (aromatics, } \\
\text { oxygenates, isoprene, } \\
\text { monoterpenes, acetonitrile }\end{array}$ & de Gouw et al., 2009 \\
\hline Penn State & A. Thompson & Ozonesonde ground station & $\mathrm{O}_{3}$ profile & Thompson et al., 2008 \\
\hline
\end{tabular}

highly capable mobile laboratory, a microlight research aircraft and several fixed mobile units deployed throughout the MCMA at representative urban and boundary sites. In addition, two health studies were carried out during the campaign.
In order to contribute to the education and training of young investigators and to raise public awareness toward atmospheric pollution problems, the Molina Center, in collaboration with the Mexican National Institute of Ecology and other local institutions, set up a series of education and outreach activities, including public lectures, workshops, guided 
Table 2. Continued.

\begin{tabular}{|c|c|c|c|c|}
\hline Institutions & $\begin{array}{l}\text { Principal } \\
\text { Investigators }\end{array}$ & Methods & Parameters & References* \\
\hline PNNL & $\begin{array}{l}\text { C. Doran, } \\
\text { W. Shaw, } \\
\text { J. Barnard }\end{array}$ & $\begin{array}{l}\text { Eppley B\&W radiometers; } \\
\text { Nephelometer; PSAP; } \\
\text { OCEC analyzer; CPC } \\
\text { MFRSR, pyrheliometer, } \\
\text { solar tracker }\end{array}$ & $\begin{array}{l}\text { solar radiation; aerosol } \\
\text { size and numbers; } \mathrm{n} \\
\text { light scattering ; Black } \\
\text { Carbon (aerosol absorption); } \\
\text { OC/EC; aerosol optical } \\
\text { depth, solar radiatio }\end{array}$ & $\begin{array}{l}\text { Doran et al., 2007, 2008; } \\
\text { Yu et al., } 2009\end{array}$ \\
\hline PNNL/EMSL & $\begin{array}{l}\text { A. Laskin, } \\
\text { M. Alexander }\end{array}$ & $\begin{array}{l}\text { DRUM Aerosol Sampler; } \\
\text { TRAC Aerosol Sampler; } \\
\text { SMPS; CCN counter }\end{array}$ & $\begin{array}{l}\text { sampling for PIXE/PESA/STEM; } \\
\text { sampling for TEM, } \\
\text { SEM/EDX analysis; Aerosol } \\
\text { size; CCN counter }\end{array}$ & Moffet et al., 2010 \\
\hline PNNL & M. Alexander & TOF-AMS & $\begin{array}{l}\text { aerosol concentration } \\
\text { and size distribution }\end{array}$ & $\begin{array}{l}\text { de Gouw et al., 2009; } \\
\text { Yu et al., } 2009\end{array}$ \\
\hline RAMA & A. Retama & Mobile unit & $\begin{array}{l}\mathrm{CO}, \mathrm{NO}_{\mathrm{x}}, \mathrm{SO}_{2}, \mathrm{O}_{3}, \mathrm{PM}_{10}, \\
\text { WD, WS, } T, \mathrm{HR}\end{array}$ & Molina et al., 2007 \\
\hline Texas A\&M U. & Don Collins & DMA, H,V-TDMA & $\begin{array}{l}\text { aerosol } 0.01-1 \text { micron } \\
\text { size, size resolved } \\
\text { hygroscopicity, volatility, } \\
\text { mixing state }\end{array}$ & Wang et al., 2010 \\
\hline U. C. Berkeley & R. Cohen & TD-LIF & $\mathrm{NO}_{2}, \mathrm{NO}_{3}, \mathrm{~N}_{2} \mathrm{O}_{5}, \mathrm{HNO}_{3}$ & Fountoukis et al., 2009 \\
\hline $\begin{array}{l}\text { U. Houston, } \\
\text { Colorado State U. }\end{array}$ & $\begin{array}{l}\text { B. Lefer, } \\
\text { J. Slusser }\end{array}$ & $\begin{array}{l}\text { SAFS, MFRSR. UV-mfr, } \\
\text { coud camera, Cimel }\end{array}$ & $\begin{array}{l}\text { Spectral actinic flux, } \\
\text { UV irradiances } \\
\text { (diffuse and total) }\end{array}$ & $\begin{array}{l}\text { Hennigan et al., 2008; } \\
\text { Corr et al., } 2009\end{array}$ \\
\hline $\begin{array}{l}\text { U. Miami, } \\
\text { U. C. Irvine }\end{array}$ & $\begin{array}{l}\text { E. Atlas, } \\
\text { D. Blake }\end{array}$ & $\begin{array}{l}\text { VOC Canister sampling; } \\
\text { adsorbent and } \\
\text { filter samples }\end{array}$ & $\begin{array}{l}\text { anthropogenic and biogenic } \\
\mathrm{HCs}, \mathrm{RONO}_{2}, \mathrm{MTBE} \\
\text { DMS, OCS, halogenated } \\
\text { organics; nitrates }\end{array}$ & de Gouw et al., 2009 \\
\hline $\begin{array}{l}\text { U. Minnesota/ } \\
\text { NCAR }\end{array}$ & $\begin{array}{l}\text { P. McMurray, } \\
\text { J. Smith }\end{array}$ & $\begin{array}{l}\text { TDCIMS; NTDMA; } \\
\text { IGMA; High-vol sampler }\end{array}$ & $\begin{array}{l}\text { ultrafine aerosol composition; } \\
\text { nanoparticle size distribution, } \\
\text { hygroscopicity and volatility; } \\
\text { ambient ions and } \\
\text { ion clusters; aerosol } \\
\text { surface tension }\end{array}$ & $\begin{array}{l}\text { Smith et al., } 2008 \text {; } \\
\text { Iida et al., } 2008\end{array}$ \\
\hline $\begin{array}{l}\text { U. Wisconsin } \\
\text { at Madison }\end{array}$ & J Schauer & $\begin{array}{l}\text { Filter samples with GC-MS } \\
\text { and various LC, GCMS }\end{array}$ & speciated organic content & Stone et al., 2009 \\
\hline U. Wisconsin & J. Schauer & $\begin{array}{l}\text { Tekran ambient } \\
\text { Hg analyzer }\end{array}$ & $\begin{array}{l}\mathrm{Hg} \text { in gas and } \\
\text { particulate phase }\end{array}$ & Rutter et al., 2009 \\
\hline UNAM & A. Muhlia & $\begin{array}{l}\text { Pyranometer, } \\
\text { AERONET; }\end{array}$ & $\begin{array}{l}\text { spectral irradiance, } \\
\text { aerosol optical depth, }\end{array}$ & Castanho et al., 2007 \\
\hline UNAM & J. Miranda & 3 MiniVol & $\mathrm{PM}_{10}, \mathrm{PM}_{2.5}$ & \\
\hline UNAM & T. Castro & $\begin{array}{l}\text { Moudi, nephelometer, } \\
\text { particle soot absorption } \\
\text { photometer, particle } \\
\text { counters, PAH monitor, } \mathrm{CO}_{2} \text { monitor }\end{array}$ & $\begin{array}{l}\text { particles (number, size, } \\
\text { chemical composition, } \\
\text { optical properties), } \\
\text { PAH, } \mathrm{CO}_{2}\end{array}$ & Marley et al., 2009b \\
\hline UNAM & M. Moya & Filter samples & $\mathrm{PM}_{1}, \mathrm{PM}_{2.5}$ & \\
\hline UNAM, Euphore & G. Ruiz & $\begin{array}{l}\text { HONO Long path } \\
\text { Absorption Photometer }\end{array}$ & HONO & \\
\hline
\end{tabular}

*The related publications where the instruments or methods have been described or mentioned.

tours, essay and poster contests, which were carried out in parallel to the scientific activities by Mexican and international researchers working at the different measurement sites (http://mce2.org/education/milagro.html).

\subsection{MAX-Mex (Megacity Aerosol Experiment: Mexico City)}

Max-Mex focused on examining how the Mexico megacity aerosol evolves during transport, and how the chemical and physical nature of the aerosol affected scattering and 
Table 3. List of participating institutions and instruments deployed at $\mathrm{T} 2$ and other sites

\begin{tabular}{|c|c|c|c|c|}
\hline Institutions & $\begin{array}{l}\text { Principal } \\
\text { Investigators }\end{array}$ & Methods & Parameters & References* \\
\hline \multicolumn{5}{|c|}{ T2 (Rancho La Bisnaga, Hidalgo) } \\
\hline $\begin{array}{l}\text { DRI, U of } \\
\text { Nevada-Reno }\end{array}$ & P. Arnott & $\begin{array}{l}\text { Photoacoustic Absorption } \\
\text { Spectrometer }\end{array}$ & $\begin{array}{l}\text { Aerosol absorption; } \\
\text { light scattering }\end{array}$ & Paredes-Miranda et al., 2009 \\
\hline PNNL & $\begin{array}{l}\text { C. Doran } \\
\text { W. Shaw }\end{array}$ & $\begin{array}{l}\text { PSAP, Aethalometer; } \\
\text { Nephelometer; PSAP; } \\
\text { OCEC analyzer; CPC }\end{array}$ & $\begin{array}{l}\text { Aaerosol size and numbers; } \\
\text { light scattering ; Black } \\
\text { Carbon (aerosol } \\
\text { absorption); OC/EC }\end{array}$ & Doran et al., 2007; \\
\hline PNNL & $\begin{array}{l}\text { C. Doran, } \\
\text { W. Shaw, } \\
\text { R. Coulter }\end{array}$ & $\begin{array}{l}\text { Radar wind profiler; } \\
\text { radiosondes, Sodar; } \\
\text { weather station; } \\
\text { radiometer, MFRSR }\end{array}$ & $\begin{array}{l}\text { WS and WD vs. height; RH, } \\
T \text { vs. height; } \\
\text { Lower Wind fields; } \\
\text { solar radiation; aerosol } \\
\text { optical depth }\end{array}$ & $\begin{array}{l}\text { Doran et al., 2007; } \\
\text { Shaw et al., } 2007\end{array}$ \\
\hline ANL & J. Gaffney & Aerosol sampler & Radionuclides & Marley et al., 2009a \\
\hline PNNL/EMSL & A. Laskin & $\begin{array}{l}\text { Time-Resolved Aerosol } \\
\text { Collector (TRAC) }\end{array}$ & XRF, Microscopy at EMSL & Johnson et al., 2006 \\
\hline UNAM & A. Muhlia & Pyranometer & Solar irradiance & \\
\hline $\begin{array}{l}\text { CENICA, CSIC } \\
\text { (Spain) }\end{array}$ & $\begin{array}{l}\text { B. Cardenas, } \\
\text { X. Querol }\end{array}$ & $\begin{array}{l}\text { Hi-Vol, } 1 \text { RAAS and } 4 \text { mini- } \\
\text { vol manual samplers for } \\
\mathrm{PM}_{2.5} \text {, TSP and } \mathrm{PM}_{10}\end{array}$ & $\begin{array}{l}\text { OC, EC, thermal optical } \\
\text { reflectance and ions in } \\
\mathrm{PM}_{2.5} ; \text { metals, morphology } \\
\text { by SEM }\end{array}$ & $\begin{array}{l}\text { Querol et al., } 2008 \\
\text { Moreno et al., } 2008\end{array}$ \\
\hline \multicolumn{5}{|l|}{ Popocatepetl Site } \\
\hline Chalmers & B. Galle & Scanning Mini-DOAS & $\begin{array}{l}\mathrm{SO}_{2} \text { Emissions from } \\
\text { Popocatepetl }\end{array}$ & Grutter et al., 2008 \\
\hline UNAM & M. Grutter & $\begin{array}{l}\text { Scanning imaging infrared } \\
\text { spectrometer }\end{array}$ & $\begin{array}{l}\text { Visualizing } \mathrm{SO}_{2} \text { plume from } \\
\text { Volcano }\end{array}$ & Grutter et al., 2008 \\
\hline \multicolumn{5}{|l|}{ Altzomoni Site } \\
\hline UNAM & $\begin{array}{l}\text { D. Baumgardner, } \\
\text { M. Grutter }\end{array}$ & $\begin{array}{l}\text { FTIR; Dual-column GC; } \\
\text { TSI scanning mobility } \\
\text { particle sizer (SMPS); } \\
\text { LasAir particle size; } \\
\text { Nephlometer (1 wavelength) }\end{array}$ & $\begin{array}{l}\mathrm{CO}, \mathrm{O}_{3}, \mathrm{SO}_{2} \\
\text { PANs; condensation } \\
\text { nuclei conc.; particle, } \\
\text { particle scattering }\end{array}$ & Baumgardner et al., 2009 \\
\hline UCSD/SIO & L. Russell & $\begin{array}{l}\text { Quadrupole AMS } \\
\text { Sub-micron filter samples } \\
\text { (off line FTIR analysis) }\end{array}$ & $\begin{array}{l}\text { aerosol mass } \\
\text { concentration; organic } \\
\text { functional group }\end{array}$ & Gilardoni et al., 2009 \\
\hline \multicolumn{5}{|c|}{ Tula Industrial Complex } \\
\hline IMP & A. Zambrano & Biomonitoring & $\begin{array}{l}\text { PAH and metals }(\mathrm{Cd}, \mathrm{Cr} \text {, } \\
\mathrm{Cu}, \mathrm{Hg}, \mathrm{Ni}, \mathrm{Pb}, \mathrm{V}, \mathrm{Zn})\end{array}$ & Zambrano García et al., 2009 \\
\hline IMP & E. Gonzales & $\begin{array}{l}\text { Moudi, Nephelometer, } \\
\text { SMPS, Aethelometer, } \\
\text { solar photometer }\end{array}$ & $\begin{array}{l}\text { size distributions, optical } \\
\text { properties, carbon } \\
\text { concentration, optical depth }\end{array}$ & \\
\hline IMP & E. Vega & MOUDI + Mini-vol & $\mathrm{PM}_{2.5}$ & \\
\hline IMP & J. L. Arriaga & Canisters and cartridges & VOC/SVOC/Carbonyls & \\
\hline IMP, Chalmers & $\begin{array}{l}\text { G. Sosa, } \\
\text { B. Galle }\end{array}$ & Mobile mini-DOAS & $\mathrm{SO}_{2}, \mathrm{NO}_{2}$ emissions & Rivera et al., 2009 \\
\hline IMP, CENICA & $\begin{array}{l}\text { G. Sosa, } \\
\text { H. Wöhrnschimmel }\end{array}$ & Radiosondes; pilot balloons & $\mathrm{WD}, \mathrm{WS}, T, P, \mathrm{RH}$, & Wöhrnschimmel et al., 2010 \\
\hline
\end{tabular}

${ }^{*}$ The related publications where the instruments or methods have been described or mentioned. 
Table 4. List of participating institutions and instruments deployed in the mobile labs and mobile units.

\begin{tabular}{|c|c|c|c|c|}
\hline Institutions & $\begin{array}{l}\text { Principal } \\
\text { Investigators }\end{array}$ & Methods & Parameters & References* \\
\hline \multicolumn{5}{|c|}{ ARI Mobile Laboratory } \\
\hline ARI & C. Kolb & $\begin{array}{l}\text { ToF - AMS; SMPS; } \\
\text { Optical Particle Counter; } \\
\text { Condensation Particle } \\
\text { Counter }\end{array}$ & $\begin{array}{l}\text { PM Size \& Composition; } \\
\text { PM size distribution; } \\
\text { Fine PM mass and number } \\
\text { Density }\end{array}$ & $\begin{array}{l}\text { Herndon et al., } \\
\text { 2008; Zavala et al., } \\
\text { 2009; Wood et al., } \\
\text { 2009, } 2010\end{array}$ \\
\hline ARI & C. Kolb & $\begin{array}{l}\text { Multi-Angle Absorption } \\
\text { Photometer (MAAP) }\end{array}$ & Fine PM BC & See above \\
\hline ARI & C. Kolb & $\begin{array}{l}4 \text { Quantum Cascade } \\
\text { Tunable IR Lasers, } \\
\text { (QC-TILDAS) }\end{array}$ & $\begin{array}{l}\mathrm{CO}, \mathrm{NO}_{2}, \mathrm{NH}_{3}, \mathrm{HNO}_{3}, \\
\mathrm{HCHO}\end{array}$ & See above \\
\hline ARI & C. Kolb & $\begin{array}{l}\text { UV Absorption Photometer; } \\
\text { Chemiluminescent detector; } \\
\text { Licor non-dispersive IR }\end{array}$ & $\begin{array}{l}\mathrm{O}_{3} \\
\mathrm{NO} \\
\mathrm{CO}_{2}\end{array}$ & See above \\
\hline ARI & C. Kolb & $\begin{array}{l}\text { Anemometer, RH sensor, } \\
\text { Pres gauge, thermocouple }\end{array}$ & Wind Velocity, RH, $T, P$ & See above \\
\hline MCE2 & L. T. Molina & Chemiluminescent Detector & $\mathrm{NO}_{\mathrm{y}}$ & See above \\
\hline Montana State U. & B. Knighton & PTR-MS & $\begin{array}{l}\text { VOCs, selected aromatics, } \\
\text { oxygenates, olefins, etc. }\end{array}$ & See above \\
\hline EPA & R. Seila & VOC canister sampler & VOCs & See above \\
\hline MCE2, VT & $\begin{array}{l}\text { L. T. Molina, } \\
\text { L. Marr }\end{array}$ & $\begin{array}{l}\text { Photo-ionization aerosol } \\
\text { counter; Diffusion Charger }\end{array}$ & $\begin{array}{l}\text { PAHs; } \\
\text { Fine PM surface area }\end{array}$ & Thornhill et al., 2009 \\
\hline LANL & M. Dubey & $\begin{array}{l}\text { Photo-acoustic Instrument; } \\
\text { PM filter samples }\end{array}$ & $\begin{array}{l}\text { aerosol absorption \& } \\
\text { scattering; SEM images }\end{array}$ & \\
\hline WSU & B. Lamb & $\mathrm{SO}_{2}$ fluorescence & $\mathrm{SO}_{2}$ & de Foy et al., 2009b \\
\hline \multicolumn{5}{|c|}{ Chalmers Mobile mini-DOAS } \\
\hline Chalmers & B. Galle & $\begin{array}{l}\text { Mobile Mini-DOAS } \\
\text { instruments }\end{array}$ & $\mathrm{SO}_{2}, \mathrm{NO}_{2}, \mathrm{HCHO}$ & Johansson et al., 2009 \\
\hline \multicolumn{5}{|c|}{ Iowa Mobile Vertical Lidar System } \\
\hline University of Iowa & W. Eichinger & $\begin{array}{l}\text { mobile upward-looking } \\
\text { lidar; Sun photometer }\end{array}$ & $\begin{array}{l}\text { aerosol vertical profile; } \\
\text { direct and indirect radiation }\end{array}$ & Lewandowski et al., 2010 \\
\hline \multicolumn{5}{|c|}{ Controlled Meteorological (CMET) Balloons } \\
\hline $\begin{array}{l}\text { Smith College, } \\
\text { PNNL }\end{array}$ & $\begin{array}{l}\text { P. Voss, } \\
\text { R. Zaveri }\end{array}$ & $\begin{array}{l}\text { Free-floating altitude- } \\
\text { controlled balloons with } T \\
\text { and humidity sensor }\end{array}$ & $\begin{array}{l}T, P, \text { horizontal winds, } \\
\text { relative humidity }\end{array}$ & Voss et al., 2010 \\
\hline
\end{tabular}

absorption of atmospheric radiation. MAX-Mex was conducted by the Atmospheric Science Program of the DOE Climate Change Research Division in collaboration with scientists supported by NSF, NASA, and Mexican agencies. Measurements were conducted using an airborne lidar operated by NASA scientists with support from DOE, the DOE G1 airborne platform that obtained gas and aerosol measurements, and also at the three supersites to examine the aerosol plume evolution. The $\mathrm{T} 0$ and $\mathrm{T} 1$ sites were heavily instru- mented in order to characterize atmospheric chemical and physical properties including the scattering and absorption of radiation by particles, particularly in the sub-micrometer fractions that are anticipated to have the longest lifetimes and have the greatest impact on regional and potentially global climate forcing. Although there were fewer instruments at the $\mathrm{T} 2$ site, they provided information on aging of pollutant plumes further downwind. 
Table 4. Continued.

\begin{tabular}{|c|c|c|c|c|}
\hline \multicolumn{5}{|l|}{ Fixed Mobile Units } \\
\hline INE - CENICA & Huixquilucan & $\begin{array}{l}\text { Mobile unit for criteria } \\
\text { pollutants and met. } \\
\text { parameters }\end{array}$ & $\begin{array}{l}\mathrm{CO}, \mathrm{NO}_{\mathrm{x}}, \mathrm{SO}_{2}, \mathrm{O}_{3}, \mathrm{PM}_{10} \\
\text { WD, WS, } T, \mathrm{RH}, P \text {, solar } \\
\text { radiation }\end{array}$ & $\begin{array}{l}\text { Note: data from } \\
\text { the mobile units } \\
\text { have been used in } \\
\text { various publications }\end{array}$ \\
\hline Guanajuato & CORENA & $\begin{array}{l}\text { Mobile unit for criteria } \\
\text { pollutants and met. } \\
\text { parameters }\end{array}$ & $\begin{array}{l}\mathrm{NO}_{\mathrm{x}}, \mathrm{SO}_{2}, \mathrm{O}_{3}, \mathrm{PM}_{10}, \\
\text { WD, WS, T, RH, P, CH} \\
\text { NMHC, THC }\end{array}$ & See above \\
\hline Hidalgo & $\mathrm{T} 2$ & $\begin{array}{l}\text { Mobile unit for criteria } \\
\text { pollutants and met. } \\
\text { parameters }\end{array}$ & $\begin{array}{l}\mathrm{CO}, \mathrm{NO}_{\mathrm{x}}, \mathrm{SO}_{2}, \mathrm{O}_{3}, \mathrm{PM}_{10}, \\
\text { WD, WS, } T, \mathrm{RH}, \\
\text { precipitation }\end{array}$ & See above \\
\hline $\begin{array}{l}\text { Estado de } \\
\text { Mexico }\end{array}$ & Avila Camacho & $\begin{array}{l}\text { Mobile unit for criteria } \\
\text { pollutants and met. } \\
\text { parameters }\end{array}$ & $\begin{array}{l}\mathrm{CO}, \mathrm{NO}_{\mathrm{x}}, \mathrm{SO}_{2}, \mathrm{O}_{3}, \mathrm{PM}_{10}, \\
\text { WD, WS, T, RH, } \\
\text { precipitation, } \mathrm{P} \text {, solar } \\
\text { radiation }\end{array}$ & See above \\
\hline Nuevo Leon & Santa Ana & $\begin{array}{l}\text { Mobile unit for criteria } \\
\text { pollutants and met. } \\
\text { parameters }\end{array}$ & $\begin{array}{l}\mathrm{CO}, \mathrm{NO}_{\mathrm{x}}, \mathrm{SO}_{2}, \mathrm{O}_{3}, \mathrm{PM}_{10}, \mathrm{PM}_{2.5} \text {, } \\
\text { WD, WS, } T, \mathrm{RH} \text {, precipitation, } P \text {, solar } \\
\text { radiation }\end{array}$ & See above \\
\hline Queretaro & Atizapan & $\begin{array}{l}\text { Mobile unit for criteria } \\
\text { pollutants }\end{array}$ & $\mathrm{CO}, \mathrm{NO}_{\mathrm{x}}, \mathrm{SO}_{2}, \mathrm{O}_{3}, \mathrm{PM}_{10}$ & See above \\
\hline $\begin{array}{l}\text { UNAM-CCA-FQA, } \\
\text { INE, IMK-IFU, } \\
\text { MCE2 }\end{array}$ & Tenango del aire & $\begin{array}{l}\text { Standard AQ monitors; } \\
\text { Surface met parameters; } \\
\text { Hantzsch (HCHO), } \\
\text { DOAS (NO2), } \\
\text { Ceilometer, Pilot balloons } \\
\text { Ultra-light plane (flew } \\
\text { around the two volcanoes) }\end{array}$ & $\begin{array}{l}\mathrm{CO}, \mathrm{NO}_{\mathrm{x}}, \mathrm{NO}_{\mathrm{y}}, \mathrm{SO}_{2}, \mathrm{O}_{3}, \\
\mathrm{WS}, T, \mathrm{RH} ; \mathrm{WD} \\
\mathrm{HCHO} ; \\
\mathrm{NO}_{2}(\text { Column }) ; \\
\mathrm{PM}_{10}, \mathrm{CN}, \\
\text { dew point monitors }\end{array}$ & Melamed et al., 2009 \\
\hline
\end{tabular}

* The related publications where the instruments or methods have been described or mentioned.

\subsection{MIRAGE-Mex (Megacity Impacts on Regional and Global Environments - Mexico)}

MIRAGE-Mex examined the chemical/physical transformations of gaseous and particulate pollutants exported from Mexico City, providing a case study of the effects of a megacity on regional and global atmospheric composition and climate. MIRAGE-Mex was led by the National Center for Atmospheric Research (NCAR) in collaboration with academic researchers under NSF sponsorship. Specific objectives were to: (i) quantify the spatial extent and temporal persistence of the polluted outflow plume; (ii) identify and quantify the chemical and physical transformations of the gases and aerosols in the plume, especially the processes that lead to the removal of these pollutants from the atmosphere; (iii) quantify the effects of the plume on regional oxidants and radiation budgets, and ultimately on re- gional climate; and (iv) examine the interactions of the urban plume with background air, as well as pollutants from other sources including regional anthropogenic pollutants, emissions from biomass fires, and biogenic emissions from vegetation. The NCAR/NSF C-130 aircraft carried a payload of state-of-the-art scientific instruments and sampled air above and at different distances from Mexico City to measure how gases and particles age during transport, specifically tracking those chemical, physical, and optical properties that have the potential to affect air quality, weather, and climate on large geographic scales. An additional aircraft (Twin Otter) conducted studies of fire emissions and their effect on the local and regional composition of the atmosphere. Other MIRAGE-Mex researchers were located at the T1 supersite, to examine the chemistry and physics of surface air as it first exits Mexico City. 
Table 5. C-130 scientific payload

\begin{tabular}{|c|c|c|c|}
\hline Parameters & Method & $\begin{array}{l}\text { Principal } \\
\text { Investigator }\end{array}$ & $\begin{array}{l}\text { Detection Limit/ } \\
\text { Response Time }\end{array}$ \\
\hline Spectral Actinic flux & SAFS & R. Shetter (NCAR) & N/A ; $1 \mathrm{~s}$ \\
\hline $\mathrm{CO}$ & VUV fluorescence & T. Campos (NCAR) & $2 \mathrm{ppbv} / 2 \mathrm{~s}$ \\
\hline $\mathrm{H}_{2} \mathrm{O} \mathrm{CO}_{2}$ & & T. Campos (NCAR) & $10 \mathrm{ppmv}, 1 \mathrm{~s} 1 \mathrm{ppmv}, 1 \mathrm{~s}$ \\
\hline $\mathrm{NO} \mathrm{NO} \mathrm{NO}_{\mathrm{y}} \mathrm{O}_{3}$ & Chemiluminescence & Weinheimer (NCAR) & 5 pptv, 3 s 20 pptv, 3 s 50 pptv, $1 \mathrm{~s} 200$ pptv, $1 \mathrm{~s}$ \\
\hline $\mathrm{HO}_{2}, \mathrm{HO}_{2}+\mathrm{RO}_{2}$ & CIMS & C. Cantrell (NCAR) & variable* $^{*}, 20 \mathrm{~s}$ \\
\hline $\mathrm{OH}$ & CIMS & Mauldin, Eisele (NCAR) & $\sim 10^{5} \mathrm{~cm}^{-3}, 30 \mathrm{~s}$ \\
\hline $\mathrm{CH}_{2} \mathrm{O}$ & DFG-TDL & A. Fried (NCAR) & $\sim 100$ pptv $^{*}, 10 \mathrm{~s}$ \\
\hline $\mathrm{SO}_{2}$ & Modified TECO & J. Holloway (NOAA) & $500 \mathrm{pptv}, 1 \mathrm{~s}$ \\
\hline VOCs, OVOCs & Fast GC-MS (TOGA) & E. Apel (NCAR) & varies by compound*, 2 min \\
\hline VOCs, OVOCs & PTR-MS & T. Karl (NCAR) & var. by compd.*, $35 \mathrm{~s}$ \\
\hline Organic trace gases & Whole Air Sampling & $\begin{array}{l}\text { E. Atlas (U. Miami), D. Blake } \\
\text { (U. California/Irvine) }\end{array}$ & var. by compd.*, variable* \\
\hline PANs & CIMS & F. Flocke (NCAR) & $2 \mathrm{pptv}, 2 \mathrm{~s}$ \\
\hline $\begin{array}{l}\text { Organic acids (formic, } \\
\text { acetic, peracetic, } \\
\text { propanoic) } \\
\mathrm{H}_{2} \mathrm{O}_{2} \\
\mathrm{HCN} \\
\mathrm{HNO}_{3} \\
\mathrm{CH}_{3}(\mathrm{OOH}) \\
\mathrm{SO}_{2} \\
\mathrm{CH}_{3} \mathrm{CN} \\
\mathrm{HO}_{2} \mathrm{NO}_{2}\end{array}$ & CIMS & P. Wennberg (Cal. Tech.) & $\begin{array}{l}150 \text { pptv, } 15 \mathrm{~s} \\
50 \text { pptv, } 15 \mathrm{~s} \\
100 \text { pptv, } 15 \mathrm{~s} \\
50 \text { pptv, } 15 \mathrm{~s} \\
50 \text { pptv, } 15 \mathrm{~s} \\
250 \text { pptv, } 15 \mathrm{~s} \\
200 \text { pptv, } 15 \mathrm{~s} \\
50 \text { pptv, } 15 \mathrm{~s}\end{array}$ \\
\hline $\begin{array}{l}\text { Size-resolved compo- } \\
\text { sition of non-refractory } \\
\text { submicron aerosols }\end{array}$ & AMS & J. Jimenez (U. Colorado) & $\begin{array}{l}0.05-0.35 \mathrm{ug} / \mathrm{m}^{3} \\
10-30 \mathrm{~s}^{*}\end{array}$ \\
\hline $\begin{array}{l}\text { Aerosol physio-chemistry } \\
\text { and optical properties }\end{array}$ & $\begin{array}{l}\text { Tandem volatility DMA, } \\
\text { FMPS, OPCs, nephelometer, } \\
\text { PSAP }\end{array}$ & A. Clarke (U. Hawaii) & $\begin{array}{l}\text { Variable by species*, } \\
\text { Variable by measurement* }\end{array}$ \\
\hline Aerosol physio-chemistry & $\begin{array}{l}\text { DMA, Tandem DMA, } \\
\text { HTDMA }\end{array}$ & D. Collins (Texas A\&M U.) & $\begin{array}{l}\text { var. by spec.*, } \\
\text { variable by meas. }\end{array}$ \\
\hline $\begin{array}{l}\text { Aerosol composition and } \\
\text { optics }\end{array}$ & $\mathrm{CCN}, \mathrm{SP} 2, \mathrm{PASS}$, filters & $\begin{array}{l}\text { L. Russell and G. Roberts } \\
\text { (UCSD/SIO); G. Kok (DMT) }\end{array}$ & $\begin{array}{l}\text { var. by spec.*, } \\
\text { variable by meas.* }\end{array}$ \\
\hline Fine particle composition & PILS & R. Weber (Georgia Tech) & $\begin{array}{l}\text { var. by spec.* } \\
\text { variable by meas.* }\end{array}$ \\
\hline Soot aerosol & $\begin{array}{l}\text { transmission electron } \\
\text { microscopy (TEM), } \\
\text { tomography }\end{array}$ & P. Buseck (Arizona State U.) & N/A, N/A* \\
\hline Aerosol lidar & SABL & Morley (NCAR) & N/A, variable* \\
\hline
\end{tabular}

* see archived data files for details

\subsection{INTEX-B (Intercontinental Chemical Transport Experiment-B)}

INTEX-B was an integrated field campaign designed to understand the transport and transformation of gases and aerosols on transcontinental/intercontinental scales and to assess their impact on air quality and climate. Central to achieving this goal was the need to relate space-based observations with those from airborne and surface platforms. Specific INTEX-B/MILAGRO objectives were to: (1) investigate the extent and persistence of the outflow of pollution from Mexico; (2) understand transport and evolution of 
Table 6. Scientific payload of the G-1 aircraft.

\begin{tabular}{|c|c|c|c|}
\hline Parameters & Method & Principal Investigator & $\begin{array}{l}\text { Detection Limit/ } \\
\text { Response Time }\end{array}$ \\
\hline $\mathrm{O}_{3}$ & UV Photometry & S. R. Springston, BNL & $2 \mathrm{ppbv} / 4 \mathrm{~s},(+/-5 \%)$ \\
\hline $\mathrm{CO}$ & VUV Fluorescence & S. R. Springston, BNL & $5 \mathrm{ppbv} / 1 \mathrm{~s}(+/-5 \%)$ \\
\hline $\mathrm{SO}_{2}$ & Pulsed Fluorescence & S. R. Springston, BNL & $0.2 \mathrm{ppbv} / 10 \mathrm{~s}(+/-5 \%)$ \\
\hline NO & $\mathrm{O}_{3}$ Chemiluminescence & S. R. Springston, BNL & $10 \mathrm{pptv} / 10 \mathrm{~s}(+/-5 \%)$ \\
\hline $\mathrm{NO}_{2}$ & $\begin{array}{l}\mathrm{NO}_{2} \text { Photolysis/O } \\
\text { Chemiluminescence }\end{array}$ & S. R. Springston, BNL & $40 \mathrm{pptv} / 10 \mathrm{~s}(+/-5 \%)$ \\
\hline $\mathrm{NO}_{\mathrm{y}}$ & Mo Catalyst $/ \mathrm{O}_{3}$ Chemiluminescence & S. R. Springston, BNL & $100 \mathrm{pptv} / 10 \mathrm{~s}(+/-5 \%)$ \\
\hline $\mathrm{H}_{2} \mathrm{O}_{2}, \mathrm{HMHP}$ & Scrubber/Derivatization/Fluorescence & $\begin{array}{l}\text { J. Weinstein-Lloyd, } \\
\text { SUNY Old Westbury }\end{array}$ & $300 \mathrm{pptv} / 1 \min (+/-10 \%)$ \\
\hline $\begin{array}{l}\mathrm{K}^{+}, \mathrm{Mg}^{++}, \mathrm{Na}^{+}, \mathrm{NH}_{4}^{+}, \mathrm{Cl}^{-}, \\
\mathrm{NO}_{3}^{-}, \mathrm{SO}_{4}^{--}\end{array}$ & PILS & Y.-N. Lee, BNL & $\sim 0.3 \mathrm{ug} \mathrm{m}^{-3} / 3 \mathrm{~min}(+/-15 \%)$ \\
\hline Particle Incandescence & Single Particle Soot Photometry & G. Senum, BNL & $0.2 \mathrm{fg}_{\text {particle }}-1 / 1 \mathrm{~s}$ \\
\hline $\begin{array}{l}\text { Aerosol } \\
\text { Size/Composition }\end{array}$ & Aerosol Mass Spectrometry (CTOF) & E. Alexander, PNNL & $\mathrm{TBD} / 15 \mathrm{~s}$ \\
\hline VOCs & Whole Air Samples/GC-FID & J. Rudolf, York University & Varies/30s $(+/-15 \%)$ \\
\hline VOCs & Proton Transfer MS & E. Alexander, PNNL & Varies/20s $(+/-35 \%)$ \\
\hline Aerosol Count $D_{P}>10 \mathrm{~nm}$ & $\mathrm{CPC}$ & J.M. Hubbe, PNNL & $50 \% @ 10 \mathrm{~nm} / 1 \mathrm{~s}$ \\
\hline Aerosol Count $D_{P}>3 \mathrm{~nm}$ & $\mathrm{CPC}$ & J. M. Hubbe, PNNL & $50 \% @ 3 \mathrm{~nm} / 1 \mathrm{~s}$ \\
\hline $\begin{array}{l}\text { Aerosol Count ( } 21 \text { bins, } \\
16-444 \mathrm{~nm})\end{array}$ & Differential Mobility Analyzer & J. Wang, BNL & single particle $/ \sim 60 \mathrm{~s}$ \\
\hline $\mathrm{N}$ (30 bins, $0.1-3 \mathrm{um})$ & Optical Probe (PCASP X100) & G. Senum, BNL & single particle $/ 1 \mathrm{~s}$ \\
\hline $\mathrm{N}(20$ bins, $0.6-60 \mathrm{um})$ & Optical Probe (CAPS probe, CAS) & G. Senum, BNL & single particle/1 s \\
\hline $\mathrm{N}$ (60 bins, $25-1550 \mathrm{um})$ & Optical Probe (CAPS probe, CIP) & G. Senum, BNL & single droplet/1 s \\
\hline Liquid Water Content & Hot Wire & G. Senum, BNL & $0.01 \mathrm{~g} \mathrm{~m}^{-3} / 1 \mathrm{~s}$ \\
\hline $\begin{array}{l}\text { Total/Back Scatter } \\
\text { ( } 3 \text { wavelengths) }\end{array}$ & Nephelometry & G. Senum, BNL & $2 \mathrm{Mm}^{-1} / 5 \mathrm{~s}$ \\
\hline $\begin{array}{l}\text { Aerosol Absorbance } \\
\text { ( } 3 \text { wavelengths) }\end{array}$ & Filter Absorption Spectrometry & S. R. Springston, BNL & $2 \mathrm{Mm}^{-1} / 8 \mathrm{~s}$ \\
\hline Vertical Wind Velocities & 200-Hz Gust Probe & G. Senum, BNL & $10 \mathrm{~cm} \mathrm{~s}^{-1} / 0.1 \mathrm{~s}$ \\
\hline Turbulence & 200-Hz Gust Probe & G. Senum, BNL & $10^{-7} \mathrm{~cm}^{2} \mathrm{~s}^{-3} / 0.1 \mathrm{~s}$ \\
\hline
\end{tabular}

Complete data set, useage guidelines and meta data is available by anonymous ftp at: ftp://ftp.asd.bnl.gov/pub/ASP\%20Field\%20Programs/2006MAXMex/ Notes:

a) Instruments on board the G-1 also measured zenith and nadir irradiance (UV and spectrally resolved Vis/IR), winds aloft, turbulence, pressure, temperature, dew point, aircraft position and orientation.

b) These are nominal values. Detailed measurement specifications are provided in the headers along with data.

Asian pollution and implications for air quality and climate; (3) map anthropogenic and biogenic emissions and relate atmospheric composition to sources and sinks; (4) characterize effects of aerosols on solar radiation; and (5) validate spaceborne observations of tropospheric composition. INTEXB/MILAGRO campaign was performed in two parts in the spring of 2006. In the first part, the DC-8 operated from
Houston, TX with research flights over Mexico and the Gulf of Mexico (1-21 March) while the J-31 and NSF/NCAR C130 operated from Veracruz, Mexico. In the second part, the DC-8 was based in Honolulu, HI (17-30 April) and Anchorage, AK (1-15 May) with the NSF/NCAR C-130 operating from Seattle, WA (17 April-15 May) in a coordinated fashion. An overview describing the INTEX-B DC-8 studies over 
Table 7. J31 aircraft instrumentation for INTEX-B/MILAGRO.

\begin{tabular}{|c|c|c|c|c|}
\hline Instrument Name & Data Products & Technique & Principal Investigator & $\begin{array}{l}\text { Detection limit } \\
\text { (Nominal accuracy) }\end{array}$ \\
\hline $\begin{array}{l}\text { Ames Airborne Tracking } \\
\text { Sunphotometer (AATS) }\end{array}$ & $\begin{array}{l}\text { Aerosol optical depth and } \\
\text { extinction, water vapor } \\
\text { column and profile }\end{array}$ & $\begin{array}{l}\text { Tracking Sun photometer, } \\
354-2138 \mathrm{~nm}\end{array}$ & $\begin{array}{l}\text { J. Redemann, } \\
\text { BAERI/NASA ARC }\end{array}$ & $\begin{array}{l}\text { Slant OD } \sim 0.002( \pm 0.01) \\
\text { Slant } \mathrm{WV} \sim 0.0005 \text { to } \\
0.006 \mathrm{~g} \mathrm{~cm}^{-2}( \pm 8 \%)\end{array}$ \\
\hline $\begin{array}{l}\text { Solar Spectral Flux } \\
\text { Radiometer (SSFR) }\end{array}$ & Solar spectral flux & $\begin{array}{l}\text { Spectrometer } \\
(380-1700 \mathrm{~nm}) \\
\text { with nadir and zenith } \\
\text { hemispheric collectors }\end{array}$ & $\begin{array}{l}\text { P. Pilewskie, } \\
\text { U. Colorado }\end{array}$ & $\begin{array}{l}\text { Absolute accuracy } 3-5 \% \text {. } \\
\text { Precision } 1 \%\end{array}$ \\
\hline $\begin{array}{l}\text { Research Scanning } \\
\text { Polarimeter (RSP) }\end{array}$ & $\begin{array}{l}\text { Polarized radiance, } \\
\text { aerosol cloud \& Earth } \\
\text { surface properties }\end{array}$ & $\begin{array}{l}\text { Angular (along-track } \\
\text { downward) scanning } \\
\text { polarimeter, 412-2250 nm }\end{array}$ & $\begin{array}{l}\text { B. Cairns, } \\
\text { Columbia U. }\end{array}$ & \\
\hline $\begin{array}{l}\text { Cloud Absorption } \\
\text { Radiometer (CAR) }\end{array}$ & $\begin{array}{l}\text { Radiance, aerosol, cloud } \\
\& \text { Earth surface properties }\end{array}$ & $\begin{array}{l}\text { Angular (cross-track } \\
\text { zenith to nadir) scanning, } \\
\text { radiometer } 340-2301 \mathrm{~nm}\end{array}$ & $\begin{array}{l}\text { C. Gatebe, } \\
\text { UMBC/NASA GSFC } \\
\text { M. King*, NASA GSFC }\end{array}$ & $\begin{array}{l}\text { Radiance absolute } \\
\text { accuracy }<5 \% \text {. }\end{array}$ \\
\hline $\begin{array}{l}\text { Position and Orientation } \\
\text { System (POS) }\end{array}$ & $\begin{array}{l}\text { Aircraft position } \\
\text { and orientation }\end{array}$ & $\begin{array}{l}\text { Applanix model } \\
\text { POS-AV } 310\end{array}$ & $\begin{array}{l}\text { R. Dominguez, UC } \\
\text { Santa Cruz/ NASA ARC }\end{array}$ & $\begin{array}{l}\text { Precision } \\
\text { lat/lon: } 0.000001^{\circ} \\
\text { pitch/roll/heading: } 0.0001^{\circ} \\
\text { Altitude: } 1.0 \mathrm{~m} \\
\text { DGPS Accuracy } \\
\text { Position: } 0.5-2.0 \mathrm{~m} \\
\text { Pitch/roll: } 0.030^{\circ} \\
\text { Heading: } 0.080^{\circ} \\
\text { Altitude: } 0.75-3.0 \mathrm{~m}\end{array}$ \\
\hline
\end{tabular}

* Current affiliation U. Colorado

the Pacific and Gulf of Mexico has been published (Singh et al., 2009). Key results from the INTEX-B flights over Mexico City, as well as J-31 and C-130 flights over the Gulf of Mexico and the Mexico City area, are included in this overview article.

The MILAGRO Campaign has generated very comprehensive data and many interesting results have emerged over the past several years. The observations from MCMA-2003 Campaign were mostly confirmed during MILAGRO; additionally MILAGRO provided more detailed gas and aerosol chemistry, aerosol particle microphysics and optics, and radiation data, as well as vertical and wider regional-scale coverage. In the following sections, we present some key results and a more detailed description of the instrumentation deployed during the campaign. Data sets are available to the entire atmospheric community for further modeling and evaluation:

- MILAGRO Campaign data sets and data sharing policy are available at: http://www.data.eol.ucar.edu/master_list/?project=MILAGRO.
- High spectral resolution lidar (HSRL) data from MILAGRO are shown at: http://science.larc.nasa.gov/hsrl/milagro2.html.

- INTEX-B/MILAGRO data from the DC-8, C-130, King Air, and $\mathrm{J}-31$ are archived at:

http://www-air.larc.nasa.gov/cgi-bin/arcstat-b.

\section{Meteorology and dynamics}

\subsection{Observational resources}

A wide range of meteorological instrumentation was deployed at T0, T1, and $\mathrm{T} 2$ to measure the evolution of wind fields and boundary layer properties that affect the vertical mixing, transport, and transformation of pollutants (see Tables $1-4)$. As described by Doran et al. (2007), radar wind profilers at each site obtained wind speed and direction profiles up to $4 \mathrm{~km}$ above ground level (a.g.l.). A radar wind profiler was also deployed at Veracruz, located on the Gulf of Mexico east of Mexico City to obtain wind information aloft farther downwind of Mexico City. Several radiosondes were launched from $\mathrm{T} 1$ and $\mathrm{T} 2$ on selected aircraft sampling 
days and once per day on other days to obtain temperature and humidity profiles that characterize boundary layer growth (Shaw et al., 2007). Some of these radiosondes also obtained wind profiles that extended above the height of the radar wind profilers measurements. Other radiosondes were released at $\mathrm{T} 1$ that obtained profiles of ozone (Thompson et al., 2008) in addition to standard meteorological parameters. Temperature and humidity profiles at $\mathrm{T} 0$ were obtained at 1-minute intervals up to $10 \mathrm{~km}$ a.g.l. from a microwave radiometer. A micro-pulse lidar and tethersondes were deployed at both $\mathrm{T} 0$ and $\mathrm{T} 1$ to obtain additional information on boundary layer properties. Semi-Lagrangian measurements of temperature, pressure, and humidity downwind of Mexico City were obtained on several days by Controlled Meteorological (CMET) balloons, also known as tetroons, launched in the vicinity of T1 (Voss et al., 2010). Pilot balloons were released four times a day from a site in the south of the city and one in the mountain gap to the south-east of the MCMA. Further releases took place at the end of the campaign to the north of the basin in conjunction with radiosonde launches (Rivera et al., 2009).

Measurements of the spatially varying wind speed, wind direction, temperature, pressure, and humidity over central Mexico were collected by the G-1 (Kleinman et al., 2008), C-130 (de Carlo et al., 2008), DC-8 (Singh et al., 2009), Twin Otter (Yokelson et al., 2007), and the FZK-ENDURO ultralight aircraft (Grutter et al., 2008). The J-31 (Livingston, et al., 2009) measured temperature, pressure, and humidity. Meteorological stations were deployed at several sites in the vicinity of Mexico City in addition to T0, T1, and T2, including CENICA and Paso de Cortes (Altzomoni) (Baumgardner et al., 2009), Tenango del Aire, Santa Ana, Pico de Tres Padres (Herndon et al., 2008), which measured near-surface wind speed, wind direction, temperature, pressure, humidity, and precipitation. Radiation and cloudiness was measured at $\mathrm{T} 1$ and $\mathrm{T} 2$ by multi-band rotating shadowband radiometers (MFRSR) and Eppley broadband radiometers (Doran et al., 2007; Fast et al., 2007). Broadband radiometers were also deployed at Paso de Cortes. At T1, all sky photos were acquired between 9 March and 1 April 2006 using a Total Sky Imager (Model \#440A Yankee Environmental Systems, Inc.) with 1 min time resolution between 10:15-23:10 UT (Corr et al., 2009). Turbulence parameters were measured using sonic anemometers at $\mathrm{T} 0$ and at the SIMAT headquarters (Velasco et al., 2009).

Operational meteorological measurements were collected by the Mexican National Weather Service (SMN) (http:// smn.cna.gob.mx/), the Ambient Air Quality Monitoring Network (Red Automatica de Monitoreo Atmosferico, RAMA) (http://www.sma.df.gob.mx/simat2) and the Programa de Estaciones Meteorológicas del Bachillerato Universitario (PEMBU) http://pembu.atmosfcu.unam.mx/. SMN collected data for the entire country with five stations in the MCMA, while RAMA had fourteen stations in the MCMA. Radiosondes with GPS were launched four times a day at 00:00, 06:00,
12:00 and 18:00 UTC at Mexico City, Veracruz and Acapulco for the duration of the field campaign. Other sites in Mexico continued with the regular, dry-season schedule of one sounding per day at 00:00 UTC.

Semi-Lagrangian measurements of temperature, pressure, and humidity downwind of Mexico City were obtained on several days by CMET balloons launched in the vicinity of T1. These balloons also tracked the long-range transport of pollutants downwind of Mexico City. During the 18-19 March outflow event, a pair of CMET balloons was launched from the north end of the MCMA basin immediately after the DOE G-1 aircraft had sampled the area. The balloons performed repeated soundings as they drifted with the outflow and helped guide the NCAR C-130 aircraft to the outflow $24 \mathrm{~h}$ later. The quasi-Lagrangian balloon profile data provided water vapor, potential temperature, and winds (Voss et al., 2010) and in combination with G-1 and C-130 aircraft measurements provided insight into the evolution of trace gases and aerosols over a period of $24 \mathrm{~h}$ (Zaveri et al., 2007).

\subsection{Meteorological overview}

\subsubsection{Synoptic conditions}

The month of March was selected for the field campaign period because of the dry, mostly sunny conditions observed over central Mexico at this time of the year (Jáuregui, 2000). Clouds and precipitation that usually increase during April would complicate aircraft sampling and scavenge a portion of the pollutants. Cluster analysis of ten years of radiosonde profiles found that synoptic conditions during March 2006 were representative of the warm dry season (de Foy et al., 2008), albeit with an under-representation of clean days and fewer wet or humid days.

As described in Fast et al. (2007), high pressure in the mid to lower troposphere slowly moved from northwestern Mexico towards the east between 1 and 8 March so that the winds over Mexico City were from the north and east. An upperlevel trough propagating through the south-central US on 9 March produced westerly winds over Mexico. The winds became southwesterly between 10 and 12 March as a trough developed over the western US. After this trough moved over the north-central US on 13 March, the winds over central Mexico became light and variable. Between 14 and 18 March a series of troughs and ridges propagated from west to east across the US that affected the position of the high pressure system over the Gulf of Mexico and led to variable wind directions over central Mexico. A stronger trough propagated into the south-central US, producing stronger southwesterly winds between 19 and 20 March. After 21 March, high pressure gradually developed over southern Mexico that produced westerly winds at this level over central Mexico for the rest of the month. 
Strong northerly near-surface flows associated with the passage of cold fronts over the Gulf of Mexico, known as Cold Surge or El Norte events, occurred on 14, 21, and 23 March. Although cold fronts gradually dissipate as they propagate into the subtropics, the interaction of the southward moving high-pressure systems with the terrain of the Sierra Madre Oriental often accelerates the northerly flow along the coast. While northerly winds occurred briefly over Mexico City after the passage of the fronts, the wind speeds were much lower than those observed along the coast at lower elevations.

In addition to affecting the local transport of pollutants over central Mexico, the cold fronts led to increased humidity, cloudiness, and precipitation. Enhanced mixing and removal processes likely contributed to the observed decrease in background concentrations of organic carbon at T1 (Doran et al., 2007) after the strongest cold front passed over the region on 23 March. Marley et al. (2009a) found that aerosol scattering decreased when rain was observed between 23 and 27 March since scattering aerosols are partially inorganic and hydrophilic and expected to be scavenged more readily. The increases in humidity and the morning clear-sky insolation over the plateau after 14 March were favorable for thermallydriven slope flows so that shallow and deep convective clouds developed preferentially over the highest terrain during the afternoon.

\subsubsection{Local circulations}

Winds measured by the operational surface monitoring network, radiosondes, and radar wind profilers were analyzed by de Foy et al. (2008) to identify dominant wind patterns in the vicinity of Mexico City. Six types of days were identified according to basin-scale circulations, providing a way for attributing meteorological effects on observed changes in trace gases and particulate matter during the field campaign, in contrast to three episode types for MCMA-2003 (de Foy et al., 2005). Well-defined drainage flows into the basin were observed every morning. Coupling with the evolving synoptic flows aloft led to near-surface convergence zones with high pollutant loadings. Days with the poorest air quality were often associated with the strongest vertical wind direction shear. In contrast, persistent southerly winds at all altitudes (e.g., 18 and 20 March) likely contributed to low pollutant concentrations in the basin. Surface wind clusters were obtained for 10 years of RAMA data, further showing that March 2006 was representative of the warm season, and enabling a comparison of transport events with specific days during MCMA-2003 and 1997 IMADA-AVER field campaigns.

\subsubsection{Boundary layer characteristics}

Shaw et al. (2007) describe how the radiosondes, radar wind profilers, sodars, and a micropulse lidar were used to estimate boundary layer depths, a key factor affecting near-surface concentrations and chemical transformation of trace gases and aerosols. They showed how various measurement techniques could lead to differences in the estimates of boundary layer depth. An example of convective boundary layer depth estimates during the day derived from lidar and radar wind profiler measurements is shown in Fig. 5. The onset of convection was found to start between 45 and 90 min after sunrise. Although growth of the convective boundary layer was similar among the three sites, the mixing layer was often slightly deeper over Mexico City during the afternoon. Topography variations in the vicinity of $\mathrm{T} 2$ did not significantly affect convective boundary layer growth. Maximum daily mixing layer depths were always at least $2 \mathrm{~km}$ deep, and frequently extended to $4 \mathrm{~km}$ a.g.l., indicating that trace gases and aerosols within the boundary layer are injected directly into the mid-troposphere in contrast to most other urban areas, since the elevation of Mexico City is $\sim 2.2 \mathrm{~km}$. The convective boundary layer growth rate and depth were found to be similar to those observed during the IMADAAVER campaign (Doran et al., 1998) in the same season during 1997, except that the depths were somewhat higher during MILAGRO after 20:00 UTC.

Herndon et al. (2008) described the effects of convective boundary layer growth on trace gas and aerosol concentrations observed at Pico de Tres Padres. Since this measurement site was $\sim 0.7 \mathrm{~km}$ above Mexico City, it sampled air within the residual layer at night that was decoupled from the shallow boundary layer over Mexico City. But concentrations of trace gases and aerosols increased considerably during the late morning as the convective boundary layer grew and enveloped the mountain, consistent with the boundary layer growth observed nearby at T0 and T1. Similarly, Baumgardner et al. (2009) report that diurnal variations in trace gases and particulate matter measured at the Paso de Cortes site were consistent with the convective boundary layer growing above the height of the site $(\sim 1.8 \mathrm{~km}$ above Mexico City). Boundary layer growth and transport through the mountain pass southeast of Tenango del Aire was measured using a mobile lidar, showing a shallow early morning layer with pollution accumulation, and a residual layer aloft mixing down to the surface as the flow exits the basin (Lewandowski et al., 2010).

Despite the dry conditions usually at the surface over central Mexico, radiosonde profiles showed relative humidity often exceeded $50 \%$ in the early morning in the upper boundary layer on many days. The higher relative humidity may result in hygroscopic growth in aerosols and consequently contribute to chemical transformation of aerosols and affect local radiative forcing. Fast et al. (2007) showed that boundary layer over the central plateau was substantially cooler and moister after the second cold front passage on 21 March for the rest of the field campaign, but the peak boundary layer depth did not change significantly. 


\subsection{Meteorological modeling studies}

de Foy et al. (2009a) found that Weather Research Forecasting (WRF) mesoscale model simulations of the basin flows during MILAGRO were an improvement over MM5 simulations and showed that the simulated wind transport was representative of the basin dynamics. Nevertheless, WRF drainage flows within the basin were too weak and the predicted vertical wind shear was too strong. Particle model simulations coupled with WRF showed rapid venting of the basin atmosphere with little recirculation of the urban plume during MILAGRO, similar to previous findings from the IMADA-AVER campaign (Fast and Zhong, 1998) and MCMA-2003 (de Foy et al., 2006a, b). Doran et al. (2008) quantified the transport periods between Mexico City, T1, and T2 using assimilation of radar wind profiler measurements into WRF and a particle dispersion model to simulate transport and mixing of urban and biomass burning sources of elemental carbon. They found that specific absorption did increase as aerosols were transported between $\mathrm{T} 1$ and $\mathrm{T} 2$. The statistical significance of the result was limited by the number of transport episodes available that did not have significant open biomass burning influence.

The surface meteorological network, boundary layer measurements, and radar wind profiler measurements have also been used to examine the performance of meteorological predictions made by coupled meteorological-chemistryparticulate models, such as WRF-Chem (Fast et al., 2009; Tie et al., 2009; Zhang et al., 2009a; Hodzic et al., 2009), to understand how forecast errors in meteorology affect predictions of trace gases and particulate matter. In general, the synoptic-scale circulations are simulated reasonably well by mesoscale models, although the details (i.e., timing and strength) of local and regional winds affected by terrain variations around Mexico City are more difficult to reproduce by models. Mesoscale modeling studies (e.g., Fast et al., 2009; Hodzic et al., 2009) show that the overall diurnal variation in the simulated boundary layer depth was similar to observation; however, boundary layer parameterizations frequently produced relatively large errors during the afternoon and at night. These errors will affect predicted dilution of trace gases and aerosols. These meteorological observations have also been incorporated into meteorological modeling through data assimilation technique such as Four-Dimensional Data Assimilation (FDDA) and 3-D variational data assimilation (3D VAR) to reduce forecast errors and improve air quality prediction (Bei et al., 2010).

\subsection{Meteorological transport studies}

Meteorological data are being used to infer transport, mixing, and chemical transformation of pollutants. For example, Doran et al. (2007) employed trajectories based on radar wind profiler measurements to infer periods of transport between Mexico City, T1, and T2. Nocturnal and early morning

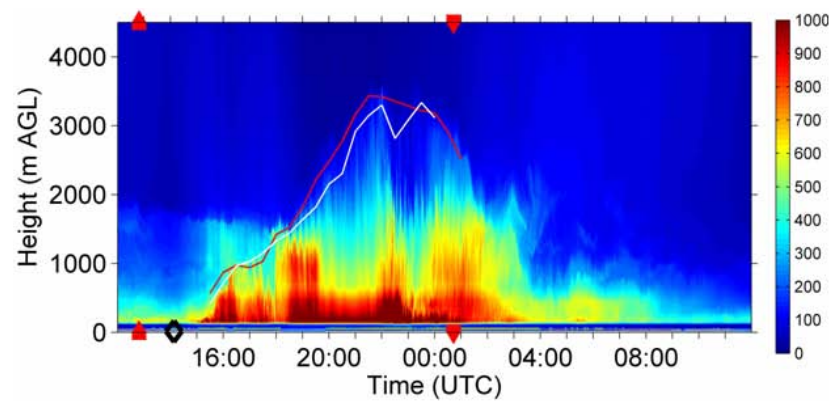

Fig. 5. Backscatter signal strength as a function height on 9 March 2006 for the lidar deployed at the T1 site. The white line denotes the subjectively determined estimate of mixed layer depth from the lidar, while the red line is the same quantity derived from the radar wind profiler. Red triangles denote sunrise and sunset (Source: Shaw et al., 2007).

buildup from local sources was inferred from organic carbon (OC) and elemental carbon (EC) at T1, while transport from the MCMA was seen at T2. Specific absorption during transport periods was lower than during other times, consistent with the likelihood of fresh emissions being found when the winds blew from Mexico City over T1 and T2. Back trajectories were employed by Moffet et al. (2009) to show that organic mass per particle increased and the fraction of carbon-carbon bonds decreased as the Mexico City plume was transported north over the T1 and T2 sites. FLEXPART Lagrangian dispersion modeling was used by several studies to investigate dispersion of $\mathrm{SO}_{2}, \mathrm{NO}_{2}$, and biomass burning aerosols, with good overall quality in the predictions (Rivera et al., 2009; Aiken et al., 2010; DeCarlo et al., 2010). Yu et al. (2009) also utilized transport categories to explain variations in OC and EC observed at T1 and T2. Melamed et al. (2009) studied the transport of the urban plume in the mountain gap southeast of the Chalco Valley using DOAS columns and surface measurements of $\mathrm{NO}_{2}$ combined with ceilometer measurements at Tenango del Aire. In addition to the urban plume, $\mathrm{NO}_{2}$ aloft was detected, possibly due to other factors such as biomass burning, volcanic sources or lightning $\mathrm{NO}_{\mathrm{x}}$. Stremme et al. (2009) measured columns of $\mathrm{CO}$ using solar and lunar FTIR and deduced mixing layer heights in the MCMA during both day and night. de Foy et al. (2009b) used $\mathrm{SO}_{2}$ transport detected by surface networks and OMI satellite retrievals to identify double impacts in the MCMA from stable shallow flow from the north transporting an industrial plume and from southerly winds aloft transporting a volcanic plume.

Concentration Field Analysis (CFA) combines simulated back trajectories with measurement time series to identify potential source regions. This type of analysis was carried out to determine source-receptor relationships of various trace gases and aerosols measured at select sites. Moffet et al. (2008a) used CFA to identify possible urban, point source, 


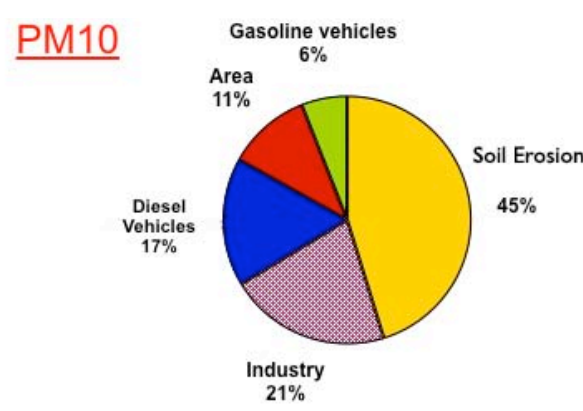

Total: 23,000 tons/yr

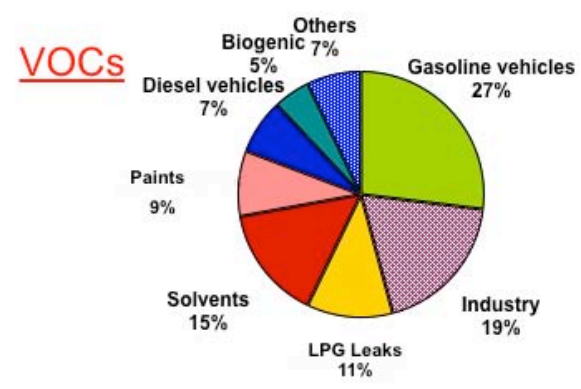

Total: 566,000 tons/yr

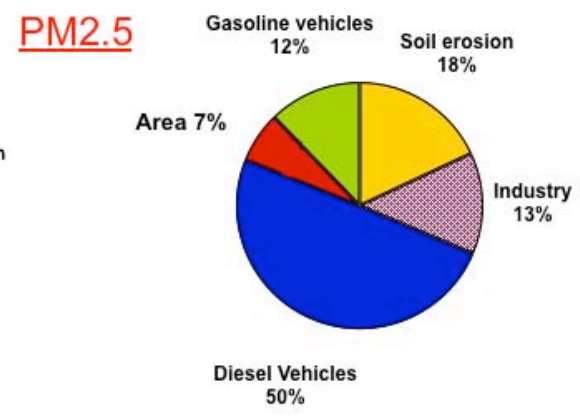

Total: 6,200 tons/yr

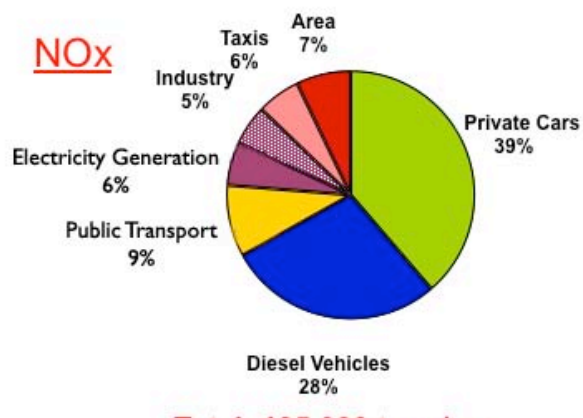

Total: 195,000 tons/yr

Fig. 6. Emissions Inventory of the MCMA for the year 2006 (Source: www.sma.df.gob.mx/simat).

and biomass burning sources of particulate matter measured by an aerosol time-of-flight mass spectrometry at T0. Rutter et al. (2009) identified possible source regions of gaseous and particulate mercury associated with measurements at T0 and T1. Salcedo et al. (2010) used CFA to identify sources of particulate lead at $\mathrm{T} 0$, and found that different chemical forms of lead had very different source footprints.

\subsection{Key meteorological results and analyses}

The overall synoptic and boundary layer circulations observed during MILAGRO over Mexico City were similar to those reported by previous studies. In contrast to previous field campaigns, the instrumentation at $\mathrm{T} 1$ and $\mathrm{T} 2$ and onboard the various aircraft during MILAGRO provided a means of quantifying flows over the central plateau. For example, horizontal wind shear was quantified between $\mathrm{T} 0$ and T1 that indicated channeling around the Sierra de Guadalupe mountains (de Foy et al., 2008), the timing of propagating density current that transports moist marine air over the central plateau into Mexico was quantified by the measurement network (Fast et al., 2007), and variations in PBL depth over the central plateau were examined (Shaw et al., 2007). The similarity of the boundary layer growth from day to day for both 1997 and 2006 suggests that the boundary layer growth over the central Mexican plateau falls within predictable bounds during the spring dry season.
Surface and airborne lidars, as well as airborne meteorological measurements have shown multiple layers of particulate matter and complex mixing processes (Rogers et al., 2009). These data have yet to be used to evaluate numerical model representations of these layering processes and determine the meteorological factors involved. Improved meteorological understanding and transport simulations are being used to analyze a large range of different measurements from MILAGRO. For example, radar wind profiler data are an invaluable supplement to surface measurements and to model results when determining transport events at the super sites. Furthermore, transport times and impact indexes are being used to relate point measurements to emission inventories and to chemical transformation processes.

\section{MCMA emissions of gases and fine PM}

Knowledge of gaseous and PM emissions is an important part of an informed air quality control policy. In a megacity, varying economic and social conditions make the characterization of accurate emissions inventories a difficult task; it presents a particularly daunting task in a rapidly developing megacity like the MCMA. The evaluation of bottom-up emissions inventories using dedicated field experiments represents a unique opportunity for reducing the associated uncertainties in the emissions estimates. Figure 6 shows the 2006 MCMA emissions inventory for $\mathrm{PM}_{10}, \mathrm{PM}_{2.5}$, VOC 
and $\mathrm{NO}_{\mathrm{x}}$. Mobile emission sources represent a substantial fraction of the total anthropogenic emissions burden. Observations from MCMA-2003 showed that MCMA motor vehicles produce abundant amounts of primary PM, elemental carbon, particle bound polycyclic aromatic hydrocarbons, $\mathrm{CO}$ and a wide range of air toxics, including formaldehyde, acetaldehyde, benzene, toluene, and xylenes (Molina et al., 2007). The MILAGRO campaign has shown the synergy of using multiple measuring platforms, instrumentation, and data analysis techniques for obtaining an improved understanding of the physical and chemical characteristics of emissions in a megacity.

\subsection{MCMA emissions inventories}

The first emissions inventory for criteria pollutants in the MCMA was completed in 1994. The use of homogenous methodologies was introduced in the 1998 inventory and since then it has been updated every two years. The 2006 inventory (Fig. 6) includes substantial improvements in the description of spatial and temporal emission patterns of the criteria pollutants (SMA-GDF, 2008a). This emissions inventory was created using bottom-up methods and emission factors which were either measured locally or taken from the literature. For example, for mobile sources the MOBILE5 emissions model was adapted to account for local vehicle characteristics, and their emissions were distributed spatially and temporally on the basis of traffic count data for primary and secondary roadways. Emissions from area sources were estimated using geographical statistics, including population density, land use and economic level of each of the districts within the metropolitan area. Emissions from industries, workshops, and commerce and service establishments were obtained from operational permits containing information about their activities, such as processes, working hours, and location. The study region of the inventory (16 delegations in the Federal District and 59 - out of 125 - municipalities of the State of Mexico) covers a total area of about $7700 \mathrm{~km}^{2}$ or about $0.25 \%$ of the Mexican territory. The study region was chosen to include the areas with the highest population densities in the MCMA. However, soil erosion, biomass burning and biogenic emissions are not limited to the city boundaries and their relative contributions depend on the chosen inventory area.

In addition, a 2006-base inventory of toxic pollutants for Mexico City has been produced containing emissions estimates for 109 species (mostly VOCs and metals) from various emission sources (SMA-GDF, 2008b). A greenhouse gas inventory for the emissions of $\mathrm{CO}_{2}, \mathrm{CH}_{4}$, and $\mathrm{N}_{2} \mathrm{O}$ has also been produced for the year 2006 (SMA-GDF, 2008c). At the national level, the first comprehensive national criteria pollutant emissions inventory for the year 1999 was released in 2006 (SEMARNAT, 2006). This inventory suggests that some of the municipalities with largest emissions in the country are located within the MCMA. A new version of the national inventory with base 2005 will be released in 2010 (CEC, 2009).

All these inventories use traditional bottom-up techniques that combine activity data and emission factors for individual sources. Although locally-measured emission factors are used whenever possible, a large fraction of the inventories in Mexico are based on emissions factors compiled and emissions models constructed in the US that are adapted for local conditions (CEC, 2009). This is an important potential source of bias that campaigns such as the MILAGRO/MCMA-2006 study are poised to address.

Anthropogenic emissions dominate the total burden of pollutants in the MCMA emissions inventories for criteria and toxic compounds. As shown in Fig. 6, mobile emissions are a large fraction of the total anthropogenic emissions. In the MCMA criteria pollutant emission inventory, it is estimated that emissions from gasoline and diesel powered vehicles each contribute substantially to the total mass emissions burden for $\mathrm{CO}(83 \%$ and $16 \%)$, VOCs (27\% and $7 \%)$, $\mathrm{NO}_{\mathrm{x}}(54 \%$ and $28 \%), \mathrm{PM}_{10}(6 \%$ and $17 \%)$, and $\mathrm{PM}_{2.5}(12 \%$ and 50\%, respectively) (SMA-GDF, 2008a). Other important sources of VOCs are solvents and painting activities (24\%), industries (19\%), and LPG leaks (11\%); whereas for $\mathrm{NO}_{\mathrm{x}}$, industries and other area sources contribute with $11 \%$ and $7 \%$, respectively. The estimated emissions of re-suspended particles from paved and unpaved roads suggests that these sources are also important contributors for $\mathrm{PM}_{10}(51 \%)$ and $\mathrm{PM}_{2.5}$ (16\%).

Several sources of uncertainty are unavoidably present when using bottom-up techniques for the development of emissions inventories, and the MCMA inventories estimates do not escape this issue. These include the uncertainties associated with the representativeness, precision (random error), accuracy (systematic error), variability, and completeness of the databases used for estimating the activity and emissions factors (NARSTO, 2005). In addition, the combination of local conditions of meteorology, topography, altitude, unique source characteristics (e.g., fleet composition, informal commerce activities, etc.), and social practices in Mexico City may introduce further uncertainties when emission factors are obtained by using emission models that were developed and validated elsewhere. It is, therefore, very important to use independent measurement-based ("top-down") evaluations of the local emissions inventories estimates as much as possible. By implementing top-down approaches for the evaluation of emissions, it is possible to identify problems and set priorities for inventory improvements.

In the following sections we summarize the results from the application of top-down techniques in the MCMA with the analysis of data obtained during MILAGRO. Additional emissions measurements are described under Sect. 6 (VOCs) and Sect. 8 (PM). 


\subsection{Mobile emissions measurements}

The vehicle fleet in the MCMA is diverse in both composition and age, and has recently shown a notable increase in its turnover rate. The MCMA experienced a large increase in motor vehicle use between 1996 and 2006. During this interval gasoline-powered passenger vehicle usage increased from 0.13 to 0.2 vehicle/person. Over the same period, this index in Los Angeles actually decreased from 0.36 to 0.34 vehicle/person. In part, this is due to relatively slow fleet turnover rates for older vehicle model years, but it is primary a response to the rapid introduction of newer vehicles (Zavala et al., 2009b). This is important because of the approximately four million gasoline-powered vehicles in the MCMA, more than $20 \%$ are 1990 models or older and do not have emission control technologies. About 7\% of MCMA gasoline vehicles are 1991-1992 models that have 2-way catalytic converters designed to reduce $\mathrm{CO}$ and VOCs but not $\mathrm{NO}_{\mathrm{x}}$, and the rest have three-way catalytic converters that are designed to reduce all three pollutants (SMA-GDF, 2008a). In addition, diesel vehicles constitute only around $4 \%$ of the vehicle fleet, but contribute disproportionally to $\mathrm{NO}_{\mathrm{x}}, \mathrm{PM}$, and selected VOCs emissions.

During MILAGRO/MCMA-2006, direct measurements of mobile emissions were obtained using the Aerodyne mobile laboratory, which contained an extensive set of sensitive, fast response (1-2 s measurement times) trace gas and fine PM instruments (Zavala et al., 2009b; Thornhill et al., 2009). These fast time response instruments were used during mobile lab transits between sites to obtain on-road vehicle emissions data (see Fig. 7). The comparison of the 2006 results to similar on-road measurements conducted during MCMA-2003 (Zavala et al., 2006) indicates some interesting trends. While the NO emission factors have remained within the measured variability ranges, emission factors of aldehyde and aromatic species were reduced in 2006 relative to 2003. The comparison with the 2006 mobile emissions inventory indicate an over-prediction of mean emissions inventory motor vehicle estimates on the order of $20-28 \%$ for $\mathrm{CO}$ and 14 $20 \%$ for NO. However, these measurements also suggest that the emissions inventory underpredicts total VOC emissions from mobile sources by a factor of 1.4 to 1.9. For speciated VOC compounds: the inventory estimates of benzene and toluene emissions from mobile sources are within the uncertainties of the corresponding measured on-road emissions estimates. This is in contrast to the results for the aldehydes from mobile emissions. Compared to on-road measurements, the 2006 inventory underpredicts formaldehyde ( $\mathrm{HCHO})$ and acetaldehyde $\left(\mathrm{CH}_{3} \mathrm{CHO}\right)$ by factors of 3 and 2, respectively (Zavala et al., 2009b).

Additional information on the chemical and physical characteristics of emissions from mobile sources has been obtained from source apportionment analysis of stationary data at T0 (Aiken et al., 2009, 2010; Paredes-Miranda et al., 2009), area-averaged emission fluxes at the SIMAT tower

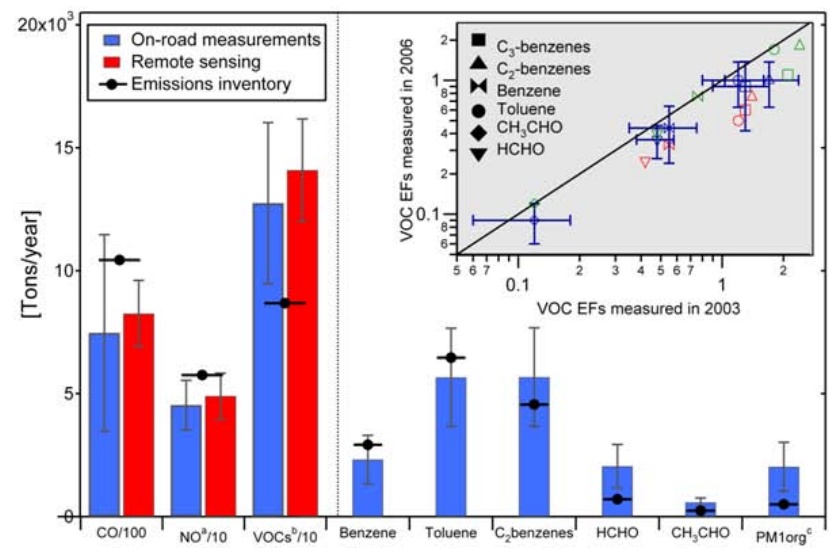

Fig. 7. Comparison among LDGV on-road mobile emissions estimated during MILAGRO, remote sensing measurements in 2006 (Schifter et al., 2008) and the mobile emissions inventories (SMAGDF, 2008a, b). The uncertainty bars displayed are standard errors of the means. For clarity, emissions of $\mathrm{CO}, \mathrm{NO}$, and VOCs are divided by factors of 100, 10 and 10, respectively. The upper-corner inset shows a comparison of on-road VOCs fuel based emission factors (EFs, g/kg) measured in 2003 and 2006 with the ARI mobile laboratory in Mexico City for SAG (green), TRA (blue) and CRU (red) driving conditions (see Zavala et al 2009a for definitions of driving conditions). Error bars are shown for TRA driving conditions and represent one standard deviation of the measured values. Notes: ${ }^{\mathrm{a}} \mathrm{NO}_{\mathrm{x}}$ (expressed as $\mathrm{NO}_{2}$ ) emissions in the inventory were assumed $90 \% \mathrm{NO}$ and $10 \% \mathrm{NO}_{2}$ in mass. ${ }^{\mathrm{b}}$ Total VOCs emissions from the inventory include evaporative emissions. The corresponding on-road VOC's are inferred rather than measured scaling $\mathrm{CO}$ emissions by a remote-sensing-based VOC/CO ratio (Schifter et al., 2008). Estimated organic mass of particles in the non-refractory $\mathrm{PM}_{1}$ range. The $\mathrm{PM}$ mass from the emissions inventory refers to $\mathrm{PM}_{2.5}$

site (Velasco et al., 2009), and aircraft measurements (Karl et al., 2009; Gilardoni et al., 2009; DeCarlo et al., 2010). Analysis of the data at $\mathrm{T} 1$ showed higher hydrocarbon emissions relative to $\mathrm{CO}$ than in the US, but similar emission ratios were found for most oxygenated VOCs and organic aerosol (de Gouw et al., 2009). Using eddy covariance techniques coupled with fast response analytical sensors, Velasco et al. (2009) showed that a representative residential district of Mexico City is a net source of $\mathrm{CO}_{2}$, olefins, aromatics and oxygenated VOCs with substantial contributions from mobile sources (see Fig. 8). Comparisons of the measured fluxes with the emissions reported in the emissions inventory for the monitored footprint (on average $1.15 \mathrm{~km}$ covering an area of $7.6 \mathrm{~km}^{2}$ ) indicate that the toluene and $\mathrm{C} 2$-benzenes (xylene isomers + ethyl-benzene) emissions from gasoline vehicles are overestimated in the inventory. In contrast, it appears that methanol is emitted by mobile sources, but is not included in the 2006 emissions inventory.

Measurements of organic mass emissions of $\mathrm{PM}_{1}$ particles from gasoline-powered vehicles suggested a large 
underprediction of $\mathrm{PM}_{2.5}$ emissions in the inventory from onroad sources (Zavala et al., 2009b). This underprediction of PM emissions from mobile sources is consistent with the results of Positive Matrix Factorization (PMF) analysis of the high resolution organic aerosol (OA) spectra of submicron aerosol measured at T0 (Aiken et al., 2009). Components of organic aerosols derived by PMF analysis of data from several Aerodyne Aerosol Mass Spectrometer (AMS) instruments deployed both at ground sites and on research aircraft were used to evaluate the WRF-Chem model during MILAGRO (Fast et al, 2009). Modeled primary OA (POA) was consistently lower than the measured $\mathrm{OA}$ at the ground sites due to lack of an SOA model, whereas a much better agreement was found when modeled POA was compared with the sum of primary anthropogenic and biomass burning components derived from PMF analyses on most days.

\subsection{Fixed site emissions measurements}

Several studies have reported that the high concentrations of propane, butane and other low molecular weight alkanes are due to liquefied petroleum gas (LPG) leakages (e.g., Blake and Rowland, 1995; Bishop et al., 1997; Mugica et al., 1998, 2003; Velasco et al., 2007). LPG is the main fuel for cooking and water heating in Mexican households. In 2006, GCFID and PIT-MS measurements of VOCs at T1 suggested that high alkane emissions from LPG usage may be responsible for photochemical formation of acetone (de Gouw et al., 2009). A small fraction of vehicles, particularly small buses used as public transport, are powered by LPG and also contribute to the emissions of low molecular weight alkanes (Schifter et al., 2003; Velasco et al., 2007).

The Eddy covariance flux measurements at the SIMAT tower site during MILAGRO/MCMA-2006 showed that evaporative emissions from commercial and other anthropogenic activities were also important sources of toluene, C2-benzenes and methanol (Velasco et al., 2009). Within the monitoring footprint extending several $\mathrm{km}$ around the site, the data show that the emissions inventory is in reasonable agreement with measured olefin and $\mathrm{CO}_{2}$ fluxes, while $\mathrm{C} 2$-benzenes and toluene emissions from gasoline vehicles and evaporative sources are overestimated in the inventory for that particular sector of the city. The SIMAT tower site also included using an Aerodyne Quadrupole Aerosol Mass Spectrometer operated in eddy covariance mode (Nemitz et al., 2008) to obtain fluxes of submicron speciated aerosols by Washington State University, Univ. of Colorado, CEHEdinburgh, and PNNL groups (see Table 1).

According to the 2006 emissions inventory (EI), about $83 \%$ of the energy consumed by the industrial sector within the MCMA is produced by natural gas. The estimated total annual emissions of $\mathrm{SO}_{2}$ in the $2006 \mathrm{EI}$ are about $7 \mathrm{ktons}$ per year for the MCMA. About 7800 industries considered in the inventory as point sources contribute more than $50 \%$ of the $\mathrm{SO}_{2}$ emissions within the MCMA. However, a current

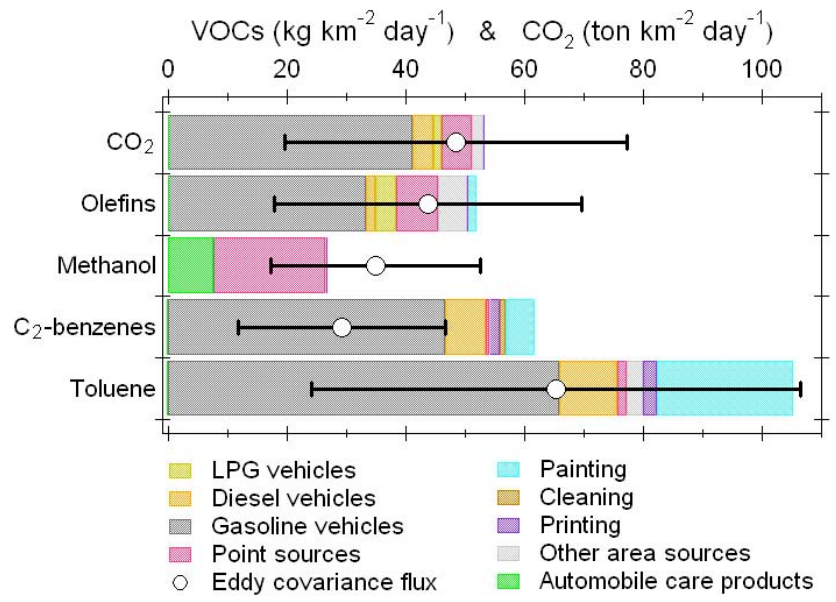

Fig. 8. Total daily measured fluxes at the SIMAT site compared to the disaggregated emissions by source type in the official 2006 emissions inventory. The emission profiles of $\mathrm{CO}_{2}$ and 4 VOCs are included (provided by E. Velasco, 2009).

challenge is quantification of the contributions of $\mathrm{SO}_{2}$ emissions from the Tula industrial complex, located $60 \mathrm{~km}$ northwest of the MCMA and not included in the inventory, to the high $\mathrm{SO}_{2}$ levels observed in the northern part of the city, especially during the winter season (de Foy et al., 2009b). Total vertical columns of $\mathrm{SO}_{2}$ and $\mathrm{NO}_{2}$ were measured during plume transects in the neighborhood of the Tula industrial complex using DOAS instruments (Rivera et al., 2009). Vertical profiles of wind speed and direction obtained from pilot balloons and radiosondes were used to calculate $\mathrm{SO}_{2}$ and $\mathrm{NO}_{2}$ fluxes in the plume. Average emissions fluxes for $\mathrm{SO}_{2}$ and $\mathrm{NO}_{2}$ were estimated to be $140 \pm 38$ and $9 \pm 3$ ktons per year, respectively; the standard deviation is due to actual variations in the observed emissions from the refinery and power plant, as well as the uncertainty in the wind fields at the time of the measurements. These values are in good agreement with available datasets obtained during MCMA2003 and with simulated trajectory plumes (de Foy et al., 2007, 2009b).

Due to its location $(60 \mathrm{~km}$ south-east of Mexico City), the Popocatepetl volcano can contribute substantially to regional levels of $\mathrm{SO}_{2}$, as well as subsequent sulfate particle formation and radiative scattering properties, although the high altitude of emission injection can also favor longrange transport. Therefore, it is important to understand the contributions from this source to the air quality levels at regional scales (de Foy et al., 2009b). $\mathrm{SO}_{2}$ emissions from the Popocatépetl volcano were measured and imaged during MILAGRO using stationary scanning DOAS (Grutter et al., 2008). An average emission rate of $894 \pm 507$ ktons per year of $\mathrm{SO}_{2}$ was estimated from all the daily averages obtained during the month of March 2006, with large variations in maximum and minimum daily averages of 5.97 and $0.56 \mathrm{Gg} /$ day, respectively. A scanning imaging 
infrared spectrometer was used for the first time for plume visualization of a specific volcanic gas, confirming observed $\mathrm{SO}_{2}$ emission plumes through 2-D scanning. In the same study, a frequency analysis of the 48-h forward trajectories calculated from the North American Regional Reanalysis (NARR) model outputs from National Centers for Environmental Prediction (NCEP) suggests that the emissions from Popocatepetl were transported towards Puebla/Tlaxcala approximately $63 \%$ of the time during March 2006.

Christian et al. (2010) measured initial emission ratios and emission factors for trace gas and particle species from five potentially important but little-studied combustion sources: wood cooking fires, garbage burning, brick and charcoal making kilns, and crop residue burning in central Mexico during the spring of 2007 , as a complementary study to the biomass burning measurements during 2006 MILAGRO (Yokelson et al., 2007). This study estimated a fine particle emission factor $\left(\mathrm{EFPM}_{2.5}\right)$ for garbage burning of $\sim 10.5 \pm 8.8 \mathrm{~g} / \mathrm{kg}$, and a large $\mathrm{HCl}$ emission factors in the range $2-10 \mathrm{~g} / \mathrm{kg}$. Garbage burning $\mathrm{PM}_{2.5}$ was found to contain levoglucosan and $\mathrm{K}$ in concentrations similar to those for biomass burning (BB); galactosan was the anhydrosugar most closely correlated with biomass burning species. Brick kilns produced low total $\mathrm{EFPM}_{2.5}(\sim 1.6 \mathrm{~g} / \mathrm{kg})$, but very high EC/OC ratios (6.72). The dirt charcoal kiln $\mathrm{EFPM}_{2.5}$ was $\sim 1.1 \mathrm{~g} / \mathrm{kg}$; some $\mathrm{PM}_{2.5}$ may be scavenged in the walls of dirt kilns. The fuel consumption and emissions due to industrial biofuel use are difficult to characterize regionally because of the diverse range of fuels used. However, the results suggest that cooking and garbage fires can be a major source of several reactive gases and fine particles with the potential for severe local impacts on air quality. Previous study by Mugica et al. (2001) in the MCMA focused on VOCs characterized by GC-FID; it has been documented in other city that meat cooking also produces carbonyls (Ho et al., 2006) (see also Sect. 8.2).

\subsection{Aircraft measurements}

Aircraft measurements can serve to develop top-down constraints for the validation of emissions inventories. The spatial variability of selected VOC emissions within MCMA was evaluated during the MILAGRO field campaign for the first time by disjunct eddy covariance flux measurements of toluene and benzene from the NCAR/NSF-C-130 aircraft (Karl et al., 2009). Twelve flights were carried out at midday across the northeast section of the city where the industrial district and the airport are located. Median toluene and benzene fluxes of $14.1 \pm 4.0 \mathrm{mg} \mathrm{m}^{-2} \mathrm{~h}^{-1}$ and $4.7 \pm 2.3 \mathrm{mg} \mathrm{m}^{-2} \mathrm{~h}^{-1}$, respectively, were measured along these flights. For comparison the 2004 EI adjusted emission inventory used by Lei et al. (2007) estimates toluene fluxes of $10 \mathrm{mg} \mathrm{m}^{-2} \mathrm{~h}^{-1}$ along the footprint of the flighttrack. These flights evidenced the strong contribution of fuel evaporation and industrial sources to the toluene emissions.
Karl et al. (2009) observed peak toluene to benzene flux ratios ranging from 10 to 15 , with a mean ratio of $3.2 \pm 0.5$. The ground flux measurements at the SIMAT site reported a mean toluene to benzene flux ratio of $4.2 \pm 0.5$, and a ratio of $7.0 \pm 1.2$ during the application of a paint resin to the sidewalks near the tower by the local district city maintenance workers (Velasco et al., 2009). Using the VOC data collected during these flights and a tracer model, it was found that vehicle exhaust, industrial and evaporative sources are the major sources ( $>87 \%$ ) of the BTEX compounds (benzene, toluene, ethylbenzene and m,p,o-xylenes) in Mexico City; in contrast to biomass burning, which contributes between $2 \%$ and $13 \%$.

Several previous studies have found that many fires occur in and around the MCMA, particularly in the pine forests on the mountains surrounding the city, both inside and outside the basin (Bravo et al., 2002; Johnson et al., 2006; Salcedo et al., 2006). Many of these fires are of human origin and can affect air quality. During MILAGRO, an instrumented US Forest Service (USFS) Twin Otter aircraft measured the emissions from 63 fires throughout south-central Mexico (Yokelson et al., 2007). The data indicate that while the emissions of $\mathrm{NH}_{3}$ are about average for forest burning, the emissions of $\mathrm{NO}_{\mathrm{x}}$ and $\mathrm{HCN}$ per unit amount of fuel burned in the pine forests that dominate the mountains surrounding the MCMA are about 2 times higher than normally observed for forest burning. The data showed that molar emission ratios of HCN/CO for the mountain fires were 29 times higher than widely used literature values for biomass burning. The nitrogen enrichment in the fire emissions may be due to deposition of nitrogen containing pollutants in the outflow from the MCMA, suggesting that this effect may occur worldwide wherever biomass burning coexists with large urban area or industrial pollution sources. PM emissions from biomass burning are summarized in Sect. 8.3 below.

NASA DC-8 flights conducted around Mexico City to measure gas-phase elemental mercury $(\mathrm{Hg})$ during 2006 showed highly concentrated pollution plumes (with mixing ratios as large as $500 \mathrm{ppqv}$ ) originating from the MCMA (Talbot et al., 2008). These high concentrations were related to combustion tracers such as $\mathrm{CO}$ but not $\mathrm{SO}_{2}$ (which is emitted mainly from fuel-oil burning, refineries, and volcanoes) suggesting that widespread multi-source urban/industrial emissions may have a more important influence on $\mathrm{Hg}$ than specific point sources for this region.

\section{Organic molecules in the atmosphere: the complexity of Mexico City Volatile Organic Compounds}

Megacities, such as the MCMA, produce a complex array of emissions including hundreds of different VOCs. Measurable VOCs considered here consist primarily of nonmethane hydrocarbons (NMHCs) and oxygenated volatile organic compounds (OVOCs). NMHCs have primary anthropogenic emission sources which can include evaporative, 
exhaust, industrial, biogenic, liquefied petroleum gas (LPG), and biomass burning emissions. Sources of OVOCs include primary anthropogenic emissions, primary biogenic emissions, biomass burning, and secondary photochemical formation from anthropogenic, biogenic, and biomass burning sources.

An excellent summary of the knowledge about VOCs in Mexico City before MILAGRO is provided by Velasco et al. (2007). During the MILAGRO field campaign, the complexity of VOCs in the MCMA was investigated using an impressive array of state-of-science measurement methods deployed at a number of fixed ground sites and in several airborne sampling platforms. In this section, the results from these varied measurement efforts are summarized to document the distribution, magnitude, and reactivity of VOCs in the photochemical environment within and downwind of Mexico City.

\subsection{Methods and sites}

VOC data were obtained from near the city center at the SIMAT tower site, from the T0 urban site, the T1 downwind site, the Aerodyne mobile laboratory platform, and with canisters collected at various city locations. VOCs were measured with various real-time and sampling/post analysis techniques on the NCAR C-130, DOE G-1, NASA DC-8, and the USFS Twin Otter aircraft.

At the SIMAT tower site, VOC concentrations and fluxes - obtained via eddy covariance methods - were measured using a PTR-MS, a continuous chemiluminescent analyzer calibrated for olefin measurements (Fast Olefin Sensor, FOS) and canister samples associated with updrafts and downdrafts which were analyzed off-line by gas chromatography (GC) separation and flame ionization detection (FID) (Velasco et al., 2009). Canister samples were collected for subsequent analyses by the UC Irvine group at the T0 and T1 sites. Each sample was analyzed for more than 50 trace gases comprising hydrocarbons, halocarbons, dimethyl sulfide (DMS), and alkyl nitrates. At T0, a quadrupole PTRMS (de Gouw and Warneke, 2007) measured 38 mass-tocharge ratios associated with VOCs including select NMHC (alkenes and aromatics), a variety of OVOCs and acetonitrile (Fortner et al., 2009). Two research grade long-path Differential Optical Absorption Spectroscopy (LP-DOAS) instruments measured numerous aromatic VOC, HCHO and glyoxal, following protocols developed in MCMA-2003 (Volkamer et al., 2005, 2010). In addition, vertical column concentrations of HCHO and glyoxal were measured by MultiAxis DOAS (MAX-DOAS). At T1, a PTR-MS using an ion trap mass analyzer (PIT-MS) (de Gouw et al., 2009) made continuous VOC measurements of a similar but not identical subset of VOCs and a GC-MS continuously measured a wide range of NMHCs. VOC measurements were obtained by the Aerodyne mobile laboratory at various locations using a quadrupole PTR-MS and canister sampling, analyzed by the US EPA, and several Mini-MAX DOAS instruments were deployed within and near the city at various locations (see Table 1). Formaldehyde was measured continuously at the T0 and $\mathrm{T} 1$ sites using a commercial instrument operated by IFU (Junkermann and Burger, 2006) and with a mobile DOAS instrument to estimate $\mathrm{HCHO}$ city plume mass flow rates (Johannson et al., 2009). Ambient samples of 13 VOCs were also measured at CENICA site (Wöhrnschimmel et al., 2010).

Onboard the C-130, there were three techniques for VOC measurements: (i) the NCAR Trace Organic Gas Analyzer (TOGA) which is a fast GC-MS system (Apel et al., 2003, 2010); (ii) the NCAR quadrupole PTR-MS (Karl et al., 2009); and (iii) UCI canister sampling with postflight analyses. For the TOGA instrument, 32 compounds were targeted including OVOCs (methanol, ethanol, methyl tertiary butyl ether, C2-C5 aldehydes, C2-C5 ketones), NMHC (C4-C9), and halogenated VOC compound classes and also acetonitrile. Simultaneous measurements were obtained for all compounds every $2.8 \mathrm{~min}$. The PTR-MS targeted OVOCs (mass to charge ratios associated with the detection of methanol, acetaldehyde, (acetone+propanal), (MEK+butanal), acetonitrile, benzene, toluene, and C8 and C9 aromatics for analysis as well as the more polar species acetic acid and hydroxyacetone. The measurement frequency was variable but the suite of species was typically recorded each minute; during some city runs the instrument recorded benzene and toluene measurements at $1 \mathrm{~Hz}$ in order to obtain vertical flux profiling by eddy covariance over the MCMA. The UCI canisters were analyzed for a full range of VOCs in the $\mathrm{C} 2-\mathrm{C} 10$ range including NMHCs, halogens, and organic nitrates. The time resolution was limited by the number of canisters available for each flight (72). For co-measured NMHC species, the TOGA NMHCs and halogenated VOCs showed excellent agreement with the UCI canisters. Agreement between TOGA and the PTR-MS was also generally good (usually within 20\%) for co-measured species but with greater overall differences than with the canister/TOGA measurements. Formaldehyde was continuously measured on the C-130 with a difference frequency generation absorption spectrometer (Weibring et al., 2007).

The DOE G-1 was equipped with a quadrupole PTR-MS that measured similar species to the NCAR PTR-MS system. A limited number of canister samples were also collected on the G-1 and analyzed for a suite of NMHCs by York University. The majority of the DOE G-1 flight hours were carried out in and around the MCMA at altitudes ranging from 2.2 to $5 \mathrm{~km}$. An in-flight comparison was conducted between the G-1 PTR-MS and the C-130 TOGA and NCAR PTR-MS and the results showed good agreement for benzene but discrepancies on the order of $30 \%$ for other species (Apel et al., 2010).

The NASA DC-8 was equipped with a canister collection system operated by UCI. After transporting the canisters back to the laboratory, these were analyzed for a full 
range of VOCs in the $\mathrm{C} 2-\mathrm{C} 10$ range including NMHCs, halogens, and organic nitrates. One hundred sixty eight canisters were available for each flight. The NASA Ames group operated PANAK (PAN-Aldehydes-Alcohols-Ketones), an in-situ three-channel gas chromatographic instrument used to measure acetone, methylethylketone, methanol, ethanol, acetaldehyde, propionaldehyde and also hydrogen cyanide and acetonitrile. Formaldehyde was continuously measured on the DC-8 aircraft using tunable diode laser spectroscopy (Fried et al., pers. comm., 2009). The DC-8 was flown out of Houston, TX with a primary objective to measure aged outflow from the MCMA although several flights sampled fresh emissions from the MCMA basin and the surrounding area.

The USFS Twin Otter was equipped with an airborne Fourier transform infrared spectrometer (AFTIR) with the primary objective of sampling biomass burning emissions within the region (Yokelson et al., 2007). Species measured included hydrogen cyanide, methane, ethene, acetylene, formaldehyde, methanol, acetic acid and formic acid. Canisters were also collected which were subsequently analyzed by the University of Miami group using GC-FID for methane, ethane, ethene, ethyne, propane, propene, isobutane, $\mathrm{n}$-butane, $\mathrm{t}$-2 butene, 1-butene, isobutene, c-2-butene, 1,3 butadiene, cyclopentane, isopentane, and $\mathrm{n}$-pentane, with detection limits in the low pptv range. Other canisters were filled for analysis by the Forest Service Fire Sciences Laboratory by $\mathrm{GC} / \mathrm{FID} / \mathrm{RGD}$ for $\mathrm{CO}_{2}, \mathrm{CO}, \mathrm{CH}_{4}, \mathrm{H}_{2}$, and several C2-C3 hydrocarbons.

\subsection{VOC emissions}

During the MILAGRO campaign, direct VOC emissions measurements were obtained using (i) the Aerodyne mobile laboratory during driving traverses (Zavala et al., 2009b); (ii) a fixed site (SIMAT) flux measurement study (Velasco et al., 2009); and (iii) disjunct eddy covariance (DEC) fluxes onboard the C-130 aircraft (Karl et al., 2009). In addition, emission ratios (pptv $\mathrm{VOC}) /(\mathrm{ppbv} \mathrm{CO}$ ) were obtained for a variety of compounds at the T0 and T1 sites (e.g., de Gouw et al., 2009). The flux measurements were analyzed in terms of diurnal patterns and vehicular activity and were compared with the most recent gridded local emissions inventory. The results show that the urban surface of Mexico City is a net source of VOCs with substantial contributions from vehicular traffic. The canister samples collected at the SIMAT tower site were used to calculate fluxes of selected NMHCs by the Disjunct Eddy Accumulation (DEA) technique (see Table 1) (Velasco et al., 2009). Results from the flux study aboard the C-130 aircraft indicate high toluene to benzene flux ratios above an industrial district (e.g., $10-15 \mathrm{~g} / \mathrm{g}$ ) including the Benito Juarez International Airport (e.g., 3$5 \mathrm{~g} / \mathrm{g}$ ) and a mean flux (concentration) ratio of $3.2 \pm 0.5 \mathrm{~g} / \mathrm{g}$ $(3.9 \pm 0.3 \mathrm{~g} / \mathrm{g})$ across Mexico City, which confirm an important role for evaporative fuel and industrial emissions for aromatic compounds in the basin (Karl et al., 2009). Previous indications for solvent sources have been obtained during the MCMA-2003 field campaign from comparisons between insitu PTR-MS and GC-FID canister measurements with LPDOAS measurements (Jobson et al., 2010). While the DOAS data agreed within $20 \%$ with both point measurements for benzene, concentrations measured by DOAS were on average a factor of 1.7 times greater than the PTRMS data for toluene, C2-alkylbenzenes, naphthalene, and styrene. The level of agreement for the toluene data was a function of wind direction, establishing that spatial gradients - horizontal, vertical, or both - in VOC mixing ratios were significant, and up to a factor of 2 despite the fact that all measurements were conducted above roof level. This analysis highlights the issue of representative sampling in an urban environment.

Spatial concentration gradients complicate the sampling of hydrocarbons and possibly other pollutants in urban areas for comparison with photochemical models (Jobson et al., 2010). More details on the VOCs measurements are provided in Sect. 4 on emissions.

\subsection{VOC distributions and patterns}

At the SIMAT tower site, and at both the $\mathrm{T} 0$ and $\mathrm{T} 1$ ground sites, VOC mixing ratios are quite high compared to typical levels in US cities, such as New York (Shirley et al., 2006). The low molecular weight alkanes are prevalent, with propane being the most abundant species with mean daytime mixing ratios of approximately $30 \mathrm{ppbv}$ at $\mathrm{T} 0$ and approximately 8 ppbv at T1, which has previously been attributed to widespread use of LPG (e.g., Blake and Rowland, 1995; Velasco et al., 2007). The most important source of alkenes is believed to be vehicular emissions (Doskey et al., 1992; Altuzar et al., 2005; Velasco et al., 2005), but LPG and industrial emissions can also be important. Aromatics result from vehicle emissions but are also widely used in paints, and industrial cleaners and solvents. Aldehydes result from fossil fuel combustion and are formed in the atmosphere from the oxidation of primary NMHCs (Atkinson, 1990). Volkamer et al. (2005) measured glyoxal for the first time directly in the atmosphere during MCMA-2003. Glyoxal is mostly formed from VOC oxidation, and provides advantages over traditional tracers for VOC oxidation, as it is less affected by primary emissions. Garcia et al. (2006) used these unique tracer properties in a tracer ratio method to discern primary emissions of $\mathrm{HCHO}$ from photochemically produced $\mathrm{HCHO}$ in the MCMA. They concluded that while primary emissions dominate in the early morning, secondary $\mathrm{HCHO}$ is responsible for up to $80 \%$ of the ambient $\mathrm{HCHO}$ for most of the day.

The two most prevalent ketones, acetone and methylethylketone, are believed to have sources similar to the aromatic compounds. They exhibit strong correlation with $\mathrm{CO}$. However, there is also evidence for ketone contributions from paints and solvents. Less is known about the emissions of the alcohols. Methanol is one of the most 

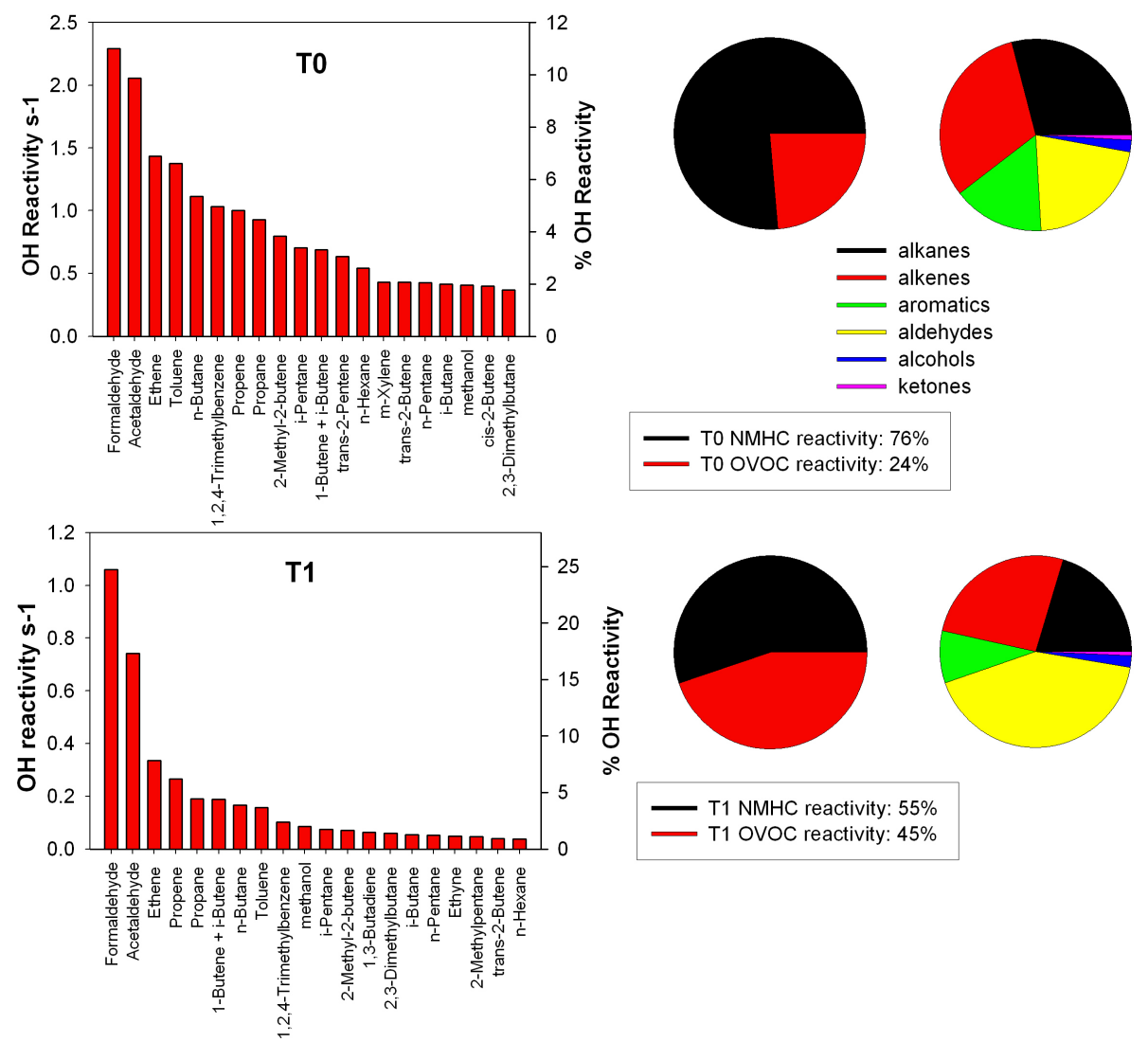

Fig. 9. The top 20 compounds measured at the supersites T0 (top panel) and T1 (bottom panel) in terms of OH reactivity between 09:00 and 18:00 local time averaged over the month of March, 2006. Shown in the first pie chart to the right of each bar graph is the breakdown for the relative contributions from NMHCs and OVOCs for T0 and T1, respectively. Shown in the second pie chart is the breakdown in terms of each compound class.

prevalent VOCs with average mixing ratios of approximately 20 ppbv at T0, 17 ppbv at the SIMAT tower site, and 4 ppbv at T1, during a season when biogenic emissions are believed to be low. During the morning rush hour at the T0 site impacted by industrial emissions and diesel fuel exhaust, methanol concentrations averaged $\cong 50$ ppbv (Fortner et al., 2009) but no more than $20 \mathrm{ppbv}$ at the SIMAT tower site located in a residential neighborhood (Velasco et al., 2009). The aldehydes are present in relatively higher amounts at T1 versus the T0 site. Biomass burning tracers measured by several investigators suggested that biomass burning is a minor source of VOCs at $\mathrm{T} 0$ or $\mathrm{T} 1$ relative to mobile and industrial emissions (e.g., de Gouw et al., 2009).

In terms of enhancement ratios, many hydrocarbon species relative to $\mathrm{CO}$ were higher in Mexico City than in the US (de Gouw et al., 2009; Apel et al., 2010), and similar enhancement ratios were found for most oxygenated VOCs (de Gouw et al., 2009). The higher hydrocarbon enhancement ratios in Mexico City compared to the US are due to the widespread use of LPG and higher industrial and evaporative emissions of aromatics.
Heald et al. (2008) compiled all the gas and particle phase organic measurements into the newly defined "Total Observed Organic Carbon", which had a daytime mean of $456 \mu \mathrm{gC} \mathrm{m}^{-3}$ at $\mathrm{T} 0$ and $17 \mu \mathrm{gC} \mathrm{m}^{-3}$ for the $\mathrm{C}-130$. The T0 levels are an order-of-magnitude higher than those measured in Pittsburgh $\left(28-45 \mu \mathrm{gC} \mathrm{m}{ }^{-3}\right)$, while those measured in the C-130 are typical of polluted airmasses in the US sampled from aircraft. The organic aerosol PM contribution increased from $\sim 3 \%$ of the TOOC at T0 to $9 \%$ for the C-130, due to SOA formation and the larger contribution of biomass burning to regional airmasses.

The total daytime average $\mathrm{OH}$ reactivity from measured VOC compounds was found to be $19.7 \mathrm{~s}^{-1}$ at T0 and $4.4 \mathrm{~s}^{-1}$ at $\mathrm{T} 1$ (Apel et al., 2010). The $\mathrm{OH}$ reactivity determined at T0 is broadly consistent with the results from the MCMA2003 study at the CENICA supersite located approximately $7 \mathrm{~km}$ SE of downtown Mexico City. During MCMA-2003 Shirley et al. (2006), using the Total OH Loss Measurement instrument (TOHLM), reported an average daily $\mathrm{OH}$ reactivity of $33 \mathrm{~s}^{-1}$, and estimated that $72 \%$ of it $\left(\sim 24 \mathrm{~s}^{-1}\right)$ was due to VOCs. NMHCs provide the majority of the measured daytime averaged VOC reactivity for $\mathrm{T} 0$ and $\mathrm{T} 1 \mathrm{(75 \%}$ 


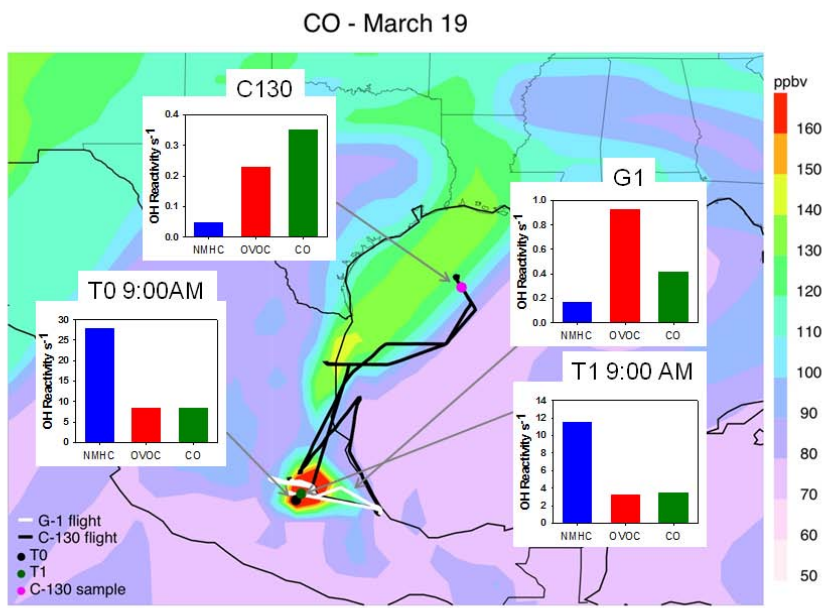

Fig. 10. MOZART depiction of the of the $\mathrm{CO}$ outflow from the 19 March 2006 plume. Superimposed on the plume are flight tracks from the G-1 on 18 March and from the C130 on 19 March. The G-1 intercepted the plume as it was emerging from the city during a transect that occurred between the times of 14:20 and 15:20 local time on the 18th and the $\mathrm{C}-130$ which intercepted the plume on the afternoon of the 19th. The $\mathrm{OH}$ reactivity distributions in terms of NMHCs, OVOCs, and CO at 09:00 a.m. are shown for the T0 and $\mathrm{T} 1$ sites, the G-1 during the transect, and the $\mathrm{C} 130$ during the plume interception that occurred at the furthest point from the city.

and $56 \%$, respectively), and OVOCs provide the remaining VOC reactivity with $25 \%$ and $44 \%$, respectively. However, the two most important measured VOCs in terms of $\mathrm{OH}$ reactivity were formaldehyde and acetaldehyde. The distribution of $\mathrm{OH}$ reactivity among $\mathrm{VOC}$ classes is shown in Fig. 9. The third most important VOC was ethene which reacts relatively quickly to form formaldehyde (e.g., Wert et al., 2003) and is therefore an important contributor to secondary formaldehyde formation (Garcia et al., 2006). On-road vehicle emissions of acetaldehyde were reported by Zavala et al. (2006) who found substantial levels of this species in vehicle exhaust, although the levels were found to be lower than formaldehyde emissions by a factor of 5 to 8 .

\subsection{In-basin VOC chemistry}

Measurements at T1 (de Gouw et al., 2009) show that diurnal variations of hydrocarbons were dominated by a high peak in the early morning when local emissions accumulated in a shallow boundary layer, and a minimum in the afternoon when the emissions were diluted in an expanded boundary layer and, in the case of reactive gases, removed by $\mathrm{OH}$. In comparison, diurnal variations of species with secondary sources, such as the aldehydes and ketones, stayed relatively high in the afternoon indicating photochemical formation. Photochemical formation of acetone is important in Mexico City due to high emissions of alkane precursors, principally propane, from the widespread use of LPG. The influence of biomass burning was investigated at $\mathrm{T} 1$ using the measurements of acetonitrile, which was found to correlate with levoglucosan in the particle phase. Diurnal variations of acetonitrile indicate a contribution from local burning sources. Scatter plots of acetonitrile versus CO suggest that the contribution of biomass burning to the enhancement of most gas and aerosol species was not dominant and perhaps not dissimilar from observations in the US Measurements of the biomass burning influence on Mexico City and the surrounding area were made on the C-130 (Crounse et al., 2009) and the US Forest Service Twin Otter (Yokelson et al., 2007). During the measurement period, fires contributed one third of the enhancement in benzene in the outflow from the Central Mexican Plateau, and by implication, contributed to the enhancement of all VOCs that are produced in fires.

\subsection{Long-range VOC transport out of the basin}

Apel et al. (2010) have summarized the overall pattern of VOC measurements during MILAGRO in terms of a diurnal process associated with the daily flushing of the MCMA basin: following morning emissions from traffic, industry, cooking, etc., into a shallow boundary layer, the boundary layer deepens rapidly and air is mixed with cleaner air aloft and eventually transported downwind of the city by strong synoptic winds. Figure 10 illustrates some features of the outflow pattern. During the MIRAGE-Mex flight on 19 March, the C-130 intercepted three times an MCMA outflow plume that had been sampled a day earlier by the G-1 over the source region. This was a typical NE transport event at altitudes ranging from $3-5 \mathrm{~km}$. Air was sampled that had aged between 1-2 days. The figure shows the results of a MOZART (Model for Ozone and Related chemical Tracers) simulation of the CO outflow from the plume. Superimposed on the plume are flight tracks from the G-1 on 18 March and from the C-130 on 19 March. The G-1 intercepted the plume as it was emerging from the city during a transect that occurred between 14:20 and 15:20 local time and the C-130 which intercepted the plume on the afternoon of the 19th. Also shown in the figure are the $\mathrm{OH}$ reactivity distributions in terms of NMHCs, OVOCs, and $\mathrm{CO}$ for the $\mathrm{T} 0$ and $\mathrm{T} 1$ sites at 09:00 a.m., the G-1 during the transect, and the C-130 during the plume interception that occurred at the furthest point from the city. It is interesting to note the extent of the plume into the US at $620 \mathrm{hPa}(\cong 4 \mathrm{~km}$ altitude). The total VOC reactivity is dominated by NMHCs in the basin in the morning with $\mathrm{CO}$ playing a relatively minor role compared to the VOCs. The total measured $\mathrm{OH}+\mathrm{VOC}$ reactivity at 09:00 a.m. at $\mathrm{T} 0$ is $50 \mathrm{~s}^{-1}$ and $14 \mathrm{~s}^{-1}$ at T1. A large part of the $\mathrm{OH}$ reactivity is provided by alkenes and aromatics $(50 \%$ of total VOC-OH reactivity, with $30 \%$ from alkenes and $20 \%$ from aromatics at T0, not shown in the figure), species that have relatively short lifetimes under the conditions present in the basin. It is apparent from the data that rapid photochemistry occurs, quickly transforming the $\mathrm{OH}-\mathrm{VOC}$ reactivity initially 
from being dominated by NMHCs to being dominated by OVOCs aloft (G-1) and further downwind (C-130 plumes). $\mathrm{CO}$ plays a relatively more important role in $\mathrm{OH}$ reactivity compared to VOCs as the plume ages. At the $\mathrm{C}-130$ plume interception point, approximately $60 \%$ of the $\mathrm{CO}$ reactivity is from the background $\mathrm{CO}$.

For the C-130 flights conducted over the city, the most abundant species measured was methanol, followed by propane and other NMHC and OVOC species. Eight of the top 20 measured VOCs were OVOCs. Similar to T0 and $\mathrm{T} 1$, the two most important VOCs in terms of reactivity were formaldehyde and acetaldehyde.

\section{Urban and regional photochemistry}

\subsection{Urban photochemistry}

The production of ozone and secondary organic aerosols $(\mathrm{SOA})$ in the atmosphere involves chemical reactions of $\mathrm{NO}_{\mathrm{x}}$ and VOCs in the presence of sunlight (although dark reactions with e.g. $\mathrm{NO}_{3}$ and $\mathrm{O}_{3}$ can play a role in $\mathrm{SOA}$ formation). The suite of measurements designed to examine the complex photochemistry in the MCMA during MILAGRO expanded upon previous measurements in 2003 (Molina et al., 2007). At T0, measurements were made of $\mathrm{NO}_{\mathrm{x}}$, several VOCs, $\mathrm{O}_{3}, \mathrm{OH}$ and $\mathrm{HO}_{2}$, as well as several radical precursors and indicators for fast $\mathrm{NO}_{\mathrm{x}}$ and $\mathrm{VOC}$ oxidation processes such as HONO, HCHO and glyoxal.

The median of the daily measured maximum $\mathrm{NO}_{\mathrm{x}}$ mixing ratios at $\mathrm{T} 0$ was approximately $200 \mathrm{ppbv}$ during the morning rush hour (Dusanter et al., 2009a), which was approximately a factor of 2 greater than that observed at the CENICA supersite during MCMA-2003 (Molina et al., 2007), and thus may reflect the influence of local sources at this site. During both campaigns, direct atmospheric measurements of $\mathrm{NO}_{2}$ were conducted by LP-DOAS (Volkamer et al., 2005). Such measurements are free from interferences that are known to be issues with commercial $\mathrm{NO}_{\mathrm{x}}$ instruments (Dunlea et al., 2007), in particular during afternoons. In the afternoon, $\mathrm{NO}_{\mathrm{x}}$ was approximately $20 \mathrm{ppb}$, similar to that observed during MCMA-2003. Median peak VOC concentrations at T0 during the morning rush hour $(1600 \mathrm{ppbC})$ were similar to that measured during MCMA-2003 (1500 ppbC) (Shirley et al., 2006; Velasco et al., 2007; Dusanter et al., 2009a), while plumes of elevated toluene as high as $216 \mathrm{ppbv}$ and ethyl acetate as high as $183 \mathrm{ppbv}$ were often observed during the late night and early morning hours at $\mathrm{T} 0$, indicating the possibility of significant industrial sources in the region around this site (Fortner et al., 2009).

\subsubsection{Radical sources and budget}

Measured concentrations of $\mathrm{OH}$ by Laser-Induced Fluorescence (LIF) were similar to that measured in other urban areas, with median midday values of approximately
$4.6 \times 10^{6} \mathrm{~cm}^{-3}$. These $\mathrm{OH}$ concentrations are approximately a factor of two lower than the corrected values measured during MCMA-2003 (Shirley et al., 2006; Mao et al., 2009; Dusanter et al., 2009a). The median diurnal maximum $\mathrm{HO}_{2}$ concentration was $1.9 \times 10^{8} \mathrm{~cm}^{-3}$, which was lower than the corrected values observed during MCMA-2003 (Shirley et al., 2006; Mao et al., 2009; Dusanter et al., 2009a). The lower measured concentrations of $\mathrm{OH}$ and $\mathrm{HO}_{2}$ are consistent with the higher observed $\mathrm{NO}_{\mathrm{x}}$ at $\mathrm{T} 0$, which would reduce $\mathrm{OH}$ and $\mathrm{HO}_{2}$ through the $\mathrm{OH}+\mathrm{NO}_{2}$ and $\mathrm{HO}_{2}+\mathrm{NO}$ reactions.

A 0-D box model based on the Regional Atmospheric Chemistry Mechanism (RACM) of the $\mathrm{HO}_{\mathrm{x}}\left(\mathrm{OH}+\mathrm{HO}_{2}\right)$ radical concentrations constrained by measurements of radical sources and sinks was used to test the ability of this mechanism to reproduce the observed radical concentrations and to perform a radical budget analysis (Dusanter et al., 2009b). Constraining the simulation to measured values of glyoxal with additional constraints on the estimated concentrations of unsaturated dicarbonyl species resulted in modeled $\mathrm{HO}_{\mathrm{x}}$ concentrations in good agreement with measured values during the afternoon. However, consistent with other urban measurements, $\mathrm{HO}_{\mathrm{x}}$ concentrations were underpredicted during the morning hours when $\mathrm{NO}_{\mathrm{x}}$ is high (Dusanter et al., 2009b). During the MCMA-2003 campaign, results from a constrained 2-D flexible top box model based on the Master Chemical Mechanism found that modeled $\mathrm{HO}_{\mathrm{x}}$ concentrations compared favorably with measured concentrations for most of the day (Volkamer et al., 2010; Sheehy et al., 2010). However, the model also underpredicted the concentrations of radicals in the early morning, which could lead to an underprediction of the integrated amount of ozone produced by a factor of two (Sheehy et al., 2010). This detailed testing of chemical models at the radical level highlights the fact that in addition to uncertainties associated with emissions and meteorology, there are additional uncertainties associated with the chemical mechanisms used in current models (Sheehy et al., 2010; Dusanter et al., 2009b; Hofzumahaus et al., 2009). The parameterization associated with the prediction of ozone by these models may mask this uncertainty and may cause models to give the right answer for the wrong reason.

During MCMA-2006, the modeling analysis predicts that the gross photolysis of HONO (35\%), photolysis of HCHO (24\%), $\mathrm{O}_{3}$-alkene reactions (19\%) and photolysis of dicarbonyls $(8 \%)$ are the main sources of radicals during the daytime at $\mathrm{T} 0$, while $\mathrm{O}_{3}$ photolysis is predicted to contribute $6 \%$ of the total radical initiation (Dusanter et al., 2009b). During MCMA-2003, a similar radical source analysis found that the photolysis of secondary OVOCs other than HCHO (33\%) was the largest contribution to the total radical production rate, followed by $\mathrm{O}_{3}$ photolysis (19\%), HCHO photolysis (19\%), $\mathrm{O}_{3}$-alkene reactions $(15 \%)$, and HONO photolysis (12\%) (Volkamer et al., 2010). The larger contribution of HONO photolysis to radical initiation at $\mathrm{T} 0$ is due to 
the higher median HONO concentrations measured in 2006 as a result of the higher $\mathrm{NO}_{\mathrm{x}}$ concentrations at this site. Notably, both studies suggest that $\mathrm{HCHO}$ is an important radical source in the MCMA that can have a substantial impact on radical and ozone production, especially during the morning (Lei et al., 2009), while $\mathrm{O}_{3}$-alkene reactions help jump start the photochemistry shortly after sunrise, and indirectly sustain radical production in the mid- morning by forming HCHO and other OVOCs (Volkamer et al., 2010).

The relative importance of $\mathrm{HONO}$ as a radical source varies by location in the MCMA, and even at a given location can vary from day to day. During a period characterized by elevated daytime HONO mixing ratios, Li et al. (2010) used the WRF-Chem model to investigate the relative contribution of several HONO sources and their impact on the formation of photochemical pollutants. The model included homogeneous production of HONO from the gas phase reaction of $\mathrm{OH}$ with $\mathrm{NO}$ and four other heterogeneous sources. Heterogeneous conversion of $\mathrm{NO}_{2}$ by condensed semivolatile organic compounds was found to be the main source of $\mathrm{HONO}$ in the MCMA, accounting for $75 \%$ of the measured ambient concentrations. Inclusion of these additional heterogeneous sources improved the agreement between the measured and modeled $\mathrm{HONO}$ and $\mathrm{HO}_{\mathrm{x}}$ concentrations and enhanced the production of $\mathrm{O}_{3}$ and SOA ( $\mathrm{Li}$ et al., 2010).

Radical termination at $\mathrm{T} 0$ was dominated by $\mathrm{OH}+\mathrm{NO}_{\mathrm{x}}$ reactions, with the formation of $\mathrm{HNO}_{3}, \mathrm{HONO}$, and organic nitrates contributing to 60,20 , and $14 \%$ of the total radical termination rate respectively (Dusanter et al., 2009b). Radical termination through the formation of peroxyacetyl nitrates (PANs) and subsequent reaction with $\mathrm{OH}$ was calculated to be negligible assuming PANs are in steady-state due to the rapid thermal dissociation of PAN species leading to the formation of $\mathrm{RO}_{2}$ radicals (Dusanter et al., 2009b). However, a modeling analysis of PAN formation using the Comprehensive Air Quality Model with extensions (CAMx) suggest that PAN is not in chemical-thermal equilibrium during photochemically active periods, and could lead to significant outflow of PAN from the urban area (Lei et al., 2007). Measurements of gaseous $\mathrm{HNO}_{3}$ reached a peak value of 0.5 to $3 \mathrm{ppb}$ in the early afternoon, which was less than that predicted from the rate of $\mathrm{HNO}_{3}$ production based on measured $\mathrm{OH}$ and $\mathrm{NO}_{2}$ concentrations (Zheng et al., 2008). However, the measured $\mathrm{HNO}_{3}$ mixing ratio was found to anti-correlate with submicron-sized aerosol nitrate, suggesting that gasparticle partitioning has a substantial effect on the gas phase concentration of $\mathrm{HNO}_{3}$ in the MCMA (Zheng et al., 2008), consistent with results from MCMA-2003 (Salcedo et al., 2006; San Martini et al., 2006a, b). Irreversible $\mathrm{HNO}_{3}$ uptake on dust was also reported by several groups (e.g., Querol et al., 2008) and was an important sink of $\mathrm{HNO}_{3}$. Gas phase $\mathrm{HNO}_{3}$ contributed a smaller fraction of oxidized $\mathrm{NO}_{x}$ products $\left(\mathrm{NO}_{\mathrm{z}}=\mathrm{NO}_{\mathrm{y}}-\mathrm{NO}_{\mathrm{x}}\right)$, while particulate nitrate comprised a large fraction due to high concentrations of $\mathrm{NH}_{3}$ and dust (Querol et al., 2008; Wood et al., 2009). Aircraft mea- surements of total alkyl nitrates in the immediate vicinity of Mexico City were found to be a substantial fraction (approximately $10 \%$ ) of total $\mathrm{NO}_{\mathrm{y}}$ (Perring et al., 2010).

The $\mathrm{HO}_{2} / \mathrm{OH}$ ratio can be used as a measure of the efficiency of radical propagation. During MCMA-2006, observed $\mathrm{HO}_{2} / \mathrm{OH}$ ratios varied from 1 to 120 for measured NO mixing ratios between 1-120 ppb. These ratios are lower than those measured during MCMA-2003, but may reflect the higher $\mathrm{NO}_{\mathrm{x}}$ environment at $\mathrm{T} 0$ resulting in greater rates of radical termination and lower $\mathrm{HO}_{2}$ concentrations (Shirley et al., 2006; Sheehy et al., 2010; Dusanter et al., 2009a). Model predicted $\mathrm{HO}_{2} / \mathrm{OH}$ ratios are in generally good agreement with the measurements during the afternoon when NO was between 1 and $5 \mathrm{ppb}$. However, the model underestimates the measured ratios by approximately a factor of $2-$ 5 at higher NO mixing ratios between $10-100$ ppb observed during the morning (Dusanter et al., 2009b). This behavior is consistent with that observed for MCMA-2003 (Shirley et al., 2006; Sheehy et al., 2010) as well as other field campaigns, suggesting that a process converting $\mathrm{OH}$ into peroxy radicals may be missing from the chemical mechanism.

The net instantaneous rate of ozone production from $\mathrm{HO}_{2}$ radicals $\left(P\left(\mathrm{O}_{3}\right) \approx k_{\mathrm{HO}_{2}+\mathrm{NO}}\left(\mathrm{HO}_{2}\right)(\mathrm{NO})\right)$ can provide insight into the chemical processes that produce ozone in the MCMA. At T0, $P\left(\mathrm{O}_{3}\right)$ was as high as $80 \mathrm{ppb} / \mathrm{h}$ in the early morning (Dusanter et al., 2009a). These instantaneous values were lower than during MCMA-2003 (Sheehy et al., 2010), where early morning values reached $120 \mathrm{ppb} / \mathrm{hr}$ and are higher than those reported for other urban areas (see references in Sheehy et al., 2010; Kleinman et al., 2005; Mao et al., 2009). An observed ozone production rate from all production mechanisms $\left(\mathrm{HO}_{2}, \mathrm{RO}_{2}\right.$, etc. $)$ of approximately $50 \mathrm{ppb} / \mathrm{h}$ was observed at a mountain-top site (Pico de Tres Padres) located within and $700 \mathrm{~m}$ above the Mexico City basin (Wood et al., 2009). These values are among the highest observed anywhere in the world and are consistent with the extremely high VOC reactivity observed in the MCMA compared to other locations (Shirley et al., 2006; Sheehy et al., 2010; Mao et al., 2009; Wood et al., 2009).

\subsubsection{Modeling urban ozone production and sensitivity}

Several chemical transport models and analysis of measurements indicate that ozone production in the MCMA is generally VOC-limited in the urban area (Lei et al., 2007, 2008; Song et al., 2010; Tie et al., 2007; Zhang and Dubey, 2009). Measurements of the production of hydrogen peroxide, which is a main radical termination product under $\mathrm{NO}_{\mathrm{x}}-$ limited conditions, was found to be negligible in the MCMA (Volkamer et al., 2010; Sheehy et al., 2010) and only increased slightly just outside of the urban area, consistent with ozone production being VOC-limited (Nunnermacker et al., 2008). A comparison of calculated radical production rates with the observed production rate of $\mathrm{NO}_{\mathrm{z}}$ also suggests that ozone production in the MCMA is VOC-limited, with the 

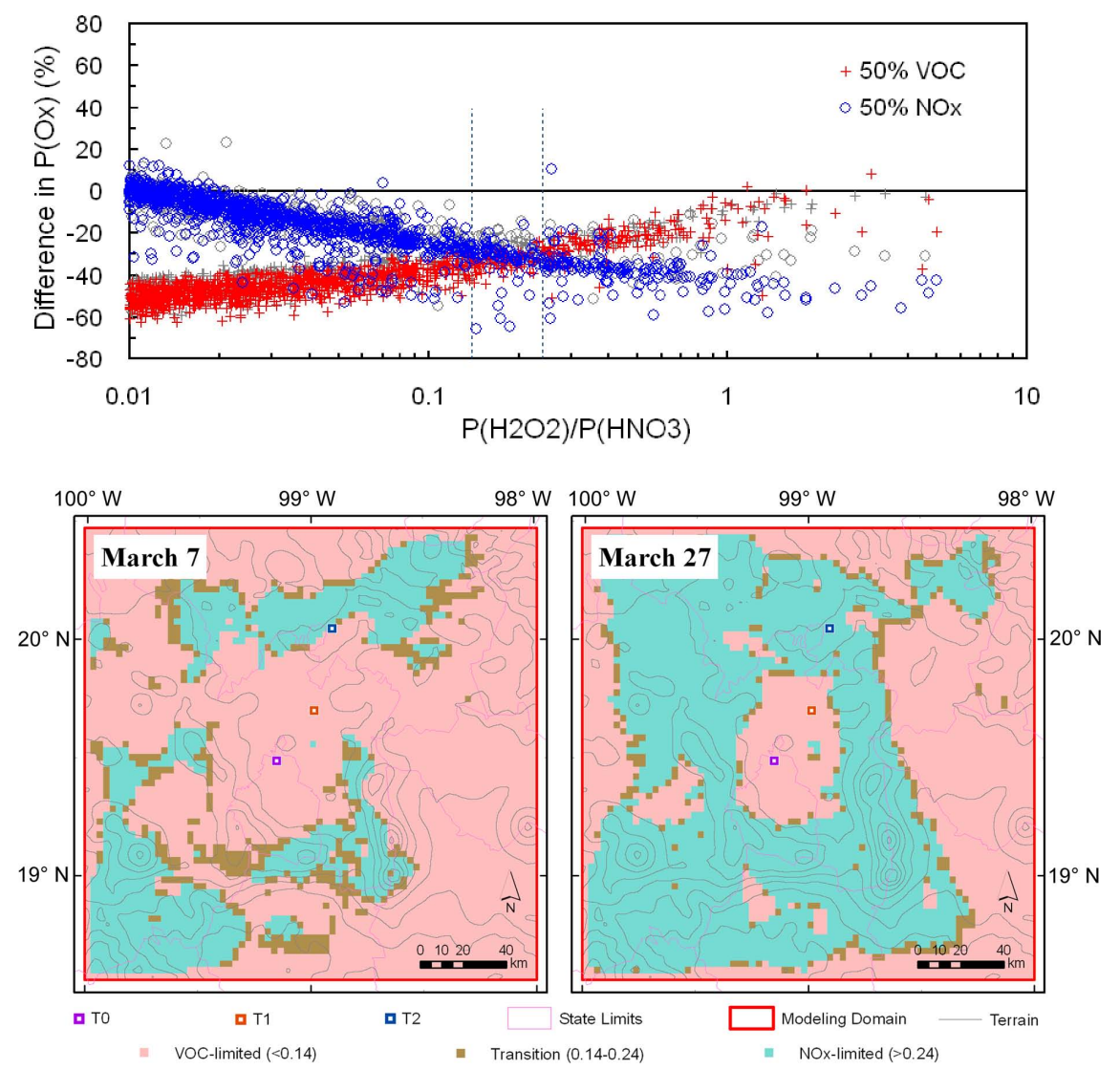

Fig. 11. Top panel: The percentage change in $\mathrm{O}_{\mathrm{x}}$ formation rate as a function of the indicator, ratio of $\mathrm{H} 2 \mathrm{O} 2$ production rate to $\mathrm{HNO} 3$ production rate at 12:00-17:00 LT during the episodes (weekends are shown in gray) within the urban area. The dashed bars envelop the transition regime. Bottom panel: Spatial distribution of the ratio at 14:00 LT on 7 and 27 March 2006 indicating the $\mathrm{NO}_{\mathrm{x}}-\mathrm{VOC}_{\mathrm{C}}$ sensitivity (source: Song et al., 2010).

main radical termination reactions involving $\mathrm{NO}_{\mathrm{x}}$ oxidation (Wood et al., 2009). An analysis of ratio of radical loss from the formation of nitric acid and organic nitrates to the total radical production for MCMA 2003 also suggests that ozone production is VOC-limited in the early morning and late afternoon, but becomes $\mathrm{NO}_{\mathrm{x}}$-limited during the early afternoon (Mao et al., 2009).

Sensitivity analyses of ozone production to precursor emissions under different meteorological conditions during MCMA-2006, along with a chemical indicator analysis using the chemical production ratios of $\mathrm{H}_{2} \mathrm{O}_{2}$ to $\mathrm{HNO}_{3}$, demonstrate that the MCMA urban core region is VOC-limited for all meteorological episodes, while the surrounding areas with relatively low- $\mathrm{NO}_{\mathrm{x}}$ emissions can be either $\mathrm{NO}_{\mathrm{x}}$ - or VOC-limited regime depending on the episode (Song et al., 2010) (see Fig. 11). Precursor emissions were constrained by the comprehensive data from the MCMA-2006 study and the RAMA network, while the simulated plume mixing and transport were examined by comparison with aircraft measurements. The CAMx model was able to reproduce the observed concentrations of ozone and precursors and suggest that controls on VOC emissions would be a more effec- tive way to reduce ozone levels in the urban area, consistent with previous results from MCMA-2003 (Lei et al., 2007, 2008). However, the degree of VOC-limitation increased for MCMA-2006 due to lower VOCs, lower VOC reactivity and moderately higher $\mathrm{NO}_{\mathrm{x}}$ emissions. Furthermore, meteorological conditions led to large variations in regime for the relatively low- $\mathrm{NO}_{\mathrm{x}}$ emitting area, implying that the effectiveness of particular emission control strategies would depend on location and meteorology (Song et al., 2010).

An analysis of the weekly pattern of surface concentrations of $\mathrm{CO}, \mathrm{NO}_{\mathrm{x}}$, particulate matter $\left(\mathrm{PM}_{10}\right)$ and $\mathrm{O}_{3}$ between 1987 and 2007 show a distinct weekend effect, as morning concentrations of $\mathrm{CO}, \mathrm{NO}_{\mathrm{x}}$ and $\mathrm{PM}_{10}$ were lower on Saturdays and Sundays compared to the rest of the week. However, afternoon ozone concentrations showed minimal changes over the weekend with occasional increases, providing direct empirical evidence that ozone production is VOClimited and $\mathrm{NO}_{\mathrm{x}}$-inhibited during workdays. Decreases in the concentrations of $\mathrm{CO}$ (and VOCs) over the past decade have decreased the $\mathrm{CO} / \mathrm{NO}_{\mathrm{x}}$ and $\mathrm{VOC} / \mathrm{NO}_{\mathrm{x}}$ ratios, increasing the VOC-limitation of ozone production in the urban area (Stephens et al., 2008). A 3-D CAMx chemical transport 
model including the estimated historical changes in ozone precursors was able to adequately reproduce the historical trends in the observed concentrations, and indicated that ozone production is currently VOC-limited. The modeled ozone concentrations were particularly sensitive to aromatics, higher alkenes, and formaldehyde emissions (Zavala et al., 2009a).

Simulations of ozone and other chemical species (CO, NO, $\mathrm{NO}_{2}$ and $\mathrm{NO}_{\mathrm{y}}$ ) in the MCMA using WRF-Chem model compare favorably with surface measurements from the RAMA monitoring network with the exception of $\mathrm{SO}_{2}$ (Zhang et al., 2009; Zhang and Dubey, 2009). Reductions of the total emissions rates of $15 \%, 25 \%$ and $10 \%$ for Saturday, Sunday and holidays, respectively, also led to predicted concentrations of the main chemical species that compared favorably to measurements (Zhang et al., 2009). Incorporating 3 -D variational data assimilation into meteorological simulations of an air quality episode during the MCMA-2003 campaign significantly improved the magnitude of the peak $\mathrm{O}_{3}$ concentration, as well as the timing of the $\mathrm{O}_{3}$ peak on most days of the episode, especially during the daytime (Bei et al., 2008). These results illustrate the importance of applying this technique to ozone simulations in the Mexico City Basin. Bei et al. (2010) further investigated the sensitivity of ozone concentration predictions to meteorological initial uncertainties and PBL parameterization schemes on four selected days during MCMA-2006 through ensemble forecasts. Their results demonstrate that uncertainties in meteorological initial conditions have significant impacts on $\mathrm{O}_{3}$ predictions, including the peak $\mathrm{O}_{3}$ concentration, as well as the horizontal and vertical $\mathrm{O}_{3}$ distributions, and temporal variations. The ensemble spread of the simulated peak $\mathrm{O}_{3}$ concentration averaged over the city's ambient monitoring sites can reach up to $10 \mathrm{ppb}$. The magnitude of the ensemble spread also varies with different PBL schemes and meteorological episodes.

\subsection{Regional photochemistry}

The composition of the regional atmosphere was sampled primarily by aircraft-based instruments, and to some extent from surface stations outside Mexico City. Many of these measurements are still being analyzed, but some general features of the character of the regional atmosphere are beginning to emerge.

Free tropospheric $\mathrm{O}_{3}$ concentrations in background air (i.e., air not obviously influenced by Mexico City) ranged between 30 and $80 \mathrm{ppb}$ as measured from the C-130 with an average value of $60 \mathrm{ppb}$ (Tie et al., 2009), and $\sim 35-55 \mathrm{ppb}$ over the Gulf of Mexico observed from the DC-8 (region 1, Singh et al., 2009). Ozone sondes launched from the T1 site showed boundary layer values ranging from 30 to $80 \mathrm{ppb}$, but free tropospheric values of only $40-60 \mathrm{ppb}$ (one standard deviation), likely due to advection of cleaner air from the Pacific (Thompson et al., 2008). Vertical profiles of $\mathrm{O}_{3}$ calculated with the global MOZART-4 model show good agree- ment with measurements obtained from both the DC- 8 and C-130 aircraft, including a marked peak between 2 and $4 \mathrm{~km}$ asl associated with the Mexico City plume outflow (Emmons et al., 2010). In the same study, Emmons et al. used tagged emissions to identify the contribution of various sources to the regional $\mathrm{CO}$ and $\mathrm{O}_{3}$ distribution. Biomass burning was found to have an influence on regional chemistry, although not a dominant one. Emissions from Mexico City were important over Central Mexico but had negligible influence beyond Mexico borders.

Substantial enhancements of $\mathrm{O}_{3}$ above background were observed in plumes that could be traced back to Mexico City (Tie et al., 2009; Mena-Carrasco et al., 2009; Emmons et al., 2010). This is particularly evident for the quasi-Lagrangian episode of 18-19 March, where air was sampled on 18 March by the G-1 near Mexico City, and on 19 March was intercepted and again sampled far downwind by the C-130 (Voss et al., 2010). Apel et al. (2010) examined correlations between $\mathrm{CO}$ and ozone, acetone, or benzene observed in the near-field plume (on $18 \mathrm{March}$ ) and in the same plume a day later (19 March). Slopes of $\mathrm{O}_{3}$ vs. $\mathrm{CO}$ were markedly steeper in the aged plume, indicating that considerable $\mathrm{O}_{3}$ production occurred during the transport time. Some acetone production was also inferred by slightly higher acetone vs. CO slopes, while benzene vs. CO slopes were essentially identical, consistent with the longer lifetime of both compounds.

Photochemical modeling shows that regional $\mathrm{O}_{3}$ production is sensitive to $\mathrm{NO}_{\mathrm{x}}$ as well as to VOCs and CO (Tie et al., 2009), and also to the reduced availability of UV radiation because of the heavy aerosol loadings (Barnard et al., 2008; Mena-Carrasco et al., 2009). WRF-Chem simulations by Tie et al. indicate that the regional $\mathrm{OH}$ reactivity is dominated by oxygenated organics and $\mathrm{CO}$, and to a lesser extent the hydrocarbons; the high levels of OVOCs lead to large concentrations of organic peroxy radicals in the plume, typically exceeding those of $\mathrm{HO}_{2}$. Simulations with the MOZART-4 model (Emmons et al., 2010) tend to underpredict observed concentrations of OVOCs, but even these lower values dominate the regional $\mathrm{OH}$ reactivity and $\mathrm{O}_{3}$ production. Measurements from the G-1 and C-130 during the 18-19 March episode confirm the importance of OVOCs and $\mathrm{CO}$, with OVOCs being dominant in the near field outflow (Apel et al., 2010) and CO increasing in relative importance for ozone production further downwind. $\mathrm{OH}$ concentrations measured from the DC- 8 are somewhat higher than predicted by MOZART-4, while $\mathrm{HO}_{2}$ concentrations show better agreement.

Ozone production efficiencies, defined as the number of $\mathrm{O}_{3}$ molecules produced per $\mathrm{NO}_{\mathrm{x}}$ consumed, and estimated from $\mathrm{O}_{3}$ vs. $\mathrm{NO}_{z}$ correlations measured from the C-130 aircraft, ranged from $4.5-4.6$ in air recently influenced by biomass burning or the Tula industrial complex, 5.3 to 5.9 over land influenced by Mexico City, and 8.5 in the marine free troposphere (Shon et al., 2008). These observation-based estimates can be compared with 


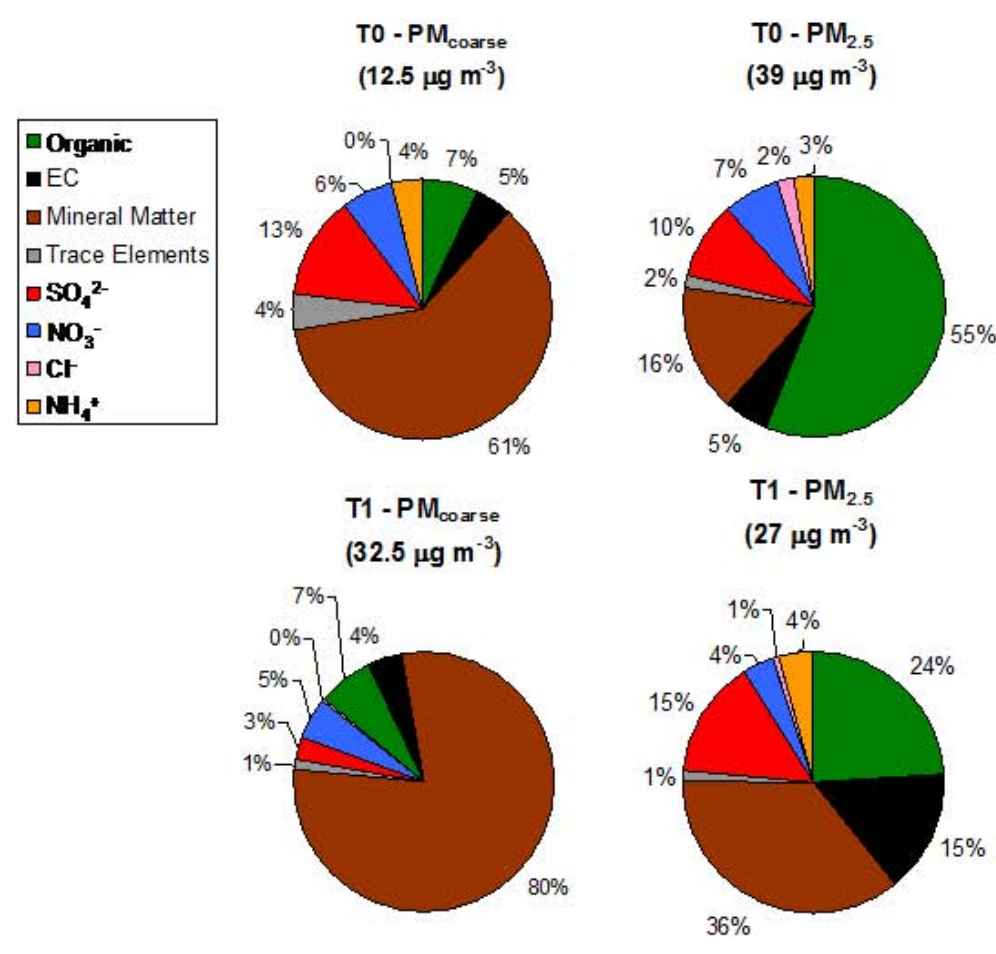

Fig. 12. Average composition of $\mathrm{PM}_{\text {coarse }}\left(\mathrm{PM}_{10}-\mathrm{PM}_{2.5}\right)$ and $\mathrm{PM}_{2.5}$ at the $\mathrm{T} 0$ and $\mathrm{T} 1$ supersites, based on the results of Querol et al. (2008). OA was calculated from the measured OC based on the average measured OA/OC ratio of 1.75 at T0 (Aiken et al., 2008). The T1 site was affected by local resuspension of dust, which explains the unusually large contribution of mineral matter at this site.

model-based estimates by Mena-Carrasco et al. (2009) (STEM model: 4.9 within $100 \mathrm{~km}$ of the city, 7.9 outside that radius) and Tie et al. (2009) (WRF-Chem model: 3.3 near the city, increasing to 5.5 on the regional scale). A separate analysis of the $\mathrm{C}-130$ observations, utilizing only data for which $\mathrm{NO}_{\mathrm{y}}$ concentrations were in the range 2-6 ppb to filter out very aged air and fresh plumes, yielded an average Ox vs. $\mathrm{NO}_{\mathrm{z}}$ slope of $5.9 \pm 0.3$, in good agreement with the previously cited regional values but somewhat lower than the value of $9.1 \pm 0.3$ predicted from the MOZART- 4 model (Emmons et al., 2010), as might be expected due to this model's lower spatial resolution.

Long-range export of reactive nitrogen from Mexico City was discussed by Mena-Carrasco et al. (2009) and found to take place primarily via the formation of PANs, in agreement with observations from the C-130. PANs can thermally decompose on the regional scale providing a source of $\mathrm{NO}_{\mathrm{x}}$ and therefore contribute to regional $\mathrm{O}_{3}$ formation. The relatively high regional $\mathrm{NO}_{\mathrm{x}}$ concentrations are consistent with low or even negative formation rates for hydrogen peroxide observed from the G-1 aircraft over most of the Mexican plateau, with higher values found only in the relatively humid coastal areas (Nunnermacker et al., 2008).

Measurements at a surface station (Altzomoni) located at high altitude ( $4010 \mathrm{~m}$ a.s.1.) $60 \mathrm{~km} \mathrm{SW}$ of Mexico City were made by Baumgardner et al. (2009). Pollutant concentrations were elevated not only when the synoptic flow came directly from Mexico City but also from the east, suggesting that other pollution sources in Central Mexico and large scale recirculation of Mexico City pollutants may be impacting regional air quality. Recirculation of pollution to the Gulf of Mexico and back over Central Mexico was identified in the modeling study of Emmons et al. (2010). Influences of biomass burning and the nearby Popocatepetl volcano were also observed.

\section{Ambient particulate matter}

Particulate matter (PM) impacts human health (Pope and Dockery, 2006) visibility (Watson et al., 2002), climate (Forster et al., 2007), and ecosystems (Zambrano et al., 2009). Negative impacts of PM on human health have been documented in the MCMA (e.g., Romieu et al., 1996; Osornio-Vargas et al., 2003; Evans et al., 2002) as discussed in more detail in Section 10 below. PM concentrations observed during the MILAGRO-2006 Campaign were similar to previous studies that measured PM in the MCMA during the late winter and early spring (Chow et al., 2002; Vega et al., 2002; Salcedo et al., 2006; Molina et al., 2007), and similar to concentrations reported by the RAMA monitoring network (http://www.sma.df.gob.mx/ simat2). $\mathrm{PM}_{10}$ concentrations, as measured from filter samples, were higher at the urban sites with 24-hour averages ranging between $50-56 \mu \mathrm{g} \mathrm{m}^{-3}$, and lower concentrations at 
rural sites ranging from 22 to $35 \mu \mathrm{g} \mathrm{m}^{-3}$ (Querol et al., 2008). $\mathrm{PM}_{2.5}$ concentrations were in the range of $24-46 \mu \mathrm{g} \mathrm{m}^{-3}$ and $13-25 \mu \mathrm{g} \mathrm{m}^{-3}$ at the urban and rural sites, respectively (Querol et al., 2008). This is consistent with previous studies (Chow et al., 2002; Vega et al., 2002, 2004) that also found $\mathrm{PM}_{2.5}$ made up approximately $50 \%$ of the $\mathrm{PM}_{10}$ in the MCMA, and with mobile lidar measurements that indicate the PM concentrations in the Mexico City basin are about twice as high as outside the basin (Lewandowski et al., 2010). $\mathrm{PM}_{1}$ and $\mathrm{PM}_{2.5}$ concentrations were similar as the amount of mass between $\mathrm{PM}_{2.5}$ and $\mathrm{PM}_{1}$ was a small fraction of the total $\mathrm{PM}_{2.5}$ (Querol et al., 2008; Aiken et al., 2009), consistent with results from MCMA-2003 (Salcedo et al., 2006).

The fractional compositions of $\mathrm{PM}_{2.5}$ and $\mathrm{PM}_{\text {coarse }}$ are illustrated in Fig. 12. Querol et al. (2008) found that mineral matter made up about $25 \%$ of the $\mathrm{PM}_{10}$ at the urban sites and a larger fraction at the suburban and rural sites. Mineral matter was found to make up a smaller, yet important, fraction of the $\mathrm{PM}_{2.5}$ at the urban and rural sites accounting for $15 \%$ and $28 \%$ of the $\mathrm{PM}_{2.5}$, respectively. The current study found about $50 \%$ of the $\mathrm{PM}_{2.5}$ and the $\mathrm{PM}_{1}$ was comprised of organic matter in the city (Querol et al., 2008; Aiken et al., 2009), which is similar or larger than reported in other cities (e.g., Zhang et al., 2007). About $25 \%$ of the $\mathrm{PM}_{2.5}$ mass was due to secondary inorganic ions (sulfate, nitrate, ammonium), and the remaining $\mathrm{PM}_{2.5}$ mass was elemental carbon and mineral matter (Querol et al., 2008; Aiken et al., 2009). These percentages are consistent with those in previous studies (Chow et al., 2002; Vega et al., 2004; Salcedo et al., 2006). A strong "weekend effect" with higher weekday than weekend concentrations has been observed for $\mathrm{PM}_{10}$ over several years, which is consistent with the large impact of human activities on PM concentrations in the MCMA (Stephens et al., 2008). The vertical structure of the PM concentrations was characterized with lidar, aircraft, and a tethered balloon and found to be relatively well-mixed during the day, although often with substantial horizontal gradients (Hair et al., 2008; DeCarlo et al., 2008; Lewandowski et al., 2010; Rogers et al., 2009; Greenberg et al., 2009).

The PM levels in the MCMA are among the highest in North America although with substantially lower levels than the most polluted Asian megacities (Querol et al., 2008; Hopke et al., 2008), e.g. 200 and $330 \mu \mathrm{g} \mathrm{m}^{-3}$ annual average concentrations of $\mathrm{PM}_{2.5}$ and $\mathrm{PM}_{10}$ respectively, in Lahore, Pakistan, about five times the levels in Mexico City during MILAGRO (Stone et al., 2010b). As in the case of many Asian megacities, carbonaceous aerosols are important contributors to $\mathrm{PM}_{2.5}$ in Mexico City. An important scientific and air quality management question in many of these megacities is quantifying the relative contributions to concentrations of PM from different sources such as mobile, industrial, biogenic, biomass burning, etc., as well as separating the contributions from primary emissions vs. secondary processes, both of which were an important objective of the MILAGRO Campaign. MILAGRO was not only able to ad- vance the understanding of the sources and atmospheric processing of PM, but was also able to improve the scientific understanding of the tools that can be used for this purpose. These advancements were made in part by the use of new aerosol measurement instruments that had not been used in large field campaigns in the past, and through the simultaneous application of a diverse set of measurement and data analysis tools that had not been widely applied in parallel. The following sections highlight the new PM measurement instruments deployed during MILAGRO, the key scientific results about different PM components, and the needs for future research. Some of the PM findings from MILAGRO have been described in other relevant sections, such as Sect. 5 (Emissions) above.

\subsection{Instruments deployed to Mexico City for the first time}

Although a very large number of instruments and PM samplers were used as part of the MILAGRO Campaign for both ground-based and aircraft measurements, many of these instruments had been used in similar field studies in Mexico City in the past. Tables 1-4 summarize the PM measurements and instruments deployed during the campaign. This study was the first time that organic aerosol (OA) functional group concentrations by FTIR (Liu et al., 2009; Gilardoni et al., 2009; Baumgardner et al., 2009), particlephase organic molecular markers (Stone et al., 2008, 2010a), Scanning Transmission X-Ray Microscopy (STXM) spectra of collected particles (Moffet et al., 2010), and ${ }^{14} \mathrm{C}$ content of carbon fractions (organic carbon, elemental carbon, water-soluble OC (WSOC), and water-insoluble OC (WIOC)) (Aiken et al., 2010) were measured in the MCMA. In addition to the new measurements applied to collected particles, several real-time measurements of PM were deployed to the MCMA for the first time. These instruments included:

- An Aerosol-Time-of-Flight Mass Spectrometer (ATOFMS) (Moffet et al., 2008a, b).

- A Thermal Desorption Chemical Ionization Mass Spectrometer (TDCIMS) for measurement of the composition of particles as small as $10 \mathrm{~nm}$ (Smith et al., 2008).

- A Particle-Into-Liquid Sampler followed by Ion Chromatography and Water-Soluble Organic Carbon detection (PILS-IC and PILS-WSOC) (Hennigan et al., 2008).

- Two High-Resolution Time-of-Flight Aerosol Mass Spectrometers (HR-ToF-AMS) (DeCarlo et al., 2008; Aiken et al., 2009; Dunlea et al., 2009), one of which sampled behind an aerosol concentrator (Khlystov et al., 2005) during part of the campaign.

- Three compact Time-of-Flight Aerosol Mass Spectrometers (C-ToF-AMS) (Canagaratna et al., 2007; 
Kleinman et al., 2008; Herndon et al., 2008; de Gouw et al., 2009).

- A Time-of-Flight Aerosol Mass Spectrometer with an internal light scattering module (LS-ToF-AMS) (Cross et al., 2009).

- A thermodenuder-AMS combination (Huffman et al., 2009a).

- A photoacoustic spectrometer (Paredes-Miranda et al., 2009).

- A TSI Fast Mobility Particle Sizer (FMPS, A. Clarke, pers. comm., 2006).

- A hygroscopicity tandem differential mobility analyzer (HTDMA) (Gasparini et al., 2004).

These measurements taken together have helped improve our understanding of physical and chemical characteristics of PM in the MCMA, as well as their primary and secondary sources.

\subsection{Primary inorganic aerosols}

Dust and metals in PM samples were studied by several research groups and were found to be relatively high compared to other Megacities in North America (Querol et al., 2008; Moffet et al., 2008a, b; Moreno et al., 2008a, b; Gilardoni et al., 2009; Salcedo et al., 2010). High levels of anthropogenic metals were observed in the urban sites, including arsenic, chromium, zinc, copper, lead, tin, antimony, and barium (Querol et al., 2008). These metals had strong temporal variations in concentration (Moreno et al., 2008a, b; Moffet et al., 2008a, b; Salcedo et al., 2010) and were largely associated with industrial and mobile sources. $\mathrm{Hg}$ seemed to have a regional rather than an urban origin (Querol et al., 2008). Rutter et al. (2009) identified possible industrial source regions of gaseous and particulate mercury associated with measurements at T0 and T1. Moreno et al. (2008b) report on the sources of lanthanoid elements (Lanthanum to Lutetium) in Mexico City, which are related to crustal particles, but also to some anthropogenic sources. Christian et al. (2010) reported emissions of 17 metals from source measurements of open trash burning, of which antimony $(\mathrm{Sb})$ was the most unique, consistent with a previous report at the USMexico border (Garcia et al., 2006). Fine particle Sb may be a useful tracer for $\mathrm{PM}_{2.5}$ from this source in the MCMA, although this topic requires further research as many other $\mathrm{Sb}$ sources also exist (Reff et al., 2009). Christian et al. (2010) also reported on the emissions from brick kilns, charcoal kilns, and cooking fires. Adachi and Buseck (2010) reported that nanosized metal-bearing particles $(<50 \mathrm{~nm}$ diameter $)$ in Mexico City aircraft samples using transmission electron microscopy. Most were attached to larger (several hundreds of $\mathrm{nm}$ ) host particles, and contained $\mathrm{Fe}, \mathrm{Zn}, \mathrm{Mn}, \mathrm{Pb}, \mathrm{Hg}, \mathrm{Sn}$,
$\mathrm{Cr}, \mathrm{Ni}, \mathrm{Ti}, \mathrm{V}$, and $\mathrm{Ag}$. $\mathrm{Hg}$ nano-particles were especially prominent. Salcedo et al. (2010) report the first use of an HR-ToF-AMS to detect $\mathrm{Pb}$ in $\mathrm{PM}_{1}$. These authors found that different chemical forms of $\mathrm{Pb}$ had different source regions in the MCMA.

\subsection{Primary carbonaceous aerosols}

Elemental carbon (EC) is an important tracer for combustion sources (Schauer, 2003) and is an important component of atmospheric PM in terms of climate forcing (Forster et al., 2007; Ramanathan et al., 2007). The optical properties of PM containing EC are strongly dependent on the mixing state of the different species, and were investigated during MILAGRO by several different approaches. Moffet et al. (2008a, 2009) used ATOFMS measurements to show that fresh EC particles were observed during rush-hour periods. However, the majority of EC particles were coated with nitrate, sulfate, and organic carbon, which are expected to increase the light absorption of these particles per unit of EC. Adachi and Buseck (2008) found similar results with laboratory-based transmission electron microscope (TEM) measurements of particles collected during aircraft overflights of the MCMA. These results are both consistent with those of Johnson et al. (2005) using electron microscopy during MCMA-2003. Somewhat surprisingly, however, very little difference in EC mass absorption efficiencies could be observed through direct measurements by Doran et al. (2007) using a pseudolagrangian study comparing observations at the $\mathrm{T} 1$ and $\mathrm{T} 2$ sites and Subramanian et al. (2010) using single particle soot photometer measurements in the C-130 aircraft. Adachi et al. (2010) obtained 3-D images of embedded soot particles and found that many of them have open, chain-like shapes similar to those of freshly emitted soot, and are located in offcenter positions within their host materials. The absorption by these geometries is $\sim 20 \%$ lower than for the commonly assumed core-shell morphology, and may help explain the lack of a larger increase in mass absorption efficiencies reported by Doran et al. (2007) and Subramanian et al. (2009). In contrast with reports at other locations, Paredes-Miranda et al. (2009) only found a small positive bias of a filter-based absorption measurement due to oxygenated organic aerosols (OOA).

Polycyclic Aromatic Hydrocarbons (PAH) are a family of species, some of which are highly mutagenic and carcinogenic, that are generally associated with EC as their emissions are largely from combustion sources. Thornhill et al. (2008) measured PAH at six locations across the MCMA and found similar levels to those measured during MCMA2003 (Marr et al., 2006; Dzepina et al., 2007), but with considerable variability in concentrations and PAH distributions across sites. This is consistent with the notion that sources of PAH vary spatially as a result of the spatial distribution of combustions sources across the metropolitan area. 
Significant efforts have been directed at understanding the sources of $\mathrm{PM}_{2.5}$ and $\mathrm{PM}_{1}$ organic aerosols and apportioning the observed organic matter into primary organic aerosol (POA) and secondary organic aerosol (SOA) during MILAGRO. Important POA sources were found to include mobile and other combustion sources, biomass burning (BB), and a minor contribution of local (presumably industrial) sources at T0 (Yokelson et al., 2007; Stone et al., 2008; DeCarlo et al., 2008, 2010; Aiken et al., 2008, 2009, 2010; Gilardoni et al., 2009; Liu et al., 2009). Stone et al. (2008), using chemical mass balance of organic molecular markers (Schauer et al., 1996), estimated POA from mobile sources to account for approximately $30-40 \%$ of the OC concentrations in MCMA. This result appears consistent with results of Aiken et al. (2009), using positive matrix factorization of highresolution AMS spectra (Ulbrich et al., 2009), who reported a contribution of "hydrocarbon-like OA" (HOA, which includes vehicle emissions) of $\sim 30 \%$ of the $\mathrm{PM}_{1}$ OA. Food cooking POA may also be apportioned as part of HOA (Mohr et al., 2009) and has been reported as an important contributor of urban POA in some previous studies elsewhere (e.g., Hildemann et al., 1994). Mugica et al. (2009) report a contribution of food cooking to $\mathrm{PM}_{2.5}$ of about $10 \%\left(\sim 5 \mu \mathrm{g} \mathrm{m}^{-3}\right)$, which would represent about $20 \%$ of the OA, although this study was not able to separately quantify biomass burning and the authors suggest that that problem may have inflated the contribution of other sources. Two measurement-based studies (Zavala et al., 2009b; Aiken et al., 2009) and one 3D modeling study (Fast et al., 2009) have concluded that the 2006 MCMA emissions inventory (SMA-GDF, 2008a) underestimates POA and primary $\mathrm{PM}_{2.5}$ emissions. The emission profiles of gas and particle emissions from biofuel use (biomass used directly as fuel for e.g. cooking) and open trash burning in Mexico City have been reported by Christian et al. (2010). The high emission factors of cooking with biofuels and open trash burning suggest a potentially important contribution to surface concentrations which is being further investigated. Open trash burning is not included in the 2006 MCMA emissions inventory (SMA-GDF, 2008a).

Wildfires in the hills and mountains near Mexico City were unusually intense during MILAGRO, with fire counts being about twice the March climatological average of recent years. Emissions from these fires made a substantial contribution to OA and other species. Aiken et al. (2010) report a good correlation between the different fire tracers (acetonitrile, levoglucosan, AMS levoglucosan-equivalent mass, and total $\mathrm{K}$ in $\mathrm{PM}_{2.5}$ ), although total $\mathrm{K}$ has a non-wildfire background of $\sim 2 / 3$ of its average concentration. These authors also compared the different estimates of biomass burning OA at the surface inside the city (Stone et al., 2008; Querol et al., 2008; Aiken et al., 2009, 2010), which are consistent in that BB was highly variable in time and accounted on average for $12-23 \%$ (range of the different estimates) of the OA during the MILAGRO Campaign inside the city. A similar estimate was derived for data from the IMADA-AVER cam- paign (Vega et al., 2009). These results are consistent with those of de Gouw et al. (2009) at T1 who report that BB was not a dominant contributor to $\mathrm{OC}$ at that site, and perhaps not dissimilar to previous observations by the same group in the Eastern US. The lowest estimate was derived by Liu et al. (2009), who report a contribution of biomass burning to OA in the range $0-8 \%$. Moffet et al. (2008a) report a larger impact of about $40 \%$ to particle number at the upper end of the accumulation-mode, based on the particles containing $\mathrm{K}$.

Crounse et al. (2009) and DeCarlo et al. (2010) concluded that the relative impact of BB was substantially larger aloft over the Central Mexican Plateau (up to 2/3 of OA) than at the surface inside the city, This is analogous to the situation for $\mathrm{SO}_{2}$, for which urban emissions contribute a major fraction of the concentrations inside the urban area, despite being far smaller than the nearby regional sources (de Foy et al., 2009b). Yokelson et al. (2007) reported an estimate of a $50 \pm 30 \%$ contribution of the wildfires to the total fine PM outflow (rather than just the OA) from the Mexico City region, whose central value is higher than the Crounse and DeCarlo estimates. The discrepancy may be due to the fact that this study used the MCMA inventory to quantify urban PM, which is known to be substantially underestimated as discussed in Sect. 5 of this overview. The wildfires near Mexico City were estimated to contribute $\sim 2-3 \%$ of the fine PM at the surface as an annual average, and their larger importance during MILAGRO arises from the timing of the campaign during the warm dry season and the unusual intensity of these fires during 2006 (Aiken et al., 2010). We do note that the BB season continues through April and peaks in May, so that higher contributions of $\mathrm{BB}$ may be expected during those months in the average year. $\mathrm{BB}$ impacts during the other 9 months are expected to be much smaller. BB in the Yucatan is a larger regional PM source (Yokelson et al., 2009), but its impact in the MCMA was very small during MILAGRO as these emissions were relatively weak and transported elsewhere (Yokelson et al., 2009; Aiken et al., 2010). This contrasts with a larger impact during the latter half of the MCMA-2003 campaign (Salcedo et al., 2006; Molina et al., 2007). Emmons et al. (2010) conclude from a large-scale modeling study that open fires made some, but not a dominant, impact on the atmospheric composition in the region around Mexico City, when averaged over the MILAGRO period.

Aiken et al. (2010) and DeCarlo et al. (2010) report a good comparison between the time trends of biomass burning $\mathrm{OA}(\mathrm{BBOA})$ at $\mathrm{T} 0$ and the $\mathrm{C} 130$, respectively and the predictions of a FLEXPART-based dispersion model. Fast et al. (2009) and Hodzic et al. (2010a) concluded that BBOA concentrations arising from some large fires are substantially overestimated in their 3-D models when using a custom inventory based on satellite fire counts. Both model studies fail to capture the early morning BBOA impact which is better reproduced by the FLEXPART study of Aiken et al. (2010), presumably due to the improved treatment of the 
evening/nighttime smoldering emissions. The MODIS satellite instrument misses some fires for various reasons (cloud cover, smoke cover, fires that are too small, timing issues) (Yokelson et al., 2007; Crounse et al., 2009), so the use of additional data from the GOES satellite instrument may help explain the better predictions of Aiken et al. (2010). The combination of these observations suggests that either the fires missed by the satellite counts only contribute a small fraction of the emissions (e.g. because they tend to be smaller fires), or that the overestimation of the emissions from some fires partially compensates the lack of emissions from the missed fires. Aiken et al. (2010) report that the wildfire BB emissions near Mexico City were nearly 20 times larger than in the 2006 MCMA emissions inventory, which uses a static value and is not based on the fire counts (SMA-GDF, 2008a), although a substantial fraction of these emissions occurred just outside of the MCMA inventory area.

${ }^{14} \mathrm{C}$ measurements have been reported by two groups. Marley et al. (2009a) report that $45-78 \%$ of the total carbon at T0 $(\mathrm{TC}=\mathrm{EC}+\mathrm{OC})$ arises from modern sources. Aiken et al. (2010) report TC modern fractions that range from an average of $46 \%$ during the high $\mathrm{BB}$ period to $30 \%$ during the low $\mathrm{BB}$ period. The reasons for the differences of about $15 \%$ in the modern carbon fractions at T0 are unclear (Marley et al., 2009a; Aiken et al., 2010). Marley et al. (2009a) did not account explicitly for the extra ${ }^{14} \mathrm{C}$ stored in forests due to the bomb radiocarbon ( $\sim 124 \%$ modern carbon), which needs to be taken into consideration when interpreting that dataset (for example for a modern carbon measurement of $60 \%$, if half of it arises from wood burning, the contemporary carbon fraction would be 54\%). During the high BB periods both datasets reported increases of modern carbon of about $15 \%$ of the total OC (Aiken et al., 2010), which is consistent with the estimates from several other apportionment techniques as discussed above. A substantial fraction of non-fossil organic carbon ( $\geq 37 \%$, (Aiken et al., 2010) is present during very low wildfire periods, which suggests the importance of urban sources of modern carbon such as food cooking or biofuel use (Hildemann et al., 1994; Mugica et al., 2009; Christian et al., 2010) and/or regional sources such as biogenic SOA (e.g., Stone et al., 2010a; Hodzic et al., 2009) and others. Hodzic et al. (2010b) present the first comparison of modern carbon measurements with the predictions of a 3-D model, and find that the observed concentrations are similar to the measurements of Aiken et al. (2010) but lower than those of Marley et al. (2009a). The model explains the observed modern carbon as the sum of similar contributions from regional biogenic SOA, biomass burning POA and SOA, and POA and SOA from urban sources of modern carbon (Hildemann et al., 1994). Sources of "hot" aerosol carbon (enriched in ${ }^{14} \mathrm{C}$ ) in the Mexico City area and/or stored in forests could produce a bias in this method and need to be further investigated (Vay et al., 2009).

\subsection{Secondary Inorganic Aerosols (SIA)}

Secondary inorganic species contribute about $1 / 4$ of the fine PM in the MCMA (Querol et al., 2008; Aiken et al., 2009). Sulfates in $\mathrm{PM}_{1}$ are generally neutralized by ammonium although they can be in more acidic forms in fresh plumes and have a regional character consistent with the large petrochemical and volcanic sources of $\mathrm{SO}_{2}$ (Moya et al., 2003; DeCarlo et al., 2008; Aiken et al., 2009), consistent with previous studies (Salcedo et al., 2006; San Martini et al., 2006a, b). The urban area and BB in the Yucatan are also substantial sources of $\mathrm{SO}_{2}$, although smaller than the petrochemical and volcanic sources (de Foy et al., 2007, 2009b; DeCarlo et al., 2008; Yokelson et al., 2009). The emissions and impacts of different $\mathrm{SO}_{2}$ sources have been studied by several groups (Grutter et al., 2008; Rivera et al., 2009; de Foy et al., 2009b).

Rapid and intense formation of submicron ammonium nitrate is observed during the morning with important evaporation in the afternoon (Zheng et al., 2008; Hennigan et al., 2008; Aiken et al., 2009), consistent with previous studies (Salcedo et al., 2006). $\mathrm{PM}_{1}$ nitrate also accounts for a high portion of the $\mathrm{NO}_{\mathrm{z}}$ budget in Mexico City, exceeding 20\% at times (Wood et al., 2009). Ammonium nitrate is highly correlated with $\mathrm{CO}$ and has low correlation with $\mathrm{HCN}$, indicating that urban sources are dominant and BB sources are a small contributor to this species (DeCarlo et al., 2008). Evaporation also plays an important role as airmasses are advected away from Mexico City with the nitrate/ $\triangle \mathrm{CO}$ ratio dropping by about a factor of 4 (DeCarlo et al., 2008). $\mathrm{HNO}_{3}$ also reacts with dust to form supermicron nitrates, which contribute about a third of the total nitrate during dry periods (Querol et al., 2008; Fountoukis et al., 2009; McNaughton et al., 2009), consistent with a recent 3-D modeling study using MCMA2003 data (Karydis et al., 2010). The suppression of dust (and thus of this $\mathrm{HNO}_{3}$ sink) by precipitation during the latter part of MILAGRO led to an increase of $\mathrm{NH}_{4} \mathrm{NO}_{3}$ concentrations by over $50 \%$ after March $23^{\text {rd }}$ (Aiken et al., 2009). Model-predicted submicron nitrate levels inside Mexico City are often sensitive to the aerosol physical state (solid vs. liquid) assumption during periods with ambient RH less than 50\% (Fountoukis et al., 2009; Karydis et al., 2010).

Chloride is also a relevant species in Mexico City although its concentrations are generally below $1 \mu \mathrm{g} \mathrm{m}^{-3}$ and typically much lower than those of sulfate, nitrate, and ammonium (Querol et al., 2008; Aiken et al., 2009). During MCMA2003 ammonium chloride was the dominant form of chloride in $\mathrm{PM}_{1}$ at the CENICA site (Salcedo et al., 2006; Johnson et al., 2008), but during MILAGRO the influence of metal or refractory chlorides was larger (Moffet et al., 2008a), on the order of one half of the submicron chloride (Huffman et al., 2009a). Open trash and crop residue burning had high chloride emission factors and are potentially important sources of this component (Christian et al., 2010). However some of the chloride is not associated with OA as it would be the 
case for burning sources (Salcedo et al., 2006), so other noncombustion urban sources are also important for chloride. Both forest fires and the urban area were important $\mathrm{PM}_{1}$ chloride sources based on aircraft data during MILAGRO (DeCarlo et al., 2008). Chlorine-containing organic species in the particle phase have not been reported to our knowledge, despite the detection of substantial concentrations of chlorinated VOCs in the MCMA (Velasco et al., 2007).

\subsection{Secondary Organic Aerosols (SOA)}

Intense SOA formation in $\mathrm{PM}_{1}$ was observed during MILAGRO (Kleinman et al., 2008, 2009; Herndon et al., 2008; DeCarlo et al., 2008, 2010; Hennigan et al., 2008; de Gouw et al., 2009; Aiken et al., 2008, 2009) at levels much higher than predicted with traditional SOA models (Kleinman et al., 2008; de Gouw et al., 2009; Hodzic et al., 2009, 2010a, b; Fast et al., 2009; Wood et al., 2010). This is consistent with previous observations and modeling from MCMA-2003 (Volkamer et al., 2006, 2007; Dzepina et al., 2009; Tsimpidi et al., 2010) and the emerging consensus from studies at other polluted locations using a variety of apportionment methods (e.g., Docherty et al., 2008; Hallquist et al., 2009; de Gouw and Jimenez, 2009). These results were consistent between the WSOC (Hennigan et al., 2008) and AMS techniques (e.g., Kleinman et al., 2008) as has been observed elsewhere (Kondo et al., 2007; Docherty et al., 2008). The substantial contribution of SOA was reported not only in the city, but also at the Altzomoni site located $2 \mathrm{~km}$ above basin level (Baumgardner et al., 2009) and from aircraft (DeCarlo et al., 2008, 2010; Kleinman et al., 2008). It is also supported by the large underprediction of afternoon OA concentrations when only POA (from urban and BB sources) is considered (Fast et al., 2009, Hodzic et al., 2009; Tsimpidi et al., 2010). The combined formation of SIA and SOA contributes about $75 \%$ of the fine PM mass at T0 in the afternoons during MILAGRO, and has a large impact on the aerosol radiative properties such as single-scattering albedo (Paredes-Miranda et al., 2009). The correlation of SOA with odd-oxygen $\left(\mathrm{O}_{\mathrm{x}}=\mathrm{O}_{3}+\mathrm{NO}_{2}\right)$ (Herndon et al., 2008; Wood et al., 2010) suggests that the use of better-characterized ozone chemistry may help constrain and provide a target for modeling of SOA production. One group (Yu et al., 2009) applied the EC-tracer method to estimate SOA in Mexico City, although it is not possible to separate SOA from primary BBOA with that method only, due to their similar and very high OC/EC ratios (Hallquist et al., 2009).

The formation of SOA from biogenic precursors within the Mexico City basin was small, consistent with previous studies (Volkamer et al., 2006; Dzepina et al., 2009). Most of the isoprene observed in the urban area is likely of anthropogenic origin (Hodzic et al., 2009), consistent with results at other urban locations (Borbon et al., 2001). Other anthropogenic alkenes add little organic mass to SOA, but indirectly add to SOA by reacting to produce radicals for the processing of other SOA precursor VOCs. This indirect SOA contribution of alkenes, i.e., to significantly add to oxidant fields, is likely to be much larger than their direct contribution to SOA mass (Volkamer et al., 2010). A modeling study (Hodzic et al., 2009) and tracer measurements (Stone et al., 2010a) indicate that biogenic SOA formed over forested areas on the coastal mountain ranges and advected over the Central Mexican Plateau contributes $\sim 1-1.5 \mu \mathrm{g} \mathrm{m}^{-3}$ of SOA background to Mexico City (out of a total SOA background of $\sim 4-5 \mu \mathrm{g} \mathrm{m}^{-3}$ ), with relatively low temporal variability. The biogenic SOA source contributes to, but is insufficient to explain, the high fraction of modern carbon in OA observed in Mexico City (30-45\%, Aiken et al., 2010) during periods in which BB is suppressed by rain. Biogenic SOA formation may be larger in this region during the wet season.

The predicted SOA from emissions of traditional precursors (aromatics, isoprene, terpenes) from BB are very small (Hodzic et al., 2009, 2010a), although these precursor emissions may be underestimated in current inventories (C. Wiedinmyer, pers. comm., 2009). There is some variability in the net effect of SOA on OA mass observed in the field from BB emissions (Capes et al., 2008; Yokelson et al., 2009; de Gouw and Jimenez, 2009). The only reported chamber study which used woodstove emissions (rather than open-fire emissions) has shown substantial SOA formation in most cases that could not be explained from the traditional precursors and was attributed to semivolatile and intermediate volatility species (Grieshop et al., 2009). SOA formation for the emissions from the forest fires near Mexico City was estimated to add a net amount of OA equivalent to $\sim 37 \%$ of the primary $\mathrm{BBOA}$, and it makes a contribution to the outflow of OA from the region (DeCarlo et al., 2010), which should be largest in the late afternoon. Net SOA formation was also observed in BB plumes in the Yucatan where the net relative effect was larger (addition of SOA equivalent to $\sim 100 \%$ of the primary BBOA) (Yokelson et al., 2009), perhaps due to the much lower POA emissions from the Yucatan fires compared to those near Mexico City. The impact of BB SOA at the ground inside Mexico City was smaller than for the regional outflow. This was likely due to the fact that BBOA concentrations inside the city peaked in the early morning from emissions in the previous evening and photochemistry was not active during most of the transport period. In contrast, $\mathrm{BBOA}$ and acetonitrile levels at $\mathrm{T} 0$ were at a minimum during mid-day when OOA was highest (Aiken et al., 2009, 2010). The limited impact of BB SOA to the urban area is also consistent with the limited net SOA formation reported by DeCarlo et al. (2010). An exception was the period around 20-22 March, when substantial SOA from BB emissions was observed at the T0 site (Aiken et al., 2010; Stone et al., 2010a). The lack of a significant decrease of OOA between the high $\mathrm{BB}$ and low $\mathrm{BB}$ periods confirms that SOA from BB sources was not a dominant contributor to OOA concentrations within the city during most of the campaign (Aiken et al., 2010). 
A recently-proposed mechanism postulates the importance of SOA formation from primary semivolatile and intermediate volatility (S/IVOC) precursors from anthropogenic combustion and biomass burning (Robinson et al., 2007). This mechanism has been implemented in a modeling study for MILAGRO (Hodzic et al., 2010a, b), with results similar to two recent studies which compared to MCMA-2003 data (Dzepina et al., 2009; Tsimpidi et al., 2010). The Robinson et al. (2007) version of this mechanism produces approximately the right amount of SOA in the near field, but its $\mathrm{O} / \mathrm{C}$ is too low and the SOA formed is too volatile (Hodzic et al., 2010a; Dzepina et al., 2009). The Grieshop et al. (2009) update to this mechanism produces too much SOA, especially in the far field, although the $\mathrm{O} / \mathrm{C}$ prediction is much closer to the observations (Hodzic et al., 2010a; Dzepina et al., 2009). The amount of SOA from anthropogenic S/IVOC reaching $\mathrm{T} 0$ and $\mathrm{T} 1$ is predicted to be much larger than that from $\mathrm{BB}$ sources (Hodzic et al., 2010a). The modern carbon predicted by the model is closer to the observations when S/IVOC precursors are considered compared with when only SOA from VOCs is implemented (Hodzic et al., 2010b). However, there are only weak constraints on the amount and reactivity of primary S/IVOC in Mexico City based on gaps in OH-reactivity and integral FTIR C-H stretches (Sheehy et al., 2010; Dzepina et al., 2009), so it is not clear whether these mechanisms close the SOA budget for the right reasons. Direct measurements of primary and oxidized S/IVOC are critically needed for further progress in this area. The uptake of glyoxal is an alternative mechanism which can produce SOA of high O/C ratios (Volkamer et al., 2009), although it is thought to contribute only the order of $\sim 15 \%$ to total SOA in Mexico City (Volkamer et al., 2007).

The current uncertainties on the OA budget led to the proposal of a new quantity, Total Observed Organic Carbon (TOOC), which groups together the carbon from organic gas and particle phase species (Heald et al., 2008). Levels of TOOC in Mexico City are dominated by gas-phase species and are much higher than at other North American locations (Heald et al., 2008). TOOC may be a useful quantify for comparison of measurements and models. However unmeasured species are not included in TOOC and are poorly constrained at present.

The volatility of $\mathrm{PM}_{1} \mathrm{OA}$ components in Mexico City was characterized for the first time using a thermodenuder + AMS combination (Huffman et al., 2008; Faulhaber et al., 2009). Both POA and SOA are semivolatile in Mexico City, with POA being at least as volatile as SOA (Huffman et al., 2009b). These results are consistent with sampling in the Los Angeles area and source tests, and contradict the traditional representation of POA as non-volatile in models (Robinson et al., 2007; Huffman et al., 2009ab). The results from the thermodenuder-AMS system have been used to produce volatility distributions ("basis sets") for the total OA and the OA components (e.g., HOA, OOA, BBOA) (Cappa and Jimenez, 2010). This analysis concludes, us- ing two different techniques, that a substantial fraction (50$80 \%$ ) of the OA (especially the aged OOA) is essentially nonvolatile and will not evaporate under any atmospheric conditions. However a semivolatile fraction is also present (Cappa and Jimenez, 2010), and Hennigan et al. (2008) reported that some of the SOA detected at the T1 site using WSOC measurements evaporated in the afternoons, although to a lesser extent than ammonium nitrate.

The elemental composition of the $\mathrm{PM}_{1} \mathrm{OA}$ was characterized with high time-resolution (down to 10 seconds from aircraft) and high-sensitivity for the first time using a new technique based on high-resolution aerosol mass spectrometry (Aiken et al., 2007). The diurnal cycle of the $\mathrm{O} / \mathrm{C}$ atomic ratio at $\mathrm{T} 0$ peaked with the afternoon photochemistry $(\sim 0.5$, $\mathrm{OA} / \mathrm{OC} \sim 1.8)$ and reached the lowest values during the morning rush hour $(\sim 0.3, \mathrm{OA} / \mathrm{OC} \sim 1.6)$. $\mathrm{H} / \mathrm{C}$ was anticorrelated with $\mathrm{O} / \mathrm{C}$. N/C was low $(\sim 0.02)$ and higher during the morning than the afternoon indicating a more important association with POA (Aiken et al., 2008), although organonitrates are not included in the AMS N/C (Farmer et al., 2010). Regional trends observed from the $\mathrm{C}-130$ aircraft were consistent with those in the city, with increasing $\mathrm{O} / \mathrm{C}$ away from the city (DeCarlo et al., 2008, 2010; Aiken et al., 2008). The chemical aging trends of OA and SOA observed in Mexico City are consistent with those at multiple other locations (Jimenez et al., 2009; $\mathrm{Ng}$ et al., 2010; Heald et al., 2010). Organic species with higher $\mathrm{O} / \mathrm{C}$ were less volatile on average than those with lower O/C (Huffman et al., 2009a). FTIR functional group analyses showed that in the urban area the molar ratio of oxidized functional group (carboxylic acid) to saturated hydrocarbon functional group (typical of primary organic aerosol) measured with FTIR varied between 0.04 and 0.14 , and ratios higher than 0.08 were observed for aged particles (Gilardoni et al. 2009). The correlation of primary metals and carboxylic acid functional groups indicated relatively rapid (less than $12 \mathrm{~h}$ since emission) formation of SOA (Liu et al., 2009). The average OA/OC ratios estimated from FTIR at SIMAT and Altzomoni were 1.8 and 2.0, respectively. Gilardoni et al. (2009) observed a larger fraction of oxygenated functional groups in samples collected inside the urban plume compared to background samples, which contrasts with the findings of Aiken et al. (2008) and DeCarlo et al. (2008) who found that urban samples were less oxygenated. The FTIR technique did not observe organonitrates or organosulfates in the particles above the respective detection limits (Gilardoni et al., 2009). Concentrations of organosulfates of $\sim 5 \mathrm{nmol} \mathrm{m}^{-3}$ were, however, detected from T0 and T1 samples using LC-MS/MS (Stone et al., 2009).

\subsection{New particle formation}

New particle formation (NPF) is important for climate (Spracklen et al., 2008), and freshly nucleated particles could affect health (Oberdorster et al., 2005). Very intense NPF 
events were observed within the Mexico City basin during MILAGRO consistent with a previous study (Dunn et al., 2004; Molina et al., 2007) in which sulfates and oxygenated organics were observed in the growing particles. Growth rates of freshly nucleated particles were typically about ten times higher than could be explained by the condensation of sulfuric acid alone (Iida et al., 2008). The TDCIMS instrument provided chemical composition measurements for smaller particles than had been characterized before (10$33 \mathrm{~nm}$ ), and it demonstrated that the high growth rates were dominated by the uptake of nitrogen-containing organic compounds, organic acids, and hydroxy organic acids, while sulfate was a minor contributor to the observed growth (Smith et al., 2008).

\subsection{Aerosol CCN activity}

Wang et al. (2010) performed a closure study between the measured CCN and those calculated using Kohler theory with the measured aerosol size distributions and composition. Their results suggest that the mixing of nonhygroscopic POA and BC with photochemically produced hygroscopic species takes place in a few hours during daytime, which is consistent with the results of Moffet et al. (2009, 2010). This rapid process suggests that during daytime, a few tens of kilometers away for POA and BC sources, $\mathrm{N}_{\mathrm{CCN}}$ may be derived with sufficient accuracy by assuming an internal mixture, and using bulk chemical composition. One of the implications is that while physically unrealistic, external mixtures, which are used in many global models, may also sufficiently predict $\mathrm{N}_{\mathrm{CCN}}$ for aged aerosol, as the contribution of non-hygroscopic POA and BC to overall aerosol volume is often substantially reduced due to the condensation of secondary species.

In situ measurements made from the $\mathrm{C}-130$ aircraft during MILAGRO were examined in an attempt to link the aerosol optical properties to cloud condensation nuclei (CCN) activity (Shinozuka et al., 2009). The wavelength dependence of visible light extinction was found to be negatively correlated with the organic fraction of submicron non-refractory aerosol mass (OMF) over Central Mexico. The OMF was, in turn, anti-correlated with the CCN activity of particles for the urban, industrial and biomass burning aerosols over Central Mexico and the US West Coast. The wide range of OMF means a stronger impact of the aerosol chemical composition in determining the $\mathrm{CCN}$ concentration over the regions we investigated compared to fixed-point studies elsewhere. These analyses provide an improved context for understanding the capabilities and limitations for inferring $\mathrm{CCN}$ from spectral remote sensing.

Further studies of $\mathrm{CCN}$ impacts from water soluble fractions of filter samples have been analyzed using Kohler theory (Padro et al., 2010). This study found that organics were causing a surface tension depression of $10-15 \%$. Lower molar masses ( $\sim 200 \mathrm{MW})$ were found for daytime samples with approximately twice that size being found in nighttime samples. This has been interpreted as being due to aging of the aerosols. The overall changes in surface tension appear to partially compensate for changes in the mean molar volume yielding an observed constant hygroscopicity and lead to the consideration that the volume/volume fraction of water-soluble organics is the key compositional parameter in predicting $\mathrm{CCN}$ activity.

Ervens et al. (2010) have compared the CCN activity of Mexico City (T0) aerosols to those at other polluted and remote locations, and concluded that $\mathrm{CCN}$ can be predicted within a factor of two assuming either externally or internally mixed soluble OA, although these simplified compositions/mixing states might not represent the actual properties of ambient aerosol populations. Under typical conditions, a factor of two uncertainty in $\mathrm{CCN}$ concentration translates to an uncertainty of $\sim 15 \%$ in cloud drop concentration, which might be adequate for large-scale models given the much larger uncertainty in cloudiness.

\section{Aerosol optical properties and radiative influences}

Aerosol radiative forcing has been identified as one of the largest uncertainties in climate change research (IPCC, 2007). Aerosol radiative impacts include direct and indirect effects. Direct effects include scattering of incoming solar radiation that can lead to cooling, and absorption of solar radiation that can lead to warming. Indirect effect of aerosol is tied to their ability to act as $\mathrm{CCN}$ and form cloud droplets. Absorption of longwave radiation can also lead to forcing by the aerosols and is another area of active research aimed at reducing the uncertainties in these processes. The amount of forcing depends on their physical (size and shape) and chemical properties (surface chemistry, hygroscopicity, etc.) and on their residence times in the troposphere. As aerosol production is tied to energy from combustion of fossil fuels, particularly in large metropolitan areas, the role of megacities as sources of these aerosols and their future evolution in terms of aerosol properties and source strengths is an area where a better fundamental understanding of aerosols is needed for improved regional and global modeling.

During MILAGRO, the MAX-Mex component was specifically focused on making measurements to examine how variable the chemical and physical properties of the megacity aerosols were and how these properties affected the scattering and absorption by the aerosol related to climate. Three surface supersites were instrumented to examine the aerosol plume evolution. As described in Sect. 7 above, the T0 and T1 sites were set up with state-of-the-art aerosol spectrometers and samplers for characterization of chemical and physical properties including the scattering and absorption of aerosols, particularly in the submicrometer fractions that are anticipated to have the longest lifetimes and have the most impact on regional and potentially global climate 
forcing. Measurements were also conducted using several airborne platforms: the DOE G-1 that obtained precursor gas and aerosol measurements; a NASA King Air equipped with a High Spectral Resolution Lidar (HSRL) to measure profiles of aerosol extinction, backscattering, and depolarization (Hair et al., 2008; Rogers et al., 2009); NCAR C-130 and the NASA J-31 (see Sect. 10). Rogers et al. (2009) describe the King Air flight operations and show the King Air flight tracks during MILAGRO.

Key findings related to aerosol optical properties obtained during MILAGRO are presented below. Some of the measurements and results related to this topic have been described also under Sect. 8 (Ambient PM).

MILAGRO provided the first-ever deployment of an airborne HSRL on a comprehensive field campaign. Unlike standard backscatter lidars, the HSRL technique enables an accurate and unambiguous measurement of aerosol extinction. Rogers et al. (2009) compared the HSRL aerosol extinction measurements with aerosol extinction derived from simultaneous measurements from the NASA Ames Airborne Sun Photometer (AATS-14) (Redemann et al., 2009) and in situ scattering and absorption measurements from the Hawaii Group for Environmental Aerosol Research (HiGEAR) (McNaughton et al., 2009) in situ instruments and found bias differences between HSRL and these instruments to be less than $3 \%\left(0.001 \mathrm{~km}^{-1}\right)$ at $532 \mathrm{~nm}$; root-mean-square (rms) differences at $532 \mathrm{~nm}$ were less than $50 \%\left(0.015 \mathrm{~km}^{-1}\right)$. These differences are well within the typical state-of-the-art systematic error of $15-20 \%$ at visible wavelengths (Schmid et al., 2006). Airborne HSRL measurements of aerosol intensive properties were used to identify aerosol types and partition the measured extinction into cumulative Aerosol Optical Depth (AOD) for each type (Ferrare et al., 2007). The aerosol type consisting of a mix of dust and urban aerosols accounted for nearly half of the AOD measured by the HSRL with urban/biomass aerosol types accounting for approximately $35 \%$ of the AOD (see Fig. 13). In contrast, during subsequent HSRL field missions over the Houston region (Parrish et al., 2009b) and the eastern US, urban/biomass aerosols accounted for $80-90 \%$ of the AOD.

While scattering by aerosols is fairly well understood and is principally dependent on size and shape of the aerosols, absorption of solar radiation by atmospheric aerosols is a major uncertainty in assessing radiative balance on regional scales. Carbonaceous aerosols are of particular concern as they are among the major light absorbing species in the troposphere. Incomplete combustion of hydrocarbon fuels leads to the formation of carbon soots or black carbon, which have been well known as a significant, if not the major, absorbing aerosol species in the troposphere (Marley, et al., 2007; Marr, et al., 2006). Fossil fuel combustion, particularly in diesel engines, has received significant attention as the major source of black carbon aerosols. Other sources of absorbing carbonaceous aerosols (i.e., black carbon and other UV-Vis active species such as PAH, conjugated ketones and other partially combusted organics) include biomass burning of agricultural fields and forest fires as well as the formation of potentially light-absorbing absorbing SOA from anthropogenic, biomass burning, and biogenic precursors. Light absorption by SOA is an active research topic (e.g., Andreae and Gelencser, 2006; Barnard et al., 2008).

Results from both ground-based and airborne measurements confirm that Mexico City is a significant source of both primary and secondary aerosols at the regional scale (Doran, et al., 2007; 2008; Fast, et al., 2009, Kleinman, et al., 2008; DeCarlo et al., 2008). Single scattering albedos in the MCMA and downwind are substantially lower than in other areas (such as the eastern United States) (Doran et al., 2007, 2008; Kleinman et al., 2008; Marley et al., 2009a; ParedesMiranda et al., 2009; Thornhill et al., 2008). These results are consistent with the significant amounts of black carbon and light-absorbing PAH coatings observed during these studies as well as during MCMA-2003 (Marr, et al., 2006; Marley et al., 2007; Stone et al., 2008; Querol et al., 2008). Carbon-14 and stable carbon-13 measurements also have indicated that a major fraction of the total carbonaceous aerosol is coming from recent carbon sources including biomass and agricultural burning activities (Marley et al., 2009a; Aiken et al., 2010). As discussed in Sect. 7, modern carbon measurements are about $15 \%$ higher during the high biomass burning periods compared to those in which BB is suppressed by rain (Aiken et al., 2010). Thus other urban and regional sources of modern carbon are important in Central Mexico, such as biogenic SOA (Hodzic et al., 2009), food cooking (Mugica et al., 2009), and other anthropogenic open burning activities (e.g., trash burning and biofuel use (Christian et al., 2010)). Larger relative amounts of biomass burning aerosols were noted at the $\mathrm{T} 1$ regional site than the urban T0 site (Stone et al., 2008; Marley et al., 2009b), consistent with the megacity having a significant fossil fuel input, but both sites were heavily impacted by recent carbon sourced carbonaceous aerosols from local and regional burning and also other modern carbon-containing sources as discussed above.

As noted, light scattering and absorption measurements in the UV-visible region found that the ground-based $\mathrm{T} 0$ and $\mathrm{T} 1$ surface sites single scattering albedo (SSA) was frequently in the $0.7-0.8$ range with some early morning values having even lower SSA (Marley, et al., 2009b; Paredes-Miranda et al., 2009). Aircraft results from several platforms (NASA King Air, DOE G-1, and NCAR C-130) aerosol instruments all indicate that there was significant transport of aerosols and that most of this aerosol is in the lower layer of the atmosphere consistent with the ground sourcing of primary aerosols and secondary aerosol precursors. Aircraft SSA values were typically found to be higher than ground-based measurements, but still lower than those typically seen in the eastern US due to absorbing aerosols (Kleinman et al., 2008). The aircraft measurements also found that substantial amounts of aerosols (primary and secondary) can be transported aloft and exported to regional and global scales via 
the free troposphere during venting events that were anticipated by pre-campaign modeling studies (Fast et al., 2007). Substantial vertical layering of the aerosol and regional differences in the Valley of Mexico for aerosol scattering and extinction was also found. Enhanced UV absorption (300$450 \mathrm{~nm}$ ) of incoming solar radiation was found to be substantial and was likely due to both SOA formation as well as from biomass burning sources (Corr et al., 2009; Marley et al., 2009b), consistent with a previous study during MCMA2003 (Barnard et al., 2008). The wavelength dependence of absorption measured at 470,530 and $660 \mathrm{~nm}$ on the C-130 was higher with higher organic fraction of non-refractory mass of submicrometer particles, and this relationship was more pronounced under high single scattering albedo, as expected for the interplay between soot and colored weak absorbers (some organic species and dust) (Shinozuka et al., 2009). The slope of SSA spectra also varied with the submicrometer aerosol composition. These observations from the $\mathrm{C} 130$ aircraft are consistent with, and extend, the results obtained elsewhere using AERONET ground-based remote sensing and airborne radiometric techniques (Russell et al., 2010). J-31 measurements of aerosol absorption over the broader wavelength range 350- 1650 nm (Bergstrom et al., 2010) also indicated the combined presence of black carbon, organic matter and possibly mineral dust and their influence on the wavelength dependence of absorption.

A strong correlation was found between the absorption Angstrom exponent (AAE) and the modern carbon content (radioactive ${ }^{14} \mathrm{C}$ ) in aerosols. The AAE values were derived from a simple exponential fit of the broadband aerosol absorption spectra obtained from either a seven-channel wavelength Aethalometer (5-min time resolution) or from 12-h integrated submicrometer aerosols samples by using an integrating sphere/spectrometer to obtain complete UV-visibleNIR spectra (Marley et al., 2009b). This result showed the significant impact that grass fires had in the region during the MILAGRO campaign on the lower atmospheric aerosol radiative forcing. Rain events during the latter portion of the campaign were found to put out the fires and both lower ${ }^{14} \mathrm{C}$ content and reduced UV-visible absorption were seen in the data (Marley et al., 2009a; Marley et al., 2009b; Aiken et al., 2010). Both biomass-burning and SOA sources are likely to add significant absorption in the UV-VIS-NIR region. These more complete spectral evaluations of aerosol absorption indicate the importance of multi-wavelength if not complete spectral characterization for absorbing carbonaceous aerosols. Previous work using single wavelengths, particularly at wavelengths longer than $500 \mathrm{~nm}$, did not detect these changes in absorption in the 300 to $500 \mathrm{~nm}$ range that are primarily due to oxidized organics (both aged primary and SOA coatings).

Studies from MILAGRO have reported significant enhanced UV-Visible absorption from biomass burning, secondary organics, and aged carbonaceous aerosol components. It will be important to add this spectral information to direct effect climate modeling efforts for these classes of organic aerosols, as this enhanced absorption will lead to warming of the atmosphere. This includes improved modeling of SOA production from megacity environments (Fast et al., 2009; Hodzic et al., 2009, 2010a, b; Dzepina et al., 2009). The importance of absorbing aerosols on regional radiative forcing has also been seen in other major field studies such as INDOEX (Ramanathan et al., 2001) and is an indication of the increasing potential importance that SOA and biomass burning aerosols may have on regional climate direct forcing, even in megacity environments. With anticipated increases in the growing seasons, reduced precipitation in summer months, and warmer climates, increases in forest and grass fires are predicted for many regions (IPCC, 2007). The potential increases in agricultural burning due to future increases in biofuel production constitute land use change that may add to carbonaceous aerosol impacts. The connection between biomass and agricultural burning with enhanced UV-visible absorbing aerosols identified during MILAGRO will need to be added to future regional climate modeling efforts.

Infrared forcing of these aerosols, particularly in the boundary layer is another area that has been identified as potentially important (Marley et al., 1993; Gaffney and Marley, 1998). FTIR and mass spectral studies have been reported that indicate that humic-like substances (HULIS) are contributing to the carbonaceous aerosols (Stone et al., 2009) and that these have strong absorption bands in the mid-IR region consistent with their HULIS structures (Marley et al., 1996, 2009a). The mid-IR absorption of carbonaceous aerosols will also add to the heating of the lower atmosphere and megacity sources of these aerosols along with associated higher greenhouse gases certainly add to urban heat island effects (Marley et al., 1993; Gaffney and Marley, 1998).

\section{INTEX-B flights over Mexico City and the Gulf}

This section presents an overview of methods and results of the Jetstream 31 (J-31) which participated in MILAGRO as part of the NASA-led INTEX-B study. As described by Singh et al. (2009), the major INTEX-B aircraft was a DC-8, which flew in two phases: 1-21 March (focused on Mexico and the Gulf during MILAGRO), and 17 April-15 May (focused on trans-Pacific Asian pollution transport). Methods and results of all DC-8 flights in INTEX-B are summarized by Singh et al. (2009).

\section{$10.1 \quad J-31$ overview}

For INTEX-B/MILAGRO the J-31 was equipped to measure many properties of solar radiant energy and how that energy is affected by atmospheric constituents and Earth's surfaces. Table 7 gives more information on J-31 instruments and the properties retrieved from their measurements. Because solar 

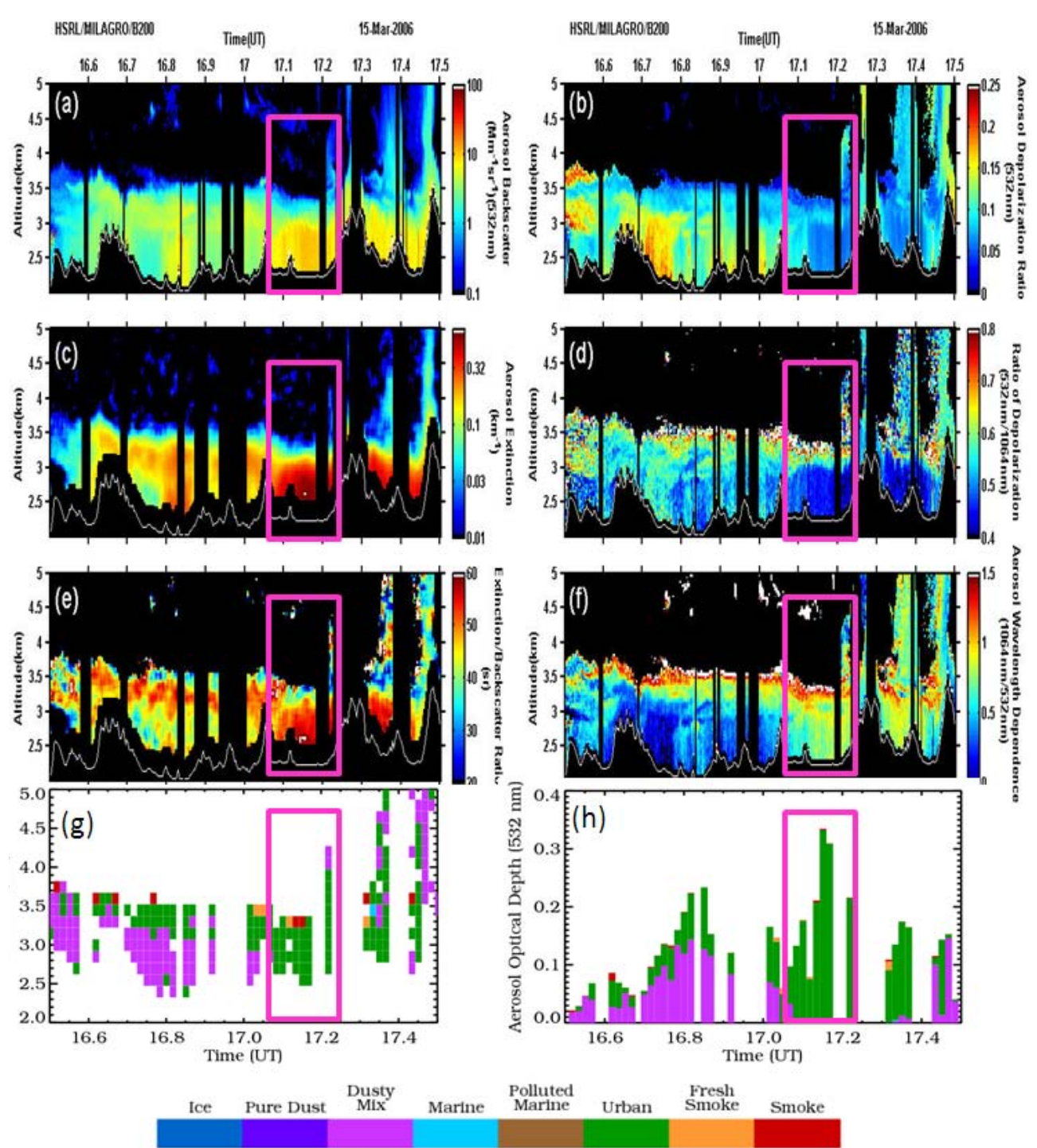

Fig. 13. Suite of airborne HSRL aerosol measurements acquired on 15 March 2006 in the Mexico City region. (a) aerosol backscatter $(532 \mathrm{~nm}),(\mathbf{b})$ aerosol depolarization $(532 \mathrm{~nm}),(\mathbf{c})$ aerosol extinction $(532 \mathrm{~nm}),(\mathbf{d})$ ratio of aerosol depolarization $(532 / 1064 \mathrm{~nm}),(\mathbf{e})$ aerosol extinction/backscatter ratio, (f) backscatter wavelength dependence $(1064 / 532 \mathrm{~nm}),(\mathrm{g})$ aerosol type inferred from the HSRL measurements, and (h) aerosol optical thickness $(532 \mathrm{~nm})$ contributed by each aerosol type. In (h), the total length of the bar represents the total aerosol optical thickness. The color bar at the bottom denotes the various aerosol types. The purple box between 17:05-17:25 UT indicates when the King Air flew directly over the city from northwest to southeast. Prior to that time, the King Air flew to the north and east of the Mexico City region. Over the city, the HSRL measurements indicate that urban (polluted) aerosols had the greatest contribution to AOD; in contrast, outside the city, a mixture of dust and urban aerosols had the greatest contribution to AOD.

energy drives Earth's climate, the J-31 suite of measurements helps show how changing atmospheric and surface properties can change the climate.

Constituents retrieved from J-31 measurements in INTEXB/MILAGRO include aerosol particles, water vapor, and clouds, in addition to properties of a variety of Earth surfaces. Specific scientific goals of these measurements were to:
- Characterize the distributions, properties, and effects of aerosol PM and water vapor advecting from Mexico City and biomass fires toward and over the Gulf of Mexico, including:

- Aerosol optical depth and extinction spectra (354$2138 \mathrm{~nm}$ ).

- Water vapor columns and profiles.

- Aerosol radiative impacts: in clear sky (direct effect) \& via clouds (indirect effect). 

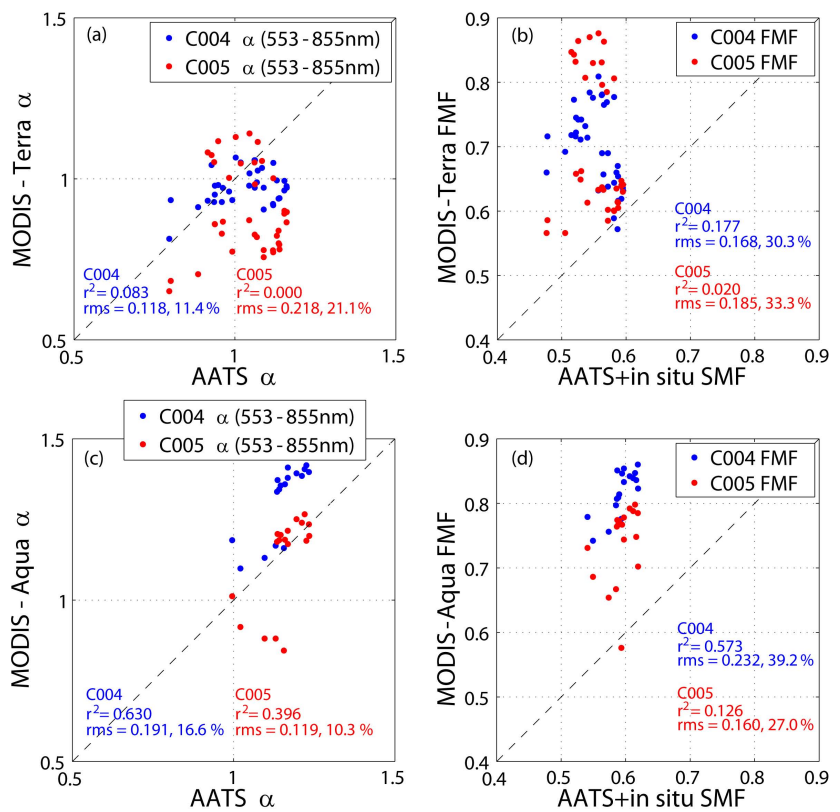

Fig. 14. (a) Comparison of MODIS-Terra and AATS-14 derived AOD Angstrom exponent for MODIS Collection 4 (C004, blue circles) and Collection 5 (C005, red circles). (b) Same as (a), but for the MODIS-Terra derived fine mode fraction, FMF, versus the AATS + in situ derived sub-micron fraction of AOD. (c-d) same as (a-b), but for MODIS-Aqua. The AATS + in situ derived submicron fraction of AOD uses DC-8 INTEX-B measurements as described by Redemann et al. (2009).

- Test the ability of Aura, other A-Train \& Terra satellite sensors, and airborne lidar, to retrieve aerosol, cloud, and water vapor properties.

- Characterize surface spectral albedo and bidirectional reflectance distribution function (BRDF) to help improve satellite retrievals.

- Quantify the relationships between the above and aerosol amount and type.

The J-31 made 13 successful flights totaling 43 flight hours out of Veracruz airport during MILAGRO. Scientific results are presented in several papers referenced below.

\subsection{Results from J-31 flights and related measurements}

Coddington et al. (2008) used J-31 Solar Spectral Flux Radiometer (SSFR) measurements of upward and downward irradiance to determine spectral surface albedo at ground stations and along the flight track, thereby linking flight-level retrieved measurements to larger-scale satellite observations in the polluted Mexico City environment. As they point out, these spectral surface albedo values strongly affect Earth's radiation balance and are also boundary conditions that need

to be accurately known for aerosol remote sensing, aerosol radiative forcing, and radiative transfer calculations. Their approach involves iteratively adjusting the surface albedo input of an SSFR-specific radiative transfer model until the modeled upward irradiance matches the SSFR measurements at flight level. They also compared spectral surface albedos derived from the SSFR, Multi-Filter Rotating Shadowband Radiometer (MFRSR), and the Moderate Resolution Imaging Spectroradiometer (MODIS) instrument onboard the NASA-EOS Terra and Aqua satellites, obtaining differences of $6-10 \%$ and $0.025-0.05$ units, respectively. Alongtrack comparisons between the SSFR and MODIS show that two instruments (aircraft and satellite) can capture inhomogeneous surface albedo scene changes.

A related MILAGRO/MCMA-2006 study on surface reflectance in the Mexico City metropolitan area was conducted by de Almeida Castanho et al. (2007). Their approach included using radiances from the MODIS satellite sensor at $1.5 \mathrm{~km}$ spatial resolution over distinct surfaces in the area to determine ratios of visible (VIS) to shortwave infrared (SWIR) reflectance for those surfaces. They also measured AOD using sunphotometers at 5 different locations over the urban area, as well as the CIMEL from the global AERONET located at the three supersites. They found that use of their derived VIS/SWIR surface reflectance ratios in the MODIS AOD retrieval algorithm greatly improved agreement between AOD measured from the surface and retrieved from MODIS.

J-31 Research Scanning Polarimeter (RSP) measurements have been used in studies of both Earth surface properties and aerosols. Chowdhary et al. (2010) use RSP measurements over the open ocean at low and high altitudes, and at azimuth angles close to and away from the solar principal plane, to show that reflectances are sensitive to variations in chlorophylla concentrations in the ocean, and that they can be matched using their hydrosol model over the full range of viewing geometries and observational heights and over the entire solar spectrum. In that study aerosol optical thickness values used in radiative transfer calculations are varied to match data from the Ames Airborne Tracking Sunphotometer (AATS) on the J-31. Cairns et al. (2009) use RSP measurements made over Mexico City to demonstrate for the first time the accurate retrieval of aerosol accumulation mode particle size, complex refractive index and spectral optical depth using downward looking passive measurements above an urban environment.

Livingston et al. (2009) use J-31 AATS measurements acquired over the Gulf of Mexico and Mexico City to evaluate retrievals of AOD from measurements by the Ozone Monitoring Instrument (OMI) aboard the Aura satellite and from the MODIS aboard the Aqua satellite. They show that MODIS and AATS AODs agree to within root mean square (RMS) differences of 0.00-0.06, depending on wavelength, but that OMI and AATS AODs can differ by considerably more. They explore how these OMI-AATS differences 
depend on the OMI retrieval algorithm used (near-UV vs. multiwavelength), on the retrieved aerosol model, and on other factors.

Redemann et al. (2009) compare J-31 AATS measurements of AOD and related aerosol properties to results from MODIS-Aqua and MODIS-Terra, with emphasis on differences between the older MODIS Collection 4 (C4) and the new Collection 5 (C5) data set, the latter representing a reprocessing of the entire MODIS data set completed during 2006. They find notable differences between MODIS C4 and C5 in AOD, Angstrom exponent, and aerosol fine mode fraction (FMF), and they explore how those differences depend on MODIS instrument (Aqua vs. Terra), on wavelength, and on other factors. An example result is shown in Fig. 14. They conclude that differences in MODIS C4 and C5 in the limited J-31 INTEX-B/MILAGRO data set can be traced to changes in the sensor calibration and recommend that they be investigated with a globally more representative data set.

Schmidt et al. (2010) introduce a method for deriving aerosol spectral radiative forcing, along with single scattering albedo, asymmetry parameter and surface albedo from airborne vertical profile measurements of shortwave spectral irradiance and spectral aerosol optical thickness. Using data collected by the SSFR and the AATS-14 on the J31 , they validate an over-ocean spectral aerosol forcing efficiency from the new method by comparing with the traditional method. Retrieved over-land aerosol optical properties are compared with in-situ measurements and AERONET retrievals. The spectral forcing efficiencies over ocean and land are remarkably similar, and agree with results from other field experiments.

Gatebe et al. (2010) use measurements by CAR on the $\mathrm{J}-31$ and an AERONET sun-sky photometer on the ground to test a new method for simultaneously retrieving aerosol properties and surface reflectance properties from combined airborne and ground-based direct and diffuse radiometric measurements. Results are shown from four campaigns at four sites having different surface characteristics and aerosol types. As an example, for 6 March 2006 over Mexico City, they retrieve an aerosol size distribution that is trimodal above the J-31 and bimodal below. Although submicrometer particles appear to dominate in both layers, there is a significant contribution to the total optical thickness from particles with $r>1 \mu \mathrm{m}$. Results for single scattering albedo and complex refractive index above and below the aircraft are also presented.

Bergstrom et al. (2010) combine J-31 measurements of solar radiation spectra by SSFR and AOD spectra by AATS to derive spectra of aerosol SSA and aerosol absorption optical depth (AAOD) for two flights over the Gulf of Mexico and three flights over Mexico City for wavelengths from 350 to $\sim 1650 \mathrm{~nm}$. They describe the results in terms of three different wavelength regions: The $350-500 \mathrm{~nm}$ region where the aerosol absorption often falls off sharply presumably due to organic carbonaceous matter and windblown dust; the
$500-1000 \mathrm{~nm}$ region where the decrease with wavelength is slower, presumably due to black carbon; and the near infrared spectral region $(1000 \mathrm{~nm}$ to $1650 \mathrm{~nm})$ where it is difficult to obtain reliable results since the aerosol absorption is relatively small and the gas absorption dominates. However, there is an indication of a small and somewhat wavelength independent absorption in the region beyond $1000 \mathrm{~nm}$. For one of the flights over the Gulf of Mexico near the coastline it appears that a cloud/fog formation and evaporation led to an increase of absorption possibly due to a water shell remaining on the particles after the cloud/fog had dissipated. For two of the Mexico City cases, the single scattering albedo is roughly constant between $350-500 \mathrm{~nm}$ consistent with other Mexico City results. In three of the cases a single absorption Angstrom exponent (AAE) fits the aerosol absorption optical depth over the entire wavelength range of 350 to $1650 \mathrm{~nm}$ relatively well $\left(r^{2}>0.86\right)$.

Additional results on Mexico City aerosol absorption wavelength dependence from C-130 measurements in MILAGRO are presented by Russell et al. (2010), who also present an analysis from previous AERONET measurements in Mexico City and other locations.

\section{Health studies}

There is strong evidence from around the world that urban air pollution affects human health (Samet and Krewski, 2007). Health effects have been associated predominately with at least one of the so-called criteria pollutants that are routinely measured to assess air quality in most cities around the world. Ozone and PM represent a common persistent problem in several cities, with important effects on public health (Craig et al., 2008). Although recent attention has been brought towards understanding the role of multipollutants interactions in air pollution related health effects (Mauderly and Samet, 2009), current methodological approaches have focused on ozone (Samoli et al., 2009) and, more importantly, in PM as the criteria pollutant with stronger associations with most of the described health effects.

Adverse health outcomes include: increased mortality, hospital admissions, altered pulmonary function, cancer, asthma, etc. (Pope and Dockery, 2006). However, PM effects are heterogeneous and vary with PM size, season and location (Bell et al., 2008; Dominici et al., 2006; Peng et al., 2005). Recent evidence at the experimental and population level indicates that variations in the PM mixture chemical composition could account for the heterogeneous health effects observed (Alfaro-Moreno et al., 2010; Dominici et al., 2007; Lippmann et al., 2006). For example, Ni and V content have been linked to increased cardiovascular disease. Local conditions, however, can drive stronger associations, as in the case of New York City where local sources could be responsible for high Ni content, causing health effects both locally and at downwind locations as due to "imported" pollution 
(Dominici et al., 2007; Lippmann et al., 2006). The emerging issue of the role of PM composition will require studies using more comprehensive data on air pollution components, e.g., EPA's Speciation Trends Network (Lippmann, 2009), and their chemical "evolution" during emission, atmospheric dispersion and transport.

The MCMA has been the subject of previous pollutionrelated health studies. Evidence on mortality and school absenteeism was first published in the 1990s (Borja-Aburto et al., 1997; Romieu et al., 1992). More recent evidence has been focused on children's health, e.g., the participation of genetic polymorphisms (Romieu et al., 2006), systemic damage (Calderon-Garciduenas et al., 2007), lung growth retardation (Barraza-Villarreal et al., 2008) and the participation of other variables such as education (O'Neill et al., 2008). Some of the published results from Mexico City describe situations relevant to information revealed by MILAGRO. Among them are the importance of coarse particles on mortality (Castillejos et al., 2000) or the existence of PM toxicological profiles depending on where the samples were obtained (Osornio-Vargas, et al., 2003) and the relative effects of their components (Rosas-Perez et al., 2007). See Sect. 8 for further information on MCMA PM levels and characteristics.

Many MILAGRO observations are relevant to human exposure and health impact. However, it is difficult to relate them directly to health effects due to the short length of the campaign, compared to the typical length for human health effects studies. The MILAGRO findings are certainly useful for the design of future health studies, including effects related to long range transport of pollutants (see e.g., Hashizume et al., 2010).

Two health-related studies were carried out during MILAGRO: one on human exposure and another at the cellular level; each are described briefly below:

(1) The human exposure study done by Tovalin et al. (2010) aimed to evaluate the contribution of regionally transported air pollutants from the MCMA to the children's personal exposure (age 9-12) and their parents during the campaign. This study included: collection of personal and microenvironmental samples of air pollutants (ozone, fine and ultrafine particles, $\mathrm{CO}, \mathrm{VOCs}$ ) at three selected sites in urban, suburban and rural areas; comparison of the indoor and outdoor concentrations and personal exposures to air pollutants at the three sites; determination of the association between the exposures and the level of oxidative stress markers among the study populations; and analysis of the relationship between the exposures and their respiratory health. Results indicate that children near T0 have decreased levels of respiratory and olfactory function as well as enhanced indicators for oxidative stress and inflammation. However, the lack of clear gradient effects between urban, suburban and rural areas suggests that local sources are also playing a role on health effects. Pollutants such as benzene, $\mathrm{O}_{3}, \mathrm{NO}_{2}, \mathrm{SO}_{2}$, $\mathrm{PM}_{10}$ showed statistical associations with biomarkers of ox- idative stress. The study design and the duration of the study did not allow for discrimination between acute and cumulative effects.

(2) Osornio-Vargas el at. (2008) described the oxidative potential of $\mathrm{PM}_{10}$ collected at $\mathrm{T} 0$ and $\mathrm{T} 1$ using Electron Paramagnetic Resonance (EPR) technique in the presence of DMPO as an $\mathrm{OH}$ trap to correlate with in vitro $\mathrm{PM}_{10^{-}}$ induced membrane disruption and degradation of isolated DNA. Daily samples were pooled and analyzed accordingly to the influence/non-influence dispersion patterns of $\mathrm{T} 0$ on T1, as defined by de Foy (2008) during MILAGRO using back trajectories. $\mathrm{PM}_{10}$ samples from $\mathrm{T} 0$ had a higher oxidative potential than those from $\mathrm{T}_{1}$. During $\mathrm{T} 0 \rightarrow \mathrm{T} 1$ influence days, the oxidative potential of $\mathrm{T} 1$ samples was lower than for other days. Additionally, $\mathrm{PM}_{10}$ samples were analyzed for elemental content and oxidative potential correlated with $\mathrm{PM}_{10} \mathrm{Cu}$ and $\mathrm{Zn}$ levels. However biological effects did not correlate with oxidative potential and were different by site, probably as a result of local influences such as $\mathrm{PM}_{10}$ composition, suggesting that oxidative stress is not the only mechanism involved in PM-toxicity. Other MILAGRO findings support these observations, for example: (1) Mexico City's air pollution "footprint" influences the receptor site, but not further than $200 \mathrm{~km}$ (Kleinman et al., 2008; Mena-Carrasco et al., 2009); (2) The plume dilutes and ages as it moves towards the receptor site (Kleinman et al., 2008); and (3) MCMA is photochemically very active and produces large amount of $\mathrm{OH}$ from various radical sources. The highly reactive $\mathrm{OH}$ controls lifetime and fate of most ambient trace gases (Dusanter et al., 2009a). Mugica et al. (2009) also describe the variability of PM oxidative potential in relation to composition, sources and meteorological conditions.

Several studies on different PM size fractions give useful information on PM composition and its evolution or aging, as described in Sect. 8 of this Overview. Of particular interest for health studies are the results on metals and PAHs, many of which have known toxic effects. Another important observation is that persistent organic pollutants (POPs) collected with passive samples had similar indoor and outdoor concentrations in Mexico City (Bohlin et al., 2008). These are important points worth keep in mind when considering human exposures.

\section{Summary and conclusions}

The MILAGRO Campaign was designed to investigate the extremely vigorous atmospheric photochemistry of North America's most populous metropolitan area. The observation phase of MILAGRO/INTEX-B has provided an extremely rich data set that will likely take years to fully analyze and evaluate. Many interesting aspects of atmospheric chemistry in and near the MCMA are emerging and have already added to our understanding of the chemical and physical properties of the city's reactive atmosphere and its 
regional impacts. Results from 2006, as well as the earlier 2002/2003 studies, have been presented at international conferences and communicated to Mexican government officials. In this paper we have reviewed over 120 papers resulting from MILAGRO/INTEX-B Campaign that have been published or submitted, as well as additional relevant papers from MCMA-2003, with the aim of providing a road map for the scientific community interested in understanding the emissions from a megacity such as the MCMA and their impacts on air quality and climate.

\subsection{Summary of key findings}

Key findings from the analysis and evaluation of the extensive MILAGRO and relevant MCMA-2003 results obtained to date are summarized below.

\subsubsection{Meteorology and dynamics}

- The overall synoptic conditions and boundary layer circulations were similar to those reported by MCMA previous studies and consistent with prior climatology, suggesting that results from MILAGRO are applicable to general conditions in the MCMA.

- Meteorological measurements at the surface and aloft coupled with measurements of trace gases and aerosols indicate that the synoptic-scale transport of the Mexico City pollutant plume was predominantly towards the northeast, although regional-scale circulations transported pollutants to the surrounding valleys and basins on some days.

- On the basin-scale, morning winds from the north transported the plume towards the south. On certain days, this was transported over the basin rim or through the mountain pass in the southeast. An afternoon gap flow from the south reversed the flow direction in the mountain pass and contributed to flushing the MCMA plume towards the northeast.

- Surface and airborne lidars, as well as airborne meteorological measurements have shown multiple layers of particulate matter resulting from complex mixing processes over central Mexico.

- Drainage flows at night have a strong impact on air pollution transport and accumulation in the basin leading to high pollutant concentrations.

- Biomass burning plumes were found to be transported into the MCMA from the surrounding basin and outlying regions.

- The Popocatepetl volcano has very limited impacts on the air quality in the MCMA because of the elevation of the emissions and the vertical stratification in the wind flows. However, these impacts can be larger at regional scales.

- CMET balloon trajectories found strong layering of the urban plume persisting as far as the Gulf of Mexico, with very rapid transport at high altitude.

- Mesoscale meteorological models were found to capture the main features of the basin wind transport and were of sufficient accuracy to assist in data analysis and interpretation.

- The combination of Radar Wind Profiler analysis and modeling studies assisted in suggesting possible source areas of heavy metals. Further analysis could be used to identify these more precisely.

\subsubsection{MCMA emissions of gases and fine PM:}

- MILAGRO demonstrated the synergy of using multiple bottom-up and top-down analysis techniques with data obtained from multiple platforms and instruments to evaluate emissions inventories. The combined process helps to reduce the associated uncertainties in the emissions estimates and provides guidance for setting priorities for improving further development and refinement of the emissions inventories.

- Several studies showed that some mobile emissions from gasoline vehicles in the MCMA decreased in recent years, $\mathrm{CO}$ in particular, but that mobile emission sources are still the main contributors of gaseous pollutants and a major contributor to PM pollution in the city.

- The relative contribution of diesel vehicles to overall $\mathrm{NO}_{\mathrm{x}}$ levels has increased over time in the city. This is expected and consistent with observations in the US, and is partially due to the increases in diesel fuel consumption and to the introduction of very effective control technologies for gasoline vehicle emissions, which have not been matched by similarly effective diesel emission control technologies (Harley et al., 2005; BanWeiss et al., 2008).

- The measurements of mobile emissions during MILAGRO identified several discrepancies between the observations and the emissions estimates in the emissions inventory. These include slight overpredictions of $\mathrm{CO}$ and NO ( $<30 \%$ and $<20 \%$, respectively), and a probable underprediction of VOCs by a factor of 1.4 to 1.9 in the inventory. Similarly, there is modeling and observational evidence that the current PM emissions estimates are severely underestimated.

- The direct flux measurements at the SIMAT tower site in the city center suggest that the local emissions inventory estimates of $\mathrm{CO}_{2}$, olefins and selected aromatic and 
oxygenated VOCs are accurate for emissions from combustion sources, but overestimate the evaporative emissions from area sources within several $\mathrm{km}$ footprint of the measurement site. In contrast, the aircraft flux measurements indicate an underestimation of the toluene and benzene emissions reported in the emissions inventory for the northeast industrial sector of the city.

- The surface and airborne flux measurements carried out during MCMA-2003 and MILAGRO-2006 demonstrated that the eddy covariance techniques coupled with fast response sensors can be used to evaluate directly emission inventories in a way that is not possible with other indirect evaluation methods, making them valuable tools for improving the air quality management process.

- Due to the uncertainties on the current estimates of PM emissions in the emissions inventory, it is important to better characterize the PM contributions from the diesel and gasoline mobile emissions sources in the MCMA.

- Additional sources from informal commerce and road side food preparation need to be characterized. The results show that there is potential for severe local impacts on air quality from cooking and garbage fires, as they can be major sources of several reactive gases and fine particles.

- The widespread multi-source urban/industrial emissions may have an important influence on $\mathrm{Hg}$ in the MCMA. Nevertheless, other species not addressed in this review (e.g., $\mathrm{NH}_{3}$, dust, metals) warrant further study in the MCMA.

\subsubsection{MCMA volatile organic compounds}

- Evaporative fuel and industrial emissions are important sources for aromatic VOCs in the basin.

- LPG use continues to be an important source of low molecular weight alkanes.

- Many hydrocarbon emissions show greater enhancement ratios to $\mathrm{CO}$ in the MCMA than the US due to the widespread use of LPG and higher industrial and evaporative emissions of aromatics in Mexico City.

- Total OH reactivity due to VOCs in the MCMA remains largely unchanged from the 2003 study; however the speciated attribution is quite different. Formaldehyde and acetaldehyde were the two most important measured VOC species in terms of $\mathrm{OH}$ reactivity in the MCMA.

- Diurnal variations suggest that photochemical formation of secondary VOCs is very important in the MCMA basin.
- Fires are a modest source of VOCs measured at surface sites.

- Rapid photochemistry transforms the VOC OH reactivity distribution from NMHCs domination in the morning hours in the MCMA basin to OVOCs domination aloft and downwind.

- There are large non-biogenic sources of methanol in the MCMA basin.

\subsubsection{Urban and regional photochemistry}

- Measured concentrations of $\mathrm{OH}$ and $\mathrm{HO}_{2}$ in the MCMA were higher than predicted in the morning when $\mathrm{NO}_{\mathrm{x}}$ is high, suggesting that there may be a significant source of radicals missing from current atmospheric chemistry models of polluted environments.

- Photolysis of HONO and HCHO and ozonolysis of alkenes are important sources of radicals in the MCMA, while photolysis of ozone is a minor contributor to total radical production. Inclusion of heterogeneous sources of HONO improves substantially the agreement between measured and modeled $\mathrm{HONO}$ and $\mathrm{HO}_{x}$ concentrations and enhanced the production of $\mathrm{O}_{3}$ and SOA.

- The net instantaneous rate of ozone production from $\mathrm{HO}_{2}$ radicals as well as the observed rate of ozone production from all production mechanisms are among the highest observed anywhere.

- Several chemical transport models and analyses of measurements indicate that ozone production in the MCMA is generally VOC-limited.

- On the regional scale, significant enhancements of $\mathrm{O}_{3}$ above background were observed in plumes that could be traced back to Mexico City, with indications that significant $\mathrm{O}_{3}$ production occurred during the plume transport time.

- Regional $\mathrm{O}_{3}$ production appears to be sensitive to $\mathrm{NO}_{\mathrm{x}}$ as well as to VOCs and $\mathrm{CO}$, with the regional $\mathrm{OH}$ radical reactivity dominated by oxygenated organics and CO.

- Long-range export of reactive nitrogen from Mexico City was found to take place primarily via the formation of PANs, which can thermally decompose leading to regeneration of $\mathrm{NO}_{\mathrm{x}}$ contributing to regional $\mathrm{O}_{3}$ formation.

- Biomass burning was found to have a significant influence on regional chemistry, contributing more than half of the organic aerosol and about one third of the benzene, reactive nitrogen, and carbon monoxide to the regional outflow. 


\subsubsection{Ambient particulate matter}

- During the study, $\mathrm{PM}_{10}$ and $\mathrm{PM}_{2.5}$ concentrations in the urban area were about double the concentrations in the rural areas surrounding Mexico City.

- $\mathrm{PM}_{2.5}$ made up about half of the $\mathrm{PM}_{10}$ concentrations, with small amounts of mass in the $\mathrm{PM}_{2.5}-\mathrm{PM}_{1.0}$ range.

- Mineral matter made up approximately $25 \%$ of the $\mathrm{PM}_{10}$ and on average $15 \%$ and $28 \%$ of the $\mathrm{PM}_{2.5}$ in the urban and rural areas, respectively. Approximately $25 \%$ of the $\mathrm{PM}_{2.5}$ was secondary inorganic ions with the remaining $\mathrm{PM}_{2.5}$ mass being comprised of largely carbonaceous aerosol.

- Except for surface measurements at the central sampling sites in Mexico City, the elemental carbon mass absorption efficiency was relatively constant for aircraft and surface measurements throughout the study.

- Although different organic aerosol source apportionment methods had some differences, there was agreement that the dominant sources of carbonaceous aerosol were secondary organic aerosol, biomass burning, and vehicle exhaust emissions.

- The impact of biomass burning on the aerosol outflow from the region was much larger than on the surface concentrations inside the city.

- SOA formation from primary semivolatile and intermediate volatility precursors has the potential to close the gap in predicted vs. measured SOA. However these predictions are poorly constrained by the data and more specific measurements are needed in future campaigns.

- Biogenic SOA advected from the coastal ranges contributes about $1 \mu \mathrm{g} \mathrm{m}^{-3}$ to concentrations in the MCMA.

- Anthropogenic alkenes add little organic mass to SOA, but indirectly add to SOA by reacting to produce radicals for the processing of other SOA precursor VOCs.

- Additional work is needed to fully quantify the sources of substantial modern carbon in organic aerosols during low biomass burning periods. Discrepancies between the two ${ }^{14} \mathrm{C}$ datasets deserve further study. A modeling study suggests that the observed modern OC may be due to a combination of regional biogenic SOA, biomass burning OA, and POA and SOA from urban sources of modern carbon.

- Primary OA from anthropogenic and biomass burning sources was found to be semivolatile, while secondary OA was less volatile than POA and aged SOA was essentially non-volatile, in contrast with current models.
- Growth rates of new particle formation in Mexico City were very large and found to be impacted by nitrogen containing organic compounds, organic acids, and hydroxyl organic acids, with only a smaller fraction of sulfate aerosol.

- CCN can be predicted well with an internal mixing assumption after a few hours of photochemical aging, which is shorter than scales in most global models.

\subsubsection{Optical properties and remote measurements of aerosol and earth surfaces}

- At the T0 and T1 surface sites single scattering albedos (SSA) were frequently in the $0.7-0.8$ range with some early morning values having even lower SSA. This is consistent with high absorbing aerosol concentrations from both fossil and biomass burning sources during MILAGRO.

- Aerosol contributions from biomass burning sources contained both black carbon and oxidized organics that yielded enhanced UV absorption. This observation indicated biomass burning activities can have important impacts on the absorption or heating by carbonaceous aerosols in megacity (urban) as well as regional scales.

- Oxidized organics from primary fires and from secondary aerosol formation were also found to have strong absorption in the $300-400 \mathrm{~nm}$ region that leads to enhanced optical absorption by these aerosols over that anticipated from black carbon alone.

- Comparisons of the HSRL aerosol extinction measurements with aerosol extinction derived from simultaneous airborne Sun photometer and in situ scattering and absorption measurements found bias differences between HSRL and these instruments to be less than $3 \%(0.01 \mathrm{~km}-1)$ at $532 \mathrm{~nm}$; root-mean-square (rms) differences at $532 \mathrm{~nm}$ were less than $50 \%\left(0.015 \mathrm{~km}^{-1}\right)$. These differences are well with range of current stateof-the-art instrumentation.

- Measurements of surface albedo and reflectance in the Mexico City metropolitan area showed that many urban surfaces are more reflective than assumed in common satellite retrieval algorithms, and that use of larger visible surface reflectance in algorithms can produce more accurate retrieved aerosol optical depth (AOD).

- Comparisons between AOD from airborne sunphotometer (AATS) and from the satellite sensors OMI and MODIS show that MODIS and AATS AODs agree to within root mean square (RMS) differences of 0.00 0.06 , depending on wavelength, but that OMI and AATS AODs can differ by considerably more. 
- Other comparisons between AATS and MODIS aerosol properties show notable differences between the older MODIS Collection 4 and the new Collection 5 in terms of AOD, Angstrom exponent, and aerosol fine mode fraction, with differences traceable to changes in sensor calibration.

\section{Future research}

As described above, a very large number of instruments were used in the MCMA during MILAGRO for both ground-based and aircraft measurements; and some innovative instruments and measurement techniques were deployed for the first time. The MILAGRO campaign has shown the synergy of using multiple measuring platforms, instrumentation, and data analysis techniques for obtaining an improved understanding of the physical and chemical characteristics of emissions in a megacity.

Furthermore, the deployment of a significant number of advanced instruments, many operating with sensitive, fast $(\sim \mathrm{s})$ response times, along with a large number of established air quality monitoring instruments deployed on aircraft and at surface sites, as well as onboard several mobile laboratories, have provided significant opportunities to intercompare and evaluate a number of instruments in a highly polluted environment. Several papers documenting and/or cross comparing the performance of instruments have been published as well.

Despite the use of many advanced PM techniques during MILAGRO, some questions remain unanswered or strongly debated and should be the focus of further research. The fraction of dust due to road resuspension vs. natural sources is unclear. There is a need for characterizing the dust source regions and the soil characteristics for those regions, not only for the Mexico City Valley, but for the entire Central Mexican plateau. The impact of gas-particle reactions is important, for example for nitrate uptake into the coarse dust mode, but needs to be further investigated to reach a quantitative understanding, including through 3-D modeling. The identities of industrial sources of metals and organic aerosols and of the urban chloride sources remain unclear. High time-resolution quantitative analyses of dust and metals may yield very useful information for source identification.

The 2006 MCMA emissions inventory underestimates primary $\mathrm{PM}_{2.5}$ and needs to be updated with the information arising from MILAGRO and other studies. Forest fire $\mathrm{PM}_{2.5}$ appears to be underestimated by an order of magnitude in the official MCMA inventory (although a fraction of the fires occur just outside the inventory area), but perhaps overestimated about two-fold on a custom satellite-based inventory used in 3-D modeling. The impact of some POA sources such as food cooking, biofuel use, and open trash burning may be important, but remains poorly characterized. Some differences in the apportionment of biomass burning PM be- tween different approaches were observed and need further research, as these techniques together represent the state of the art for source apportionment. The differences in the relative oxidation of OA in urban vs. background samples between the FTIR and AMS techniques need to be further investigated.

Further study is needed of the reasons for the differences between the two datasets of modern carbon. The mix of sources that contribute to $30-45 \%$ modern carbon in OC during low regional fire periods need to be identified, including a quantification of the urban sources of modern carbon. The influence of "hot" sources of radiocarbon in aerosols needs to be further investigated as it could bias assessments of fossil vs. modern carbon. SOA from traditional precursors such as aromatics is much smaller than the observed SOA in the Mexico City urban area, but the dominant sources of anthropogenic SOA are still poorly characterized. SOA from biomass burning sources, although not dominant in the city, remains poorly characterized and appears to be underpredicted by traditional models. The relative impacts of MCMA vs. regional sources for the different components deserve further study. The sources and chemical species leading to the very intense new particle formation events observed are only starting to be characterized.

Measurements of aerosol optical absorption in Mexico City and downwind also benefitted from the variety of techniques applied during MILAGRO, leading to several results summarized above. However, not all results are in perfect agreement, and lack of perfect spatiotemporal coincidence between different measurements makes it impossible to say whether different results stem from different techniques or from different aerosols sampled. Future campaigns need increased focus on spatiotemporal coincidence between different techniques, to help resolve these questions. There are also persistent differences among different satellite retrievals of aerosols, as well as between results from satellite and suborbital techniques. This is an area that requires continued effort, with attention not only to spatiotemporal coincidence of different techniques, but also to statistical significance and geophysical representativeness of comparison data sets.

In summary, observations from MILAGRO/INTEX-B have provided extremely comprehensive characterization on the urban and regional atmospheric composition and chemistry of the Mexico Megacity. All data sets and publications are available to the scientific community interested in evaluating the impact of urban emissions on human health, ecosystem viability, and climate change. We anticipate new results from MILAGRO/INTEX-B will continue to contribute to our understanding of megacity air pollution and its potential impacts on human health, ecosystem viability, and climate change on urban, regional, and even hemispheric scales. This information will improve significantly the scientific understanding that decision makers in Mexico will need to craft effective policies as well as provide insights to air pollution problems in other megacities around the world. 


\section{Appendix A}

\section{List of acronyms}

\begin{tabular}{|c|c|}
\hline AAE: & Absorption Angstrom Exponent \\
\hline AATS: & Ames Airborne Tracking Sunphotometer \\
\hline ACP: & Atmospheric Chemistry and Physics \\
\hline AERONET: & AErosol RObotic NETwork \\
\hline AMS: & Aerosol Mass Spectrometer \\
\hline ANL: & Argonne National Laboratory \\
\hline AOD: & Aerosol Optical Depth \\
\hline APS: & Aerosol Polarimetry Sensor \\
\hline ARI & - Aerodyne Research, Inc. \\
\hline ATOFMS: & Aerosol-Time-of-Flight Mass Spectrometer \\
\hline BBOA: & Biomass-Burning Organic Aerosol \\
\hline BNL: & Brookhaven National Laboratory \\
\hline BTEX: & Benzene, Toluene, Ethylbenzene and m,p,o-Xylenes \\
\hline CAM: & $\begin{array}{l}\text { Comisión Ambiental Metropolitana } \\
\text { (Metropolitan Environmental Commission) }\end{array}$ \\
\hline $\mathrm{CCN}$ : & Cloud Condensation Nuclei \\
\hline CEH: & Center for Ecology and Hydrology, Edingburgh \\
\hline CENICA: & $\begin{array}{l}\text { Centro Nacional de Investigatión y Capcitación Ambiental } \\
\text { (National Center for Environmental Research and Training) }\end{array}$ \\
\hline CIMS: & Chemical Ionization Mass Spectrometer \\
\hline CMET: & Controlled Meteorological balloons \\
\hline CONACyT: & $\begin{array}{l}\text { Consejo Nacional de Ciencia y Technología } \\
\text { (National Council for Science and Technology) }\end{array}$ \\
\hline CPC: & Condensation Particle Counter \\
\hline CSIC: & Consejo Superior de Investigaciones Científicas, Spain \\
\hline CTM: & Chemical Transport Model \\
\hline DEC: & Disjunct Eddy Covariance \\
\hline DOAS: & Differential Optical Absorption Spectroscopy \\
\hline FMPS: & Fast Mobility Particle Sizer \\
\hline FOS: & Fast Olefin Sensor \\
\hline GC-FID: & Gas Chromatography / Flame Ionization Detection \\
\hline HOA: & Hydrocarbon-like Organic Aerosol \\
\hline HR-ToF-AMS: & High-Resolution Time-of-Flight Aerosol Mass Spectrometer \\
\hline HSRL: & High Spectral Resolution Lidar \\
\hline HTDMA: & Hygroscopicity Tandem Differential Mobility Analyzer \\
\hline HULIS: & Humic-like Substances \\
\hline IC-MS: & Ion Chromatography - Mass Spectrometry \\
\hline IGMA: & Inclined Grid Mobility Analyzer \\
\hline IMK-IFU: & $\begin{array}{l}\text { Institute for Meteorology and Climate Research, } \\
\text { Atmospheric Environmental Research, } \\
\text { Karlsruhe Institute of Technology. }\end{array}$ \\
\hline IMP: & Instituto Mexicano del Petróleo (Mexican Petroleum Institute) \\
\hline INE: & Instituto Nacional de Ecologia (National Institute of Ecology) \\
\hline INTEX-B: & Intercontinental Chemical Transport Experiment-Phase B \\
\hline IRGA: & Infrared Gas Analyzer \\
\hline ITESM: & Instituto Tecnologico y de Estudios Superiores de Monterrey (TEC) \\
\hline LBNL & - Lawrence Berkeley National Laboratory \\
\hline LPG: & liquefied Petroleum Gas \\
\hline MAX-Mex: & Megacity Aerosol Experiment: Mexico City \\
\hline MCE2: & Molina Center for Energy and the Environment \\
\hline MCMA: & Mexico City Metropolitan Area \\
\hline MFRSR: & Multi-Filter Rotating Shadowband Radiometer \\
\hline MILAGRO: & $\begin{array}{l}\text { Megacity Initiative: } \\
\text { Local And Global Research Observations }\end{array}$ \\
\hline MIRAGE-Mex: & $\begin{array}{l}\text { Megacity Impacts on Regional } \\
\text { and Global Environments - Mexico }\end{array}$ \\
\hline MISR: & Multiangle Imaging Spectroradiometer \\
\hline MODIS: & Moderate Resolution Imaging Spectroradiometer \\
\hline MOZART: & Model for OZone And Related chemical Tracers \\
\hline MSU: & Montana State University \\
\hline NARR: & North American Regional Reanalysis \\
\hline NASA: & National Aeronautics and Space Administration \\
\hline NCAR: & National Center for Atmospheric Research \\
\hline NCEP: & National Centers for Environmental Prediction \\
\hline NTDMA: & Nanoparticle Tandem Differential Mobility Analyzer \\
\hline OA: & Organic Aerosol \\
\hline OC: & Organic Carbon \\
\hline OMI: & Ozone Monitoring Instrument \\
\hline OOA: & Oxygenated organic aerosol \\
\hline OPC: & Optical Particle Counter \\
\hline OVOC: & Oxygenated Volatile Organic Chemicals \\
\hline PAHs: & Polycyclic Aromatic Hydrocarbons \\
\hline
\end{tabular}

\begin{tabular}{|c|c|}
\hline PANs: & Peroxyacetyl Nitrates \\
\hline PAS: & Photoacoustic Absorption Spectrometer \\
\hline PEMEX: & Petróleos Mexicanos (Mexican Petroleum) \\
\hline PMF: & Positive Matrix Factorization \\
\hline PNNL & - Pacific Northwest National Laboratory \\
\hline POA: & Primary Organic Aerosol \\
\hline POPs: & Persistent Organic Pollutants \\
\hline PSAP: & Particle Soot Absorption Photometer \\
\hline PSU & - Pennsylvania State University \\
\hline PTR-MS: & Proton Transfer Reaction Mass Spectrometry \\
\hline RAMA: & $\begin{array}{l}\text { Red Automatica de Monitoreo Atmosferico } \\
\text { (Ambient Air Quality Monitoring Network) }\end{array}$ \\
\hline RSP: & Research Scanning Polarimeter \\
\hline SEMARNAT: & $\begin{array}{l}\text { Secretaria de Medio Ambiente y Recursos Naturales } \\
\text { (Mexican Ministry of the Environment } \\
\text { and Natural Resources) }\end{array}$ \\
\hline SIMAT: & $\begin{array}{l}\text { Sistema de Monitoreo Atmosférico } \\
\text { (Atmospheric Monitoring System) }\end{array}$ \\
\hline S/IVOC: & $\begin{array}{l}\text { Semivolatile and Intermediate Volatility } \\
\text { Organic Compounds }\end{array}$ \\
\hline SMA-GDF: & $\begin{array}{l}\text { Secretaria de Medio Ambiente - } \\
\text { Gobierno del Distrito Federal } \\
\text { (Environmental Secretariat- } \\
\text { Government of the Federal District) }\end{array}$ \\
\hline SMN: & $\begin{array}{l}\text { Servicio Meteorológico Nacional } \\
\text { (National Weather Service) }\end{array}$ \\
\hline SMPS: & Scanning Mobility Particle Sizer \\
\hline SOA: & Secondary Organic Aerosol \\
\hline SSA: & Single Scattering Albedos \\
\hline SSFR: & Solar Spectral Flux Radiometer \\
\hline STEM (Model): & Sulfur Transport and Deposition Model \\
\hline STEM (Technique): & Scanning Transmission Electron Microscopy \\
\hline STXM: & Scanning Transmission X-Ray Microscopy \\
\hline TDCIMS: & $\begin{array}{l}\text { Thermal Desorption Chemical Ionization } \\
\text { Mass Spectrometry }\end{array}$ \\
\hline TDMA: & Tandem Differential Mobility Analyzer, \\
\hline TD-LIF: & Thermal Dissociation-Laser Induced Fluorescence \\
\hline TEM: & Transmission Electron Microscope \\
\hline TOOC: & Total Observed Organic Carbon \\
\hline TSP: & Total Suspended Particles \\
\hline UAH: & University of Alabama at Huntsville \\
\hline UAM-A: & Universidad Autónoma Metropolitana - Azcapotzalco \\
\hline UNAM: & Universidad Nacional Autónoma de México \\
\hline UTC: & Coordinated Universal Time \\
\hline VT: & Virginia Tech \\
\hline WIOC: & Water-insoluble Organic Carbon \\
\hline WSU: & Washington State University \\
\hline WRF-Chem (Model): & $\begin{array}{l}\text { Weather Research and Forecast (WRF) } \\
\text { model coupled with Chemistry }\end{array}$ \\
\hline WSOC: & Water Soluble Organic Carbon \\
\hline
\end{tabular}

Acknowledgements. The MILAGRO/INTEX-B Campaign is the collaborative efforts of a large number of participants with the support of multi-national agencies. The MILAGRO/INTEX-B participants would like to thank the governments of the Federal District, the States of Mexico, Hidalgo and Veracruz, the Mexican Ministries of the Environment, Foreign Relations, Defense and Finance, the US Embassy in Mexico and the Molina Center for Energy and the Environment for their logistical support; IMP, U-Tecámac, and Rancho La Bisnega for hosting the supersites as well as many other Mexican institutions for their support. The MILAGRO/INTEX-B participants are grateful for funding from the Mexican Metropolitan Environmental Commission, Mexican Ministry of the Environment, CONACyT, PEMEX, NSF Atmospheric Chemistry Program, DOE Atmospheric Science Program and NASA Tropospheric Chemistry and Radiation Science Programs.

We would like to thank many MILAGRO investigators for reviewing the manuscript and for their comments and suggestions. We are grateful to R. Ramos, A. Retama and the operators and analyst personnel of the RAMA Monitoring Network for administering and gathering the surface air quality and meteorological data, and 
M. Rosengaus and the personnel of the Mexican National Meteorological Service for providing EMA and radiosonde data. We thank E. Velasco for preparing Fig. 8, C. Hostetler for contributing to the King Air section and C. Kolb for helpful discussion.

Edited by: U. Pöschl

\section{References}

Adachi, K. and Buseck, P. R.: Internally mixed soot, sulfates, and organic matter in aerosol particles from Mexico City, Atmos. Chem. Phys., 8, 6469-6481, doi:10.5194/acp-8-6469-2008, 2008.

Adachi, K., Chung, S. H., and Buseck, P. R.: Shapes of soot aerosol particles and implications for their effects on climate, J. Geophys. Res.-Atmos., 115, D15206, doi:10.1029/2009JD012868, 2010.

Adachi, K. and Buseck, P. R.: Hosted and Free-Floating Metalbearing Atmospheric Nanoparticles in Mexico City, Environ. Sci. Technol., 44, 2299-2304, 2010.

Aiken, A. C., DeCarlo, P. F., and Jimenez, J. L.: Elemental Analysis of Organic Species with Electron Ionization HighResolution Mass Spectrometry, Anal. Chem., 79, 8350-8358, doi:10.1021/ac071150w, 2007.

Aiken, A. C., DeCarlo, P. F., Kroll, J. H., Worsnop, D. R., Huffman, J. A., Docherty, K. S., Ulbrich, I. M., Mohr, C., Kimmel, J. R., Sueper, D., Sun, Y., Zhang, Q., Trimborn, A., Northway, M., Ziemann, P. J., Canagaratna, M. R.,, Onasch, T. B., Alfarra, M. R., Prevot, A. S. H., Dommen, J., Duplissy, J, Metzger, A., Baltensperger, U., and Jimenez, J. L.: O/C and OM/OC Ratios of Primary, Secondary, and Ambient Organic Aerosols with High Resolution Time-of-Flight Aerosol Mass Spectrometry, Environ. Sci. Technol., 42, 4478-4485, doi:10.1021/es703009q, 2008.

Aiken, A. C., Salcedo, D., Cubison, M. J., Huffman, J. A., DeCarlo, P. F., Ulbrich, I. M., Docherty, K. S., Sueper, D., Kimmel, J. R., Worsnop, D. R., Trimborn, A., Northway, M., Stone, E. A., Schauer, J. J., Volkamer, R. M., Fortner, E., de Foy, B., Wang, J., Laskin, A., Shutthanandan, V., Zheng, J., Zhang, R., Gaffney, J., Marley, N. A., Paredes-Miranda, G., Arnott, W. P., Molina, L. T., Sosa, G., and Jimenez, J. L.: Mexico City aerosol analysis during MILAGRO using high resolution aerosol mass spectrometry at the urban supersite (T0) - Part 1: Fine particle composition and organic source apportionment, Atmos. Chem. Phys., 9, 66336653, doi:10.5194/acp-9-6633-2009, 2009.

Aiken, A. C., de Foy, B., Wiedinmyer, C., DeCarlo, P. F., Ulbrich, I. M., Wehrli, M. N., Szidat, S., Prevot, A. S. H., Noda, J., Wacker, L., Volkamer, R., Fortner, E., Wang, J., Laskin, A., Shutthanandan, V., Zheng, J., Zhang, R., Paredes-Miranda, G., Arnott, W. P., Molina, L. T., Sosa, G., Querol, X., and Jimenez, J. L.: Mexico city aerosol analysis during MILAGRO using high resolution aerosol mass spectrometry at the urban supersite (T0) - Part 2: Analysis of the biomass burning contribution and the non-fossil carbon fraction, Atmos. Chem. Phys., 10, 5315-5341, doi:10.5194/acp-10-5315-2010, 2010.

Alfaro Moreno, E., García Cuellar, C., De Vizcaya Ruiz, A., RojasBracho, L., and Osornio-Vargas, A. R.: Cellular Mechanisms behind Particulate Matter Air Pollution Related Health Effects, in: Air Pollution: Health \& Environmental Impacts, edited by:
Gurjar, R., Molina, L. T., and Ojha, C. S. P., Taylor \& Francis, Chapter 9, 249-274, 2010.

Altuzar, V., Tomás, S. A., Zelaya-Angel, O., Sánchez-Sinencio, F., and Arriaga, J. L.: Atmospheric ethene concentrations in Mexico City: Indications of strong diurnal and seasonal dependences, Atmos. Env., 39, 5219-5225, 2005.

Andreae, M. O. and Gelencsér, A.: Black carbon or brown carbon? The nature of light-absorbing carbonaceous aerosols, Atmos. Chem. Phys., 6, 3131-3148, doi:10.5194/acp-6-3131-2006, 2006.

Andreae, M. O. and Gelencsér, A.: Black carbon or brown carbon? The nature of light-absorbing carbonaceous aerosols, Atmos. Chem. Phys., 6, 3131-3148, doi:10.5194/acp-6-3131-2006, 2006.

Apel, E. C., Emmons, L. K., Karl, T., Flocke, F., Hills, A. J., Madronich, S., Lee-Taylor, J., Fried, A., Weibring, P., Walega, J., Richter, D., Tie, X., Mauldin, L., Campos, T., Weinheimer, A., Knapp, D., Sive, B., Kleinman, L., Springston, S., Zaveri, R., Ortega, J., Voss, P., Blake, D., Baker, A., Warneke, C., Welsh-Bon, D., de Gouw, J., Zheng, J., Zhang, R., Rudolph, J., Junkermann, W., and Riemer, D. D.: Chemical evolution of volatile organic compounds in the outflow of the Mexico City Metropolitan area, Atmos. Chem. Phys., 10, 2353-2375, doi:10.5194/acp-10-23532010, 2010.

Apel, E. C., Hills, A. J., Lueb, R., Zindel, S., Eisele, S. and Riemer, D. D.: A Fast-GC/MS system to measure $C_{2}$ to $C_{4}$ carbonyls, and methanol aboard aircraft, J. Geophys. Res., 108, 8794, doi:10.1029/2002JD003199, 2003.

Atkinson, R.: Gas phase tropospheric chemistry of organic compounds: a review, Atmos. Environ., 24A, 1-41, 1990.

Ban-Weiss, G. A., McLaughlin, J. P., Harley, R. A., Lunden, M. M., Kirchstetter, T. W., Kean, A. J., Strawa, A. W., Stevenson, E. D., and Kendall, G. R.: Long-term changes in emissions of nitrogen oxides and particulate matter from on-road gasoline and diesel vehicles, Atmos. Environ., 42, 220-232, 2008.

Barnard, J. C., Volkamer, R., and Kassianov, E. I.: Estimation of the mass absorption cross section of the organic carbon component of aerosols in the Mexico City Metropolitan Area, Atmos. Chem. Phys., 8, 6665-6679, doi:10.5194/acp-8-6665-2008, 2008.

Barraza-Villarreal, A., Sunyer, J., Hernandez-Cadena, L., Escamilla-Nunez, M. C., Sienra-Monge, J. J., Ramirez-Aguilar, M., Sienra-Monge, J. J., Cortez-Lugo, M., Texcalac, J. L., del Rio-Navarro, B., and Romieu, I.: Air pollution, airway inflammation, and lung function in a cohort study of Mexico City schoolchildren, Environ. Health Perspect., 116, 832-838, 2008.

Baumgardner, D., Grutter, M., Allan, J., Ochoa, C., Rappenglueck, B., Russell, L. M., and Arnott, P.: Physical and chemical properties of the regional mixed layer of Mexico's Megapolis, Atmos. Chem. Phys., 9, 5711-5727, doi:10.5194/acp-9-5711-2009, 2009.

Bei, N., de Foy, B., Lei, W., Zavala, M., and Molina, L. T.: Using 3DVAR data assimilation system to improve ozone simulations in the Mexico City basin, Atmos. Chem. Phys., 8, 7353-7366, doi:10.5194/acp-8-7353-2008, 2008.

Bei, N., Lei, W., Zavala, M., and Molina, L. T.: Ozone predictabilities due to meteorological uncertainties in the Mexico City basin using ensemble forecasts, Atmos. Chem. Phys., 10, 6295-6309, doi:10.5194/acp-10-6295-2010, 2010.

Bell, M. L., Ebisu, K., Peng, R. D., Walker, J., Samet, J. M., 
Zeger, S. L., and Dominici, F.: Seasonal and regional shortterm effects of fine particles on hospital admissions in 202 US counties, 1999-2005, Am. J. Epidemiol., 168(11), 1301-1310, doi:10.1093/aje/kwn252, 2008.

Bergstrom, R. W., Schmidt, K. S., Coddington, O., Pilewskie, P., Guan, H., Livingston, J. M., Redemann, J., and Russell, P. B.: Aerosol spectral absorption in the Mexico City area: results from airborne measurements during MILAGRO/INTEX B, Atmos. Chem. Phys., 10, 6333-6343, doi:10.5194/acp-10-63332010, 2010.

Bishop, G. A., Stedman, D. H., de la Garza, J., and Davalos, F.: On road remote sensing of vehicle emissions in Mexico, Environ. Sci. Technol., 31, 3505-3510, 1997.

Blake, D. R. and Rowland, F. S.: Urban leakage of liquefied petroleum gas and its impact on Mexico City air quality, Science, 269, 953-956, 1995.

Bohlin, P., Jones, K. C., Tovalin, H., and Strandberg, B.: Observations on persistent organic pollutants in indoor and outdoor air using passive polyurethane foam samplers, Atmos. Environ., 42, 7234-7241, 2008.

Borbon, A., Fontaine, H., Veillerot, M., Locoge, N., Galloo, J. C., and Guillermo, R.: An investigation into the traffic-related fraction of isoprene at an urban location, Atmos. Environ., 35, 37493760, 2001.

Borja-Aburto, V. H., Loomis, D. P., Bangdiwala, S. I., Shy, C. M., and Rascon-Pacheco, R. A.: Ozone, suspended particulates, and daily mortality in Mexico City, Am. J. Epidemiol., 145, 258-268, 1997.

Bravo, A., Sosa, E., Sanchez, A., Jaimes, P., and Saavedra, R.: Impact of wildfires on the air quality of Mexico City, 1992-1999, Environ. Pollut., 117, 243-253, 2002.

Cairns, B., Waquet, F., Knobelspiesse, K., Chowdhary, J., and Deuzé, J. L.: Polarimetric remote sensing of aerosols over land surfaces, in Aerosol Remote Sensing over Land edited by: Kokhanovsky, A. A. and de Leeuw, G., Springer, 295-325, 2009.

Calderon-Garciduenas, L., Franco-Lira, M., Torres-Jardon, R., Henriquez-Roldan, C., Barragan-Mejia, G., Valencia-Salazar, G. González-Maciel A., Reynoso-Robles, R., Villarreal-Calderón, R., and Reed, W.: Pediatric respiratory and systemic effects of chronic air pollution exposure: Nose, lung, heart, and brain pathology, Toxicol. Pathol., 35, 154-162, 2007.

Canagaratna, M. R., Jayne, J. T., Jimenez, J. L., Allan, J. D., Alfarra, M. R., Zhang, Q., Onasch, T. B. Drewnick, F., Coe, H., Middlebrook, A., Delia, A., Williams, L. R., Trimborn, A. M., Northway, M. J., DeCarlo, P. F., Kolb, C. E., Davidovits, P., and D. R. Worsnop: Chemical and Microphysical Characterization of Ambient Aerosols with the Aerodyne Aerosol Mass Spectrometer, Mass Spec. Rev., 26, 185-222, 2007.

Cappa, C. D. and Jimenez, J. L.: Quantitative estimates of the volatility of ambient organic aerosol, Atmos. Chem. Phys., 10, 5409-5424, doi:10.5194/acp-10-5409-2010, 2010.

Capes, G., Johnson, B., McFiggans, G., Williams, P. I., Haywood, J., and Coe, H.: Aging of biomass burning aerosols over West Africa: aircraft measurements of chemical composition, microphysical properties, and emission ratios, J. Geophys. Res., 113, D00C15, doi:10.1029/2008JD009845, 2008.

Castillejos M., Borja-Aburto, V. H., Dockery, D. W., Gold, D. R., and Loomis, D.: Coarse Particles and Mortality in Mexico City, Inhal. Toxicol., 12, 61-72, 2000.
CEC 2009, Comprehensive Assessment of North American Air Emissions Inventories and Ambient Air Monitoring Networks, available at: http://www.cec.org/Storage/88/8537_Air_ Assessment_Report_en.pdf, last access: 15 August 2010.

Chow, J. C., Watson, J. G., Edgerton, S. A., and Vega, E.: Chemical composition of $\mathrm{PM}_{2.5}$ and $\mathrm{PM}_{10}$ in Mexico City during winter 1997, Sci. Total Environ., 287, 177-201, 2002.

Chowdhary, J., Cairns, B., Waquet, F., Knobelspiesse, K., Ottaviani, M., Redemann, J., Travis, L., and Mishchenko, M.: Sensitivity of multiangle, multispectral polarimentric remote sensing over open oceans to water-leaving radiances: Analyses of RSP data acquired during the MILAGRO campaign10, submitted to Remote Sens. Environ., June, 2010.

Christian, T. J., Yokelson, R. J., Cárdenas, B., Molina, L. T., Engling, G., and Hsu, S.-C.: Trace gas and particle emissions from domestic and industrial biofuel use and garbage burning in central Mexico, Atmos. Chem. Phys., 10, 565-584, doi:10.5194/acp-10-565-2010, 2010.

Coddington, O., Schmidt, K. S., Pilewskie, P., Gore, W. J., Bergstrom, R. W., Roma'n, M., Redemann, J., Russell, P. B., Liu, J. and Schaaf, C. C.: Aircraft measurements of spectral surface albedo and its consistency with ground-based and space-borne observations, J. Geophys. Res., 113, D17209, doi:10.1029/2008JD010089, 2008.

Corr, C. A., Krotkov, N., Madronich, S., Slusser, J. R., Holben, B., Gao, W., Flynn, J., Lefer, B., and Kreidenweis, S. M.: Retrieval of aerosol single scattering albedo at ultraviolet wavelengths at the T1 site during MILAGRO, Atmos. Chem. Phys., 9, 58135827, doi:10.5194/acp-9-5813-2009, 2009.

Craig, L., Brook, J. R., Chiotti, Q., Croes, B., Gower, S., Hedley, A., Krewski, D., Krupnick, A., Krzyzanowski, M., Moran, M. D., Pennell, W., Samet, J. M., Schneider, J., Shortreed, J., Williams, M.: Air pollution and public health: a guidance document for risk managers, J. Toxicol. Environ. Health A, 71, 588-698, 2008.

Cross, E. S., Onasch, T. B., Canagaratna, M., Jayne, J. T., Kimmel, J., Yu, X.-Y., Alexander, M. L., Worsnop, D. R., and Davidovits, P.: Single particle characterization using a light scattering module coupled to a time-of-flight aerosol mass spectrometer, Atmos. Chem. Phys., 9, 7769-7793, doi:10.5194/acp-9-7769-2009, 2009.

Crounse, J. D., DeCarlo, P. F., Blake, D. R., Emmons, L. K., Campos, T. L., Apel, E. C., Clarke, A. D., Weinheimer, A. J., McCabe, D. C., Yokelson, R. J., Jimenez, J. L., and Wennberg, P. O.: Biomass burning and urban air pollution over the Central Mexican Plateau, Atmos. Chem. Phys., 9, 4929-4944, doi:10.5194/acp-9-4929-2009, 2009.

de Almeida Castanho, A. D., Prinn, R., Martins, V., Herold, M., Ichoku, C., and Molina, L. T.: Analysis of Visible/SWIR surface reflectance ratios for aerosol retrievals from satellite in Mexico City urban area, Atmos. Chem. Phys., 7, 5467-5477, doi:10.5194/acp-7-5467-2007, 2007.

DeCarlo, P. F., Kimmel, J. R., Trimborn, A., Northway, M. J., Jayne, J. T., Aiken, A. C, Gonin, M., Fuhrer, K., Horvath, T., Docherty, K. S., Worsnop, D. R., and Jimenez, J. L.: Field-Deployable, High-Resolution, Time-of-Flight Aerosol Mass Spectrometer, Anal. Chem., 78, 8281-8289, 2006.

DeCarlo, P. F., Dunlea, E. J., Kimmel, J. R., Aiken, A. C., Sueper, D., Crounse, J., Wennberg, P. O., Emmons, L., Shinozuka, Y., Clarke, A., Zhou, J., Tomlinson, J., Collins, D. R., Knapp, D., 
Weinheimer, A. J., Montzka, D. D., Campos, T., and Jimenez, J. L.: Fast airborne aerosol size and chemistry measurements above Mexico City and Central Mexico during the MILAGRO campaign, Atmos. Chem. Phys., 8, 4027-4048, doi:10.5194/acp8-4027-2008, 2008.

DeCarlo, P. F., Ulbrich, I. M., Crounse, J., de Foy, B., Dunlea, E. J., Aiken, A. C., Knapp, D., Weinheimer, A. J., Campos, T., Wennberg, P. O., and Jimenez, J. L.: Investigation of the sources and processing of organic aerosol over the Central Mexican Plateau from aircraft measurements during MILAGRO, Atmos. Chem. Phys., 10, 5257-5280, doi:10.5194/acp-10-52572010, 2010.

de Foy, B., Caetano, E., Magañaa, V., Zitácuaro, A., Cárdenas, B., Retama, A., Ramos, R., Molina, L. T., and Molina, M. J.: Mexico City basin wind circulation during the MCMA-2003 field campaign, Atmos. Chem. Phys., 5, 2267-2288, doi:10.5194/acp-52267-2005, 2005.

de Foy, B., Clappier, A., Molina, L. T., and Molina, M. J.: Distinct wind convergence patterns in the Mexico City basin due to the interaction of the gap winds with the synoptic flow, Atmos. Chem. Phys., 6, 1249-1265, doi:10.5194/acp-6-1249-2006, 2006.

de Foy, B., Varela, J. R., Molina, L. T., and Molina, M. J.: Rapid ventilation of the Mexico City basin and regional fate of the urban plume, Atmos. Chem. Phys., 6, 2321-2335, doi:10.5194/acp-6-2321-2006, 2006b.

de Foy, B., Lei, W., Zavala, M., Volkamer, R., Samuelsson, J., Mellqvist, J., Galle, B., Martínez, A.-P., Grutter, M., Retama, A., and Molina, L. T.: Modelling constraints on the emission inventory and on vertical dispersion for $\mathrm{CO}$ and $\mathrm{SO}_{2}$ in the Mexico City Metropolitan Area using Solar FTIR and zenith sky UV spectroscopy, Atmos. Chem. Phys., 7, 781-801, doi:10.5194/acp-7781-2007, 2007.

de Foy, B., Fast, J. D., Paech, S. J., Phillips, D., Walters, J. T., Coulter, R. L., Martin, T. J., Pekour, M. S., Shaw, W. J., Kastendeuch, P. P., Marley, N. A., Retama, A., and Molina, L. T.: Basinscale wind transport during the MILAGRO field campaign and comparison to climatology using cluster analysis, Atmos. Chem. Phys., 8, 1209-1224, doi:10.5194/acp-8-1209-2008, 2008.

de Foy, B., Zavala, M., Bei, N., and Molina, L. T.: Evaluation of WRF mesoscale simulations and particle trajectory analysis for the MILAGRO field campaign, Atmos. Chem. Phys., 9, 44194438, doi:10.5194/acp-9-4419-2009, 2009a.

de Foy, B., Krotkov, N. A., Bei, N., Herndon, S. C., Huey, L. G., Martínez, A.-P., Ruiz-Suárez, L. G., Wood, E. C., Zavala, M., and Molina, L. T.: Hit from both sides: tracking industrial and volcanic plumes in Mexico City with surface measurements and OMI SO2 retrievals during the MILAGRO field campaign, Atmos. Chem. Phys., 9, 9599-9617, doi:10.5194/acp-9-9599-2009, 2009b.

de Gouw, J. and Warneke, C.: Measurements of volatile organic compounds in the earths atmosphere using proton-transferreaction mass spectrometry, Mass Spec. Rev. 26, 223-257, 2007.

de Gouw, J. A., Welsh-Bon, D., Warneke, C., Kuster, W. C., Alexander, L., Baker, A. K., Beyersdorf, A. J., Blake, D. R., Canagaratna, M., Celada, A. T., Huey, L. G., Junkermann, W., Onasch, T. B., Salcido, A., Sjostedt, S. J., Sullivan, A. P., Tanner, D. J., Vargas, O., Weber, R. J., Worsnop, D. R., Yu, X. Y., and Zaveri, R.: Emission and chemistry of organic carbon in the gas and aerosol phase at a sub-urban site near Mexico City in
March 2006 during the MILAGRO study, Atmos. Chem. Phys., 9, 3425-3442, doi:10.5194/acp-9-3425-2009, 2009.

de Gouw, J. and Jimenez, J. L.: Organic Aerosols in the Earth's Atmosphere, Environ. Sci. Technol., 43, 7614-7618, doi:10.1021/es9006004, 2009.

Docherty, K. S., Stone, E. A., Ulbrich, I. M., DeCarlo, P. F., Snyder, D. C., Schauer, J. J, Peltier, R. E., Weber, R. J., Murphy, S. M., Seinfeld, J. H., Grover, B. D., Eatough, D. J., and Jimenez, J. L.: Apportionment of Primary and Secondary Organic Aerosols in Southern California during the 2005 Study of Organic Aerosols in Riverside (SOAR), Environ. Sci. Technol., 42, 7655-7662, doi:10.1021/es8008166, 2008.

Dominici, F., Peng, R. D., Bell, M. L., Pham, L., McDermott, A., Zeger, S. L. and Samet, J. M.: Fine particulate air pollution and hospital admission for cardiovascular and respiratory diseases, JAMA, 295, 1127-1134, 2006.

Dominici, F., Peng, R. D., Ebisu, K., Zeger, S. L., Samet, J. M., Bell, M. L.: Does the effect of $\mathrm{PM}_{10}$ on mortality depend on PM nickel and vanadium content?, A reanalysis of the NMMAPS data, Environ. Health Perspect., 115, 1701-1703, 2007.

Doran, J. C., Fast, J. D., Barnard, J. C., Laskin, A., Desyaterik, Y., and Gilles, M. K.: Applications of lagrangian dispersion modeling to the analysis of changes in the specific absorption of elemental carbon, Atmos. Chem. Phys., 8, 1377-1389, doi:10.5194/acp-8-1377-2008, 2008.

Doran, J. C., Barnard, J. C., Arnott, W. P., Cary, R., Coulter, R., Fast, J. D., Kassianov, E. I., Kleinman, L., Laulainen, N. S., Martin, T., Paredes-Miranda, G., Pekour, M. S., Shaw, W. J., Smith, D. F., Springston, S. R., and Yu, X.-Y.: The T1-T2 study: evolution of aerosol properties downwind of Mexico City, Atmos. Chem. Phys., 7, 1585-1598, doi:10.5194/acp-7-1585-2007, 2007.

Doran, J. C., Abbott, S., Archuleta, J., Bian, X., Chow, J., Coulter, R. L., de Wekker, S. F. J., Edgerton, S., Elliott, S., Fernandez, A., Fast, D. J., Hubbe, J. M., King, C., Langley, D., Leach, J., Lee, J. T., Martin, T. J., Martinez, D., Martinez, J. L., Mercado, G., Mora, V., Mulhearn, M., Pena, J. L., Petty, R., Porch, W., Russell, C., Salas, R., Shannon, J. D., Shaw, W. J., Sosa, G., Tellier, L., Templeman, B., Watson, J. G., White, R., Whiteman, C. D., and Wolfe, D.: The IMADA-AVER boundary-layer experiment in the Mexico City area, B. Am. Meteor. Soc., 79, 2497-2508, 1998.

Doskey, P. V., Porter, J. A., and Scheff, P. A.: Source fingerprints for volatile non-methane hydrocarbons, J. Air Waste Manag. Assoc., 42, 1437-1445, 1992.

Dunlea, E. J., DeCarlo, P. F., Aiken, A. C., Kimmel, J. R., Peltier, R. E., Weber, R. J., Tomlinson, J., Collins, D. R., Shinozuka, Y., McNaughton, C. S., Howell, S. G., Clarke, A. D., Emmons, L. K., Apel, E. C., Pfister, G. G., van Donkelaar, A., Martin, R. V., Millet, D. B., Heald, C. L., and Jimenez, J. L.: Evolution of Asian aerosols during transpacific transport in INTEX-B, Atmos. Chem. Phys., 9, 7257-7287, doi:10.5194/acp-9-7257-2009, 2009.

Dunlea, E. J., Herndon, S. C., Nelson, D. D., Volkamer, R. M., San Martini, F., Sheehy, P. M., Zahniser, M. S., Shorter, J. H., Wormhoudt, J. C., Lamb, B. K., Allwine, E. J., Gaffney, J. S., Marley, N. A., Grutter, M., Marquez, C., Blanco, S., Cardenas, B., Retama, A., Ramos Villegas, C. R., Kolb, C. E., Molina, L. T., and Molina, M. J.: Evaluation of nitrogen dioxide chemilumines- 
cence monitors in a polluted urban environment, Atmos. Chem. Phys., 7, 2691-2704, doi:10.5194/acp-7-2691-2007, 2007.

Dunn, M., Jimenez, J. L., Baumgardner, D., Castro, T., McMurry, P. H., and Smith, J. N.: Measurements of Mexico City nanoparticle size distributions: Observations of new particle formation and growth, Geophys. Res. Lett., 31, L10102, doi:10.1029/2004GL019483, 2004.

Dusanter, S., Vimal, D., Stevens, P. S., Volkamer, R., and Molina, L. T.: Measurements of $\mathrm{OH}$ and $\mathrm{HO}_{2}$ concentrations during the MCMA-2006 field campaign - Part 1: Deployment of the Indiana University laser-induced fluorescence instrument, Atmos. Chem. Phys., 9, 1665-1685, doi:10.5194/acp-9-1665-2009, 2009a.

Dusanter, S., Vimal, D., Stevens, P. S., Volkamer, R., Molina, L. T., Baker, A., Meinardi, S., Blake, D., Sheehy, P., Merten, A., Zhang, R., Zheng, J., Fortner, E. C., Junkermann, W., Dubey, M., Rahn, T., Eichinger, B., Lewandowski, P., Prueger, J., and Holder, H.: Measurements of $\mathrm{OH}$ and $\mathrm{HO} 2$ concentrations during the MCMA-2006 field campaign - Part 2: Model comparison and radical budget, Atmos. Chem. Phys., 9, 6655-6675, doi:10.5194/acp-9-6655-2009, 2009b.

Dzepina, K., Arey, J., Marr, L.C., Worsnop, D. R., Salcedo, D., Zhang, Q., Onasch, T. B., Molina, L. T., Molina, M. J., and Jimenez, J. L.: Detection of Particle-Phase Polycyclic Aromatic Hydrocarbons in Mexico City using an Aerosol Mass Spectrometer, Int. J. Mass Spec., 263, 152-170, 2007.

Dzepina, K., Volkamer, R. M., Madronich, S., Tulet, P., Ulbrich, I. M., Zhang, Q., Cappa, C. D., Ziemann, P. J., and Jimenez, J. L.: Evaluation of recently-proposed secondary organic aerosol models for a case study in Mexico City, Atmos. Chem. Phys., 9, 5681-5709, doi:10.5194/acp-9-5681-2009, 2009.

Edgerton, S. A., Bian, X., Doran, J. C., Fast, J. D., Hubbe, J. M., Malone, E. L., Shaw, W. J., Whiteman, C. D., Zhong, S., Arriaga, J. L., Ortiz, E., Ruiz, M., Sosa, G., Vega, E., Limon, T., Guzman, F., Archuleta, J., Bossert, J. E., Elliot, S., Lee, J. T., McNair, L. A., Chow, J. C., Watson, J. G., Coulter, R. L., , Doskey, P. V., Gaffney, J. S., Marley, N. A., Neff, W., and Petty, R.: Particulate Air pollution in Mexico City: A Collaborative Research Project, J. Air Waste Manag. Assoc., 49, 1221-1229, 1999.

Emmons, L. K., Apel, E. C., Lamarque, J.-F., Hess, P. G., Avery, M., Blake, D., Brune, W., Campos, T., Crawford, J., DeCarlo, P. F., Hall, S., Heikes, B., Holloway, J., Jimenez, J. L., Knapp, D. J., Kok, G., Mena-Carrasco, M., Olson, J., O’Sullivan, D., Sachse, G., Walega, J., Weibring, P., Weinheimer, A., and Wiedinmyer, C.: Impact of Mexico City emissions on regional air quality from MOZART-4 simulations, Atmos. Chem. Phys., 10, 6195-6212, doi:10.5194/acp-10-6195-2010, 2010.

Ervens, B., Cubison, M. J., Andrews, E., Feingold, G., Ogren, J. A., Jimenez, J. L., Quinn, P. K., Bates, T. S., Wang, J., Zhang, Q., Coe, H., Flynn, M., and Allan, J. D.: CCN predictions using simplified assumptions of organic aerosol composition and mixing state: a synthesis from six different locations, Atmos. Chem. Phys., 10, 4795-4807, doi:10.5194/acp-10-4795-2010, 2010.

Evans, J., Levy, J., Hammitt, J., Santos-Burgoa, C., Castillejos, M., Caballero-Ramirez, M., Hernandez-Avila, M., RiojasRodriguez, H., Rojas-Bracho, L., Serrano-Trespalacios, P., Spengler, J. D., and Suh, H.: Health benefits of air pollution control, in: "Air Quality in the Mexico Megacity: an Integrated Assessment”, edited by: Molina, L. T. and Molina, M. J. , Kluwer Aca- demic Publishers, 103-136, 2002.

Farmer, D. K., Matsunaga, A., Docherty, K. S.,Surratt, J. D., Seinfeld, J. H., Ziemann, P. J., and Jimenez, J. L.: Response of the Aerosol Mass Spectrometer to organonitrates and organosulfates and implications for field studies, P. Natl. Acad. Sci. USA, 107, 6670-6675, doi:10.1073/pnas.0912340107, 2010.

Fast, J. D. and Zhong, S., Meteorological factors associated with inhomogeneous ozone concentrations within the Mexico City basin, J. Geophys. Res., 103, 18927-18946, 1998.

Fast, J., Aiken, A. C., Allan, J., Alexander, L., Campos, T., Canagaratna, M. R., Chapman, E., DeCarlo, P. F., de Foy, B., Gaffney, J., de Gouw, J., Doran, J. C., Emmons, L., Hodzic, A., Herndon, S. C., Huey, G., Jayne, J. T., Jimenez, J. L., Kleinman, L., Kuster, W., Marley, N., Russell, L., Ochoa, C., Onasch, T. B., Pekour, M., Song, C., Ulbrich, I. M., Warneke, C., WelshBon, D., Wiedinmyer, C., Worsnop, D. R., Yu, X.-Y., and Zaveri, R.: Evaluating simulated primary anthropogenic and biomass burning organic aerosols during MILAGRO: implications for assessing treatments of secondary organic aerosols, Atmos. Chem. Phys., 9, 6191-6215, doi:10.5194/acp-9-6191-2009, 2009.

Fast, J. D., de Foy, B., Acevedo Rosas, F., Caetano, E., Carmichael, G., Emmons, L., McKenna, D., Mena, M., Skamarock, W., Tie, X., Coulter, R. L., Barnard, J. C., Wiedinmyer, C., and Madronich, S.: A meteorological overview of the MILAGRO field campaigns, Atmos. Chem. Phys., 7, 2233-2257, doi:10.5194/acp-7-2233-2007, 2007.

Faulhaber, A. E., Thomas, B. M., Jimenez, J. L., Jayne, J. T., Worsnop, D. R., and Ziemann, P. J.: Characterization of a thermodenuder-particle beam mass spectrometer system for the study of organic aerosol volatility and composition, Atmos. Meas. Tech., 2, 15-31, doi:10.5194/amt-2-15-2009, 2009.

Ferrare, R., Hostetler, C., Hair, J., Cook, A., Harper, D., Burton, S., Clayton, M. Clarke, A., Russell, P., Redemann, J.: Airborne High Spectral Resolution Lidar Aerosol Measurements During MILAGRO and TEXAQS/GoMACCS, Ninth Conference on Atmospheric Chemistry, 2007 Annual AMS Conference, San Antonio, TX, http://ams.confex.com/ams/pdfpapers/119758.pdf, January 2007.

Forster, P., Ramaswamy, V., Artaxo, P., et al.: Changes in Atmospheric Constituents and in Radiative Forcing, in: "Climate Change 2007: the Physical Science Basis. Contribution of Working Group I to the Fourth Assessment Report of the Intergovernmental Panel on Climate Change", edited by: Solomon, S., Qin, D., Manning, M., Chen, Z., Marquis, M., Averyt, K. B., Tignor, M., and Miller, H. L., Cambridge University Press, Cambridge, United Kingdom and New York, NY, USA, 2007.

Fortner, E. C., Zheng, J., Zhang, R., Berk Knighton, W., Volkamer, R. M., Sheehy, P., Molina, L., and André, M.: Measurements of Volatile Organic Compounds Using Proton Transfer Reaction - Mass Spectrometry during the MILAGRO 2006 Campaign, Atmos. Chem. Phys., 9, 467-481, doi:10.5194/acp-9-467-2009, 2009.

Fountoukis, C., Nenes, A., Sullivan, A., Weber, R., Van Reken, T., Fischer, M., Matas, E., Moya, M., Farmer, D., and Cohen, R. C.: Thermodynamic characterization of Mexico City aerosol during MILAGRO 2006, Atmos. Chem. Phys., 9, 2141-2156, doi:10.5194/acp-9-2141-2009, 2009.

Gaffney, J. S. and Marley, N. A.: Uncertainties of aerosol effects in global climate models, Atmospheric Environment, 32, 2873 
2874, 1998.

Garcia, J. H., Li, W. W., Cardenas, N., Arimoto, R., Walton, J., and Trujillo, D.: Determination of $\mathrm{PM}_{2.5}$ sources using timeresolved integrated source and receptor models, Chemosphere, 65, 2018-2027, 2006.

Gasparini, R., Li, R. J., and Collins, D. R.: Integration of size distributions and size-resolved hygroscopicity measured during the Houston Supersite for compositional categorization of the aerosol, Atmos. Environ., 38(20), 3285-3303, 2004.

Gatebe, C. K., Dubovik, O., King, M. D., and Sinyuk, A.: Simultaneous retrieval of aerosol and surface optical properties from combined airborne- and ground-based direct and diffuse radiometric measurements, Atmos. Chem. Phys., 10, 2777-2794, doi:10.5194/acp-10-2777-2010, 2010.

Gilardoni, S., Liu, S., Takahama, S., Russell, L. M., Allan, J. D., Steinbrecher, R., Jimenez, J. L., De Carlo, P. F., Dunlea, E. J., and Baumgardner, D.: Characterization of organic ambient aerosol during MIRAGE 2006 on three platforms, Atmos. Chem. Phys., 9, 5417-5432, doi:10.5194/acp-9-5417-2009, 2009.

Greenberg, J. P., Guenther, A. B., and Turnipseed, A.: Tethered balloon-based soundings of ozone, aerosols, and solar radiation near Mexico City during MIRAGE-MEX, Atmos. Environ., 16, 2672-2677, doi:10.1016/j.atmosenv.2009.02.019, 2009.

Grieshop, A. P., Logue, J. M., Donahue, N. M., and Robinson, A. L.: Laboratory investigation of photochemical oxidation of organic aerosol from wood fires 1: measurement and simulation of organic aerosol evolution, Atmos. Chem. Phys., 9, 1263-1277, doi:10.5194/acp-9-1263-2009, 2009.

Grutter, M., Basaldud, R., Rivera, C., Harig, R., Junkerman, W., Caetano, E., and Delgado-Granados, $\mathrm{H} .: \mathrm{SO}_{2}$ emissions from Popocatépetl volcano: emission rates and plume imaging using optical remote sensing techniques, Atmos. Chem. Phys., 8, 6655-6663, doi:10.5194/acp-8-6655-2008, 2008.

Gurjar, B. R., Butler, T. M., Lawrence, M. G., and Lelieveld, J.: Evaluation of emissions and air quality in megacities, Atmos. Environ., 42, 1593-1606, 2008.

Hair, J. W., Hostetler, C. A., Cook, A. L., Harper, D. B., Ferrare, R. A., Mack, T. L., Welch, W., Isquierdo, L. R., and Hovis, F. E.: Airborne high spectral resolution Lidar for profiling aerosol optical properties, Appl. Opt., 47, 6734-6752, 2008.

Hallquist, M., Wenger, J. C., Baltensperger, U., Rudich, Y., Simpson, D., Claeys, M., Dommen, J., Donahue, N. M., George, C., Goldstein, A. H., Hamilton, J. F., Herrmann, H., Hoffmann, T., Iinuma, Y., Jang, M., Jenkin, M. E., Jimenez, J. L., Kiendler-Scharr, A., Maenhaut, W., McFiggans, G., Mentel, Th. F., Monod, A., Prévôt, A. S. H., Seinfeld, J. H., Surratt, J. D., Szmigielski, R., and Wildt, J.: The formation, properties and impact of secondary organic aerosol: current and emerging issues, Atmos. Chem. Phys., 9, 5155-5236, doi:10.5194/acp-95155-2009, 2009.

Harley, R. A., Marr, L. C., Lehner, J. K., and Giddings, S. N.: Changes in motor vehicle emissions on diurnal to decadal time scales and effects on atmospheric composition, Environ. Sci. Technol., 39, 5356-5362, 2005.

Hashizume, M., Ueda, K., Nishiwaki, Y., Michikawa, T., and Onozuka, D.: Health effects of Asian dust events: a review of the literature, Nippon Eiseigaku Zasshi, 65, 13-421, 2010.

Heald, C. L., Goldstein, A. H., Allan, J. D., Aiken, A. C., Apel, E., Atlas, E. L., Baker, A. K., Bates, T. S., Beyersdorf, A. J., Blake,
D. R., Campos, T., Coe, H., Crounse, J. D., DeCarlo, P. F., de Gouw, J. A., Dunlea, E. J., Flocke, F. M., Fried, A., Goldan, P., Griffin, R. J., Herndon, S. C., Holloway, J. S., Holzinger, R., Jimenez, J. L., Junkermann, W., Kuster, W. C., Lewis, A. C., Meinardi, S., Millet, D. B., Onasch, T., Polidori, A., Quinn, P. K., Riemer, D. D., Roberts, J. M., Salcedo, D., Sive, B., Swanson, A. L., Talbot, R., Warneke, C., Weber, R. J., Weibring, P., Wennberg, P. O., Worsnop, D. R., Wittig, A. E., Zhang, R., Zheng, J., and Zheng, W.: Total observed organic carbon (TOOC) in the atmosphere: a synthesis of North American observations, Atmos. Chem. Phys., 8, 2007-2025, doi:10.5194/acp-82007-2008, 2008.

Heald, C. L., Kroll, J. H., Jimenez, J. L., Docherty, K. S., DeCarlo, P. F., Aiken, A. C., Chen, Q., Martin, S. T., Farmer, D. K., and Artaxo, P.: A simplified description of organic aerosol composition and implications for atmospheric aging, Geophys. Res. Lett., 37, L08803, doi:10.1029/2010GL042737, 2010.

Hennigan, C. J., Sullivan, A. P., Fountoukis, C. I., Nenes, A., Hecobian, A., Vargas, O., Peltier, R. E., Case Hanks, A. T., Huey, L. G., Lefer, B. L., Russell, A. G., and Weber, R. J.: On the volatility and production mechanisms of newly formed nitrate and water soluble organic aerosol in Mexico City, Atmos. Chem. Phys., 8, 3761-3768, doi:10.5194/acp-8-3761-2008, 2008.

Herndon, S. C., Onasch, T. B., Wood, E. C., Kroll, J. H., Canagaratna, M. R., Jayne, J. T., Zavala, M. A., Knighton, W. B., Mazzoleni, C., Dubey, M.K., Ulbrich, I. M., Jimenez, J.L., Seila, R. de Gouw, J. A., de Foy, B., Fast, J., Molina, L. T., Kolb, C. E., and Worsnop, D. R.: The correlation of secondary organic aerosol with odd oxygen in a megacity outflow, Geophys. Res. Lett., 35, L15804, doi:10.1029/2008GL034058, 2008.

Hildemann, L. M., Klinedinst, D. B., Klouda, G. A., Currie, L. A., and Cass, G. R.: Sources of Urban Contemporary Carbon Aerosol, Environ. Sci. Technol., 28, 1565-1576, 1994.

Ho, S. S. H., Yu, J. Z., Chu, K. W. and Yeung, L. L.: Carbonyl Emissions from Commercial Cooking Sources in Hong Kong, J. Air Waste Manage. Assoc., 56, 1091-1098, 2006.

Hodzic, A., Jimenez, J. L., Madronich, S., Aiken, A. C., Bessagnet, B., Curci, G., Fast, J., Lamarque, J.-F., Onasch, T. B., Roux, G., Schauer, J. J., Stone, E. A., and Ulbrich, I. M.: Modeling organic aerosols during MILAGRO: importance of biogenic secondary organic aerosols, Atmos. Chem. Phys., 9, 6949-6981, doi:10.5194/acp-9-6949-2009, 2009.

Hodzic, A., Jimenez, J. L., Madronich, S., Canagaratna, M. R., DeCarlo, P. F., Kleinman, L., and Fast, J.: Modeling organic aerosols in a megacity: potential contribution of semi-volatile and intermediate volatility primary organic compounds to secondary organic aerosol formation, Atmos. Chem. Phys., 10, 5491-5514, doi:10.5194/acp-10-5491-2010, 2010a.

Hodzic, A., Jimenez, J. L., Prvt, A. S. H., Szidat, S., Fast, J. D., and Madronich, S.: Can 3-D models explain the observed fractions of fossil and non-fossil carbon in and near Mexico City?, Atmos. Chem. Phys. Discuss., 10, 14513-14556, doi:10.5194/acpd-1014513-2010, 2010 b.

Hofzumahaus, A., Rohrer, F., Lu, K., Bohn, B., Brauers, T., Chang, C., Fuchs, H., Holland, F., Kita, K., Kondo, Y., Li, X., Lou, S., Shao, M., Zeng, L., Wahner, A. and Zhang, Y.: Amplified Trace Gas Removal in the Troposphere, Science, 324, 1702 1704, 2009.

Hopke, P. K., Cohen, D. D., Begum, B. A., Biswas, S. K., Ni, B., 
Pandit, G. G., Santoso, M., Chung, Y.-S., Davy, P., Markwitz, A., Waheed, S., Siddique, N., Santos, F. L., Pabroa, P. C. B., Seneviratne, M. C. S., Wimolwattanapun, W., Bunprapob, S., Vuong, T. B. , Hien, P. D., and Markowicz, A.: Urban air quality in the Asian region, Sci. Total Environ., 404, 103-112, 2008.

Huffman, J. A., Ziemann, P. J., Jayne, J. T., Worsnop, D. R., and Jimenez., J. L.: Development and Characterization of a Fast-Stepping/Scanning Thermodenuder for ChemicallyResolved Aerosol Volatility Measurements, Aerosol Sci. Technol., 42, 395-407, 2008.

Huffman, J. A, Docherty, K. S., Mohr, C., Cubison, M. J., U1brich, I. M., Ziemann, P. J., Onasch, T. B., and Jimenez, J. L: Chemically-Resolved Volatility Measurements of Organic Aerosol from Different Sources, Environ. Sci. Technol., 43, 5351-5357, doi:10.1021/es803539d, 2009a.

Huffman, J. A., Docherty, K. S., Aiken, A. C., Cubison, M. J., U1brich, I. M., DeCarlo, P. F., Sueper, D., Jayne, J. T., Worsnop, D. R., Ziemann, P. J., and Jimenez, J. L.: Chemically-resolved aerosol volatility measurements from two megacity field studies, Atmos. Chem. Phys., 9, 7161-7182, doi:10.5194/acp-9-71612009, 2009b.

IMP (Instituto Mexicano el Petróleo), Investigación sobre materia particulada y deterioro atmosférico, Subdirección de Protección Ambiental, 1994-1998, 1998.

IPCC, Fourth Assessment Report: Climate Change 2007. Intergovernmental Panel on Climate Change, 4 volumes, http://www.ipcc.ch/publications_and_data/ publications_and_data_reports.htm \#1, last access: $15 \mathrm{Au}-$ gust 2010.

Iida, K., Stolzenburg, M. R., McMurry, P. H., and Smith, J. N.: Estimating nanoparticle growth rates from sizedependent charged fractions - Analysis of new particle formation events in Mexico City, J. Geophys. Res., 113, D05207, doi:10.1029/2007JD009260, 2008.

Jáuregui ,E.: El Clima de la Ciudad de México, Publisher Instituto de Geografia - UNAM, 129 pp., ISBN: 968-856-819-8 (in Spanish), 2000

Jimenez, J. L., Canagaratna, M. R., Donahue, N. M., et al.: Evolution of Organic Aerosols in the Atmosphere, Science, 326, 15251529, doi:10.1126/science.1180353, 2009.

Jobson, B. T., Volkamer, R. A., Velasco, E., Allwine, G., Westberg, H., Lamb, B. K., Alexander, M. L., Berkowitz, C. M., and Molina, L. T.: Comparison of aromatic hydrocarbon measurements made by PTR-MS, DOAS and GC-FID during the MCMA 2003 Field Experiment, Atmos. Chem. Phys., 10, 1989-2005, doi:10.5194/acp-10-1989-2010, 2010.

Johansson, M., Rivera, C., de Foy, B., Lei, W., Song, J., Zhang, Y., Galle, B., and Molina, L.: Mobile mini-DOAS measurement of the outflow of $\mathrm{NO}_{2}$ and $\mathrm{HCHO}$ from Mexico City, Atmos. Chem. Phys., 9, 5647-5653, doi:10.5194/acp-9-5647-2009, 2009.

Johnson, K. S., Zuberi, B., Molina, L. T., Molina, M. J., Iedema, M. J., Cowin, J. P., Gaspar, D. J., Wang, C., and Laskin, A.: Processing of soot in an urban environment: case study from the Mexico City Metropolitan Area, Atmos. Chem. Phys., 5, 30333043, doi:10.5194/acp-5-3033-2005, 2005.

Johnson, K. S., de Foy, B., Zuberi, B., Molina, L. T., Molina, M. J., Xie, Y., Laskin, A., and Shutthanandan, V.: Aerosol composition and source apportionment in the Mexico City Metropoli$\tan$ Area with PIXE/PESA/STIM and multivariate analysis, At- mos. Chem. Phys., 6, 4591-4600, doi:10.5194/acp-6-4591-2006, 2006.

Johnson, K. S., Laskin, A., Jimenez, J. L., Shutthanandan, V., Molina, L. T., Salcedo, D., Dzepina, K., and Molina, M. J.: Comparative Analysis of Urban Atmospheric Aerosol by ParticleInduced X-ray Emission (PIXE), Proton Elastic Scattering Analysis (PESA), and Aerosol Mass Spectrometry (AMS), Environ. Sci. Technol, 42, 6619-6624, doi:10.1021/es800393e, 2008.

Junkermann, W. and Burger, J. M.: A new portable instrument for continuous measurement of formaldehyde in ambient air, J, Atmos, Ocean, Tech, 23, 38-45, 2006.

Karl, T., Apel, E., Hodzic, A., Riemer, D. D., Blake, D. R., and Wiedinmyer, C.: Emissions of volatile organic compounds inferred from airborne flux measurements over a megacity, Atmos. Chem. Phys., 9, 271-285, doi:10.5194/acp-9-271-2009, 2009.

Karydis, V. A., Tsimpidi, A. P., Fountoukis, C., Nenes, A., Zavala, M., Lei, W., Molina, L. T. and Pandis, S.: Simulating the fine and coarse inorganic particulate matter concentrations in a polluted Megacity, Atmos. Environ., 44, 608-620, 2010.

Kleinman, L. I., Daum, P. H., Lee, Y. N., Nunnermacker, L. J., Springston, S. R., Weinstein-Lloyd, J., and Rudolph, J.: A comparative study of ozone production in five US metropolitan areas, J. Geophys. Res.-Atmos., 110, D02301, doi:10.1029/2004JD005096, 2005.

Kleinman, L. I., Springston, S. R., Daum, P. H., Lee, Y.-N., Nunnermacker, L. J., Senum, G. I., Wang, J., Weinstein-Lloyd, J., Alexander, M. L., Hubbe, J., Ortega, J., Canagaratna, M. R., and Jayne, J.: The time evolution of aerosol composition over the Mexico City plateau, Atmos. Chem. Phys., 8, 1559-1575, doi:10.5194/acp-8-1559-2008, 2008.

Kleinman, L. I., Springston, S. R., Wang, J., Daum, P. H., Lee, Y.-N., Nunnermacker, L. J., Senum, G. I., Weinstein-Lloyd, J., Alexander, M. L., Hubbe, J., Ortega, J., Zaveri, R. A., Canagaratna, M. R., and Jayne, J.: The time evolution of aerosol size distribution over the Mexico City plateau, Atmos. Chem. Phys., 9, 4261-4278, doi:10.5194/acp-9-4261-2009, 2009.

Khlystov, A., Zhang, Q., Jimenez, J. L., Stanier, C., Pandis, S. N., Canagaratna, M. R., Fine, P., Misra, C., and Sioutas. C.: In-situ concentration of semi-volatile aerosol using watercondensation technology, Journal of Aerosol Science, 36, 866880, doi:10.1016/j.jaerosci.2004.11.005, 2005.

Kondo, Y., Miyazaki, Y., Takegawa, N., Miyakawa, T., Weber, R. J., Jimenez, J. L., Zhang, Q., and Worsnop, D. R.: Oxygenated and water-soluble organic aerosols in Tokyo, J. Geophys. Res., 112, D01203, doi:10.1029/2006JD007056, 2007.

LANL/IMP (Los Alamos National Laboratory and Instituto Mexicano del Petróleo). Mexico City Air Quality Research Initiative. Los Alamos, NM, 1994.

Lawrence, M. G., Butler, T. M., Steinkamp, J., Gurjar, B. R., and Lelieveld, J.: Regional pollution potentials of megacities and other major population centers, Atmos. Chem. Phys., 7, 39693987, doi:10.5194/acp-7-3969-2007, 2007.

Lei, W., de Foy, B., Zavala, M., Volkamer, R., and Molina, L. T.: Characterizing ozone production in the Mexico City Metropolitan Area: a case study using a chemical transport model, Atmos. Chem. Phys., 7, 1347-1366, doi:10.5194/acp-7-1347-2007, 2007.

Lei, W., Zavala, M., de Foy, B., Volkamer, R., and Molina, L. T.: Characterizing ozone production and response under different 
meteorological conditions in Mexico City, Atmos. Chem. Phys., 8, 7571-7581, doi:10.5194/acp-8-7571-2008, 2008.

Lei, W., Zavala, M., de Foy, B., Volkamer, R., Molina, M. J., and Molina, L. T.: Impact of primary formaldehyde on air pollution in the Mexico City Metropolitan Area, Atmos. Chem. Phys., 9, 2607-2618, doi:10.5194/acp-9-2607-2009, 2009.

Lewandowski, P. A., Eichinger, W. E., Holder, H., Prueger, J., Wang, J., and Kleinman, L. I.: Vertical distribution of aerosols in the vicinity of Mexico City during MILAGRO-2006 Campaign, Atmos. Chem. Phys., 10, 1017-1030, doi:10.5194/acp-10-10172010, 2010.

Lezama, J. L., Favela, R., Galindo, L. M., Ibarrarán, M. E., Sánchez, S., Molina, L. T., Molina, M. J., Connors, S. R., and Fernandez Bremauntz, F.: Forces driving pollutant emissions in the MCMA, in: "Air Quality in the Mexico Megacity: an Integrated Assessment", edited by: Molina, L. T. and Molina, M. J., Kluwer Academic Publishers, 61-104, 2002.

Li, G., Lei, W., Zavala, M., Volkamer, R., Dusanter, S., Stevens, P., and Molina, L. T.: Impacts of HONO sources on the photochemistry in Mexico City during the MCMA-2006/MILAGO Campaign, Atmos. Chem. Phys., 10, 6551-6567, doi:10.5194/acp10-6551-2010, 2010.

Lippmann, M.: Semi-continuous speciation analyses for ambient air particulate matter: An urgent need for health effects studies, J. Expo. Sci Environ. Epidemiol., 19, 235-247, 2009.

Lippmann M., Ito, K., Hwang, J. S., Maciejczyk, P., and Chen, L. C.: Cardiovascular effects of nickel in ambient air, Environ. Health Perspect., 114, 1662-1669, 2006.

Liu, S., Takahama, S., Russell, L. M., Gilardoni, S., and Baumgardner, D.: Oxygenated organic functional groups and their sources in single and submicron organic particles in MILAGRO 2006 campaign, Atmos. Chem. Phys., 9, 6849-6863, doi:10.5194/acp9-6849-2009, 2009.

Livingston, J. M., Redemann, J., Russell, P. B., Torres, O., Veihelmann, B., Veefkind, P., Braak, R., Smirnov, A., Remer, L., Bergstrom, R. W., Coddington, O., Schmidt, K. S., Pilewskie, P., Johnson, R., and Zhang, Q.: Comparison of aerosol optical depths from the Ozone Monitoring Instrument (OMI) on Aura with results from airborne sunphotometry, other space and ground measurements during MILAGRO/INTEX-B, Atmos. Chem. Phys., 9, 6743-6765, doi:10.5194/acp-9-6743-2009, 2009.

Mao, J., Ren, X., Chen, S., Brune, W. H., Chen, Z., Martinez, M., Harder, H., Lefer, B., Rappengluck, B., Flynn, J., and Leuchner, M.: Atmospheric oxidation capacity in the summer of Houston 2006: comparison with summer measurements in other metropolitan studies, Atmos. Environ., doi:10.1016/j.atmosenv.2009.01.013, in press, 2009.

Marley, N. A., Gaffney, J. S., and Cunningham, M. M.: Aqueous Greenhouse Species in Clouds, Fogs, and Aerosols. Environ. Sci. Technol., 27, 2864-2869, 1993.

Marley, N. A., Gaffney, J. S., and Orlandini, K. A.: Characterization of Aquatic Humic and Fulvic Materials by Cylindrical Internal Reflectance Infrared Spectroscopy. Chapter 7, Humic/Fulvic Acids and Organic Colloidal Materials in the Environment, ACS Symposium Series 651, American Chemical Society, Washington, D.C., 96-107, 1996.

Marley, N. A., Gaffney, J. S., Ramos-Villegas, R., and Cárdenas González, B.: Comparison of measurements of peroxyacyl ni- trates and primary carbonaceous aerosol concentrations in Mexico City determined in 1997 and 2003, Atmos. Chem. Phys., 7, 2277-2285, doi:10.5194/acp-7-2277-2007, 2007.

Marley, N. A., Gaffney, J. S., Ramos-Villegas, R., and Cárdenas González, B.: Comparison of measurements of peroxyacyl nitrates and primary carbonaceous aerosol concentrations in Mexico City determined in 1997 and 2003, Atmos. Chem. Phys., 7, 2277-2285, doi:10.5194/acp-7-2277-2007, 2007.

Marley, N. A., Gaffney, J. S., Tackett, M., Sturchio, N. C., Heraty, L., Martinez, N., Hardy, K. D., Marchany-Rivera, A., Guilderson, T., MacMillan, A., and Steelman, K.: The impact of biogenic carbon sources on aerosol absorption in Mexico City, Atmos. Chem. Phys., 9, 1537-1549, doi:10.5194/acp-9-1537-2009, 2009a.

Marley, N. A., Gaffney, J. S., Castro, T., Salcido, A., and Frederick, J.: Measurements of aerosol absorption and scattering in the Mexico City Metropolitan Area during the MILAGRO field campaign: a comparison of results from the T0 and T1 sites, Atmos. Chem. Phys., 9, 189-206, doi:10.5194/acp-9-189-2009, 2009b.

Marr, L. C., Dzepina, K., Jimenez, J. L., Reisen, F., Bethel, H. L., Arey, J., Gaffney, J. S., Marley, N. A., Molina, L. T., and Molina, M. J.: Sources and transformations of particle-bound polycyclic aromatic hydrocarbons in Mexico City, Atmos. Chem. Phys., 6, 1733-1745, doi:10.5194/acp-6-1733-2006, 2006.

Mauderly, J. L. and Samet, J. M.: Is there evidence for synergy among air pollutants in causing health effects?, Environ. Health Perspect, 117, 1-6, 2009.

McNaughton, C. S., Clarke, A. D., Kapustin, V., Shinozuka, Y., Howell, S. G., Anderson, B. E., Winstead, E., Dibb, J., Scheuer, E., Cohen, R. C., Wooldridge, P., Perring, A., Huey, L. G., Kim, S., Jimenez, J. L., Dunlea, E. J., DeCarlo, P. F., Wennberg, P. O., Crounse, J. D., Weinheimer, A. J., and Flocke, F.: Observations of heterogeneous reactions between Asian pollution and mineral dust over the Eastern North Pacific during INTEX-B, Atmos. Chem. Phys., 9, 8283-8308, doi:10.5194/acp-9-8283-2009, 2009.

Melamed, M. L., Basaldud, R., Steinbrecher, R., Emeis, S., RuzSurez, L. G., and Grutter, M.: Detection of pollution transport events southeast of Mexico City using ground-based visible spectroscopy measurements of nitrogen dioxide, Atmos. Chem. Phys., 9, 4827-4840, doi:10.5194/acp-9-4827-2009, 2009.

Mena-Carrasco, M., Carmichael, G. R., Campbell, J. E., Zimmerman, D., Tang, Y., Adhikary, B., D'allura, A., Molina, L. T., Zavala, M., García, A., Flocke, F., Campos, T., Weinheimer, A. J., Shetter, R., Apel, E., Montzka, D. D., Knapp, D. J., and Zheng, W.: Assessing the regional impacts of Mexico City emissions on air quality and chemistry, Atmos. Chem. Phys., 9, 37313743, doi:10.5194/acp-9-3731-2009, 2009.

Moffet, R. C., de Foy, B., Molina, L. T., Molina, M. J., and Prather, K. A.: Measurement of ambient aerosols in northern Mexico City by single particle mass spectrometry, Atmos. Chem. Phys., 8, 4499-4516, doi:10.5194/acp-8-4499-2008, 2008a.

Moffet, R., Desyaterik, Y., Hopkins, R. J., Tavanski, A. V., Gilles, M. K., Wang, Y., Shutthanandan, V., Molina, L. T., Gonzalez, R., Johnson, K. S., Mugica, V., Molina, M. J., Laskin, A., Prather, K. A., Characterization of Aerosols Containing $\mathrm{Zn}, \mathrm{Pb}$, and $\mathrm{Cl}$ from an Industrial Region of Mexico City, Environ. Sci. Technol., 42, 7091-7097, 2008b.

Moffet, R. C. and Prather, K. A.: In-situ measurements of the mix- 
ing state and optical properties of soot with implications for radiative forcing estimates, P. Natl. Acad. Sci. USA, 106, 11872$11877,2009$.

Moffet, R. C., Henn, T. R., Tivanski, A. V., Hopkins, R. J., Desyaterik, Y., Kilcoyne, A. L. D., Tyliszczak, T., Fast, J., Barnard, J., Shutthanandan, V., Cliff, S. S., Perry, K. D., Laskin, A., and Gilles, M. K.: Microscopic characterization of carbonaceous aerosol particle aging in the outflow from Mexico City, Atmos. Chem. Phys., 10, 961-976, doi:10.5194/acp-10-961-2010, 2010.

Mohr, C., Huffman, J. A., Cubison, M. J., Aiken, A. C., Docherty, K. S., Kimmel, J. R., Ulbrich, I. M., Hannigan, M., Garcia, J., and Jimenez, J. L.: Characterization of Primary Organic Aerosol Emissions from Meat Cooking, Trash Burning, and Motor Vehicles with High-Resolution Aerosol Mass Spectrometry and Comparison with Ambient and Chamber Observations, Environ. Sci. Technol., 43, 2443-2449, doi:10.1021/es8011518, 2009.

Molina, L. T. and Molina, M. J.: Air Quality in the Mexico Megacity: An Integrated Assessment, Kluwer Academic Publishers: Dordrecht, The Netherlands, 384 pp., 2002.

Molina L. T., Molina, M. J., Favela, R., Fernandez Bremauntz, F., Slott, R., and Zavala, M. A., Cleaning the Air: A Comparative Study, in: "Air Quality in the Mexico Megacity: An Integrated Assessment", edited by: Molina, L. T. and Molina, M. J., Kluwer Academic Publishers, 21-59, 2002.

Molina, L. T., Molina, M. J., Slott, R., Kolb, C. E., Gbor, P. K., Meng, F., Singh, R., Galvez, O., Sloan, J. J., Anderson, W., Tang, X. Y., Shao, M., Zhu, T., Zhang, Y. H., Hu, M., Gurjar, B. R., Artaxo, P., Oyola, P., Gramsch, E., Hidalgo, P., and Gertler A.: 2004 Critical Review Supplement: Air Quality in Selected Megacities, J. Air Waste Manage. Assoc, http://www.awma.org, 2004.

Molina, L. T., Kolb, C. E., de Foy, B., Lamb, B. K., Brune, W. H., Jimenez, J. L., Ramos-Villegas, R., Sarmiento, J., ParamoFigueroa, V. H., Cardenas, B., Gutierrez-Avedoy, V., and Molina, M. J.: Air quality in North America's most populous city overview of the MCMA-2003 campaign, Atmos. Chem. Phys., 7, 2447-2473, doi:10.5194/acp-7-2447-2007, 2007.

Molina, M. J. and Molina, L. T.: 2004 Critical Review: Megacities and atmospheric pollution, J. Air Waste Manage. Assoc., 54(6), 644-680, 2004.

Moreno ,T., Querol, X., Alastuey, A.: Lanthanoid geochemistry of urban atmospheric particulate matter, Environ. Sci. Technol., 42, 6502-6507, 2008a.

Moreno T., Querol X., Pey J., Pey, J., Minguillon, M. C., Perez, N., Bernabe, R. M., Blanco, S., Cerdenas, B., Eichinger, W., Salcido, A., and Gibbons, W.: Spatial and temporal variations in inhalable $\mathrm{CuZnPb}$ aerosols within the Mexico City pollution plume, J. Environ. Monitoring, 10, 370-378, 2008b.

Moya, M., Castro, T., Zepeda, M., and Baez, A.: Characterization of size-differentiated inorganic composition of aerosols in Mexico City, Atmos. Environ., 37, 3581-3591, 2003.

Mugica, V., Vega, E., Arriaga, J. L., Ruiz, M. E.: Determination of motor vehicle profiles for non-methane organic compounds in the Mexico City Metropolitan Area, J. Air Waste Manage. Assoc., 48, 1060-1068, 1998.

Mugica, V., Vega, E., Chow, J., Reyes, E., Sánchez, G., Arriaga, J., Egami, R. and Watson, J. (), Speciated non-methane organic compounds emissions from food cooking in Mexico, Atmos. Eviron, 35, 1729-1734, 2001.

Mugica, V., Ruiz, M. E., Watson, J., and Chow, J.: Volatile aro- matic compounds in Mexico City atmosphere: levels and source apportionment, Atmosfera, 16, 15-27, 2003.

Mugica V., Ortiz, E., Molina L., De Vizcaya-Ruiz A., Nebot A., Quintana R., Aguilar J., and Alcantara, E.: PM Composition and Source Reconciliation in Mexico City, Atmos. Environ. 43, 5068-5074, 2009.

NARSTO, (North American Research Strategy for Tropospheric Ozone): Improving emissions inventories for effective air quality management across North America, a NARSTO assessment, NARSTO-05-001, 2005.

Nemitz, E., Jimenez, J. L., Huffman, J. A., Canagaratna, M. R., Worsnop, D. R., and Guenther, A. B.: An eddy-covariance system for the measurement of surface/atmosphere exchange fluxes of submicron aerosol chemical species - first application above an urban area, Aerosol Sci. Technol., 42, 636-657, 2008.

Ng, N. L., Canagaratna, M. R., Zhang, Q., Jimenez, J. L., Tian, J., Ulbrich, I. M., Kroll, J. H., Docherty, K. S., Chhabra, P. S., Bahreini, R., Murphy, S. M., Seinfeld, J. H., Hildebrandt, L., Donahue, N. M., DeCarlo, P. F., Lanz, V. A., Prévôt, A. S. H., Dinar, E., Rudich, Y., and Worsnop, D. R.: Organic aerosol components observed in Northern Hemispheric datasets from Aerosol Mass Spectrometry, Atmos. Chem. Phys., 10, 46254641, doi:10.5194/acp-10-4625-2010, 2010.

Nunnermacker, L. J., Weinstein-Lloyd, J. B., Hillery, B., Giebel, B., Kleinman, L. I., Springston, S. R., Daum, P. H., Gaffney, J., Marley, N., and Huey, G.: Aircraft and ground-based measurements of hydroperoxides during the 2006 MILAGRO field campaign, Atmos. Chem. Phys., 8, 7619-7636, doi:10.5194/acp8-7619-2008, 2008.

O’Neill, M. S., Bell, M. L., Ranjit, N., Cifuentes, L. A., Loomis, D., Gouveia, N. and Borja-Aburto V. H.: Air pollution and mortality in Latin America: The role of education, Epidemiology, 19, 810819, 2008.

Oberdorster, G., Oberdorster, E., and Oberdorster, J.: Nanotoxicology: An emerging discipline evolving from studies of ultrafine particles, Environ. Health Persp., 113, 823-839, 2005.

Osornio-Vargas, A. R., Bonner, J. C., Alfaro-Moreno, E., Martínez L., García-Cuellar C., Ponce-de-León Rosales S., Miranda J., and Rosas, I.: Proinflammatory and cytotoxic effects of Mexico City air pollution particulate matter in vitro are dependent on particle size and composition, Environ. Health Perspect., 111, 1289-1293, 2003.

Osornio-Vargas, A. R, Quintana, R., Gómez, V., Serrano, J., Vázquez, I., Flores, G., Miranda, J., Vega, E., Ruiz, H., Escalona, S., de Foy, B., De Vizcaya-Ruiz, A., Garcia, C., Rosas, I., and Molina, L. T.: Oxidative potential and cellular effects induced by $\mathrm{PM}_{10}$ obtained in Mexico City and at a receptor site (2077). The Toxicologist CD, 102(S1), 427, 2008.

Padró, L. T., Tkacik, D., Lathem, T., Hennigan, C. J., Sullivan, A. P., Weber, R. J., Huey, L. G., and Nenes, A.: Investigation of CCN properties and droplet growth kinetics of water-soluble aerosol fraction in Mexico City, J. Geophys. Res., 115, D09204, doi:10.1029/2009JD013195, 2010.

Paredes-Miranda, G., Arnott, W. P., Jimenez, J. L., Aiken, A. C., Gaffney, J. S., and Marley, N. A.: Primary and secondary contributions to aerosol light scattering and absorption in Mexico City during the MILAGRO 2006 campaign, Atmos. Chem. Phys., 9, 3721-3730, doi:10.5194/acp-9-3721-2009, 2009.

Parrish D. D., Kuster W. C., Shao M., Yokouchi Y., Kondo Y., 
Goldan P. D., deGouw J. A., Koike M., and Shirai T., Comparison of air pollutant emissions among mega-cities, Atmos. Environ., 43, 6435-6441, 2009a.

Parrish, D. D., Allen, D. T., Bates, T. S., Estes, M., Fehsenfeld, F. C., Feingold, G., Ferrare, R., Hardesty, R. M., Meagher, J. F., Nielsen-Gammon, J. W., Pierce, R. B., Ryerson, T. B., Seinfeld, J. H., and Williams, E. J. : Overview of the Second Texas Air Quality Study (TexAQS II) and the Gulf of Mexico Atmospheric Composition and Climate Study (GoMACCS), J. Geophys. Res., 114, D00F13, doi:10.1029/2009JD011842, 2009 b.

Peng, R. D., Dominici, F., Pastor-Barriuso, R., Zeger, S. L., and Samet, J. M.: Seasonal analyses of air pollution and mortality in 100 US cities, Am. J. Epidemiol., 161, 585-594, doi:10.1093/aje/kwi075, 2005.

Perring, A. E., Bertram, T. H., Farmer, D. K., Wooldridge, P. J., Dibb, J., Blake, N. J., Blake, D. R., Singh, H. B., Fuelberg, H., Diskin, G., Sachse, G., and Cohen, R. C.: The production and persistence of $\sum \mathrm{RONO}_{2}$ in the Mexico City plume, Atmos. Chem. Phys., 10, 7215-7229, doi:10.5194/acp-10-7215-2010, 2010.

Pope, C. A. and Dockery, D. W.: Health effects of fine particulate air pollution: lines that connect, Journal of Air and Waste Management Assoc., 56, 709-742, 2006.

Querol, X., Pey, J., Minguillón, M. C., Pérez, N., Alastuey, A., Viana, M., Moreno, T., Bernabé, R. M., Blanco, S., Cárdenas, B., Vega, E., Sosa, G., Escalona, S., Ruiz, H., and Artínano, B.: PM speciation and sources in Mexico during the MILAGRO-2006 Campaign, Atmos. Chem. Phys., 8, 111-128, doi:10.5194/acp8-111-2008, 2008.

Ramanathan, V., Crutzen, P. J., Kiehl, J. T., and Rosenfeld, D.: Aerosols, Climate, and the Hydrological Cycle, Science, 294, 2119-2124, 2001.

Ramanathan, V., Ramana, M. V., Roberts, G., Kim, D., Corrigan, C., Chung, C., and Winker, D.: Warming trends in Asia amplified by brown cloud solar absorption, Nature, 448, 575-578, 2007.

Redemann, J., Zhang, Q., Livingston, J., Russell, P., Shinozuka, Y., Clarke, A., Johnson, R., and Levy, R.: Testing aerosol properties in MODIS Collection 4 and 5 using airborne sunphotometer observations in INTEX-B/MILAGRO, Atmos. Chem. Phys., 9, 8159-8172, doi:10.5194/acp-9-8159-2009, 2009.

Reff, A., Bhave, P. V., Simon, H., Pace, T. G., Pouliot, G. A., Mobley, J. D., and Houyoux, M.: Emissions Inventory of $\mathrm{PM}_{2.5}$ Trace Elements across the United States, Environ. Sci. Technol., 43, 5790-5796, 2009.

Rivera, C., Sosa, G., Wöhrnschimmel, H., de Foy, B., Johansson, M., and Galle, B.: Tula industrial complex (Mexico) emissions of $\mathrm{SO}_{2}$ and $\mathrm{NO}_{2}$ during the MCMA 2006 field campaign using a mobile mini-DOAS system, Atmos. Chem. Phys., 9, 6351-6361, doi:10.5194/acp-9-6351-2009, 2009.

Robinson, A. L., Donahue, N. M., Shrivastava, M. K., Weitkamp, E. A., Sage, A. M., Grieshop, A. P., Lane, T. E., Pandis, S. N., Pierce, J. R.: Rethinking organic aerosols: Semivolatile emissions and photochemical aging, Science, 315, 1259-1262, 2007.

Rogers, R. R., Hair, J. W., Hostetler, C. A., Ferrare, R. A., Obland, M. D., Cook, A. L., Harper, D. B., Burton, S. P., Shinozuka, Y., McNaughton, C. S., Clarke, A. D., Redemann, J., Russell, P. B., Livingston, J. M., and Kleinman, L. I.: NASA LaRC airborne high spectral resolution lidar aerosol measurements during MILAGRO: observations and validation, Atmos. Chem. Phys., 9,
4811-4826, doi:10.5194/acp-9-4811-2009, 2009.

Romieu, I., Lugo, M. C., Velasco, S. R., Sanchez, S., Meneses, F., and Hernandez, M.: Air pollution and school absenteeism among children in Mexico City, Am. J. Epidemiol., 136, 1524-1531, 1992.

Romieu, I., Meneses, F., Ruiz, S., Sienra, J. J, Huerta, J., White, M. C., and Etzel, R. A.: Effects of air pollution on the respiratory health of asthmatic children living in Mexico City, Am. J. Resp. Crit. Care Med. 154, 300-307, 1996.

Romieu. I., Ramirez-Aguilar, M., Sienra-Monge, J. J., MorenoMacias, H., del Rio-Navarro, B. E., David, G., Marzec, J., Hernández-Avila, M., and London, S.: GSTM1 and GSTP1 and respiratory health in asthmatic children exposed to ozone, Eur. Respir. J., 28(5), 953-959, doi:10.1183/09031936.06.00114905, 2006.

Rosas-Perez, I., Serrano, J., Alfaro-Moreno, E., Baumgardner, D., García-Cuella, C., Miranda-Martin del Campo, J., Raga, G. B., Castillejos, M., Drucker-Colín, R., and Osornio-Vargas, A.: Relations between $\mathrm{PM}_{10}$ composition and cell toxicity: a multivariate and graphical approach, Chemosphere, 67, 1218-1228, 2007.

Russell, P. B., Bergstrom, R. W., Shinozuka, Y., Clarke, A. D., DeCarlo, P. F., Jimenez, J. L., Livingston, J. M., Redemann, J., Dubovik, O., and Strawa, A.: Absorption Angstrom Exponent in AERONET and related data as an indicator of aerosol composition, Atmos. Chem. Phys., 10, 1155-1169, doi:10.5194/acp10-1155-2010, 2010.

Rutter, A. P., Snyder, D. C., Stone, E. A., Schauer, J. J., GonzalezAbraham, R., Molina, L. T., Márquez, C., Cárdenas, B., and de Foy, B.: In situ measurements of speciated atmospheric mercury and the identification of source regions in the Mexico City Metropolitan Area, Atmos. Chem. Phys., 9, 207-220, doi:10.5194/acp-9-207-2009, 2009.

Salcedo, D., Onasch, T. B., Dzepina, K., Canagaratna, M. R., Zhang, Q., Huffman, J. A., DeCarlo, P. F., Jayne, J. T., Mortimer, P., Worsnop, D. R., Kolb, C. E., Johnson, K. S., Zuberi, B., Marr, L. C., Volkamer, R., Molina, L. T., Molina, M. J., Cardenas, B., Bernabé, R. M., Márquez, C., Gaffney, J. S., Marley, N. A., Laskin, A., Shutthanandan, V., Xie, Y., Brune, W., Lesher, R., Shirley, T., and Jimenez, J. L.: Characterization of ambient aerosols in Mexico City during the MCMA-2003 campaign with Aerosol Mass Spectrometry: results from the CENICA Supersite, Atmos. Chem. Phys., 6, 925-946, doi:10.5194/acp-6-9252006, 2006.

Salcedo, D., Onasch, T. B., Dzepina, K., Canagaratna, M. R., Zhang, Q., Huffman, J. A., DeCarlo, P. F., Jayne, J. T., Mortimer, P., Worsnop, D. R., Kolb, C. E., Johnson, K. S., Zuberi, B., Marr, L. C., Volkamer, R., Molina, L. T., Molina, M. J., Cardenas, B., Bernab, R. M., Márquez, C., Gaffney, J. S., Marley, N. A., Laskin, A., Shutthanandan, V., Xie, Y., Brune, W., Lesher, R., Shirley, T., and Jimenez, J. L.: Characterization of ambient aerosols in Mexico City during the MCMA-2003 campaign with Aerosol Mass Spectrometry: results from the CENICA Supersite, Atmos. Chem. Phys., 6, 925-946, doi:10.5194/acp-6-9252006, 2006.

Salcedo, D., Onasch, T. B., Aiken, A. C., Williams, L. R., de Foy, B., Cubison, M. J., Worsnop, D. R., Molina, L. T., and Jimenez, J. L.: Determination of particulate lead using aerosol mass spectrometry: MILAGRO/MCMA-2006 observations, Atmos. Chem. Phys., 10, 5371-5389, doi:10.5194/acp-10-5371- 
2010, 2010.

Samet, J. and Krewski, D.: Health effects associated with exposure to ambient air pollution, J. Toxicol. Environ. Health A, 70, $227-$ 242, 2007.

Samoli, E., Zanobetti, A., Schwartz, J., Atkinson, R., LeTertre, A., Schindler, C., Perez, L., Cadum, E., Pekkanen, J., Paldy, A., Touloumi, G., Katsouyanni, K.: The temporal pattern of mortality responses to ambient ozone in the APHEA project, J. Epidemiol Community Health, 63(12), 960-966, 2009.

San Martini, F. M., Dunlea, E. J., Volkamer, R., Onasch, T. B., Jayne, J. T., Canagaratna, M. R., Worsnop, D. R., Kolb, C. E., Shorter, J. H., Herndon, S. C., Zahniser, M. S., Salcedo, D., Dzepina, K., Jimenez, J. L., Ortega, J. M., Johnson, K. S., McRae, G. J., Molina, L. T., and Molina, M. J.: Implementation of a Markov Chain Monte Carlo method to inorganic aerosol modeling of observations from the MCMA-2003 campaign Part II: Model application to the CENICA, Pedregal and Santa Ana sites, Atmos. Chem. Phys., 6, 4889-4904, doi:10.5194/acp6-4889-2006, 2006.

San Martini, F. M., Dunlea, E. J., Volkamer, R., Onasch, T. B., Jayne, J. T., Canagaratna, M. R., Worsnop, D. R., Kolb, C. E., Shorter, J. H., Herndon, S. C., Zahniser, M. S., Salcedo, D., Dzepina, K., Jimenez, J. L., Ortega, J. M., Johnson, K. S., McRae, G. J., Molina, L. T., and Molina, M. J.: Implementation of a Markov Chain Monte Carlo method to inorganic aerosol modeling of observations from the MCMA-2003 campaign Part II: Model application to the CENICA, Pedregal and Santa Ana sites, Atmos. Chem. Phys., 6, 4889-4904, doi:10.5194/acp-64889-2006, 2006b.

Schauer, J. J.: Evaluation of elemental carbon as a marker for diesel particulate matter, J. Expos. Anal. Environ. Epidemiol, 13, 443453, 2003

Schauer, J. J., Rogge, W. F., HildemannL, M., Mazurek, M. A., Cass, G. R., and Simoneit, B. R. T.: Source Apportionment of Airborne Particulate Matter Using Organic Compounds as Tracers, Atmos. Environ., 30, 3837-3855, 1996.

Schifter, I., Diaz, L., Duran, J., Guzman, E., Chavez, O., and LopezSalinas, E.: Remote sensing study of emissions from motor vehicles in the Metropolitan Area of Mexico City, Environ. Sci. Technol., 37, 395-401, 2003.

Schifter, I., D $\imath$ az, L., Rodrıguez, R., Duran, J., and Chavez. O.: Trends in exhaust emissions from in-use Mexico City vehicles, 2000-2006. A remote sensing study, Environ. Monit. Assess., 137, 459-470, doi:10.1007/s10661-007-9781-4, 2008.

Schmid, B., Ferrare, R., Flynn, C., Elleman, R., Covert, D., Strawa, A., Welton, E., Turner, D.,Jonsson, H., Redemann, J., Eilers, J., Ricci, K., Hallar, A. G., Clayton, M., Michalsky, J.,Smirnov, A., Holben, B., and Barnard, J.: How well do state-of-theart techniques measur-ing the vertical profile of tropospheric aerosol extinction compare?, J. Geophys. Res., 111, D05S07, doi:10.1029/2005JD005837, 2006.

Schmidt, K. S., Pilewskie, P., Bergstrom, R., Coddington, O., Redemann, J., Livingston, J., Russell, P., Bierwirth, E., Wendisch, M., Gore, W., Dubey, M. K., and Mazzoleni, C.: A new method for deriving aerosol solar radiative forcing and its first application within MILAGRO/INTEX-B, Atmos. Chem. Phys. Discuss., 10, 2731-2767, doi:10.5194/acpd-10-2731-2010, 2010.

SEMARNAT: Inventario Nacional de Emisiones de Mexico, 1999, Instituto Nacional de Ecologia, available at: http://www.ine.gob.mx/dgicur/calaire/inem.html, 2006.

Shaw, W. J., Pekour, M. S., Coulter, R. L., Martin, T. J., and Walters, J. T.: The daytime mixing layer observed by radiosonde, profiler, and lidar during MILAGRO, Atmos. Chem. Phys. Discuss., 7, 15025-15065, doi:10.5194/acpd-7-15025-2007, 2007.

Sheehy, P. M., Volkamer, R., Molina, L. T., and Molina, M. J.: Oxidative capacity of the Mexico City atmosphere - Part 2: A $\mathrm{RO}_{\mathrm{x}}$ radical cycling perspective, Atmos. Chem. Phys., 10, 69937008, doi:10.5194/acp-10-6993-2010, 2010.

Shinozuka, Y., Clarke, A. D., DeCarlo, P. F., Jimenez, J. L., Dunlea, E. J., Roberts, G. C., Tomlinson, J. M., Collins, D. R., Howell, S. G., Kapustin, V. N., McNaughton, C. S., and Zhou, J.: Aerosol optical properties relevant to regional remote sensing of $\mathrm{CCN}$ activity and links to their organic mass fraction: airborne observations over Central Mexico and the US West Coast during MILAGRO/INTEX-B, Atmos. Chem. Phys., 9, 6727-6742, doi:10.5194/acp-9-6727-2009, 2009.

Shirley, T. R., Brune, W. H., Ren, X., Mao, J., Lesher, R., Cardenas, B., Volkamer, R., Molina, L. T., Molina, M. J., Lamb, B., Velasco, E., Jobson, T., and Alexander, M.: Atmospheric oxidation in the Mexico City Metropolitan Area (MCMA) during April 2003, Atmos. Chem. Phys., 6, 2753-2765, doi:10.5194/acp-62753-2006, 2006.

Shon, Z.-H., Madronich, S., Song, S.-K., Flocke, F. M., Knapp, D. J., Anderson, R. S., Shetter, R. E., Cantrell, C. A., Hall, S. R., and Tie, X.: Characteristics of the NO-NO2-O3 system in different chemical regimes during the MIRAGE-Mex field campaign, Atmos. Chem. Phys., 8, 7153-7164, doi:10.5194/acp-8-7153-2008, 2008.

Singh, H. B., Brune, W. H., Crawford, J. H., Flocke, F., and Jacob, D. J.: Chemistry and transport of pollution over the Gulf of Mexico and the Pacific: spring 2006 INTEX-B campaign overview and first results, Atmos. Chem. Phys., 9, 2301-2318, doi:10.5194/acp-9-2301-2009, 2009.

SMA-GDF (Secretaria del Medio Ambiente del Gobierno del Distrito Federal): Inventario de emisiones criterio para el año de 2006 de la Zona Metropolitana del Valle de México, Secretaría del Medio Ambiente, Gobierno de México, México, available at: http://www.sma.df.gob.mx/, 2008a.

SMA-GDF (Secretaria del Medio Ambiente del Gobierno del Distrito Federal): Inventario de emisiones toxicas para el año de 2006 de la Zona Metropolitana del Valle de México, Secretaría del Medio Ambiente, Gobierno de México, México, available at: http://www.sma.df.gob.mx/, 2008b.

SMA-GDF (Secretaria del Medio Ambiente del Gobierno del Distrito Federal): Inventario de emisiones de gases de efecto invernadero para el año de 2006 de la Zona Metropolitana del Valle de México, Secretaría del Medio Ambiente, Gobierno de México, México, available at: http://www.sma.df.gob.mx/, 2008c.

Smith, J. N., Dunn, M. J., VanReken, T. M., Iida, K., Stolzenburg, M. R., McMurry, P. H., and Huey, L. G.: Chemical composition of atmospheric nanoparticles formed from nucleation in Tecamac, Mexico: Evidence for an important role for organic species in nanoparticle growth, Geophys. Res. Lett., 35, L04808, doi:10.1029/2007GL032523, 2008.

Song, J., Lei, W., Bei, N., Zavala, M., de Foy, B., Volkamer, R., Cardenas, B., Zheng, J., Zhang, R., and Molina, L. T.: Ozone response to emission changes: a modeling study during the MCMA-2006/MILAGRO Campaign, Atmos. Chem. Phys., 10, 
3827-3846, doi:10.5194/acp-10-3827-2010, 2010.

Spracklen, D. V., Carslaw, K. S., Kulmala, M., Kerminen, V.-M., Sihto, S.-L., Riipinen, I., Merikanto, J.,. Mann, G. W, Chipperfield, M. P., Wiedensohler, A., Birmili, W., and Lihavainen, H.: Contribution of particle formation to global cloud condensation nuclei concentrations, Geophys. Res. Lett., 35, L06808, doi:10.1029/2007GL033038, 2008.

Stephens, S., Madronich, S., Wu, F., Olson, J. B., Ramos, R., Retama, A., and Muñoz, R.: Weekly patterns of Mxico City's surface concentrations of $\mathrm{CO}, \mathrm{NO}_{\mathrm{x}}, \mathrm{PM}_{10}$ and $\mathrm{O}_{3}$ during 19862007, Atmos. Chem. Phys., 8, 5313-5325, doi:10.5194/acp-85313-2008, 2008.

Stone, E. A., Snyder, D. C., Sheesley, R. J., Sullivan, A. P., Weber, R. J., and Schauer, J. J.: Source apportionment of fine organic aerosol in Mexico City during the MILAGRO experiment 2006, Atmos. Chem. Phys., 8, 1249-1259, doi:10.5194/acp-81249-2008, 2008.

Stone, E. A., Hedman, C. J., Sheesley, R. J., Shafer, M. M., and Schauer, J. J.: Investigating the chemical nature of humic-like substances (HULIS) in North American atmospheric aerosols by liquid chromatography tandem mass spectrometry, Atmos. Environ., 43, 4205-4213, 2009.

Stone, E. A., Hedman, C. J., Zhou, J., Mieritz, M., and Schauer, J. J.: Insights into the Nature of Secondary Organic Aerosol in Mexico City during the MILAGRO Experiment 2006, Atmos. Environ., 44, 312-319, 2010a.

Stone, E. A., Schauer, J. J., Quraishi, T. A., and Mahmood, A.: Chemical Characterization and Source Apportionment of Fine and Coarse Particulate Matter in Lahore, Pakistan, Atmos. Environ., 44, 1062-1070, 2010b.

Stremme, W., Ortega, I., and Grutter, M.: Using ground-based solar and lunar infrared spectroscopy to study the diurnal trend of carbon monoxide in the Mexico City boundary layer, Atmos. Chem. Phys., 9, 8061-8078, doi:10.5194/acp-9-8061-2009, 2009.

Streit, G. E. and Guzman, F.: Mexico City Air Quality: Progress of an International Collaborative Project to Define Air Quality Management Options. Atmos. Environ., 30, 723-733, 1996.

Subramanian, R., Kok, G. L., Baumgardner, D., Clarke, A., Shinozuka, Y., Campos, T. L., Heizer, C. G., Stephens, B. B., de Foy, B., Voss, P. B., and Zaveri, R. A.: Black carbon over Mexico: the effect of atmospheric transport on mixing state, mass absorption cross-section, and BC/CO ratios, Atmos. Chem. Phys., 10, 219-237, doi:10.5194/acp-10-219-2010, 2010.

Talbot, R., Mao, H., Scheuer, E., Dibb, J., Avery, M., Browell, E., Sachse, G., Vay, S., Blake, D., Huey, G., and Fuelberg, H.: Factors influencing the large-scale distribution of $\mathrm{Hg}^{\circ}$ in the Mexico City area and over the North Pacific, Atmos. Chem. Phys., 8, 2103-2114, doi:10.5194/acp-8-2103-2008, 2008.

Thompson, A. M., Yorks, J. E., Miller, S. K., Witte, J. C., Dougherty, K. M., Morris, G. A., Baumgardner, D., Ladino, L., and Rappenglück, B.: Tropospheric ozone sources and wave activity over Mexico City and Houston during MILAGRO/Intercontinental Transport Experiment (INTEX-B) Ozonesonde Network Study, 2006 (IONS-06), Atmos. Chem. Phys., 8, 5113-5125, doi:10.5194/acp-8-5113-2008, 2008.

Thornhill, D. A., de Foy, B., Herndon, S. C., Onasch, T. B., Wood, E. C., Zavala, M., Molina, L. T., Gaffney, J. S., Marley, N. A., and Marr, L. C.: Spatial and temporal variability of particulate polycyclic aromatic hydrocarbons in Mexico City, Atmos. Chem.
Phys., 8, 3093-3105, doi:10.5194/acp-8-3093-2008, 2008.

Thornhill, D. A., Williams, A. E., Onasch, T. B., Wood, E., Herndon, S. C., Kolb, C. E., Knighton, W. B., Zavala, M., Molina, L. T., and Marr, L. C.: Application of positive matrix factorization to on-road measurements for source apportionment of diesel- and gasoline-powered vehicle emissions in Mexico City, Atmos. Chem. Phys., 10, 3629-3644, doi:10.5194/acp-10-36292010, 2010.

Tie, X., Madronich, S., Li, G. H., Ying, Z. M., Zhang, R., Garcia, A., Lee-Taylor, J., and Liu, Y.: Characterizations of chemical oxidants in Mexico City: a regional chemical/dynamical model (WRF-Chem) study, Atmos. Environ., 41, 1989-2008, 2007.

Tie, X., Madronich, S., Li, G., Ying, Z., Weinheimer, A., Apel, E., and Campos, T.: Simulation of Mexico City plumes during the MIRAGE-Mex field campaign using the WRF-Chem model, Atmos. Chem. Phys., 9, 4621-4638, doi:10.5194/acp-9-4621-2009, 2009.

Tovalin, H., Herbarth, O., Sierra-Vargas, M. P., Strandberg, B., Blanco, S., Vega ,L., Sioutas, C. Hicks, J., Marroquín, R., Acosta, G., Guarneros, M., Hernández, V., Estrada-Muñiz, E., Olivares, I., Pérez, D., Torres-Ramos, Y., Ulrich, F., Hudson, R., Reyes, E., Rodríguez, T., Elizondo, G., and Cantellano, E.: Air pollutants exposure and health effects: A multi-pollutant approach during the MILAGRO-MCMA2006 campaign, in: "Air Pollution: Health \& Environmental Impacts", edited by: Gurjar, B. R., Molina, L. T., Ojha, C. S. P., Taylor \& Francis, 203-228, 2010.

Tsimpidi, A. P., Karydis, V. A., Zavala, M., Lei, W., Molina, L., Ulbrich, I. M., Jimenez, J. L., and Pandis, S. N.: Evaluation of the volatility basis-set approach for the simulation of organic aerosol formation in the Mexico City metropolitan area, Atmos. Chem. Phys., 10, 525-546, doi:10.5194/acp-10-525-2010, 2010.

Ulbrich, I. M., Canagaratna, M. R., Zhang, Q., Worsnop, D. R., and Jimenez, J. L.: Interpretation of organic components from Positive Matrix Factorization of aerosol mass spectrometric data, Atmos. Chem. Phys., 9, 2891-2918, doi:10.5194/acp-9-2891-2009, 2009.

Vay, S. A., Tyler, S. C., Choi, Y., Blake, D. R., Blake, N. J., Sachse, G. W., Diskin, G. S., and Singh, H. B.: Sources and transport of $\Delta^{14} \mathrm{C}$ in $\mathrm{CO} 2$ within the Mexico City Basin and vicinity, Atmos. Chem. Phys., 9, 4973-4985, doi:10.5194/acp-9-4973-2009, 2009.

Vega, E., Reyes, E., Sanchez, G., Ortiz, E., Ruiz, M., Chow, J., Watson, J., and Edgerton, S.: Basic statistics of $\mathrm{PM}_{2.5}$ and $\mathrm{PM}_{10}$ in the atmosphere of Mexico City, Sci. Total Environ., 287, 167176, 2002.

Vega, E., Reyes, E., Ruiz, H., García, J., Sánchez, G., MartínezVilla, G., González, U., Chow, J. C., and Watson, J. G.: Analysis of $\mathrm{PM}_{2.5}$ and $\mathrm{PM}_{10}$ in the Atmosphere of Mexico City during 2000-2002, J. Air \& Waste Manage. Assoc., 54, 786-798, 2004.

Vega, E., Lowenthal, D. H., Ruiz, H., Reyes, E., Watson, J. G., Chow, J. C., Viana, M., Querol, X., and Alastuey, A.: Fine Particle Receptor Modeling in the Atmosphere of Mexico City, J. Air Waste Manage. Assoc., 59, 1417-1428, 2009.

Velasco, E., Lamb, B., Pressley, S., Allwine, E., Westberg, H., Jobson, B. T., Alexander, M., Prazeller, P., Molina, L. T., and Molina, M. J.: Flux measurements of volatile organic compounds from an urban landscape, Geophys. Res. Lett., 32, L20802, doi:10.1029/2005GL023356, 2005. 
Velasco, E., Lamb, B., Westberg, H., Allwine, E., Sosa, G., ArriagaColina, J. L., Jobson, B. T., Alexander, M. L., Prazeller, P., Knighton, W. B., Rogers, T. M., Grutter, M., Herndon, S. C., Kolb, C. E., Zavala, M., de Foy, B., Volkamer, R., Molina, L. T., and Molina, M. J.: Distribution, magnitudes, reactivities, ratios and diurnal patterns of volatile organic compounds in the Valley of Mexico during the MCMA 2002 \& 2003 field campaigns, Atmos. Chem. Phys., 7, 329-353, doi:10.5194/acp-7-329-2007, 2007.

Velasco, E., Márquez, C., Bueno, E., Bernabé, R. M., Sánchez, A., Fentanes, O., Wöhrnschimmel, H., Cárdenas, B., Kamilla, A., Wakamatsu, S., and Molina, L. T.: Vertical distribution of ozone and VOCs in the low boundary layer of Mexico City, Atmos. Chem. Phys., 8, 3061-3079, doi:10.5194/acp-8-3061-2008, 2008.

Velasco, E., Pressley, S., Grivicke, R., Allwine, E., Coons, T., Foster, W., Jobson, B. T., Westberg, H., Ramos, R., Hernández, F., Molina, L. T., and Lamb, B.: Eddy covariance flux measurements of pollutant gases in urban Mexico City, Atmos. Chem. Phys., 9, 7325-7342, doi:10.5194/acp-9-7325-2009, 2009.

Velasco, E., Pressley, S., Grivicke, R., Allwine, E., Molina, L. T., and Lamb, B.: Energy balance in urban Mexico City: observation and parameterization during the MILAGRO/MCMA-2006 field campaign, Theor. Appl. Climatol., 102, doi:10.1007/s00704-010-0314-7, 2010.

Volkamer, R., Molina, L. T., Molina, M. J., Shirley, T., and Brune, W. H.: DOAS measurement of glyoxal as an indicator for fast VOC chemistry in urban air, Geophys. Res. Lett., 32, L08806, doi:10.1029/2005GL022616, 2005.

Volkamer, R., Jimenez, J. L., San Martini, F., Dxepina, K., Zhang, Q., Salcedo, D., Molina, L. T., Worsnop, D. R., and Molina, M. J.: Secondary Organic Aerosol Formation from Anthropogenic Air Pollution: rapid and Higher than Expected, Geophys. Res. Lett, 33, L17811, doi:10.1029/2006GL026899, 2006.

Volkamer, R., San Martini, F., Molina, L. T., Salcedo, D., Jimenez, J. L., and Molina, M. J.: A Missing Sink for Gas-Phase Glyoxal in Mexico City: formation of Secondary Organic Aerosol, Geophys. Res. Lett., 34, L19807, doi:10.1029/2007GL030752, 2007.

Volkamer, R., Sheehy, P., Molina, L. T., and Molina, M. J.: Oxidative capacity of the Mexico City atmosphere - Part 1: A radical source perspective, Atmos. Chem. Phys., 10, 6969-6991, doi:10.5194/acp-10-6969-2010, 2010.

Volkamer, R., Ziemann, P. J., and Molina, M. J.: Secondary Organic Aerosol Formation from Acetylene $\left(\mathrm{C}_{2} \mathrm{H}_{2}\right)$ : seed effect on SOA yields due to organic photochemistry in the aerosol aqueous phase, Atmos. Chem. Phys., 9, 1907-1928, doi:10.5194/acp9-1907-2009, 2009.

Voss, P. B., Zaveri, R. A., Flocke, F. M., Mao, H., Hartley, T. P., DeAmicis, P., Deonandan, I., Contreras-Jiménez, G., MartínezAntonio, O., Figueroa Estrada, M., Greenberg, D., Campos, T. L., Weinheimer, A. J., Knapp, D. J., Montzka, D. D., Crounse, J. D., Wennberg, P. O., Apel, E., Madronich, S., and de Foy, B.: Long-range pollution transport during the MILAGRO-2006 campaign: a case study of a major Mexico City outflow event using free-floating altitude-controlled balloons, Atmos. Chem. Phys., 10, 7137-7159, doi:10.5194/acp-10-7137-2010, 2010.

Wallace, L.: Indoor sources of ultrafine and accumulation mode particles: Size distributions, size-resolved concentrations, and source strengths, Aerosol Sci. Technol., 40, 348-360, 2006.

Wang, J., Cubison, M. J., Aiken, A. C., Jimenez, J. L., and Collins, D. R.: The importance of aerosol mixing state and size-resolved composition on $\mathrm{CCN}$ concentration and the variation of the importance with atmospheric aging of aerosols, Atmos. Chem. Phys., 10, 7267-7283, doi:10.5194/acp-10-7267-2010, 2010.

Watson, J. G.: Visibility: science and regulation, J. Air Waste Manag. Assoc., 52(6), 628-713, 2002.

Weibring, P., Richter, D., Walega, J. G., and Fried, A.: Airborne difference frequency spectrometer for ultra sensitive formaldehyde measurements, in Conference on Lasers and ElectroOptics/Quantum Electronics and Laser Science Conference and Photonic Applications Systems Technologies, OSA Technical Digest Series (CD), Optical Society of America, 2007.

Wert, B. P., Trainer, M., Fried, A., Ryerson, T. B., Henry, B., Potter, W., Angevine, W. M., Atlas, E., Donnelly, S. G., Fehsenfeld, F. C., Frost, G. J., Goldan, P. D., Hansel, A., Holloway, J. S. , Hubler, G., Kuster, W. C., Nicks Jr., D. K., Neuman, J. A., Parrish, D. D., Schauffler, S., Stutz, J., Sueper, D. T., Wiedinmyer, C., Wisthaler, A.: Signatures of terminal alkene oxidation in airborne formaldehyde measurements during TexAQS 2000, J. Geophys. Res., 108, 4104, doi:10.1029/2002JD002502, 2003.

Wöhrnschimmel, H., Magaña, M., Stahel, W. A., Blanco, S., Acuña, S., Pérez, J. M., González, S., Gutiérrez, V., Wakamatsu, S., and Cárdenas, B.: Measurements and receptor modeling of volatile organic compounds in south-eastern Mexico City, 20002007, Atmos. Chem. Phys. Discuss., 10, 3319-3346, doi:10.5194/acpd10-3319-2010, 2010.

Wood, E. C., Herndon, S. C., Onasch, T. B., Kroll, J. H., Canagaratna, M. R., Kolb, C. E., Worsnop, D. R., Neuman, J. A., Seila, R., Zavala, M., and Knighton, W. B.: A case study of ozone production, nitrogen oxides, and the radical budget in Mexico City, Atmos. Chem. Phys., 9, 2499-2516, doi:10.5194/acp-9-2499-2009, 2009.

Wood, E. C., Canagaratna, M. R., Herndon, S. C., Kroll, J. H., Onasch, T. B., Kolb, C. E., Worsnop, D. R., Knighton, W. B., Seila, R., Zavala, M., Molina, L. T., DeCarlo, P. F., Jimenez, J. L., Weinheimer, A. J., Knapp, D. J., Jobson, B. T., Stutz, J., Kuster, W. C., and Williams, E. J.: Investigation of the correlation between odd oxygen and secondary organic aerosol in Mexico City and Houston, Atmos. Chem. Phys. Discuss., 10, 35473604, doi:10.5194/acpd-10-3547-2010, 2010.

Yokelson, R. J., Urbanski, S. P., Atlas, E. L., Toohey, D. W., Alvarado, E. C., Crounse, J. D., Wennberg, P. O., Fisher, M. E., Wold, C. E., Campos, T. L., Adachi, K., Buseck, P. R., and Hao, W. M.: Emissions from forest fires near Mexico City, Atmos. Chem. Phys., 7, 5569-5584, doi:10.5194/acp-7-5569-2007, 2007.

Yokelson, R. J., Crounse, J. D., DeCarlo, P. F., Karl, T., Urbanski, S., Atlas, E., Campos, T., Shinozuka, Y., Kapustin, V., Clarke, A. D., Weinheimer, A., Knapp, D. J., Montzka, D. D., Holloway, J., Weibring, P., Flocke, F., Zheng, W., Toohey, D., Wennberg, P. O., Wiedinmyer, C., Mauldin, L., Fried, A., Richter, D., Walega, J., Jimenez, J. L., Adachi, K., Buseck, P. R., Hall, S. R., and Shetter, R.: Emissions from biomass burning in the Yucatan, Atmos. Chem. Phys., 9, 5785-5812, doi:10.5194/acp-9-5785-2009, 2009.

Yu, X.-Y., Cary, R. A., and Laulainen, N. S.: Primary and secondary organic carbon downwind of Mexico City, Atmos. Chem. Phys., 
9, 6793-6814, doi:10.5194/acp-9-6793-2009, 2009.

Yuan, T., Li, Z., Zhang, R., and Fan, J.: Increase of cloud droplet size with increasing aerosol loading, J. Geophys. Res., 113, D04201, doi:10.1029/2007JD008632, 2008.

Zambrano García, A., Medina Coyotzin, C., Rojas Amaro, A., López Veneroni, D., Chang Martínez, L., and Sosa Iglesias, G.: Distribution and sources of bioaccumulative air pollutants at Mezquital Valley, Mexico, as reflected by the atmospheric plant Tillandsia recurvata L., Atmos. Chem. Phys., 9, 64796494, doi:10.5194/acp-9-6479-2009, 2009.

Zavala, M., Herndon, S. C., Slott, R. S., Dunlea, E. J., Marr, L. C., Shorter, J. H., Zahniser, M., Knighton, W. B., Rogers, T. M., Kolb, C. E., Molina, L. T., and Molina, M. J.: Characterization of on-road vehicle emissions in the Mexico City Metropolitan Area using a mobile laboratory in chase and fleet average measurement modes during the MCMA-2003 field campaign, Atmos. Chem. Phys., 6, 5129-5142, doi:10.5194/acp-6-5129-2006, 2006.

Zavala, M., Lei, W., Molina, M. J., and Molina, L. T.: Modeled and observed ozone sensitivity to mobile-source emissions in Mexico City, Atmos. Chem. Phys., 9, 39-55, doi:10.5194/acp-9-392009, 2009a.

Zavala, M., Herndon, S. C., Wood, E. C., Onasch, T. B., Knighton, W. B., Marr, L. C., Kolb, C. E., and Molina, L. T.: Evaluation of mobile emissions contributions to Mexico City's emissions inventory using on-road and cross-road emission measurements and ambient data, Atmos. Chem. Phys., 9, 6305-6317, doi:10.5194/acp-9-6305-2009, 2009b.

Zaveri, R., Chapman, E. G., Easter, R. C., Fast, J. D., Flocke, F., Kleinman, L. I., Madronich, S., Springston, S. R., Voss, P. B., and Weinheimer, A.: Modeling gas-aerosol processes during MILAGRO 2006, Fall American Geophysical Union Meeting, San Francisco, CA, A33D-1570, 2007.
Zhang, Q., Jimenez, J. L., Canagaratna, M. R., Allan, J. D., Coe, H., Ulbrich, I., Alfarra, M. R., Takami, A., Middlebrook, A. M., Sun, Y. L., Dzepina, K., Dunlea, E., Docherty, K., DeCarlo, P. F., Salcedo, D., Onasch, T., Jayne, J. T., Miyoshi, T., Shimono, A., Hatakeyama, S., Takegawa, N., Kondo, Y., Schneider, J., Drewnick, F., Borrmann, S., Weimer, S., Demerjian, K., Williams, P., Bower, K., Bahreini, R., Cottrell, L., Griffin, R. J., Rautiainen, J., Sun, J. Y., Zhang, Y. M., and Worsnop, D. R.: Ubiquity and dominance of oxygenated species in organic aerosols in anthropogenically-influenced Northern Hemisphere midlatitudes, Geophys. Res. Lett., 34, L13801, doi:13810.11029/12007GL029979, 2007.

Zhang, Y., Dubey, M. K., Olsen, S. C., Zheng, J., and Zhang, R.: Comparisons of WRF/Chem simulations in Mexico City with ground-based RAMA measurements during the 2006-MILAGRO, Atmos. Chem. Phys., 9, 3777-3798, doi:10.5194/acp-9-3777-2009, 2009.

Zhang, Y., and Dubey, M. K.: Comparisons of WRF/Chem simulated $\mathrm{O}_{3}$ concentrations in Mexico City with ground-based RAMA measurements during the MILAGRO period, Atmos. Environ., 43, 4622-4631, 2009.

Zheng, J., Zhang, R., Fortner, E. C., Volkamer, R. M., Molina, L., Aiken, A. C., Jimenez, J. L., Gaeggeler, K., Dommen, J., Dusanter, S., Stevens, P. S., and Tie, X.: Measurements of $\mathrm{HNO}_{3}$ and $\mathrm{N}_{2} \mathrm{O}_{5}$ using ion drift-chemical ionization mass spectrometry during the MILAGRO/MCMA-2006 campaign, Atmos. Chem. Phys., 8, 6823-6838, doi:10.5194/acp-8-6823-2008, 2008. 